\section{Pacific Northwest}

National Laboratory

Operated by Battelle for the

U.S. Department of Energy

\title{
Development and Testing of ICV Glasses for Hanford LAW
}

$\begin{array}{ll}\text { D. S. Kim } & \text { D. E. Smith } \\ \text { J. D. Vienna } & \text { G. J. Sevigny } \\ \text { P. R. Hrma } & \text { W. C. Buchmiller } \\ \text { M. J. Schweiger } & \text { J. S. Tixier, Jr. } \\ \text { J. Matyáš } & \text { J. D. Yeager } \\ \text { J. V. Crum } & \text { K. B. Belew }\end{array}$

July 2003

Prepared for the U.S. Department of Energy under Contract DE-AC06-76RL01830 


\title{
DISCLAIMER
}

This report was prepared as an account of work sponsored by an agency of the United States Government. Neither the United States Government nor any agency thereof, nor Battelle Memorial Institute, nor any of their employees, makes any warranty, express or implied, or assumes any legal liability or responsibility for the accuracy, completeness, or usefulness of any information, apparatus, product, or process disclosed, or represents that its use would not infringe privately owned rights. Reference herein to any specific commercial product, process, or service by trade name, trademark, manufacturer, or otherwise does not necessarily constitute or imply its endorsement, recommendation, or favoring by the United States Government or any agency thereof, or Battelle Memorial Institute. The views and opinions of authors expressed herein do not necessarily state or reflect those of the United States Government or any agency thereof.

\author{
PACIFIC NORTHWEST NATIONAL LABORATORY \\ operated by \\ BATTELLE \\ for the \\ UNITED STATES DEPARTMENT OF ENERGY \\ under Contract DE-AC06-76RL01830
}

This document was printed on recycled paper. 


\title{
Development and Testing of ICV Glasses for Hanford LAW
}

\author{
D.-S. Kim \\ J. D. Vienna \\ P. R. Hrma \\ M. J. Schweiger \\ J. Matyáš \\ J. V. Crum \\ D. E. Smith \\ G. J. Sevigny \\ W. C. Buchmiller \\ J. S. Tixier, Jr. \\ J. D. Yeager \\ K. B. Belew
}

July 2003

Prepared for the U.S. Department of Energy

under Contract DE-AC06-76RL01830

Pacific Northwest National Laboratory

Richland, WA 99352 


\begin{abstract}
Preliminary glass compositions for immobilizing Hanford low-activity waste (LAW) by the in-container vitrification (ICV) process were fabricated at crucible- and engineering-scale and tested at Pacific

Northwest National Laboratory. This testing showed that glasses with LAW loading of 20 mass\% (that corresponds to 20 mass $\% \mathrm{Na}_{2} \mathrm{O}$ in glass) can readily be made and meet all product constraints by a wide margin. It was found that the response constraint of the $200^{\circ} \mathrm{C}$ vapor hydration test (VHT) of less than 50 $\mathrm{g} /\left(\mathrm{m}^{2} \cdot \mathrm{d}\right)$ alteration rate was the most restrictive constraint placed on LAW glasses. Glasses with over 22 mass $\% \mathrm{Na}_{2} \mathrm{O}$ can be made to meet this constraint along with all other product quality and processability constraints imposed by the ICV process. The results of crucible melts with simulated waste were scaledup to engineering scale. Crucible melts were also tested with actual (radioactive) LAW. All the results suggest that the baseline glass can be successfully processed by the ICV technology and can meet all the constraints related to product quality. Details of the tests performed and results obtained are described in this report. A summary of the work is found in Section 7.0.
\end{abstract}




\section{Acknowledgements}

The authors wish to acknowledge the guidance and funding for this project by Leo Thompson and Pat Lowery of AMEC, Geomelt Division. The successful completion of this work scope performed under a very tight schedule is largely attributed to the open teaming relationship that they developed with Pacific Northwest National Laboratory (PNNL).

We would like to acknowledge the support of Savannah River Technology Center (SRTC) staff, primarily David Peeler and David Best. All non-radioactive chemical analyses were performed at the SRTC mobile laboratory that consistently produced very high quality results under tight time restrictions. The staff of the PNNL Analytical Services Organization, particularly Karl Pool and Thomas Farmer; and the Southwest Research Institute, particularly Mike Dammen; are acknowledged for their analytical support with radioactive samples.

Wayne Cosby (PNNL), Pat Lowery (AMEC), John Mucha (PNNL), Larry Bagaasen (PNNL), and Denis Strachan (PNNL) are acknowledged for their review of this document and helpful comments and suggestions. We thank John Mucha and Teresa Schott for assistance in quality assurance, quality control, and documentation throughout this project.

Thanks also go to Phil Gauglitz and Evan Jones for management support. 


\section{Abbreviations and Acronyms}

\begin{tabular}{|c|c|}
\hline AES & atomic emission spectroscopy \\
\hline AMBG & AMEC bulk vitrification glass \\
\hline AMOG & AMEC oxidation state glass \\
\hline ARCM & AMEC radioactive crucible melt \\
\hline ASCM & AMEC simulant crucible melt \\
\hline ASTM & American Society for Testing and Materials \\
\hline APEL & Applied Processing Engineering Laboratory \\
\hline ASTM & American Society for Testing and Materials \\
\hline CFR & Code of Federal Regulations \\
\hline $\mathrm{CHG}$ & CH2M Hill Hanford Group \\
\hline DIW & deionized water \\
\hline DOE & U.S. Department of Energy \\
\hline EDS & energy dispersive spectroscopy \\
\hline EPA & U.S. Environmental Protection Agency \\
\hline ES & engineering-scale \\
\hline GDL & Glass Development Laboratory \\
\hline GDL-ECC & Glass Development Laboratory-Electrical Conductivity Calibration \\
\hline GDL-ELC & Glass Development Laboratory-Electrical Conductivity \\
\hline GDL-GBM & Glass Development Laboratory-Glass Batching and Melting \\
\hline GDL-VIS & Glass Development Laboratory-Viscosity \\
\hline GDL-VSC & Glass Development Laboratory-Viscosity Calibration \\
\hline HLW & high-level waste \\
\hline IA & image analysis \\
\hline
\end{tabular}




\begin{tabular}{|c|c|}
\hline $\mathrm{ICP}$ & inductively coupled plasma \\
\hline ICV & in-container vitrification \\
\hline ISE & ion selective electrode \\
\hline ISV & in-situ vitrification \\
\hline LAW & low-activity waste \\
\hline LOI & loss on ignition \\
\hline LOD & loss on drying \\
\hline LRM & low-activity reference material \\
\hline MS & mass spectroscopy \\
\hline NIST & National Institute for Standards and Technology \\
\hline NQARD & Nuclear Quality Assurance Requirements Description \\
\hline $\mathrm{OM}$ & optical microscopy \\
\hline ORP & Office of River Protection \\
\hline PA & Performance Assessment (Hanford Site) \\
\hline PCT & product consistency test \\
\hline PTFE & Polytetrafluoro-ethlene \\
\hline PNNL & Pacific Northwest National Laboratory \\
\hline QA & quality assurance \\
\hline QC & quality control \\
\hline RCRA & Resource Conservation and Recovery Act \\
\hline redox & oxidation reduction \\
\hline $\mathrm{SC}$ & slow cooling \\
\hline SEM & scanning electron microscopy \\
\hline SOW & statement of work \\
\hline SRTC & Savannah River Technology Center \\
\hline
\end{tabular}




$\begin{array}{ll}\text { S/V } & \text { surface area-to-volume ratio } \\ \text { TCLP } & \text { Toxicity Characteristic Leach Procedure } \\ \text { TIC } & \text { total inorganic carbon } \\ \text { TOC } & \text { total organic carbon } \\ \text { UTS } & \text { Universal Treatment Standard } \\ \text { UV-VIS-NIR } & \text { ultraviolet visible near infrared } \\ \text { VHT } & \text { vapor hydration test } \\ \text { WSRC } & \text { Westinghouse Savannah River Company } \\ \text { WTP } & \text { Waste Treatment Plant } \\ \text { XRD } & \text { X-ray diffraction }\end{array}$




\section{List of Symbols}

\begin{tabular}{|c|c|}
\hline$A$ & Arrhenius or Fulcher coefficient (log of pre-exponential factor) \\
\hline$a$ & absorbance \\
\hline$a$ & oxidation-reduction equation coefficient \\
\hline$B$ & Arrhenius or Fulcher coefficient (activation energy in K) \\
\hline$b$ & oxidation-reduction equation coefficient \\
\hline$c$ & concentration \\
\hline$c_{G}$ & glass-forming components concentration in saltcake solution \\
\hline$c_{i}$ & $i$-th element TCLP release \\
\hline$d$ & sample thickness \\
\hline$d_{i}$ & initial specimen thickness \\
\hline$d_{r}$ & remaining glass average thickness \\
\hline$e$ & extinction coefficient \\
\hline$F$ & viscosity spindle factor \\
\hline$f_{i}$ & $i$-th element mass fraction in glass \\
\hline g & target composition matrix \\
\hline $\mathbf{G}$ & measured composition matrix \\
\hline$g_{i}$ & i-th component mass fraction in glass \\
\hline$G_{i}$ & i-th component mass fraction in glass with dissolved sand \\
\hline$\Delta H$ & reaction enthalpy \\
\hline$L$ & cell constant \\
\hline$l_{i}$ & initial specimen length \\
\hline$m$ & mass loss to corrosion \\
\hline$M$ & mass of glass to be produced \\
\hline$m_{B D}$ & dry batch mass \\
\hline$M_{B i}$ & $i$-th batch component molecular mass \\
\hline$m_{C}$ & calcine mass \\
\hline$m_{G}$ & glass mass \\
\hline$M_{G i}$ & $i$-th glass component molecular mass \\
\hline$m_{i}$ & initial specimen mass \\
\hline$M_{\mathrm{i}}$ & i-th component molecular mass \\
\hline$m_{\mathrm{Re} 2 \mathrm{O} 7}$ & total $\operatorname{Re}_{2} \mathrm{O}_{7}$ mass to be dissolved \\
\hline
\end{tabular}




\begin{tabular}{|c|c|}
\hline$M_{\mathrm{ReO} 2}$ & $\mathrm{ReO}_{2}$ molecular mass \\
\hline$m_{S}$ & silica mass \\
\hline$m_{\text {sugar }}$ & sugar mass \\
\hline$m_{W}$ & saltcake-solution mass \\
\hline$p_{\mathrm{O} 2}$ & oxygen partial pressure \\
\hline$R$ & electrical resistance \\
\hline$r_{\infty}$ & final corrosion rate \\
\hline$r_{a}$ & average corrosion rate \\
\hline$r_{i}$ & i-the element normalized PCT release \\
\hline$S$ & dissolved sand mass fraction in glass \\
\hline$t$ & corrosion time \\
\hline$T$ & temperature \\
\hline$T_{0}$ & Fulcher coefficient for viscosity \\
\hline$V$ & solution volume \\
\hline$W$ & waste loading \\
\hline$w_{G}$ & glass mass per saltcake solution mass unit \\
\hline$w_{i}$ & initial specimen width \\
\hline$w_{\mathrm{Re} 2 \mathrm{O} 7}$ & $\mathrm{Re}_{2} \mathrm{O}_{7}$ mass fraction in solution \\
\hline$x_{i}$ & $i$-th glass component mass fraction \\
\hline$x_{N}$ & nitrogen molar concentration \\
\hline$\alpha$ & mass-reduction coefficient \\
\hline$\beta$ & fraction of nitrogen from the waste that forms sodalite \\
\hline$\gamma_{i}$ & $i$-th component stoichiometric coefficient \\
\hline$\varepsilon$ & electrical conductivity \\
\hline$\eta$ & viscosity \\
\hline$\lambda_{i}$ & $i$-th component batch chemical loss on drying. \\
\hline$\xi$ & $\mathrm{C}: \mathrm{N}$ ratio for the sugar-sodalite reaction \\
\hline$\rho$ & glass density. \\
\hline$\rho_{S}$ & saltcake solution density \\
\hline$\tau$ & torque \\
\hline$\omega$ & spindle speed \\
\hline
\end{tabular}




\section{Contents}

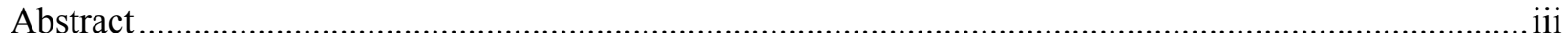

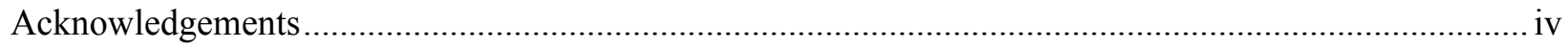

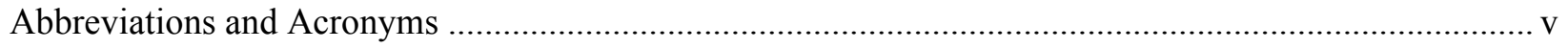

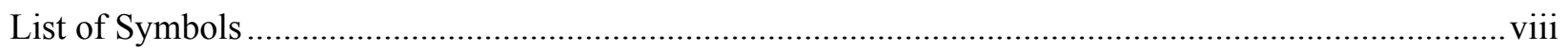

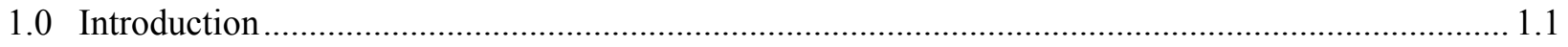

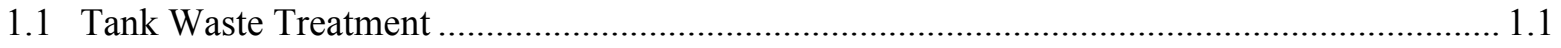

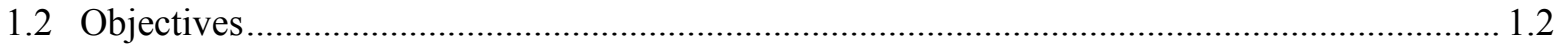

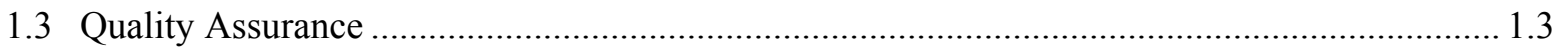

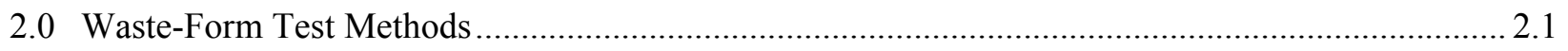

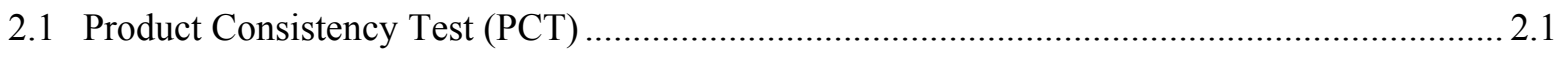

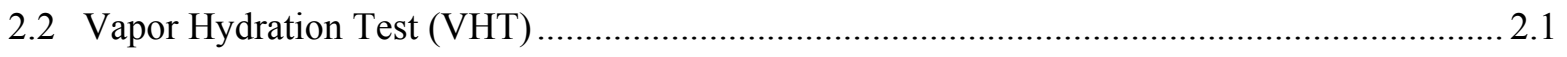

2.3 Toxicity Characteristic Leach Procedure (TCLP) …............................................................... 2.2

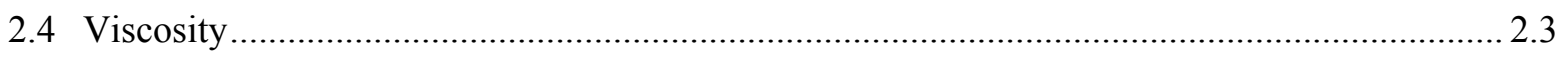

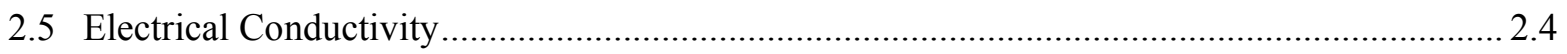

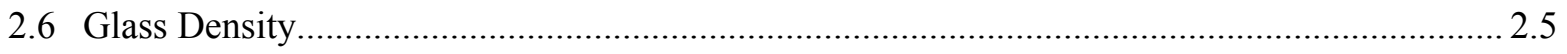

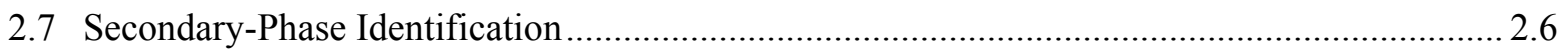

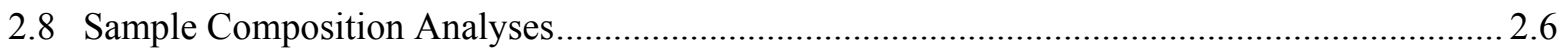

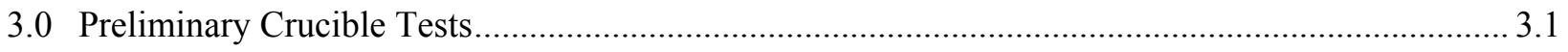

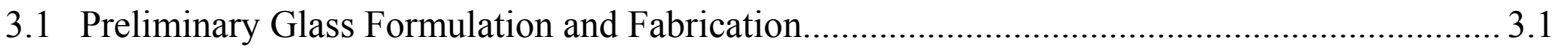

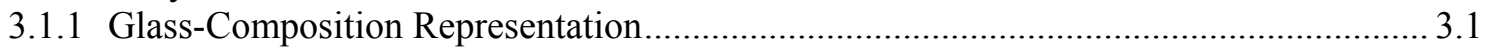

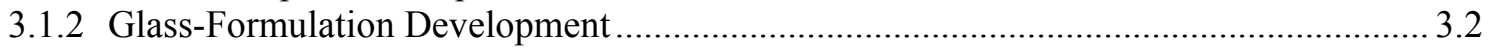

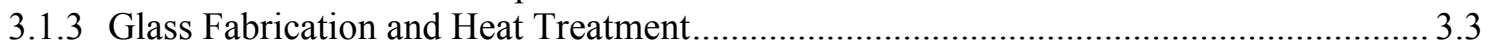

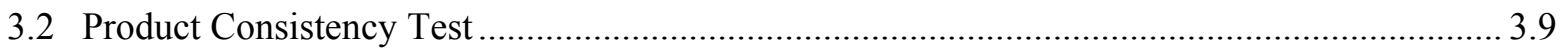

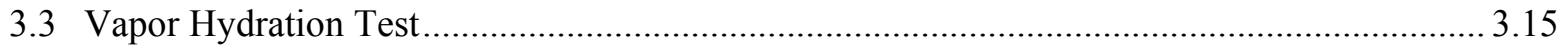

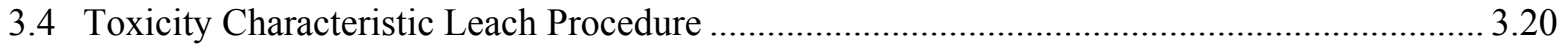

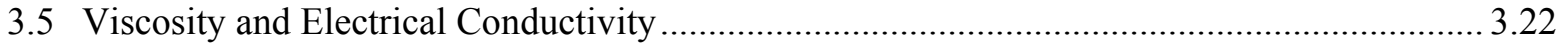




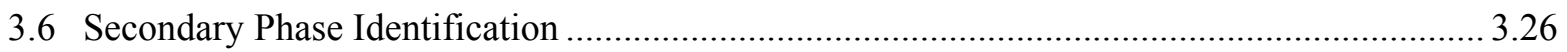

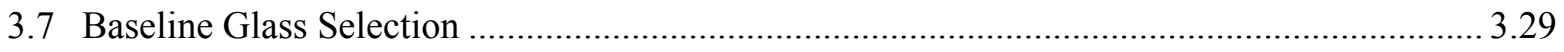

4.0 Simulant and Actual Waste-Crucible Tests ................................................................................. 4.1

4.1 Simulant and Actual Waste-Crucible Glass Formulation and Sample Fabrication................... 4.1

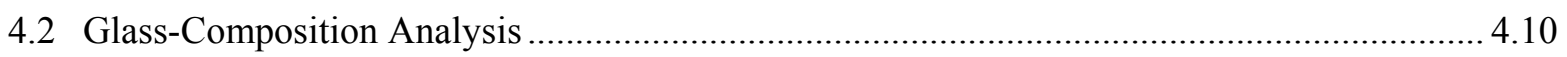

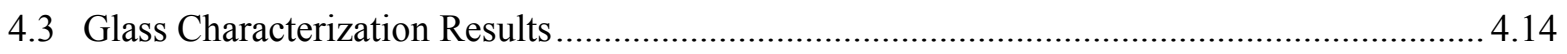

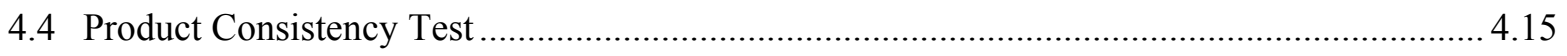

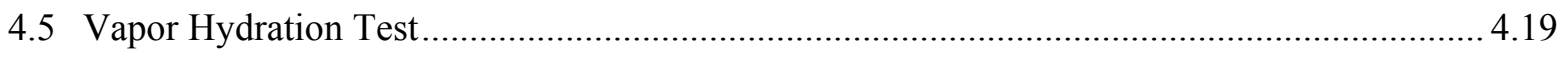

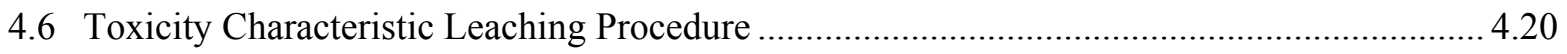

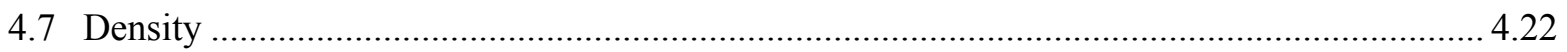

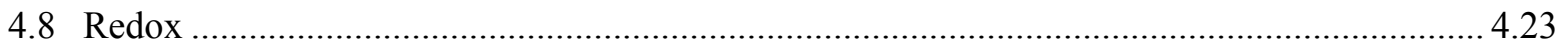

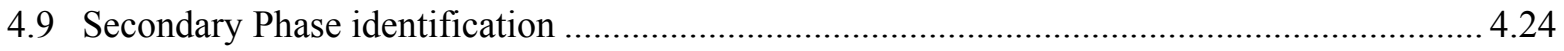

4.10 Comparison of Simulant and Actual LAW Glass Properties .............................................. 4.27

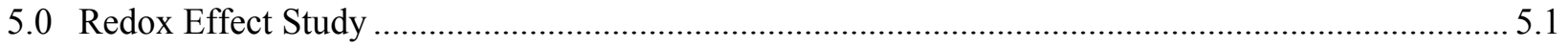

5.1 Redox Effect Study Sample Fabrication ……................................................................. 5.1

5.2 Redox and Vapor Hydration Test................................................................................. 5.4

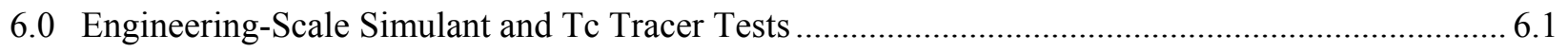

6.1 Engineering-Scale Simulant and Tc Tracer Tests Feed Preparation ........................................ 6.1

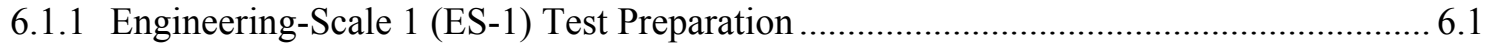

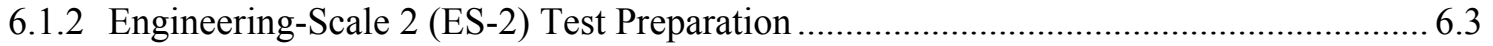

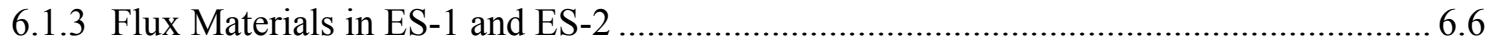

6.2 Sample Position and Identification for ES-1 Glass-Composition Analysis ............................ 6.7

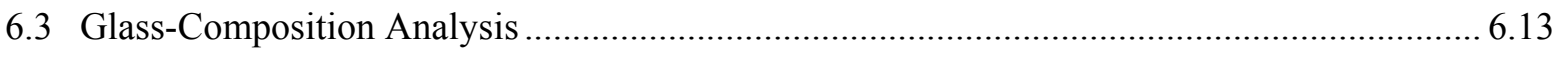

6.4 Sample Position and Identification for Glass Characterization........................................... 6.16

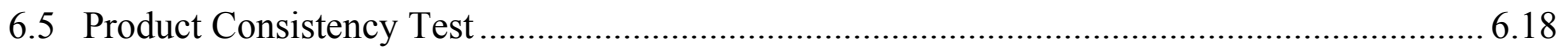

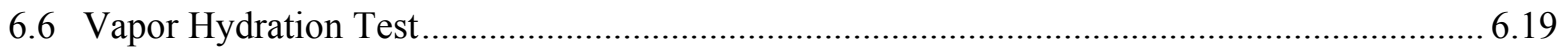

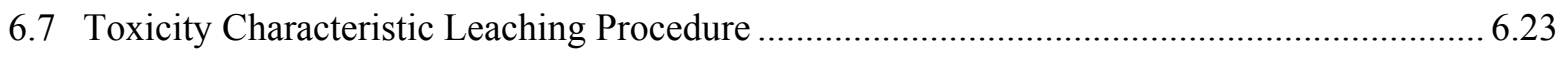

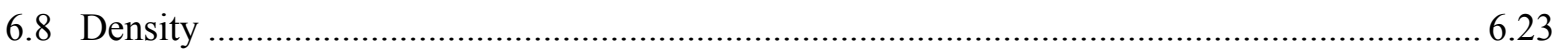




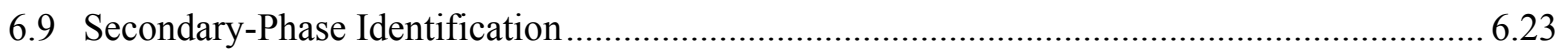

6.10 Sample Position and Identification for ES-2 Glass Composition Analyses........................... 6.29

6.11 ES-2 Glass Composition Analyses Results and Comparison with ES-1 ............................... 6.30

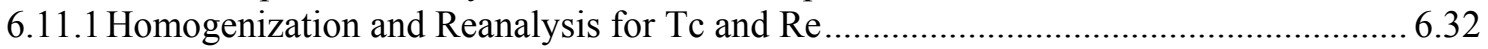

6.11.2 Analyses of Tc and Re in Condensates in Foam Glass samples ................................. 6.33

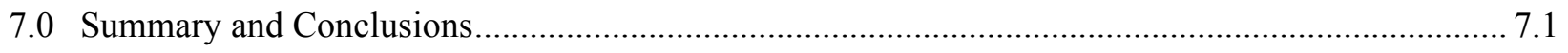

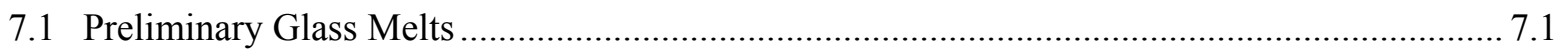

7.2 Simulant Crucible Melts.................................................................................................. 7.1

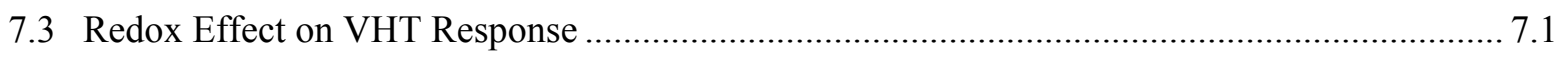

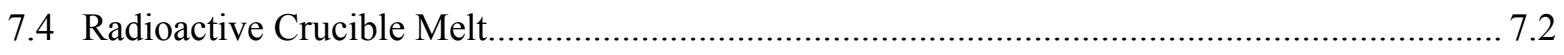

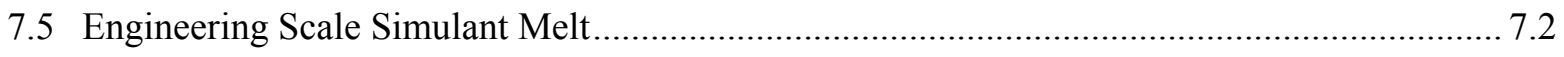

7.6 Engineering Scale Technetium Tracer Melt.................................................................. 7.2

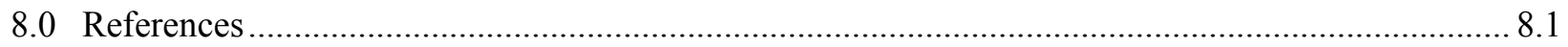

Appendix A: PNNL Technical Procedures Used.......................................................................... 1

Appendix B: XRD Patterns of the SC Treated Glasses .................................................................. 1

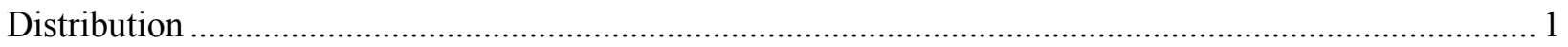




\section{Figures}

Figure 1.1. Current ORP Schematic (from Allen et al. 2002) ............................................................ 1.1

Figure 3.1. Waste Glass Time-Temperature Function During Slow Cooling ......................................... 3.9

Figure 3.2. Comparison of PCT Na Concentrations Measured by ICP-AES and Na ISE .....................3.11

Figure 3.3. Comparison of PCT Elemental Releases of Various Components from Quenched Samples ( $r$ in $\mathrm{g} / \mathrm{m}^{2}$ ) with Na Release (dotted lines indicate $2 \mathrm{~g} / \mathrm{m}^{2}$ limit)

Figure 3.4. Comparison of PCT Normalized Releases of Various Components from SC Samples with Normalized $\mathrm{Na}$ Release $\left(r_{\mathrm{i}}\right.$ in $\left.\mathrm{g} / \mathrm{m}^{2}\right)$ (dotted lines indicate $2 \mathrm{~g} / \mathrm{m}^{2}$ limit) ...................................... 3.13

Figure 3.5. Effect of Slow Cooling Treatment on Normalized Na Release .......................................... 3.14

Figure 3.6. Measured vs. Predicted Normalized Na Release ............................................................ 3.14

Figure 3.7. Comparison of PCT Responses for AMBG-13, 14, and 16 Glasses with those from Typical

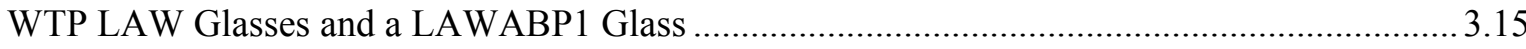

Figure 3.8. VHT Mass Loss a Function of Time for AMBG-05, -06, -09, and -13 to -16 Glasses ......... 3.17

Figure 3.9. Comparison of VHT Responses for AMBG-13, -14, and -16 with those from LAW-A33,

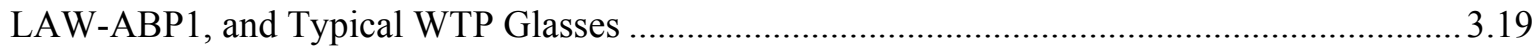

Figure 3.10. Comparison of VHT Corrosion Rates in Quenched and SC Samples ...............................3.19

Figure 3.11. Comparison of TCLP Normalized Releases for AMBG-13 Glasses with Those from Typical

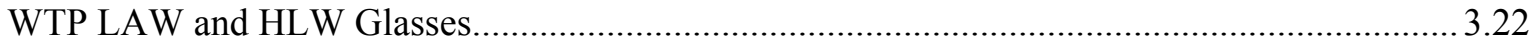

Figure 3.12. $\ln (\eta)$ Versus $1 / T$ ( $T$ in K) Plot for AMBG-13 and 16 Glasses (the Lines for Arrhenius fit of measured data and for model prediction are also included) .....................................................23

Figure 3.13. Viscosity Versus Temperature (in ${ }^{\circ} \mathrm{C}$ ) Plot for AMBG-13 and 16 Glasses (the curves for Arrhenius fit of measured data and for model prediction are also included)

Figure 3.14. Electrical Conductivity versus Temperature for AMBG-13 and 16 Glasses......

Figure 3.15. $\ln (\varepsilon)$ Versus $1 / T(T$ in $\mathrm{K})$ Plot for AMBG-13 and 16 Glasses at $1 \mathrm{kHz}$ (the lines for Arrhenius fit of measured data and for model prediction are also included)

Figure 3.16. SEM Micrograph Showing Nepheline and Zirconia Crystals Formed at the Surface Layer of the SC Treated AMBG-10 Glass

Figure 3.17. Optical Micrographs Showing Baddeleyite Crystals Formed and Settled at the Bottom of the SC Treated AMBG-14 Glass 3.27 
Figure 3.18. SEM Micrographs of Baddeleyite Crystals in Slow-Cooled AMBG-14 Glass

Figure 4.1. Photograph of Melted and Unmelted PTFE Crucibles Used to Dry ARCM-01 Batches ....... 4.7

Figure 4.2. Photograph of ARCM-01 Melt Being Poured Onto Stainless Steel Plate............................. 4.9

Figure 4.3. Photograph of ARCM-01 Sample at the Completion of the Second Melt ......................... 4.10

Figure 4.4. Photograph of ARCM-01 Melt Being Cast into Two Molds for VHT (small cube) and SC

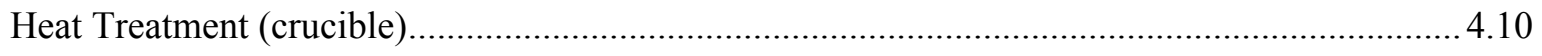

Figure 4.5. The Ratio of Measured to Target Concentrations for Selected Major Components in ASCM

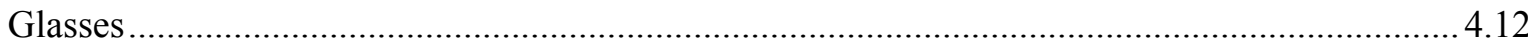

Figure 4.6. 7-Day PCT $r_{\mathrm{Na}}$ as a Function of $\mathrm{Na}_{2} \mathrm{O}$ Concentration in ASCM Glasses........................... 4.17

Figure 4.7. 7-Day PCT $\ln \left(r_{N a}\right)$ as a Function of $\mathrm{Na}_{2} \mathrm{O}$ Concentration in ASCM Glasses ..................... 4.17

Figure 4.8. Comparison of PCT Elemental Releases of Various Components from Quenched ASCM

Glasses with Na Release ........................................................................................... 4.18

Figure 4.9. Comparison of PCT Elemental Releases of Various Components from SC Treated ASCM

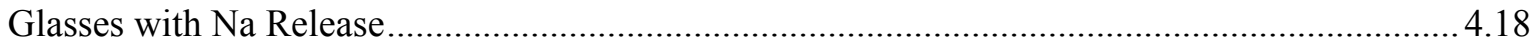

Figure 4.10. 14-day VHT $r_{a}$ as a Function of $\mathrm{Na}_{2} \mathrm{O}$ Concentration in ASCM Glasses ........................ 4.19

Figure 4.11. 14-day VHT $r_{a}$ as a Function of $\mathrm{Na}_{2} \mathrm{O}$ Concentration in ASCM Glasses (shown in Log

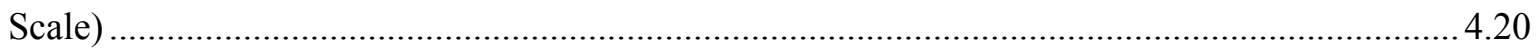

Figure 4.12. TCLP $r_{B}$ as a Function of $\mathrm{Na}_{2} \mathrm{O}$ Concentration in ASCM Glasses................................. 4.21

Figure 4.13. TCLP $c_{C r}$ as a Function of $\mathrm{Na}_{2} \mathrm{O}$ Concentration in ASCM Glasses ............................... 4.22

Figure 4.14. Density as a Function of $\mathrm{Na}_{2} \mathrm{O}$ Concentration in ASCM Glasses ................................... 4.23

Figure 4.15. Iron Redox [Fe(II)/Fe(total)] as a Function of $\mathrm{Na}_{2} \mathrm{O}$ Concentration in ASCM Glasses ..... 4.24

Figure 4.16. SEM Micrograph of Inclusions in SC-Treated ASCM-02 Glass .................................. 4.25

Figure 4.17. SEM Image of an Inclusion in SC-Treated ASCM-02 Glass ........................................ 4.25

Figure 4.18. SEM EDS Dot Map of SC-Treated ASCM-02 Glass .................................................. 4.26

Figure 4.19. Targeted Mass Fractions of Components in Simulated (ASCM-01) and Radioactive

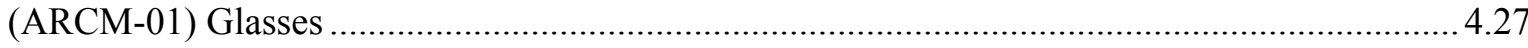

Figure 4.20. Analytical Mass Fractions of Components in Simulated (ASCM-01) and Radioactive

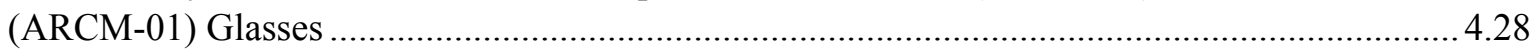


Figure 4.21. 7-Day PCT Leachate Concentrations from Simulated (ASCM-01) and Radioactive (ARCM01) Quenched Glasses

Figure 4.22. 7-Day PCT Leachate Concentrations from Simulated (ASCM-01) and Radioactive (ARCM01) SC Glasses.

Figure 4.23. 7-Day PCT Normalized Releases from Simulated (ASCM-01) and Radioactive (ARCM-01) Quenched Glasses.

Figure 4.24. 7-Day PCT Normalized Releases from Simulated (ASCM-01) and Radioactive (ARCM-

01) SC Glasses. 4.30

Figure 5.1. Experimental Setup Used to Control Atmospheres for Preparation of AMOG Glasses .5 .4

Figure 5.2. VHT $200^{\circ} \mathrm{C}$ Mass Losses versus Time for AMOG Samples .5 .5

Figure 5.3. VHT Effect of the Oxidation-Reduction State of Iron on the VHT Mass Loss for AMOG Glasses 5.6

Figure 6.1. Glass Block from the ES-1 Run 6.3

Figure 6.2. Addition of Soil and $\mathrm{ZrO}_{2}$ Mixture to LAW Simulant for ES-2....... 6.5

Figure 6.3. ES-2 Feed after Transfer into Water Bath. 6.5

Figure 6.4. ES-2 Feed During Drying. 6.6

Figure 6.5. ES-2 Glass Block Inside of the Cavity of the Melter 6.6

Figure 6.6. Position of Glass Samples Taken for Composition Analysis from the ES-1 Glass Block ..... 6.8

Figure 6.7. ES-1-1, -4, and -5 Samples and their Positions in ES-1 Glass Block ${ }^{0}$. 6.9

Figure 6.8. ES-1-2, and -4 Samples and their Positions in ES-1 Glass Block 6.10

Figure 6.9. ES-1-3 Sample and its Position in ES-1 Glass Block

Figure 6.10. Cross-Section of ES-1 Glass Block with Glass-Sand Interface Magnified in Areas to Illustrate Movement of Insulating Sand into the Bulk Glass.

Figure 6.11. Example of Glass-Sand Interface at the Bottom of the Melt

Figure 6.12. Example of Glass-Sand Interface at the Side-Wall and Top of Melt (side-wall is top of this photo).

Figure 6.13. Ratio of Measured and Target Concentrations of $\mathrm{ReO}_{2}, \mathrm{SO}_{3}$, and Selected Major Components in ES-1 Glasses.

Figure 6.14. Ratio of Measured Concentrations of ES-1 Glasses to that of ASCM-01 Glass for Selected 
Figure 6.15. ES-1 Glass Block Showing the Areas from Where PCT, VHT, TCLP and Density Samples Were Obtained $^{0}$

Figure 6.16. Illustration of How the ES-1-8 Samples for Glass Characterization Were Obtained from Side-Wall Area of the ES-1 Glass Block ${ }^{0}$

Figure 6.17. Optical Micrographs of VHT Coupons from Sand-Glass Interface Area, ES-1-8 (top view before the test, top, and cross-sections after 14 days at $200^{\circ} \mathrm{C}$, bottom)

Figure 6.18. Optical Micrographs of VHT Coupons from Sandy Area (ES-1-7S, left) and Sand-Glass Interface Area (ES-1-7M, right) after 14 days at $200^{\circ} \mathrm{C}$ (length and width of coupon are $10 \mathrm{~mm}$ )

Figure 6.19. Optical Micrograph of VHT Coupon from Sand Area, ES-1-7S after 14 days at $200^{\circ} \mathrm{C}$ (the Cavity in Center of Micrograph Contains Needle-Like Crystals) ${ }^{0}$

Figure 6.20. Optical Micrographs of VHT Coupon Cross-Section from Sand-Glass Interface Area (ES-1$7 \mathrm{M}$ ) after 14 days at $200^{\circ} \mathrm{C}$ (length of a coupon is $10 \mathrm{~mm}$ and width is $1.5 \mathrm{~mm}$ ).

Figure 6.21. Optical Micrograph of the Surface of VHT Coupon from Sand-Glass Interface Area, ES-1$7 \mathrm{M}$, after 14 days at $200^{\circ} \mathrm{C}$. Note the needle-like crystals. ${ }^{0}$.

Figure 6.22. VHT Coupon from Glass near Electrode 3 (ES-1-10) with Metallic Droplets Precipitated at the Contact with the Graphite Electrode (iron was oxidized during the 14-days exposure to steam at $\left.200^{\circ} \mathrm{C}\right)$.

Figure 6.23. A Typical Section of Glass with Metallic Droplets (SEM micrograph)

Figure 6.24. Metallic Droplets Released from ES-1 Glass Block During Sampling ${ }^{0}$ 6.25

Figure 6.25. EDS Dot Map Showing Composition of a Metallic Droplet in ES-1-10. 6.26

Figure 6.26. A Metallic Droplet in ES-1-10 Sample 6.26

Figure 6.27(a). EDS Dot Map of Iron Droplets in ES-1-3... 6.27

Figure 6.28(b). EDS Dot Map of Iron Droplets in ES-1-3 6.28

Figure 6.29(c). EDS Dot Map of Iron Droplets in ES-1-3 6.28

Figure 6.30. $\mathrm{SiO}_{2}$ Concentration as a Function of Distance from the Surface of the ES-1 Block...... 6.29

Figure 6.31. ES-2 Melt Samples with Designation of Where Analytical Samples Were Obtained ${ }^{(}{ }_{\text {....... } 6.30}$ Figure 6.32. Ratio of Measured and Target Concentrations of Selected Major Components in ES-2 Glasses 
Figure 6.33. Cavities from the Top of ES-2 Melt Near an Electrode with White- to Reddish-Colored Condensate

Figure 6.34. SEM Micrographs of White Condensate on the Inside of Large Glass Bubble from ES-1

Melter Test (similar to the condensate from ES-2 that was dissolved in DIW for analyses) .......6.34 


\section{Tables}

Table 2.1. Acceptable Concentrations of Some Restricted Metals in TCLP Solution............................2.3

Table 2.2. Electrical Conductivity of $\mathrm{KCl}$ Solution as a Function of Concentration...............................2.5

Table 3.1. Local Soil Compositions in Mass Fractions ........................................................................ 3.2

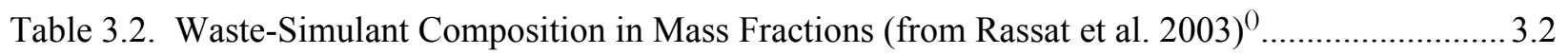

Table 3.3. Compositions of AMBG Test Glasses in Mass Fractions.......................................................... 3.4

Table 3.4. Predicted Properties of AMBG Glasses................................................................................. 3.5

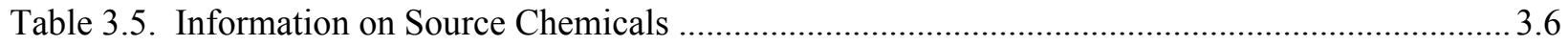

Table 3.6. Masses of Batch Chemicals to Make $500 \mathrm{~g}$ of AMBG Glass ................................................... 3.7

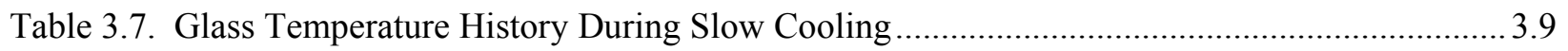

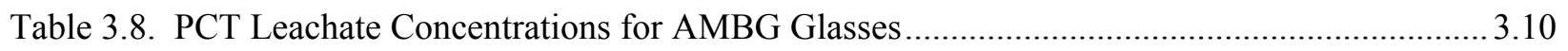

Table 3.9. PCT Normalized Releases from AMBG Glasses ............................................................... 3.12

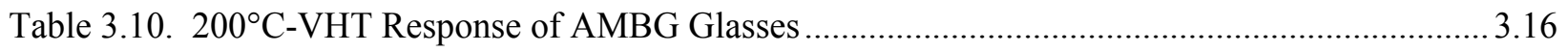

Table 3.11. VHT Average Corrosion Rates of AMBG Glasses ............................................................17

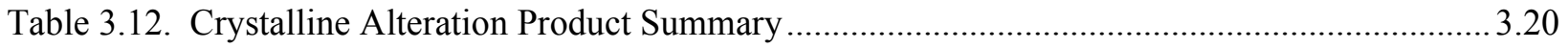

Table 3.13. TCLP Responses of Selected Glasses Compared to the Predicted Values ......................... 3.21

Table 3.14. Viscosity Results for AMBG-13 and 16 Glasses..............................................................22

Table 3.15. Electrical Conductivity Results for AMBG-13 and 16 Glasses...........................................24

Table 3.16. Crystalline Phases, in Mass\%, Determined by XRD in SC Samples within $\sim 1.5-\mathrm{mm}$ at Pt-

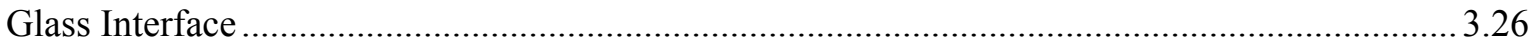

Table 4.1. ASCM Target Glass Formulations in Mass \% of Components ............................................. 4.1

Table 4.2. Concentrations of Reagents in Saltcake Solution Simulant...................................................2

Table 4.3. Analyte Concentrations in Saltcake Solution Simulant and in Actual Waste........................ 4.2

Table 4.4. Glass Component Concentration in Saltcake Solution Simulant and Actual Waste............... 4.3

Table 4.5. Compositions of ASCM and ARCM Glasses (in mass fractions) ....................................... 4.3 
Table 4.6. Predicted Properties of ASCM and ARCM Glasses .......................................................... 4.4

Table 4.7. Rhenium Addition to Saltcake Solution for ASCM Glasses .............................................. 4.5

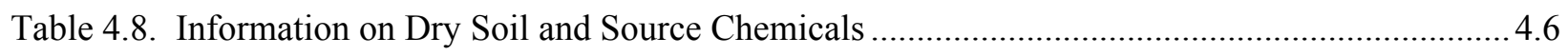

Table 4.9. Masses (g) of Batch Materials to Make 500-g ASCM Glasses ............................................ 4.6

Table 4.10. Masses (g) of Batch Materials and Volume of Actual Waste to Make 500-g ARCM Glass 4.7

Table 4.11. Calculated Reductant Required to Reduce all $\mathrm{Fe}_{2} \mathrm{O}_{3}$ to $\mathrm{FeO}$ for ASCM Glasses ${ }^{(\mathrm{a})}$.............. 4.8

Table 4.12. Analyzed Compositions of ASCM and ARCM Glasses (in mass fractions) ${ }^{(\mathrm{a})}{ }^{2 . . . . . . . . . . . . . . . . . ~} 4.11$

Table 4.13. Concentration of Radioactive Components in Actual Waste and in ARCM-01 glass......... 4.13

Table 4.14. Summary of Properties for Simulant and Actual Waste Crucible Test Glasses ................. 4.14

Table 4.15. Comparison of PCT Leachate Concentrations in LRM Glass Measured in this Study to the Standard Reference Data (Ebert and Wolf 2000) .................................................................. 4.16

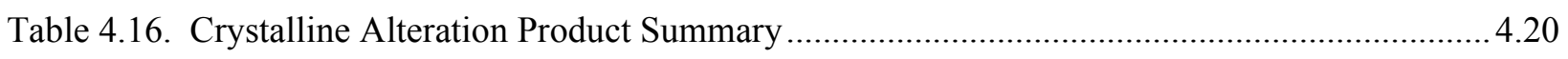

Table 4.17. Concentration of Tc in PCT Solutions from ARCM-01 Glasses and Normalized Tc Releases

Table 5.1. Fe Sources and Gas Compositions for Glasses with Varied Iron Redox Melted at $1270^{\circ} \mathrm{C} . . .5 .1$

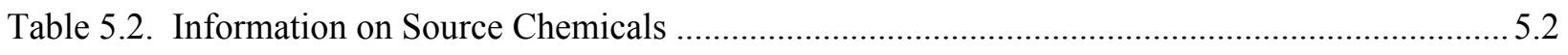

Table 5.3. Masses of Batch Chemicals to Make 100-g AMOG Glass..................................................5.3

Table 5.4. Measured Redox Ratio for AMOG Samples ................................................................ 5.4

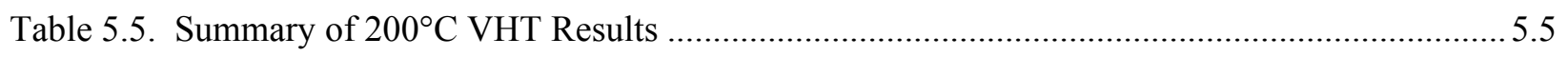

Table 6.1. ES-1 Glass Composition in Terms of Mass Fractions from Source Materials ...................... 6.1

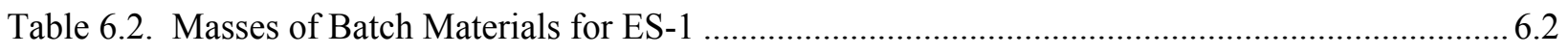

Table 6.3. Masses of Batch Materials Required for ES-2 ............................................................. 6.4

Table 6.4. Amount of Flux Materials Used in Each ES Test............................................................. 6.7

Table 6.5. Oxide Concentration of Flux Materials Used in ES Tests (ES-1 and 2) .............................6.7

Table 6.6. Analyzed Compositions (in mass fractions) and Redox of ES-1 Glasses........................... 6.14

Table 6.7. Estimated Mass Fraction of Sand Dissolved in the ES-1 Glass Samples $(S)$ Calculated from 


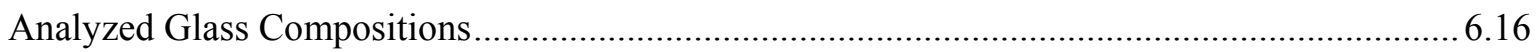

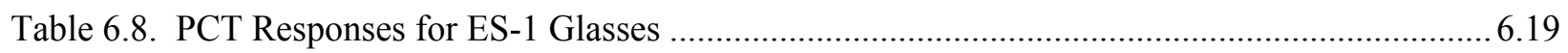

Table 6.9. 14-day VHT Responses for ES-1 Glasses....................................................................... 6.19

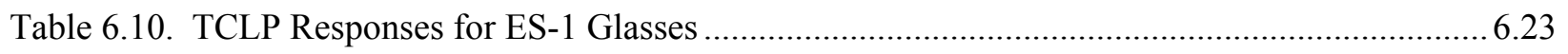

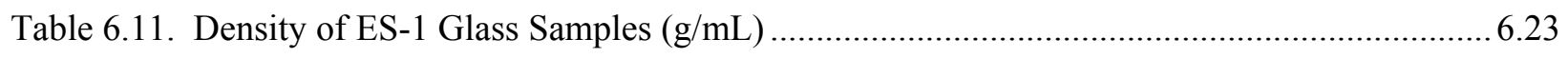

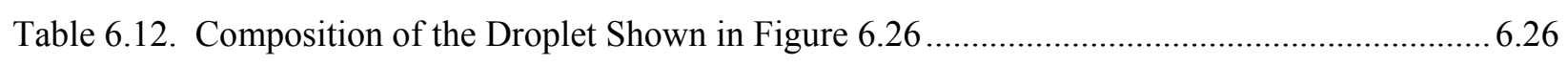

Table 6.13. Analyzed Compositions (in mass fractions) of ES-2 Glasses ......................................... 6.31

Table 6.14. Estimated Mass Fraction of Sand Dissolved in the ES-2 Glass Samples $(S)$ Calculated from

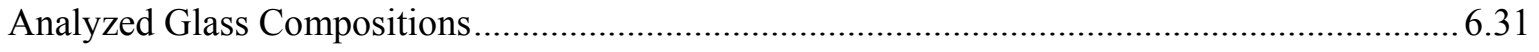

Table 6.15. Measured Concentrations of ${ }^{99} \mathrm{Tc}$ and Re in ES-2 Homogenized Samples ${ }^{(\mathrm{a})}$.................... 6.32 


\subsection{Introduction}

\subsection{Tank Waste Treatment}

Roughly 51-million gallons of radioactive waste are stored in 177 underground tanks at the Hanford site in central Washington. This waste was generated from over four decades of heavy metal separations and nuclear materials processing conducted by the U.S. Department of Energy (DOE) and its predecessors. The DOE Office of River Protection (ORP) plans to retrieve the tank waste, separate it into low-activity waste (LAW) and high-level waste (HLW) fractions and separately treat the waste streams for disposal. Figure 1.1 shows a schematic of the current ORP flowsheet This process includes the retrieval and delivery of tank waste to the Waste Treatment Plant (WTP), which will separate the HLW and LAW fractions and separately vitrify them (Bechtel National Inc. 2003). However, with the current planned capacity of the WTP only a fraction of the LAW that can be treated by the scheduled completion date of 2028. Therefore, ORP, through its tank farm operator - CH2M Hill Hanford Group (CHG) - is considering supplemental treatment technologies for LAW. There are two possible insertion points for the supplemental treatment technologies in the current strategy: 1) divert the LAW radioactive waste tanks directly to the supplemental treatment, which may or may not include radionuclide separations steps and 2) divert the LAW fraction of tank waste from the WTP to the supplemental treatment technology. By either option, the waste will be treated for disposal in the Hanford Site Near-Surface Burial Facility for retrievable disposal.

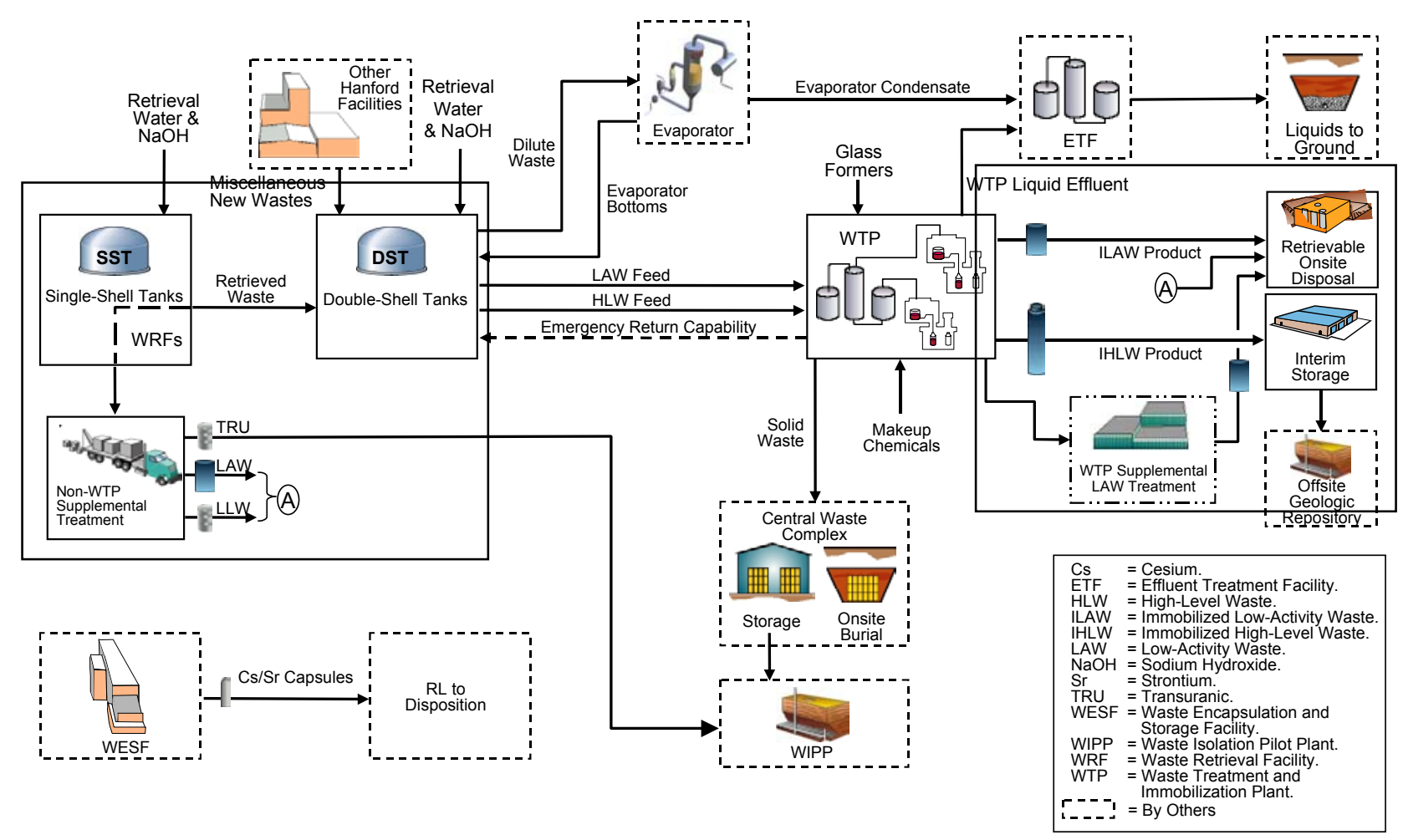

Figure 1.1. Current ORP Schematic (from Allen et al. 2002) 
One of the supplemental treatment technologies being considered by $\mathrm{CH} 2 \mathrm{M}$ Hill Hanford Group (CHG) and ORP is in-container vitrification (ICV). ICV is a technology developed by AMEC, GeoMelt Division, based on in situ vitrification (ISV, for example, Buelt et al. 1987; Geosafe 1998; Spalding et al. 1992). In this technology, the waste is mixed with soil and possibly additional additives, dried, and loaded into a refractory-lined metal box. The dried mixture is melted with current supplied by two graphite electrodes imbedded in the batch. The process is fundamentally similar to the WTP LAW vitrification process with a few key differences. The "melter" used in the ICV is also the disposal container, reducing the concern for corrosion-related processes lowering the melter life. Therefore, ICV can typically be operated at higher temperatures than the WTP process. ICV process is not susceptible to molten salt accumulation, which limits the loading of higher sulfur LAWs in WTP glass, due primarily to the higher operating temperatures. ICV waste-form composition can be lower in fluxes that must be used in the WTP to maintain adequate transport properties at lower temperatures. The ICV waste-form is typically an alumino-silicate glass but can include boron or other components if desired to maintain adequate properties (such as chemical durability). Since, the ICV "melter" is used only once and the glass is not poured out into a different container, the process is more tolerant to crystalline phase formation in the melt. Therefore, secondary phases are not detrimental to the waste-form as long as they do not cause the properties of the overall waste form to fail any performance requirements. Since the ICV product is primarily composed of soil and waste, the materials cost is significantly lower than that of the WTP LAW vitrification, which produces a waste glass primarily out of high-cost chemicals.

Generally, the chemical durability of the LAW glass produced by the ICV process is expected to be better than that of the WTP process for comparable waste loadings. The improved durability is possible due to the capability to operate at higher temperatures than the WTP process. With higher temperatures, lower concentrations of non-waste flux components are required to maintain adequate melt viscosity and electrical conductivity. The lower flux concentrations generally lead to higher chemical durability.

\subsection{Objectives}

AMEC has contracted with Pacific Northwest National Laboratory (PNNL) for technical support in waste-form development and product testing for a process demonstration with Hanford LAW. There are several components to the activities being performed as highlighted below.

1. Glass formulation and preliminary testing was performed with the primary objectives of identifying baseline glass composition(s) to be used in scale-up and radioactive testing. The baseline glass should have the appropriate properties for processing by ICV and meet product quality constraints. (While the baseline formulation is quite feasible, it is by no means optimized.)

2. Simulant crucible testing was performed with the primary objectives of determining the ICV product quality as a function of waste loading and other key process variables and to supply product samples to $\mathrm{CHG}$ for further testing.

3. Radioactive crucible testing was performed using actual Hanford LAW with the primary objectives of validating the simulants used in crucible and scaled ICV tests and to demonstrate that the product meets performance constraints. 
4. Engineering-scale simulant testing was performed with the primary objectives of demonstrating the ICV process and product quality using scaled prototypical equipment and to generate off-gas and mass-balance data. Only the product quality testing results are reported here.

5. Engineering-scale Tc tracer testing was performed with the primary objectives of determining the fate of Tc during the ICV process and to demonstrate the process with radioactive materials. Only the glass-composition data are discussed in this report.

In addition to these tasks, large-scale tests, engineering and design, and other activities were performed by AMEC and their contractors in support of CHG and ORP. These activities are reported elsewhere and described in the project Demonstration and Test Plan (AMEC 2002).

\subsection{Quality Assurance}

The work described in this report was performed under the PNNL Nuclear Quality Assurance Requirements Description (NQARD) procedures in accordance with the AMEC Bulk Vitrification Project Quality Assurance Plan. These quality assurance procedures and program plan are compliant with the NQA-1 quality assurance (QA) program requirements passed down in the statement of work. ${ }^{\text {(a) }}$

(a) Statement of Work, Supplemental Technology - Bulk Vitrification, Requisition \#93505, "Phase I - Bulk Vitrification", Rev.0, dated October 2, 2002, CH2M Hill Hanford Group. 


\subsection{Waste-Form Test Methods}

In this section, the experimental methods used to characterize the waste-form samples from each task are summarized. Glass formulation, experimental approach, glass fabrication, and test results from each task are treated in separate sections following this section. Appendix A lists the PNNL procedures used in this study.

\subsection{Product Consistency Test (PCT)}

The PCT was performed as defined in American Society for Testing and Materials (ASTM) C 1285 (ASTM 1998). Samples were ground, washed, and prepared according to procedure. Then between 15 and $20 \mathrm{~mL}$ of deionized water (DIW) were added to a corresponding clean-glass-sample size of 1.5 to $2.0 \mathrm{~g}$ of glass so that the ratio between the DIW and the glass was exactly 10 to 1 , resulting in a surface area-to-volume ratio (S/V) of approximately $2000 \mathrm{~m}^{-1}$. The vessels used for PCT were desensitized Type 304L stainless steel. The vessel was closed, sealed, and placed into an oven at $90 \pm 2{ }^{\circ} \mathrm{C}$ where it remained for 7 days \pm 3 hours.

After the 7-day test, the vessel was removed from the oven and allowed to cool to room temperature. The final mass of the vessel and the solution $\mathrm{pH}$ were recorded on the data sheet. Test solutions were then filtered through a $0.45-\mu \mathrm{m}$-size filter and acidified with concentrated, high-purity $\mathrm{HNO}_{3}$ to $1 \mathrm{vol} \%$ to assure that the cations remain in solution. Test solutions were then analyzed for $\mathrm{Si}, \mathrm{Na}$, and selected other components if present in the glass (e.g., B). The concentrations of $\mathrm{Si}, \mathrm{Na}, \mathrm{B}$, and $\mathrm{Ca}$ were determined by inductively coupled plasma-atomic emission spectroscopy (ICP-AES).

\subsection{Vapor Hydration Test (VHT)}

In the VHT, monolithic samples were exposed to water vapor at $200^{\circ} \mathrm{C}$ in a sealed stainless steel vessel (described in the PCT procedure) according to the procedure supplied by CHG in the Statement of Work (SOW) describing this scope. Using a diamond-impregnated saw, $10 \times 10 \times 1.5 \mathrm{~mm}(0.4 \times 0.4 \times 0.06 \mathrm{in}$.), samples were prepared from heat-treated glass bars. All sides were polished to 600-grit surface finishes with silicon carbide paper.

Samples, stainless steel vessels, lids, and supports were cleaned, samples were suspended from stainless steel supports on Pt wire, and $0.20 \mathrm{~g}$ of DIW water were added to the vessel. The sealed vessel was held at $200^{\circ} \mathrm{C}$ for a predetermined amount of time (typically 14 days) in a convection oven. After removal, vessels were weighed and quenched in water.

Specimens were then removed from the vessel and divided into two parts with a diamond-impregnated saw. One part was used for optical microscopy/image analysis (OM/IA) evaluation of the specimen cross section, and the other part was used for phase identification with X-ray diffraction (XRD) and scanning electron microscopy/energy dispersive spectroscopy (SEM/EDS).

The remaining glass thickness of the VHT specimen was determined by performing at least 10 measurements distributed (roughly equally) across the crack-free cross section of the sample. This step 
yields the average thickness of the remaining glass and the standard deviation of the measurements. The amount of glass altered per unit surface area of specimen was determined from the average thickness of unaltered glass according to:

$$
m=\frac{1}{2} \rho\left(d_{i}-d_{r}\right)=\frac{m_{i}}{2 w_{i} l_{i}}\left(1-\frac{d_{r}}{d_{i}}\right)
$$

where

$$
\begin{aligned}
w_{i}, d_{i}, l_{i} & =\text { specimen width, thickness, and length, respectively } \\
d_{i} & =\text { initial specimen thickness } \\
d_{r} & =\text { average thickness of remaining glass layer } \\
m_{i} & =\text { initial specimen mass } \\
m & =\text { mass of glass converted to alteration products per unit surface area } \\
\rho & =\text { glass density. }
\end{aligned}
$$

The average rate of corrosion was calculated as $r_{a}=m / t$, where $t$ is the corrosion time. Vienna et al. (2001) showed that, if the average rate of corrosion at $200^{\circ} \mathrm{C}$ is

$$
r_{a}=m / t<50 \mathrm{~g} /\left(\mathrm{m}^{2} \cdot \mathrm{d}\right)
$$

then the final rate of corrosion, $r_{\infty}<50 \mathrm{~g} /\left(\mathrm{m}^{2} \cdot \mathrm{d}\right)$, meets the current ORP requirement for LAW glass performance.

\subsection{Toxicity Characteristic Leach Procedure (TCLP)}

The TCLP testing was performed by Severn Trent Laboratories, Inc. (STL St. Louis, 13725 Rider Trail North, Earth City, MO 63045). The extraction and analyses was performed according to SW 846 method 1311 (EPA 1992) and quality assurance/quality control requirements.

In the TCLP, glass pieces, $\leq 9.5 \mathrm{~mm}(0.4 \mathrm{in}$.) in size and $\geq 100 \mathrm{~g}$ in mass, were placed in dilute acetic acid ( $\mathrm{pH}$ value of $4.98 \pm 0.05$ ) and agitated at $30 \pm 2 \mathrm{rpm}$ for $18 \pm 2$ hours at room temperature. The concentrations of hazardous metals in solution were then measured—see Table 2.1.

The values listed in Table 2.1 are based upon Resource Conservation and Recovery Act (RCRA) regulation and the more stringent Universal Treatment Standard (UTS) put forth by the U.S.

Environmental Protection Agency (EPA) 40 CFR 268.48 (2001) for certain waste categories defined in 40 CFR 268.40 (2001). According to Table 2.1, Cr is the only TCLP metal in the waste. However, additional metals may be introduced when soil is used as the raw materials. 
Table 2.1. Acceptable Concentrations of Some Restricted Metals in TCLP Solution

\begin{tabular}{|l|c|c||}
\hline Metal & $\begin{array}{c}\text { Characteristic Limit } \\
\text { ppm }\end{array}$ & $\begin{array}{c}\text { UTS Limit } \\
\text { ppm }\end{array}$ \\
\hline $\mathrm{Ag}$ & 5 & 0.14 \\
\hline $\mathrm{As}$ & 5 & 5 \\
\hline $\mathrm{Ba}$ & 100 & 21 \\
\hline $\mathrm{Cd}$ & 1 & 0.11 \\
\hline $\mathrm{Cr}$ & 5 & 0.6 \\
\hline $\mathrm{Pb}$ & 5 & 0.75 \\
\hline $\mathrm{Se}$ & 1 & 5.7 \\
\hline $\mathrm{Zn}$ & --- & 4.3 \\
\hline $\mathrm{Ni}$ & --- & 11 \\
\hline $\mathrm{Sb}$ & --- & 1.15 \\
\hline $\mathrm{Be}$ & --- & 1.22 \\
\hline $\mathrm{Tl}$ & --- & 0.2 \\
\hline $\mathrm{V}$ & --- & 1.6 \\
\hline \hline
\end{tabular}

\subsection{Viscosity}

The viscosities $(\eta)$ of selected glasses were measured as functions of temperature to support AMEC design and large-scale testing. The $\eta$ was measured with a fully automated rotating-spindle Brookfield Digital Viscometer according to the PNNL procedures GDL-VIS (for measurement) and GDL-VSC (for calibration). The Pt-20\% Rh spindle was submerged in molten glass in a Pt crucible. The viscometer was set up above a high-temperature furnace. The Pt-20\%Rh spindle (a cylindrical disc $14 \mathrm{~mm}$ [0.55 in.] in diameter and $2 \mathrm{~mm}$ [0.08 in.] thick located $8 \mathrm{~mm}$ [0.3 in.] from the end of a Pt rod) was suspended from the viscometer into the molten pool of glass in a Pt crucible.

Before the measurement, the positions of the crucible in the furnace and the spindle in the crucible were carefully centered, and the viscometer was leveled in all directions. The spindle was lowered into the melt so its lower end was $2 \mathrm{~mm}(0.08 \mathrm{in}$.) from the bottom of the crucible. As the spindle rotates at a constant speed, the torque value is registered by the viscometer. The spindle speed is adjusted automatically.

Each sample of the glass was prepared by crushing the glass into pieces 5 to $25 \mathrm{~mm}$ (0.2 to 1 in.) in size. The glass volume of $50 \mathrm{~mL}$ was measured using liquid (ethanol) displacement. The glass was melted in a 5-cm (2-in.)-diameter platinum crucible. The melt was heated to each set-point and held for 25 minutes to reach thermal equilibrium. The viscometer was set to record the temperature, time, torque, and spindle speed at 30 -sec intervals throughout the run. The average of the last 20 readings at each set temperature was used to calculate $\eta$. The effect of volatilization on $\eta$ was assumed to be negligible considering the low surface-to-volume ratio of the melts.

The viscometer was calibrated using National Institute for Standards and Technology (NIST) 710a sodalime-silica glass (NIST 1980), for which 


$$
\log (\eta)=A+\frac{B}{T-T_{0}}
$$

where $T$ is the temperature and $A, B$, and $T_{0}$ are coefficients that have the following values: $T_{0}=240.8^{\circ} \mathrm{C}$, $A=-1.7290$ (for $\eta$ in $\mathrm{dPa} \cdot \mathrm{s}$ ), and $B=4560.0 \mathrm{~K}$. The calibration data were used to calculate the spindle factor, $F$, defined as

$$
F=\eta \frac{\omega}{\tau}
$$

where $\tau$ is the torque and $\omega$ is the spindle speed. The viscometer was calibrated at the beginning of the series of measurements.

The $\eta$ of glasses was calculated using Equation 2.4 rearranged as

$$
\eta=F \frac{\tau}{\omega}
$$

For the melting-temperature interval, the Arrhenius equation is a fully adequate expression of the $\eta$ vs. $T$ relationship:

$$
\ln \eta=A+\frac{B}{T}
$$

where $A$ and $B$ are the Arrhenius coefficients. These coefficients were evaluated for each glass tested.

\subsection{Electrical Conductivity}

The electrical conductivities $(\varepsilon)$ of selected glasses were measured as functions of temperature to support AMEC design and large scale testing. The $\varepsilon$ was measured according to the procedures GDL-ELC (for measurement) and GDL-ECC (for calibration). To calibrate the conductivity probe, a standard $\mathrm{KCl}$ solution method was used. A probe with two platinum-10\% rhodium blades is inserted into the solution to the depth of $12.5 \mathrm{~mm}(0.5 \mathrm{in}$.). The $\varepsilon$ of $\mathrm{KCl}$ solutions as a function of room temperature listed in Table 2.2 (ASTM D 1125-95) (ASTM 1999) was used to calibrate the conductivity probe to obtain the cell constant. 
Table 2.2. Electrical Conductivity of KCl Solution as a Function of Concentration

\begin{tabular}{||c|c|c|c||}
\hline \hline Solution & $\mathbf{K C l}$ mass per 1-L solution at $\mathbf{2 0}^{\circ} \mathbf{C}(\mathbf{g})$ & $\mathbf{T}\left({ }^{\circ} \mathbf{C}\right)$ & $\boldsymbol{\varepsilon}(\mathbf{S} / \mathbf{m})$ \\
\hline \multirow{2}{*}{$1 \mathrm{M}$} & \multirow{3}{*}{74.246} & 0 & 6.5176 \\
& & 18 & 9.7838 \\
& & 25 & 11.1342 \\
\hline \multirow{2}{*}{$0.1 \mathrm{M}$} & 7.4365 & 0 & 0.7138 \\
& & 18 & 1.1167 \\
& & 25 & 1.2856 \\
\hline
\end{tabular}

The cell constant, $L$, is defined by the formula

$$
L=\varepsilon R
$$

where $R$ is the electrical resistance of the cell.

The glass melt from viscosity measurement was transferred to the electric conductivity furnace. The probe was inserted into the melt to the depth of $12.5 \mathrm{~mm}(0.5 \mathrm{in}$.). The same configuration of the probe was carefully maintained for each measurement. Measurements started at the $T_{\max }$ determined in viscosity measurements. The glass was held at each temperature for 25 minutes to reach thermal equilibrium. The resistance of the glass melt was recorded at the frequency of $100 \mathrm{~Hz}$ to $100 \mathrm{kHz}$. The measurements were made at $100^{\circ} \mathrm{C}$ intervals.

The $\varepsilon$ of glasses was calculated using Equation 2.7 rearranged as

$$
\varepsilon=L / R
$$

The Arrhenius equation was used to represent $\varepsilon$ as a function of $T$ :

$$
\ln \varepsilon=A+\frac{B}{T}
$$

where $A$ and $B$ are the Arrhenius coefficients.

\subsection{Glass Density}

The waste-form density was measured using an Accupyc 1330 Gas Pycnometer according to the procedure APEL-PIP-4-PIP-4. Annealed glasses were cut to obtain solid specimens with a nominal volume sufficient to fill at least $10 \%$ of the sample chamber in the gas pycnometer. Samples were washed with DIW, placed into a glass beaker filled with ethanol, and ultrasonically cleaned before analysis. The sample dry mass was determined with a calibrated four-decimal-place balance. The glass density was measured with the pycnometer calibrated before and after the experiment with a tungsten carbide ball, a NIST traceable standard. After five runs for each glass, the average glass densities were calculated. 


\subsection{Secondary-Phase Identification}

Samples of the waste-form were characterized for the amount and type of secondary phases that formed during the process of cooling. The amount of crystallinity was determined by examining portions of the glass with XRD. The quantitative XRD could detect and quantify as little as $0.25 \mathrm{wt} \%$ of a crystalline phase in the glass (though the actual detection limit depends on the type of the crystalline material). The PNNL procedure "Quantitative and Semi-Quantitative Analysis using X-Ray Diffraction" (GDL-XRD) was followed. The internal standard for quantitative XRD was 5 mass $\% \mathrm{CaF}_{2}$.

The sample mass of 1 to $2 \mathrm{~g}$ was milled for 2 minutes in the tungsten-carbide milling chamber, and the powder was then mounted in an XRD sample holder. Scanning proceeded with $0.04^{\circ} 2-\theta$ step size, 6 -s dwell time, and 5 to $70^{\circ} 2-\theta$ scan range.

The secondary phase identification and quantification was aided by OM with IA and SEM with EDS for selected samples. For OM and SEM-EDS examination, selected samples were sliced and polished. Glass composition and crystal compositions were determined by EDS. Standard glasses were analyzed with each of the selected samples to provide reference composition for bias adjustments.

\subsection{Sample Composition Analyses}

The chemical compositions of non-radioactive glasses were measured by Westinghouse Savannah River Company (WSRC, Aiken, SC 29808), and chemical and radiochemical compositions of radioactive glass samples were measured by PNNL Analytical Services Organization (ASO) with similar procedures (with exceptions where noted). The samples were fused in $\mathrm{KOH}$ and $\mathrm{Na}_{2} \mathrm{O}_{2}$. The fused samples were dissolved in dilute nitric acid in an analytical volumetric flask. The resulting solutions were analyzed using ICPAES for major components and by ICP-mass spectroscopy (MS) for minor components (e.g., Tc and Re). In selected cases, ion chromatography was used to determine the concentrations of $\mathrm{F}, \mathrm{SO}_{4}$, and $\mathrm{PO}_{4}$ in the solution. The concentrations of $\mathrm{U}$ and $\mathrm{Cs}$ were determined by U-KPA and gamma energy analyses, respectively. Appropriate quality-control standards were used to assess accuracy and uncertainties associated with the measurements. In addition to quality control (QC) standards, samples of low-activity reference material (LRM)-1 glass (Wolf et al. 1998) were included as blind-standard glasses for the analyses.

Wet colorimetry was used at PNNL to measure the $\mathrm{Fe}^{2+} / \Sigma \mathrm{Fe}$ ratio in glasses. $\mathrm{Fe}^{2+}$ ions react with 1,10 phenanthroline and form an orange-red complex $\left[\left(\mathrm{C}_{12} \mathrm{H}_{8} \mathrm{~N}_{2}\right)_{3} \mathrm{Fe}^{2+}\right]$ in solution over a $\mathrm{pH}$ range of 2 to 9 . The optical absorbance of this complex at $510 \mathrm{~nm}$ follows the Lambert-Beer law,

$$
a=e c d
$$

where

$a=$ absorbance (dimensionless)

$e=$ extinction coefficient $\left(\mathrm{mm}^{-1}\right)$

$c=$ concentration of ferrous ion

$d=$ sample thickness $(\mathrm{mm})$. 
Calibration curves for converting measured absorbance to $\mathrm{Fe}^{2+}$ concentration are established at $510 \mathrm{~nm}$, using an atomic absorption iron standard solution.

To determine the $\mathrm{Fe}^{2+} / \Sigma \mathrm{Fe}$ ratio in a glass, a sample is ground with an alumina mortar and pestle to a fine powder. About 20 to $30 \mathrm{mg}$ of the powder are added to a $100-\mathrm{mL}$ plastic beaker and digested by adding $0.5 \mathrm{~mL}$ of concentrated $\mathrm{H}_{2} \mathrm{SO}_{4}$ and $1.5 \mathrm{~mL}$ of concentrated HF. Immediately after dissolution of the glass (within $15 \mathrm{~s}$ of adding the acids), an indicating solution, kept in a second $100-\mathrm{mL}$ plastic beaker, is added, and the $\mathrm{pH}$ of the solution is adjusted to 3.3 to 3.5 using diluted $\mathrm{NH}_{4} \mathrm{OH}$ and/or diluted $\mathrm{H}_{2} \mathrm{SO}_{4}$. This solution is transferred to a $100-\mathrm{mL}$ volumetric flask and diluted to $100 \mathrm{~mL}$ by adding iron-free DIW. The indicating solution contains $25 \mathrm{~mL}$ of $4 \%$ boric acid, $7 \mathrm{~mL}$ of $10 \%$ potassium hydrogen phthalate, $6 \mathrm{~mL}$ of $0.25 \%$ 1,10-phenanthroline solution, and $2 \mathrm{~mL}$ of concentrated $\mathrm{NH}_{4} \mathrm{OH}$.

The ferrous ion is quantified spectrophotometrically at a wavelength of $510 \mathrm{~nm}$ using an UV-VIS-NIR spectrophotometer (Cary 500 Scan, Varian) with Cary WinUV software. For the analysis of total iron, 20 $\mathrm{mL}$ of the above solution is transferred to a $100-\mathrm{mL}$ plastic bottle. Hydroquinone $(25 \pm 5 \mathrm{mg})$ is added to the solution to reduce all the $\mathrm{Fe}^{3+}$ ions to $\mathrm{Fe}^{2+}$ ions. The absorbance of this solution is measured after the complete color development of the orange-red complex. Using the calibration curve, the measured absorbances are converted to the concentrations of $\mathrm{Fe}^{2+}$ and total iron present in the solution to obtain the $\mathrm{Fe}^{2+} / \Sigma \mathrm{Fe}$ ratio.

The above PNNL methods were used for indication or rough estimates only before the determinative measurements were taken at Savannah River Technology Center (SRTC): they were based on a QA procedure $^{(a)}$ The SRTC procedure is similar to PNNL wet colorimetry and consists of the following steps:

- Dissolve the pulverized glass sample in a sulfuric-hydrofluoric acid mixture containing ammonium vanadate, which preserves the $\mathrm{Fe}^{2}+$ content.

- Add boric acid to destroy iron-fluoride complexes, making the $\mathrm{Fe}^{2}+$ available for complexation with ferrozine.

- Add pH 5 buffer and ferrozine reagent to form the magenta-colored ferrous-ferrozine complex, with measurement of the absorbance for the determination of $\mathrm{Fe}^{2}+$ content.

- Add ascorbic acid to reduce $\mathrm{Fe}^{3}+$ to $\mathrm{Fe}^{2}$, with a second absorbance measurement that determines total Fe.

(a) L28 Manual, Procedure 1.8, Rev. 2 "Determining $\mathrm{Fe}^{2+} / \mathrm{Fe}^{3+}$ and $\mathrm{Fe}^{2+} / \mathrm{Fe}$ (total) using the HP8452A Diode Array Spectrometer." 


\subsection{Preliminary Crucible Tests}

This section describes the procedure for glass formulation and fabrication for preliminary crucible tests, the test results on PCT, VHT, TCLP, viscosity and electrical conductivity, and secondary phase identification, and the process for selecting baseline glass.

\subsection{Preliminary Glass Formulation and Fabrication}

Waste-glass formulation includes determining the composition of glass-forming and glass-modifying additives dependent on the specifics of the processing technology. In the ICV process, the major additive to the waste is soil. However, other additions are necessary for glasses to pass the VHT specifications because the local soil used in the preliminary formulation effort contains high enough levels of $\mathrm{Al}_{2} \mathrm{O}_{3}$ to impair the VHT response. The most effective additives to improve the VHT response are $\mathrm{ZrO}_{2}$ and $\mathrm{B}_{2} \mathrm{O}_{3}$, but these additives increase the cost of the process. The 16 preliminary glass compositions were formulated in four groups to investigate the impacts of waste loading, soil composition variation (only $\mathrm{Al}_{2} \mathrm{O}_{3}$ and $\mathrm{Fe}_{2} \mathrm{O}_{3}$ content), and additive composition and concentration on key glass properties that cannot be predicted with current tools. Glasses were prepared from raw materials that would yield the same composition as from simulants to select the baseline compositions to be used in the next phases of the tests - use of simulants was not required for the present preliminary crucible tests. The results from testing these glasses, AMBG-01 to 16, are reported in Sections 3.2 through 3.6.

\subsubsection{Glass-Composition Representation}

Some simplifying, usually tacit, assumptions are customarily employed for glass-formulation calculations. These assumptions are mere conventions that avoid the complexity of the final partitioning of the elements in mass-balance calculations. The main assumptions used in this study are as follows.

1. All $\mathrm{NO}_{\mathrm{x}}$ and $\mathrm{CO}_{\mathrm{x}}$ are released into the off-gas. Though some elemental carbon is retained in the waste package, it is not considered a glass component because it is not a part of glass structure (except some negligible dissolved $\mathrm{CO}_{2}$ ).

2. All metal cations enter the glass. The volatilization of alkali metals, such as $\mathrm{Na}$ that evaporates as $\mathrm{NaOH}, \mathrm{NaBO}_{2}, \mathrm{NaF}, \mathrm{NaCl}$, etc., is disregarded. It significantly affects glass composition only under unusual circumstances, such as long-time exposure of small-volume, large-surface-area samples to high temperatures.

3. Non-metals other than $\mathrm{N}$ and $\mathrm{C}$ dissolve in the glass. Thus, all $\mathrm{F}, \mathrm{Cl}, \mathrm{P}$, and $\mathrm{S}$ are treated as glass components. This is assumed for the sake of simplicity. In reality, the halogens (e.g., F, Cl, I) are not retained totally in the glass (see Goles 1996 for example). Some of the $\mathrm{S}$ precipitates in the form of sulfide, and some will be lost as $\mathrm{SO}_{2}$ or $\mathrm{Na}_{2} \mathrm{SO}_{4}$ to the off-gas (see Darab et al. 2001 for example); thus, it will not be a part of the glass structure. Phosphorus may precipitate in phase-separated droplets or crystals (see Jantzen et al. 2001). However, these effects are neglected in defining the target glass compositions.

4. All elements are treated as single metal oxides except halogens, which are conventionally treated as elements. The assignments do not insinuate structural units within the melt or glass but are used merely as a convenient and consistent method to represent composition. 
5. All multivalent oxides are represented by a single, preferably prevalent, valence. This simplified treatment is fully adequate for most glass and process-characterization purposes. It is always possible to refine this treatment for special needs. In fact, this appeared necessary for Fe, which is present at too high concentrations to disregard its oxidation-reduction (redox) state. For the purposes of most of the composition representation, $\mathrm{Fe}_{2} \mathrm{O}_{3}$ is used to represent all of the $\mathrm{Fe}$ in the glass. However, in certain cases, as appropriate, the $\mathrm{Fe}(\mathrm{II}) / \mathrm{Fe}$ fraction is discussed.

\subsubsection{Glass-Formulation Development}

The ICV process uses soil as the primary additive to the waste. Table 3.1 lists the compositions of soils native to the immediate area. Table 3.2 lists the simplified waste composition used for the AMBG preliminary glass formulation.

Table 3.1. Local Soil Compositions in Mass Fractions

\begin{tabular}{|c|c|c|c|c|c|c|c|c|c|}
\hline & Surface $^{(\mathbf{a})}$ & $\mid$ PSFT-1 $^{\text {(a) }}$ & PSFT-2 ${ }^{\text {(a) }}$ & PSCT-1 ${ }^{\text {(a) }}$ & LSOAT-2 $^{(\mathbf{a})}$ & AMEC Site $^{(\mathbf{b})}$ & Min & Average & Max \\
\hline $\mathrm{Al}_{2} \mathrm{O}_{3}$ & 0.1250 & 0.1360 & 0.1390 & 0.1380 & 0.1440 & 0.1396 & 0.1250 & 0.1369 & 0.1440 \\
\hline $\mathrm{CaO}$ & 0.0681 & 0.0537 & 0.0641 & 0.0544 & 0.0596 & 0.0550 & 0.0537 & 0.0592 & 0.0681 \\
\hline $\mathrm{Fe}_{2} \mathrm{O}_{3}$ & 0.1150 & 0.0816 & 0.0986 & 0.0917 & 0.0906 & 0.0928 & 0.0816 & 0.0950 & 0.1150 \\
\hline $\mathrm{K}_{2} \mathrm{O}$ & 0.0157 & 0.0143 & 0.0156 & 0.0245 & 0.0198 & 0.0248 & 0.0143 & \begin{tabular}{|l|}
0.0191 \\
\end{tabular} & 0.0248 \\
\hline $\mathrm{MgO}$ & 0.0340 & 0.0251 & 0.0302 & 0.0141 & 0.0289 & 0.0143 & 0.0141 & 0.0244 & 0.0340 \\
\hline $\mathrm{Na}_{2} \mathrm{O}$ & 0.0314 & 0.0287 & 0.0269 & 0.0317 & 0.0323 & 0.0321 & 0.0269 & 0.0305 & 0.0323 \\
\hline $\mathrm{P}_{2} \mathrm{O}_{5}$ & 0.0047 & 0.0000 & 0.0052 & 0.0029 & 0.0040 & 0.0029 & 0.0000 & 0.0033 & 0.0052 \\
\hline $\mathrm{SiO}_{2}$ & 0.5800 & 0.6440 & 0.6010 & 0.6170 & 0.6050 & 0.6242 & 0.5800 & 0.6119 & 0.6440 \\
\hline $\mathrm{TiO}_{2}$ & 0.0206 & 0.0139 & 0.0160 & 0.0141 & 0.0157 & 0.0143 & 0.0139 & 0.0158 & 0.0206 \\
\hline $\mathrm{ZrO}_{2}$ & 0.0003 & 0.0000 & 0.0000 & 0.0000 & 0.0000 & 0.0000 & 0.0000 & 0.0001 & 0.0003 \\
\hline Total & 0.9948 & 0.9973 & 0.9966 & 0.9884 & 0.9999 & 1.0000 & & & \\
\hline \multicolumn{10}{|c|}{$\begin{array}{l}\text { (a) From Buelt et al. (1987). } \\
\text { (b) From this study. }\end{array}$} \\
\hline
\end{tabular}

Table 3.2. Waste-Simulant Composition in Mass Fractions (from Rassat et al. 2003) ${ }^{(a)}$

\begin{tabular}{|c|c|}
\hline Component & Fraction \\
\hline $\mathrm{Al}_{2} \mathrm{O}_{3}$ & 0.0188 \\
\hline $\mathrm{Cl}$ & 0.0090 \\
\hline $\mathrm{Cr}_{2} \mathrm{O}_{3}$ & 0.0046 \\
\hline$F$ & 0.0035 \\
\hline $\mathrm{K}_{2} \mathrm{O}$ & 0.0034 \\
\hline $\mathrm{Na}_{2} \mathrm{O}$ & 0.8983 \\
\hline $\mathrm{P}_{2} \mathrm{O}_{3}$ & 0.0202 \\
\hline $\mathrm{ReO}_{2}{ }^{(\mathrm{a})}$ & 0.0001 \\
\hline $\mathrm{SO}_{3}$ & 0.0418 \\
\hline Total & 1.0000 \\
\hline $\begin{array}{l}\text { (a) Re was added to the sir } \\
\text { as a Tc simulant that } \mathrm{w}\end{array}$ & $\begin{array}{l}\text { d by Rassat et al. (2003) } \\
\text { g. }\end{array}$ \\
\hline
\end{tabular}

(a) Since only a single LAW simulant composition was used, the influences of LAW composition variations were not directly tested. However, a number of glass component concentrations (e. g., Al, $\mathrm{Fe}$, and $\mathrm{Na}$ ) were evaluated as described later in this report. 
For the 16 AMBG crucible tests, glass formulations were focused on achieving target $\mathrm{Na}_{2} \mathrm{O}$ loadings in the vitrified product ranging from 17 to 26 mass \% with soil (of the composition of "AMEC Site" in Table 3.1 ) as the major additive. The contribution to $\mathrm{Na}_{2} \mathrm{O}$ loading from the soil, which contains 3.21 mass $\%$ $\mathrm{Na}_{2} \mathrm{O}$ and thus decreases the fraction of $\mathrm{Na}_{2} \mathrm{O}$ supplied from waste, was accounted for in all formulations. Glasses were formulated in four general sets:

1. The first set of glasses formulated (AMBG-01 through 04) was strictly soil-LAW mixtures that ranged from 17 to 26 mass $\% \mathrm{Na}_{2} \mathrm{O}$.

2. The second set of glasses formulated (AMBG-05 through 08) contained small amounts of additives in addition to soil (5 mass $\% \mathrm{ZrO}_{2}$ and 2.5 mass $\% \mathrm{ZrO}_{2}+2.5$ mass $\% \mathrm{~B}_{2} \mathrm{O}_{3}$ ) with 20 and 23 mass $\%$ $\mathrm{Na}_{2} \mathrm{O}$.

3. The third set of glasses formulated (AMBG-09 through 12) was based on AMBG-07 (5 mass $\% \mathrm{ZrO}_{2}$ and 23 mass $\% \mathrm{Na}_{2} \mathrm{O}$ in glass). In these glasses, the concentrations of $\mathrm{Al}_{2} \mathrm{O}_{3}$ and $\mathrm{Fe}_{2} \mathrm{O}_{3}$ in soil were varied, keeping the same proportions of soil, $\mathrm{LAW}$, and $\mathrm{ZrO}_{2}$.

4. The final set of glasses formulated (AMBG-13 through 16) contained greater concentrations of additives. Each of these glasses contain 5 mass $\% \mathrm{~B}_{2} \mathrm{O}_{3}$ and vary in primarily $\mathrm{ZrO}_{2}$ concentration. Glass AMBG- 15 contains $\mathrm{P}_{2} \mathrm{O}_{5}, \mathrm{La}_{2} \mathrm{O}_{3}$, and $\mathrm{TiO}_{2}$ as additional additives, and AMBG-16 contains lower $\mathrm{Na}_{2} \mathrm{O}\left(17\right.$ mass $\%$ ) with 3 mass $\% \mathrm{SiO}_{2}$ as an additive.

Table 3.3 summarizes the compositions thus formulated. Before the actual testing, glass properties were calculated using the response functions previously developed. Table 3.3 also lists the mass fractions of waste, soil, and total additives in the glasses. These properties include $\eta, \varepsilon$, density $(\rho), T_{L}$, the solubility of key waste components, PCT releases, and the TCLP response. Table 3.4 displays the calculated values.

\subsubsection{Glass Fabrication and Heat Treatment}

Table 3.3 shows the test matrix for preliminary crucible melts from this study. Glass compositions are given in mass fractions for each of the major components. Table 3.5 contains the manufacture, lot number, and LOD information for each of the chemicals used to fabricate the glasses. The LOD numbers were used in the glass batch sheets to account for additional water in the source chemicals. The 16 AMBG glasses were fabricated and tested in accordance with the procedure GDL-GBM. In preparation for chemical batching, precautions were taken as follows:

1. Chemicals of reagent grade or higher purity were used as source chemicals. These chemicals were designated by a cognizant scientist by marking the container and recording the chemical information from the container onto the Test Instruction sheet.

2. A limitation of $\pm 1 \%$ error for weighing chemicals was required for batching glasses. To obtain this accuracy, a suitable three-place calibrated balance was used. For the final mass of the entire batch, the same weight limitations applied. The amount weighed, as exactly recorded by the operator, was well within the limits described above.

3. Cross-contamination between samples from outside sources was minimized at each step. Tools that are reused were washed and rinsed before reuse. 
Table 3.3. Compositions of AMBG Test Glasses in Mass Fractions

\begin{tabular}{|c|c|c|c|c|c|c|c|c|c|c|c|c|c|c|c|c|}
\hline & 01 & 02 & 03 & 04 & 05 & 06 & 07 & 208 & 09 & 10 & 11 & 12 & 13 & 14 & 15 & 16 \\
\hline $\mathrm{Al}_{2} \mathrm{O}_{3}$ & 0.1204 & 0.1162 & 0.1120 & 0.1078 & 0.1090 & 0.1090 & 0.1048 & 0.1048 & 0.0848 & 0.1248 & 0.1080 & 0.1016 & 0.0989 & 0.0946 & 0.0946 & 0.0988 \\
\hline $\mathrm{B}_{2} \mathrm{O}_{3}$ & 0.0000 & 0.0000 & 0.0000 & 0.0000 & 0.0000 & 0.0250 & 0.0000 & 0.0250 & 0.0000 & 0.0000 & 0.0000 & 0.0000 & 0.0500 & 0.0500 & 0.0500 & 0.0500 \\
\hline $\mathrm{CaO}$ & 0.0462 & 0.0443 & 0.0424 & 0.0405 & 0.0415 & 0.0415 & .0396 & 0.0396 & 0.0409 & 0.0383 & 0.0408 & 0.0383 & 0.0375 & 0.0358 & 0.0358 & 0.0377 \\
\hline $\mathrm{Cl}$ & 0.0014 & 0.0017 & 0.0021 & 0.0024 & 0.0018 & 0.0018 & 0.0021 & 0.0021 & 0.0021 & 0.0021 & 0.0021 & 0.0021 & 0.0018 & 0.0018 & 0.0018 & 0.0015 \\
\hline $\mathrm{Cr}_{2} \mathrm{O}_{3}$ & 0.0007 & 0.0009 & 0.0011 & 0.0012 & 0.0009 & 0.0009 & 0.0011 & 0.0011 & 0.0011 & 0.0011 & 0.0011 & 0.0011 & 0.0009 & 0.0009 & 0.0009 & 0.0008 \\
\hline $\mathrm{F}$ & 0.0006 & 0.0007 & 0.0008 & 0.0009 & 0.0007 & 0.0007 & 0.0008 & 0.0008 & 0.0008 & 0.0008 & 0.0008 & 0.0008 & 0.0007 & 0.0007 & 0.0007 & 0.0006 \\
\hline $\mathrm{Fe}_{2} \mathrm{O}_{3}$ & 0.0780 & 0.0748 & 0.0716 & 0.0684 & 0.0700 & 0.0700 & 0.0668 & 0.0668 & 0.0690 & 0.0645 & 0.0468 & 0.0868 & 0.0633 & 0.0604 & 0.0604 & 0.0636 \\
\hline $\mathrm{K}_{2} \mathrm{O}$ & 0.0214 & 0.0207 & 0.0199 & 0.0192 & 0.0194 & 0.0194 & 0.0186 & 0.0186 & 0.0192 & 0.0180 & 0.0192 & 0.0181 & 0.0176 & 0.0168 & 0.0168 & 0.0176 \\
\hline $\mathrm{La}_{2} \mathrm{O}_{3}$ & & & & & & & & & & & & & & & 0200 & \\
\hline $\mathrm{MgO}$ & 0.0120 & 0.0115 & 0.0110 & 0.0105 & 0.0108 & 0.0108 & 0.0103 & 0.0103 & 0.0106 & 0.0099 & 0.0106 & 0.0100 & 0.0097 & 0.0093 & 0.0093 & 0.0098 \\
\hline $\mathrm{Na}_{2} \mathrm{O}$ & 0.1700 & 0.2000 & 0.2300 & 0.2600 & 0.2000 & 0.2000 & 0.2300 & 0.2300 & 0.2300 & 0.2300 & 0.2300 & 0.2300 & 0.2000 & 0.2000 & 0.2000 & 0.1700 \\
\hline $\mathrm{P}_{2} \mathrm{O}_{5}$ & 0.0057 & 0.0063 & 0.0069 & 0.0075 & 0.0061 & 0.0061 & 0.0067 & 0.0067 & 0.0068 & 0.0067 & 0.0068 & 0.0067 & 0.0060 & 0.0059 & 0.0159 & 0.0053 \\
\hline $\mathrm{ReO}_{2}$ & 0.0001 & 0.0001 & 0.0001 & 0.0001 & 0.0001 & 0.0001 & 0.0001 & 0.0001 & 0.0001 & 0.0001 & 0.0001 & 0.0001 & 0.0001 & 0.0001 & 0.0001 & 0.0001 \\
\hline $\mathrm{SiO}_{2}$ & 0.5248 & 0.5032 & 0.4816 & 0.4600 & 0.4707 & 0.4707 & 0.4492 & 0.4492 & 0.4644 & 0.4341 & 0.4635 & 0.4347 & 0.4255 & 0.4061 & 0.4061 & 0.4575 \\
\hline $\mathrm{SO}_{3}$ & 0.0067 & 0.0081 & 0.0095 & 0.0110 & 0.0082 & 0.0082 & 0.0096 & 0.0096 & 0.0096 & 0.0097 & 0.0096 & 0.0097 & 0.0083 & 0.0083 & 0.0083 & 0.0069 \\
\hline $\mathrm{TiO}_{2}$ & 0.0120 & 0.0115 & 0.0110 & 0.0105 & 0.0108 & 0.0108 & 0.0103 & 0.0103 & 0.0106 & 0.0099 & 0.0106 & 0.0100 & 0.0097 & 0.0093 & 0.0193 & 0.0098 \\
\hline $\mathrm{ZrO}_{2}$ & 0.0000 & 0.0000 & 0.0000 & 0.0000 & 0.0500 & 0.0250 & 0.0500 & 0.0250 & 0.0500 & 0.0500 & 0.0500 & 0.0500 & 0.0700 & 0.1000 & 0.0600 & 0.0700 \\
\hline Total & 1.0000 & 1.0000 & 1.0000 & 1.0000 & 1.0000 & 1.0000 & 1.0000 & 1.0000 & 1.0000 & 1.0000 & 1.0000 & 1.0000 & 1.0000 & 1.0000 & 1.0000 & 1.0000 \\
\hline Soil $^{(\mathrm{a})}$ & 0.841 & 0.806 & 0.772 & 0.737 & 0.754 & 0.754 & 0.720 & 0.720 & 0.721 & 0.719 & 0.720 & 0.719 & 0.682 & 0.651 & 0.651 & 0.685 \\
\hline Waste $^{(a)}$ & 0.159 & 0.194 & 0.228 & 0.263 & 0.196 & 0.196 & 0.230 & 0.230 & 0.229 & 0.231 & 0.230 & 0.231 & 0.198 & 0.199 & 0.199 & 0.165 \\
\hline Additive & & & & & 0.050 & 0.050 & 0.050 & 0.050 & 0.050 & 0.050 & 0.050 & 0.050 & 0.120 & 0.150 & 0.150 & 0.150 \\
\hline $\mathrm{Na}_{2} \mathrm{O}$ from Soil ${ }^{(\mathrm{a})}$ & 0.0270 & 0.0259 & 0.0248 & 0.0237 & 0.0242 & 0.0242 & 0.0231 & 0.0231 & 0.0239 & 0.0223 & 0.0238 & 0.0223 & 0.0219 & 0.0209 & 0.0209 & 0.0220 \\
\hline $\mathrm{Na}_{2} \mathrm{O}$ from Waste ${ }^{(\mathrm{a})}$ & 0.1430 & 0.1741 & 0.2052 & 0.2363 & 0.1758 & 0.1758 & 0.2069 & 0.2069 & 0.2061 & 0.2077 & 0.2062 & 0.2077 & 0.1781 & 0.1791 & 0.1791 & 0.1480 \\
\hline
\end{tabular}

(a) The fraction of soil or waste that consists of the glass formulation. AMBG preliminary crucible test glasses were prepared from raw chemicals, not from simulated waste and soil. 
Table 3.4. Predicted Properties of AMBG Glasses

\begin{tabular}{|c|c|c|c|c|c|c|c|c|c|c|c|c|c|c|c|c|c|c|c|}
\hline Property & Symbol & Unit & Reference & 01 & 02 & 03 & 04 & 05 & 06 & 07 & 08 & 09 & 10 & 11 & 12 & 13 & 14 & 15 & 16 \\
\hline \multirow{2}{*}{ Viscosity } & $T_{\eta=5 \text { Pa:s }}$ & ${ }^{\circ} \mathrm{C}$ & Vienna & 1512 & 1429 & 1349 & 1271 & 1405 & 1357 & 1332 & 1283 & 1313 & 1351 & 1353 & 1310 & 1290 & 1284 & 1258 & 1364 \\
\hline & $T_{\eta=10 \text { Pas }}$ & ${ }^{\circ} \mathrm{C}$ & Vienna & 1402 & 1326 & 1251 & 1179 & 1313 & 1266 & 1245 & 1197 & 1229 & 1262 & 1264 & 1225 & 1213 & 1211 & 1182 & 1282 \\
\hline \multirow{2}{*}{$\begin{array}{l}\text { Electrical } \\
\text { conductivity }\end{array}$} & $\varepsilon_{\eta}=5$ Pass & $\mathrm{S} / \mathrm{m}$ & Hrma et al. 1994 & 60 & 61 & 63 & 67 & 57 & 52 & 60 & 54 & 57 & 63 & 62 & 58 & 43 & 42 & 44 & 41 \\
\hline & $\varepsilon_{\eta=10} \mathrm{~Pa} \cdot \mathrm{s}$ & $\mathrm{S} / \mathrm{m}$ & Hrma et al. 1994 & 45 & 46 & 48 & 51 & 44 & 39 & 47 & 41 & 44 & 49 & 48 & 45 & 33 & 33 & 33 & 32 \\
\hline \multirow{3}{*}{ PCT } & $r_{\mathrm{B}}$ & $\mathrm{g} / \mathrm{m}^{2}$ & Vienna et al. 2002 & 0.04 & 0.08 & 0.15 & 0.31 & 0.06 & 0.11 & 0.12 & 0.23 & 0.16 & 0.09 & 0.12 & 0.13 & 0.16 & 0.14 & 0.15 & 0.08 \\
\hline & $r_{\mathrm{Li}}$ & $\mathrm{g} / \mathrm{m}^{2}$ & Vienna et al. 2002 & 0.05 & 0.09 & 0.17 & 0.32 & 0.07 & 0.12 & 0.14 & 0.24 & 0.19 & 0.10 & 0.13 & 0.14 & 0.16 & 0.14 & 0.17 & 0.09 \\
\hline & $r_{\mathrm{Na}}$ & $\mathrm{g} / \mathrm{m}^{2}$ & Vienna et al. 2002 & 0.09 & 0.19 & 0.41 & 0.88 & 0.16 & 0.26 & 0.35 & 0.56 & 0.47 & 0.27 & 0.34 & 0.37 & 0.33 & 0.30 & 0.31 & 0.16 \\
\hline TCLP & $c_{\mathrm{Cr}}$ & $\mathrm{mg} / \mathrm{L}$ & Kim and Vienna 2002 & 0.011 & 0.026 & 0.057 & 0.123 & 0.022 & 0.034 & 0.049 & 0.076 & 0.056 & 0.043 & 0.050 & 0.048 & 0.043 & 0.039 & 0.038 & 0.018 \\
\hline Density & $\rho$ & $\mathrm{g} / \mathrm{mL}$ & Vienna et al. 2002 & 2.614 & 2.630 & 2.646 & 2.662 & 2.692 & 2.654 & 2.709 & 2.670 & 2.718 & 2.699 & 2.684 & 2.733 & 2.704 & 2.743 & 2.743 & 2.682 \\
\hline $\mathrm{S} /(\mathrm{S}+\mathrm{A}+\mathrm{N})^{(\mathrm{a})}$ & & & & 0.644 & 0.614 & 0.585 & 0.556 & 0.604 & 0.604 & 0.573 & 0.573 & 0.596 & 0.550 & 0.578 & 0.567 & 0.587 & 0.580 & 0.580 & 0.630 \\
\hline
\end{tabular}


Table 3.5. Information on Source Chemicals

\begin{tabular}{|c|c|c|c|}
\hline Component & Manufacturer & $\begin{array}{c}\text { Lot } \\
\text { Number }\end{array}$ & $\begin{array}{c}\text { LOD }^{(a)} \\
(\operatorname{mass} \%)\end{array}$ \\
\hline $\mathrm{Al}_{2} \mathrm{O}_{3}$ & Fisher & 006627 & 0.000 \\
\hline $\mathrm{H}_{3} \mathrm{BO}_{3}$ & Noah & $20032 / 2.1$ & $44.26^{(\mathrm{b})}$ \\
\hline $\mathrm{Cr}_{2} \mathrm{O}_{3}$ & Fisher & 851377 & 0.000 \\
\hline $\mathrm{FeO}$ & Alfa products & C03N06 & 0.208 \\
\hline $\mathrm{K}_{2} \mathrm{CO}_{3}$ & Fisher & 005661 & 0.763 \\
\hline $\mathrm{Na}_{2} \mathrm{CO}_{3}$ & Fisher & 025436 & 0.000 \\
\hline $\mathrm{SiO}_{2}$ & Fisher & 016166 & 0.000 \\
\hline $\mathrm{ZrO}_{2}$ & Noah & $18151 / 1.1$ & 0.000 \\
\hline $\mathrm{CaCO}_{3}$ & Fisher & 007112 & 0.372 \\
\hline $\mathrm{NaCl}$ & Sigma & 74H1061 & 0.272 \\
\hline $\mathrm{NaF}$ & Mallinckrodt & WBXZ & 0.000 \\
\hline $\mathrm{MgO}$ & Fisher & 700694 & 0.904 \\
\hline $\mathrm{NaPO}_{3}$ & J.T. Baker & X09610 & 0.371 \\
\hline $\mathrm{ReO}_{2}$ & Alfa products & G23J09 & 0.000 \\
\hline $\mathrm{Na}_{2} \mathrm{SO}_{4}$ & J.T. Baker & 22102 & 0.086 \\
\hline $\mathrm{TiO}_{2}$ & J.T. Baker & 525355 & 0.273 \\
\hline \multicolumn{4}{|c|}{$\begin{array}{l}\text { (a) LOD is loss on drying at } 105^{\circ} \mathrm{C} \text { for } 24 \text { hours. } \\
\text { (b) Loss on ignition (LOI) at } 1050^{\circ} \mathrm{C} \text { for } 2 \text { hours is given for } \\
\mathrm{H}_{3} \mathrm{BO}_{3} \text { instead of LOD. }\end{array}$} \\
\hline
\end{tabular}

The masses of all chemicals (except for sodium carbonate) required to make $500 \mathrm{~g}$ of ABMG glasses are obtained from the compositions listed in Table 3.3 using the formula

$$
M_{i}=x_{i} \frac{M_{B i}}{\gamma_{i} M_{G i}} \frac{M}{1-\lambda_{i}}
$$

where

$x_{i}=i$-th glass component mass fraction

$M_{B i}=i$-th batch component molecular mass

$M_{G i}=i$-th glass component molecular mass

$\gamma_{i}=i$-th component stoichiometric coefficient

$M=$ mass of glass to be produced

$\lambda_{i}=i$-th component batch chemical loss on drying.

The mass of sodium carbonate was reduced by the equivalent amount of sodium added with the chloride, fluoride, meta-phosphate, and sulfate. The resulting amounts of chemicals to be weighed for $500 \mathrm{~g}$ of ABMG glasses were calculated and are listed in Table 3.6.

$\mathrm{FeO}$ was used as the source of iron in these preliminary melts because the ICV process is expected to operate in a relatively reducing mode. For example, the glass produced by ISV of soil near Hanford was 
found to have a $\mathrm{Fe}(\mathrm{II}) / \mathrm{Fe}$ (total) value of $50 \%$ on average. ${ }^{(\mathrm{a})}$ The ICV melts with Hanford LAW are expected to be more oxidized relative to the ISV melts because the high soda content of the LAW will increase glass basicity and decrease melt temperature. Both of these factors will tend to decrease the average melt redox. However, the process includes melting with graphite electrodes and a graphite rich starter path, which will cause redox variations in the melt with some portions of the melt likely to be fully reduced to FeO. For the purposes of product quality testing, fully reduced glass [e.g., nearly all Fe in the amorphous state is in the form of $\mathrm{Fe}(\mathrm{II})$ ] is expected to have conservatively high leach rates so $\mathrm{FeO}$ was used as the iron source in the preliminary crucible tests. Additional testing (see Section 5.0) was conducted to determine the impact of redox on key property values.

Table 3.6. Masses of Batch Chemicals to Make $500 \mathrm{~g}$ of AMBG Glass

\begin{tabular}{|c|c|c|c|c|c|c|c|c|}
\hline & 01 & 02 & 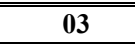 & 04 & 05 & 06 & $\overline{07}$ & $\overline{008}$ \\
\hline $\mathrm{Al}_{2} \mathrm{O}_{3}$ & 60.20 & 58.10 & 56.00 & 53.90 & 54.50 & 54.50 & 52.40 & 52.40 \\
\hline $\mathrm{H}_{3} \mathrm{BO}_{3}$ & 0.00 & 0.00 & 0.00 & 0.00 & 0.00 & 22.43 & 0.00 & 22.43 \\
\hline $\mathrm{CaCO}_{3}$ & 41.23 & 39.53 & 37.84 & 36.14 & 37.03 & 37.03 & 35.34 & 35.34 \\
\hline $\mathrm{NaCl}$ & 1.154 & 1.401 & 1.731 & 1.978 & 1.484 & 1.484 & 1.731 & 1.731 \\
\hline $\mathrm{Cr}_{2} \mathrm{O}_{3}$ & 0.350 & 0.450 & 0.550 & 0.600 & 0.450 & 0.450 & 0.550 & 0.550 \\
\hline $\mathrm{NaF}$ & 0.663 & 0.774 & 0.884 & 0.995 & 0.774 & 0.774 & 0.884 & 0.884 \\
\hline $\mathrm{FeO}$ & 35.17 & 33.72 & 32.28 & 30.84 & 31.56 & 31.56 & 30.12 & 30.12 \\
\hline $\mathrm{K}_{2} \mathrm{CO}_{3}$ & 15.82 & 15.30 & 14.71 & 14.19 & 14.34 & 14.34 & 13.75 & 13.75 \\
\hline $\mathrm{MgO}$ & 6.02 & 5.77 & 5.52 & 5.27 & 5.42 & 5.42 & 5.17 & 5.17 \\
\hline $\mathrm{Na}_{2} \mathrm{CO}_{3}$ & 137.28 & 161.49 & 185.61 & 209.75 & 161.42 & 161.42 & 185.62 & 185.62 \\
\hline $\mathrm{NaPO}_{3}$ & 4.09 & 4.53 & 4.96 & 5.39 & 4.38 & 4.38 & 4.81 & 4.81 \\
\hline $\mathrm{ReO}_{2}$ & 0.0505 & 0.0505 & 0.0505 & 0.0505 & 0.0505 & 0.0505 & 0.0505 & 0.0505 \\
\hline $\mathrm{SiO}_{2}$ & 263.38 & 252.54 & 241.70 & 230.86 & 236.23 & 236.23 & 225.44 & 225.44 \\
\hline $\mathrm{Na}_{2} \mathrm{SO}_{4}$ & 5.94 & 7.19 & 8.43 & 9.76 & 7.27 & 7.27 & 8.52 & 8.52 \\
\hline $\mathrm{TiO}_{2}$ & 6.01 & 5.75 & 5.50 & 5.25 & 5.40 & 5.40 & 5.15 & 5.15 \\
\hline $\mathrm{ZrO}_{2}$ & 0.00 & 0.00 & 0.00 & 0.00 & 25.07 & 12.53 & 25.07 & 12.53 \\
\hline \multirow[t]{2}{*}{ Total } & 577.358 & 586.595 & 595.764 & 604.973 & 585.388 & 595.280 & 594.601 & 604.492 \\
\hline & 09 & 10 & $\overline{111}$ & 12 & 13 & 14 & 15 & 16 \\
\hline $\mathrm{Al}_{2} \mathrm{O}_{3}$ & 42.40 & 62.40 & 54.00 & 50.80 & 49.45 & 47.30 & 47.30 & 49.40 \\
\hline $\mathrm{H}_{3} \mathrm{BO}_{3}$ & 0.00 & 0.00 & 0.00 & 0.00 & 44.85 & 44.85 & 44.85 & 44.85 \\
\hline $\mathrm{CaCO}_{3}$ & 36.50 & 34.18 & 36.41 & 34.18 & 33.47 & 31.95 & 31.95 & 33.64 \\
\hline $\mathrm{NaCl}$ & 1.731 & 1.731 & 1.731 & 1.731 & 1.484 & 1.484 & 1.484 & 1.236 \\
\hline $\mathrm{Cr}_{2} \mathrm{O}_{3}$ & 0.550 & 0.550 & 0.550 & 0.550 & 0.450 & 0.450 & 0.450 & 0.400 \\
\hline $\mathrm{NaF}$ & 0.884 & 0.884 & 0.884 & 0.884 & 0.774 & 0.774 & 0.774 & 0.663 \\
\hline $\mathrm{FeO}$ & 31.11 & 29.08 & 21.10 & 39.13 & 28.54 & 27.23 & 27.23 & 28.67 \\
\hline $\mathrm{K}_{2} \mathrm{CO}_{3}$ & 14.19 & 13.31 & 14.19 & 13.38 & 13.01 & 12.42 & 12.42 & 13.01 \\
\hline $\mathrm{MgO}$ & 5.32 & 4.97 & 5.32 & 5.02 & 4.87 & 4.67 & 4.67 & 4.92 \\
\hline $\mathrm{Na}_{2} \mathrm{CO}_{3}$ & 185.59 & 185.56 & 185.59 & 185.56 & 161.39 & 161.43 & 157.69 & 137.23 \\
\hline $\mathrm{NaPO}_{3}$ & 4.88 & 4.81 & 4.88 & 4.81 & 4.31 & 4.24 & 11.42 & 3.81 \\
\hline $\mathrm{ReO}_{2}$ & 0.0505 & 0.0505 & 0.0505 & 0.0505 & 0.0505 & 0.0505 & 0.0505 & 0.0505 \\
\hline $\mathrm{SiO}_{2}$ & 233.06 & 217.86 & 232.61 & 218.16 & 213.54 & 203.81 & 203.81 & 229.60 \\
\hline $\mathrm{Na}_{2} \mathrm{SO}_{4}$ & 8.52 & 8.60 & 8.52 & 8.60 & 7.36 & 7.36 & 7.36 & 6.12 \\
\hline $\mathrm{TiO}_{2}$ & 5.30 & 4.95 & 5.30 & 5.00 & 4.85 & 4.65 & 9.66 & 4.90 \\
\hline $\mathrm{La}_{2} \mathrm{O}_{3}$ & & & & & & & 10.00 & \\
\hline $\mathrm{ZrO}_{2}$ & 25.07 & 25.07 & 25.07 & 25.07 & 35.10 & 50.14 & 30.08 & 35.10 \\
\hline Total & 595.160 & 594.003 & 596.210 & 592.932 & 603.497 & 602.801 & 601.190 & 593.603 \\
\hline
\end{tabular}

(a) Preliminary data generated in support of the AMEC Geomelt Demonstration and Testing plan for Hanford LAW. 
Batch chemicals were placed into a well-fitted poly storage bag inside a collection container large enough for $500 \mathrm{~g}$ of glass. The collection container was labeled with the glass identification, project name, and the tare weight of the container with lid. Each component of the batch was weighed to within $\pm 1 \%$ relative precision. The appropriate scale was used to weigh each of the components based on the number of decimal places given on the batch sheet. The batch would be rejected and re-batched if there were a $>1 \%$ difference between the total and the calculated mass.

Batches were mixed inside the plastic bag for at least 30 seconds until a uniform color was achieved. The batch was transferred into an agate milling chamber in the Angstrom milling machine for approximately 4-min mixing. After milling, each batch for crucible tests was transferred into a clean Pt-10\%Rh crucible. The crucible was filled to $<1 / 2$ its height to minimize the chance of losing material to foaming. Melting the batch began at a temperature indicated in Table 3.4 as $T_{\eta=5 \text { Pass }}$ or higher. Charges were added to the crucible when the batch melted down and the foam collapsed. Once the entire batch had completely melted and stopped foaming, the crucible was covered with a lid with a center hole through which argon was introduced to prevent the oxidation of FeO. After 1 hour of melting, the glass was quenched on a stainless steel plate. The glass was homogenized by grinding the quenched and crucible wall glass into a fine powder in a tungsten-carbide milling chamber in the Angstrom milling machine for $4 \mathrm{~min}$. The ground glass was transferred into a Pt-10\%Rh crucible. The glass was then remelted with a tight lid under flowing argon at the same temperature as the first melt. If the first-melt glass contained crystals, the melting temperature of the second melt was raised by $50^{\circ} \mathrm{C}$.

The melt was poured to fill a small stainless steel mold $(15 \times 15 \times 20 \mathrm{~mm}[0.6 \times 0.6 \times 0.8 \mathrm{in}$.] $)$ heated on a hot plate for the VHT sample of the quenched glass and a larger platinum mold $(25.4 \times 25.4 \times 88.9 \mathrm{~mm}$ [1×1×3.5 in.]) for the SC heat-treatment sample (to be used for density, XRD, OM, SEM, VHT, TCLP, and PCT). The remaining glass melt was poured onto a clean stainless steel quench plate. The small mold was transferred into a preheated oven for annealing.

Each composition underwent two extreme heat treatments: a rapid cooling (air quenched after pouring, subsequently referred to as "quenched") and a slow cooling (SC, which represents the anticipated slowest cooling rate that glass will experience during ICV at full scale, an estimated value calculated by AMEC and provided to PNNL for these crucible melts). The estimated SC is defined in Table 3.7 and Figure 3.1. The average cooling rate from $1600^{\circ} \mathrm{C}$ to $500^{\circ} \mathrm{C}$ in $\mathrm{SC}$ is $9.2^{\circ} \mathrm{C} / \mathrm{hr}\left(0.15^{\circ} \mathrm{C} / \mathrm{min}\right)$ whereas it is expected to be at least $200{ }^{\circ} \mathrm{C} / \mathrm{min}$ or faster during rapid cooling. The starting temperature for SC heat treatment was determined as the temperature at which the predicted $\eta=10 \mathrm{~Pa} \cdot \mathrm{s}$. The rest of the cooling schedule was the same as in Figure 3.1. When more than one glass was heat treated at the same time, then the highest temperature at $\eta=10 \mathrm{~Pa} \cdot \mathrm{s}$ of all samples was used as the starting temperature.

Glass samples with these two temperature histories (i.e., quenched and SC) were tested for key properties (i.e., VHT, PCT, TCLP, $\rho$, and crystal-phase identification and quantification). 
Table 3.7. Glass Temperature History During Slow Cooling

\begin{tabular}{||c|c|}
\hline $\begin{array}{c}\text { Time } \\
\mathbf{h}\end{array}$ & $\begin{array}{c}\text { Temperature } \\
{ }^{\circ} \mathbf{C}\end{array}$ \\
\hline 0 & 1600 \\
\hline 6 & 1400 \\
\hline 10 & 1300 \\
\hline 24 & 1080 \\
\hline 48 & 880 \\
\hline 72 & 720 \\
\hline 96 & 600 \\
\hline 120 & 500 \\
\hline
\end{tabular}

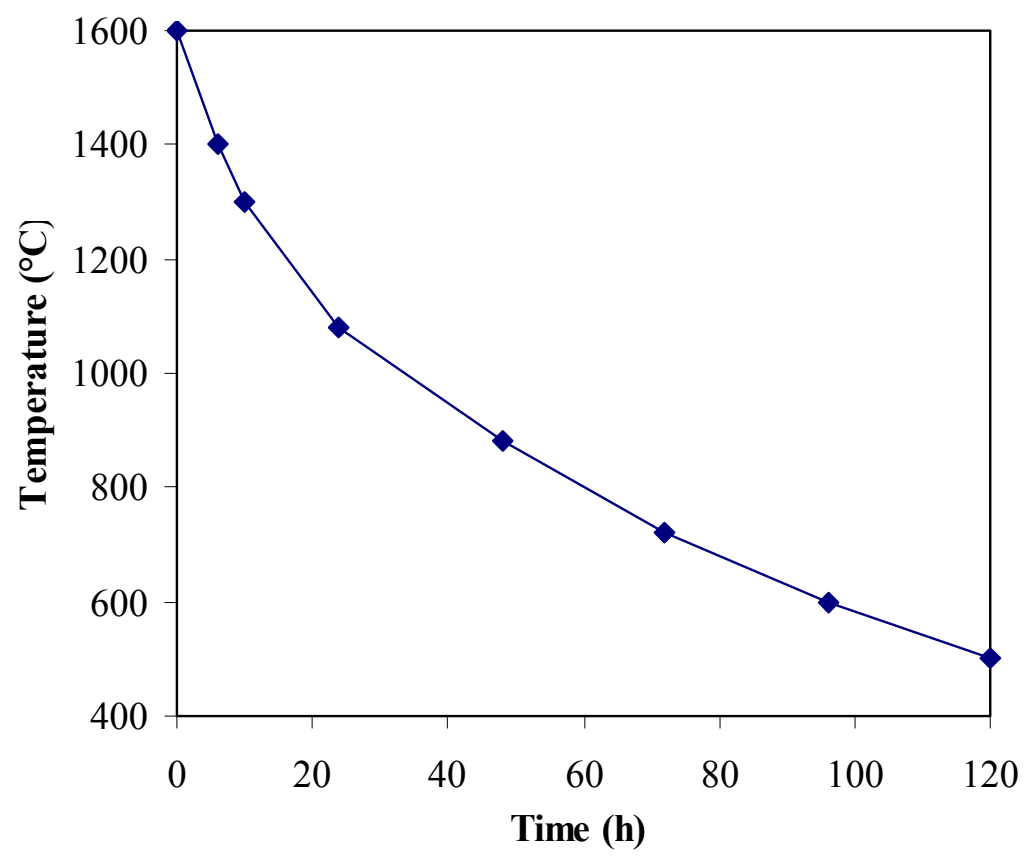

Figure 3.1. Waste Glass Time-Temperature Function During Slow Cooling

\subsection{Product Consistency Test}

Table 3.8 summarizes the leachate concentrations from the 7-day PCT tests for quenched and SC-treated samples of glasses AMBG-01 through 16. Table 3.8 shows the elemental releases of six major elements by ICP-AES and Na release obtained by Na ISE..$^{(a, b)}$ The Na releases by Na ISE were measured before the ICP-AES results become available to obtain the preliminary indication of PCT response to assist in determining the next formulations. Figure 3.2 compares Na concentrations in PCT solutions by the two methods, showing excellent agreement. Table 3.9 lists the normalized elemental releases for these glasses All glasses except for AMBG-04 passed the $2 \mathrm{~g} / \mathrm{m}^{2}$ constraint for PCT for both quenched and SC

(a) Cole-Parmer Instrument Company, 625 East Bunker Court, Vernon Hills, IL 60061.

(b) Non-QA procedure - this method was used for indication only to rapdly assess glass durability before receiving ICP-AES results from SRTC. 
samples, and glasses AMBG-13 through 16 passed by nearly an order of magnitude. The results and discussion on PCT tests presented below are all based on the ICP-AES analyses.

Table 3.8. PCT Leachate Concentrations for AMBG Glasses

\begin{tabular}{|c|c|c|c|c|c|c|c|}
\hline \multirow[b]{3}{*}{ Glass } & \multicolumn{7}{|c|}{$\begin{array}{c}\text { Concentrations of Components in Leachate from } \\
\text { Quenched Glasses }(\mathrm{mg} / \mathrm{L})\end{array}$} \\
\hline & \multicolumn{6}{|c|}{ ICP-AES } & \multirow{2}{*}{$\begin{array}{c}\text { Na ISE } \\
\text { can }\end{array}$} \\
\hline & $c_{\mathrm{Na}}$ & $c_{\mathrm{Al}}$ & $c_{\mathrm{B}}$ & $c_{\mathrm{Ca}}$ & $c_{\mathrm{K}}$ & $c_{\mathrm{Si}}$ & \\
\hline AMBG-01-Q & 102.69 & 14.17 & & 0.578 & 3.89 & 51.50 & 101 \\
\hline AMBG-02-Q & 242.22 & 24.46 & & 0.849 & 8.28 & 60.70 & 246 \\
\hline AMBG-03-Q & 563.07 & 39.41 & & 0.400 & 18.79 & 146.00 & 724 \\
\hline AMBG-04-Q & 1246.20 & 63.40 & & 0.515 & 41.86 & 236.00 & 1997 \\
\hline AMBG-05-Q & 185.92 & 19.29 & & 0.650 & 5.60 & 70.50 & 175 \\
\hline AMBG-06-Q & 164.16 & 18.31 & 3.10 & 0.910 & 4.85 & 72.60 & 152 \\
\hline AMBG-07-Q & 398.59 & 28.49 & & 0.593 & 11.15 & 102.00 & 436 \\
\hline AMBG-08-Q & 324.98 & 26.78 & 4.70 & 0.442 & 8.97 & 104.00 & 339 \\
\hline AMBG-09-Q & 510.82 & 24.19 & & 0.583 & 15.46 & 114.00 & 596 \\
\hline AMBG-10-Q & 274.28 & 31.47 & & 0.291 & 9.59 & 86.00 & 355 \\
\hline AMBG-11-Q & 407.50 & 28.96 & & 0.258 & 13.06 & 105.00 & 481 \\
\hline AMBG-12-Q & 407.32 & 29.07 & & 0.413 & 13.25 & 99.80 & 510 \\
\hline AMBG-13-Q & 108.00 & 13.50 & 7.85 & 0.432 & 4.02 & 50.20 & 105 \\
\hline AMBG-14-Q & 106.00 & 13.70 & 6.27 & 0.431 & 3.23 & 45.70 & 105 \\
\hline AMBG-15-Q & 148.00 & 15.50 & 9.82 & 0.472 & 6.04 & 58.50 & 147 \\
\hline AMBG-16-Q & 67.80 & 9.95 & 5.70 & 0.412 & 3.28 & 41.10 & 69 \\
\hline & \multicolumn{7}{|c|}{$\begin{array}{c}\text { Concentrations of Components in Leachate from } \\
\text { SC-Treated Glasses (mg/L) }\end{array}$} \\
\hline AMBG-01-SC & 88.11 & 12.74 & & 0.519 & 3.32 & 54.50 & 85 \\
\hline AMBG-02-SC & 216.64 & 21.94 & & 0.643 & 7.46 & 88.70 & 198 \\
\hline AMBG-03-SC & 472.33 & 36.21 & & 0.426 & 15.03 & 142.00 & 474 \\
\hline AMBG-04-SC & 1269.70 & 62.21 & & & 68.33 & 248.00 & 1278 \\
\hline AMBG-05-SC & 121.11 & 16.53 & & 0.478 & 3.91 & 60.30 & 141 \\
\hline AMBG-06-SC & 148.82 & 16.98 & 2.76 & 0.287 & 3.84 & 69.30 & 135 \\
\hline AMBG-07-SC & 325.10 & 25.56 & & 0.270 & 9.09 & 90.30 & 331 \\
\hline AMBG-08-SC & 172.16 & 25.34 & 4.32 & 0.423 & 7.59 & 97.90 & 299 \\
\hline AMBG-09-SC & 400.22 & 22.48 & & 0.581 & 11.54 & 108.00 & 423 \\
\hline AMBG-10-SC & 294.08 & 34.17 & & 0.338 & 7.21 & 80.40 & 308 \\
\hline AMBG-11-SC & 306.99 & 25.05 & & 0.386 & 8.93 & 90.30 & 350 \\
\hline AMBG-12-SC & 334.00 & 28.80 & & 0.631 & & 95.00 & 347 \\
\hline AMBG-13-SC & 121.75 & 14.61 & 8.96 & 1.519 & 9.38 & 53.24 & 96 \\
\hline AMBG-14-SC & 107.00 & 12.80 & 5.53 & 0.413 & 3.37 & 44.40 & 84 \\
\hline AMBG-15-SC & 130.00 & 14.70 & 8.67 & 0.412 & 5.48 & 54.90 & 104 \\
\hline AMBG-16-SC & 61.70 & 9.39 & 5.24 & 0.411 & 3.06 & 38.40 & 46 \\
\hline
\end{tabular}




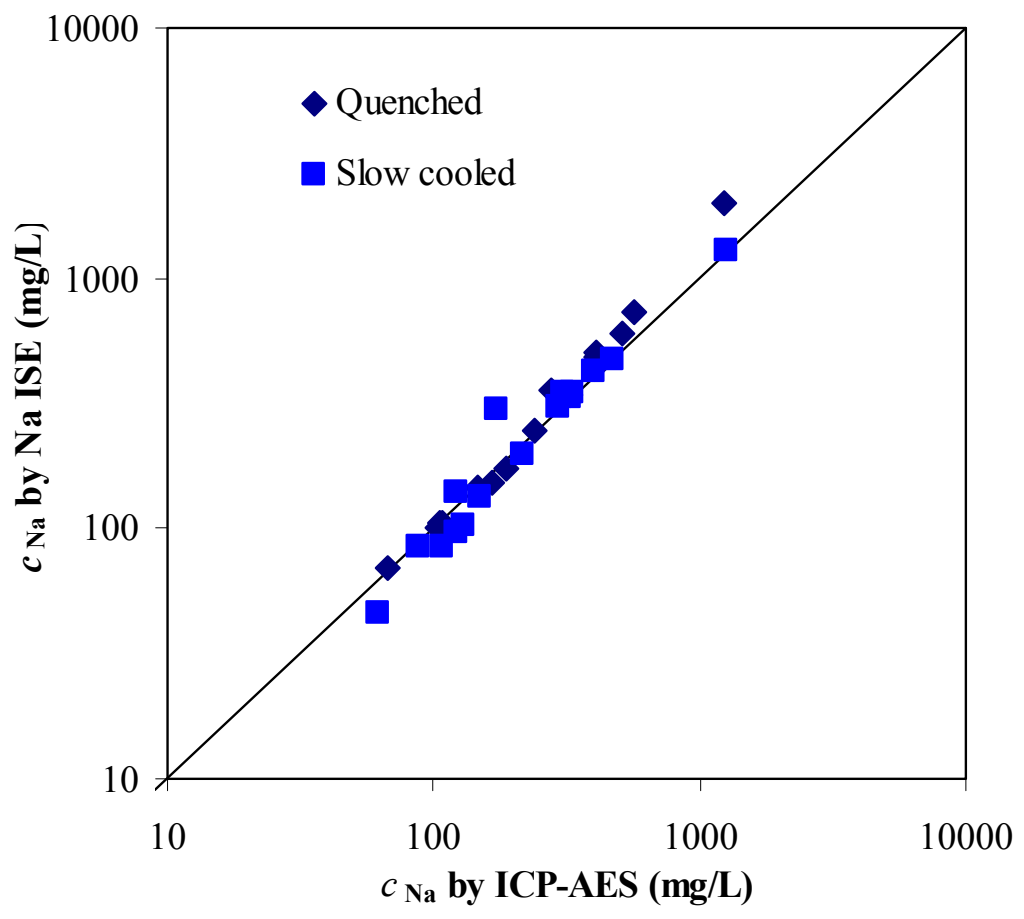

Figure 3.2. Comparison of PCT Na Concentrations Measured by ICP-AES and Na ISE

Figure 3.3 and Figure 3.4 compare the PCT normalized releases of Al, B, K, and Si with the normalized $\mathrm{Na}$ release for quenched and SC-treated samples, respectively. The normalized release of Ca was not included because of its extremely low values compared to the rest. Figure 3.3 and Figure 3.4 show that the normalized release of $\mathrm{Na}$ is the most conservative indication of glass dissolution in PCT conditions.

Figure 3.5 shows the effect of SC treatment on the PCT Na normalized release for 16 AMBG glasses, indicating that the SC treatment had no adverse effect on the PCT response. There is a weak trend that $\mathrm{SC}$ treatment results in lower PCT releases as compared to quenched glass, but this may be caused by partial oxidation of $\mathrm{FeO}$ to $\mathrm{Fe}_{2} \mathrm{O}_{3}$ during $\mathrm{SC}$ in air.

Figure 3.6 compares measured and predicted normalized Na releases for quenched samples of 16 AMBG glasses. The measured releases were larger than predicted for all glasses. This can be partly attributed to iron being batched as FeO. The present PCT model (Vienna et al. 2002) is based on tests conducted with glasses containing iron present dominantly as $\mathrm{Fe}_{2} \mathrm{O}_{3}$. Ferric oxide, being a glass former in soda-rich glasses, decreases PCT releases compared to FeO, a glass modifier.

Data in Figure 3.6 fall into two groups according to the $\mathrm{B}_{2} \mathrm{O}_{3}$ fraction in glass. AMBG glasses have 0, 2.5 , or 5 mass $\% \mathrm{~B}_{2} \mathrm{O}_{3}$. One group contains glasses with $\mathrm{B}_{2} \mathrm{O}_{3}(2.5$ and 5 mass $\%)$, and the other contains glasses with 0 mass $\% \mathrm{~B}_{2} \mathrm{O}_{3}$. The PCT models were developed for glasses with minimum 4 mass $\% \mathrm{~B}_{2} \mathrm{O}_{3}$. Not surprisingly, AMBG glasses with 2.5 and 5 mass $\% \mathrm{~B}_{2} \mathrm{O}_{3}$ show better agreement between measured and predicted values than glasses without $\mathrm{B}_{2} \mathrm{O}_{3}$, which have higher-than-predicted $\mathrm{Na}$ releases. This agrees with the observation that small additions of $\mathrm{B}_{2} \mathrm{O}_{3}$ have a beneficial effect on the PCT response. The linear-fit slopes in these two groups of glasses are close to the $45^{\circ}$ line, indicating that the component effects of the model apply to AMBG glasses with a nearly constant shift caused by iron redox and $\mathrm{B}_{2} \mathrm{O}_{3}$. 
The PCT responses of selected AMBG glasses are compared to data from literature in Figure 3.7 as a function of $\mathrm{Na}_{2} \mathrm{O}$ concentration in glass. The WTP LAW glasses are those reported by Muller et al. (2001), which represent current baseline compositions for the various waste sub-envelopes. All glasses except for one have the normalized Na release below $2 \mathrm{~g} / \mathrm{m}^{2}$ requirement. The AMBG glasses belong to the group of WTP glasses with lower Na releases, suggesting that typical ICV glasses perform at least as well as typical WTP glasses.

Table 3.9. PCT Normalized Releases from AMBG Glasses

\begin{tabular}{|c|c|c|c|c|c|c|c|c|c|}
\hline \multirow[b]{3}{*}{ Glass } & \multicolumn{7}{|c|}{ Normalized Releases from Quenched Glasses $\left(\mathrm{g} / \mathrm{m}^{2}\right)$, Measured } & \multirow{3}{*}{$\begin{array}{c}\text { Model } \\
\text { Predicted } \\
r_{\mathrm{Na}}\end{array}$} & \multirow{3}{*}{$\begin{array}{c}\mathrm{B}_{2} \mathrm{O}_{3} \\
\text { Mass fr } \\
\text { in glass }\end{array}$} \\
\hline & \multicolumn{6}{|c|}{ ICP } & \multirow{2}{*}{$\frac{\text { Na ISE }}{r_{\mathrm{Na}}}$} & & \\
\hline & $r_{\mathrm{Na}}$ & $r_{\mathrm{Al}}$ & $r_{\mathrm{B}}$ & $r_{\mathrm{Ca}}$ & $r_{\mathrm{K}}$ & $r_{\mathrm{Si}}$ & & & \\
\hline AMBG-01-Q & 0.407 & 0.111 & & 0.009 & 0.109 & 0.105 & 0.400 & 0.088 & \\
\hline AMBG-02-Q & 0.816 & 0.199 & & 0.013 & 0.241 & 0.129 & 0.829 & 0.191 & \\
\hline AMBG-03-Q & 1.650 & 0.332 & & 0.007 & 0.569 & 0.324 & 2.122 & 0.411 & \\
\hline AMBG-04-Q & 3.230 & 0.556 & & 0.009 & 1.313 & 0.549 & 5.177 & 0.882 & \\
\hline AMBG-05-Q & 0.627 & 0.167 & & 0.011 & 0.174 & 0.160 & 0.590 & 0.162 & \\
\hline AMBG-06-Q & 0.553 & 0.159 & 0.200 & 0.015 & 0.150 & 0.165 & 0.512 & 0.259 & 0.025 \\
\hline AMBG-07-Q & 1.168 & 0.257 & & 0.010 & 0.361 & 0.243 & 1.278 & 0.354 & \\
\hline AMBG-08-Q & 0.952 & 0.241 & 0.303 & 0.008 & 0.290 & 0.248 & 0.993 & 0.563 & 0.025 \\
\hline AMBG-09-Q & 1.497 & 0.270 & & 0.010 & 0.485 & 0.263 & 1.746 & 0.466 & \\
\hline AMBG-10-Q & 0.804 & 0.238 & & 0.005 & 0.321 & 0.212 & 1.040 & 0.268 & \\
\hline AMBG-11-Q & 1.194 & 0.253 & & 0.004 & 0.410 & 0.242 & 1.410 & 0.344 & \\
\hline AMBG-12-Q & 1.194 & 0.270 & & 0.008 & 0.441 & 0.246 & 1.494 & 0.365 & \\
\hline AMBG-13-Q & 0.364 & 0.129 & 0.253 & 0.008 & 0.138 & 0.126 & 0.354 & 0.334 & 0.050 \\
\hline AMBG-14-Q & 0.357 & 0.137 & 0.202 & 0.008 & 0.116 & 0.120 & 0.354 & 0.304 & 0.050 \\
\hline AMBG-15-Q & 0.499 & 0.155 & 0.316 & 0.009 & 0.217 & 0.154 & 0.495 & 0.306 & 0.050 \\
\hline \multirow[t]{2}{*}{ AMBG-16-Q } & 0.269 & 0.095 & 0.184 & 0.008 & 0.112 & 0.096 & 0.274 & 0.159 & 0.050 \\
\hline & \multicolumn{7}{|c|}{$\begin{array}{c}\text { Normalized Releases from SC Treated Glasses }\left(\mathrm{g} / \mathrm{m}^{2}\right), \\
\text { Measured }\end{array}$} & & \\
\hline AMBG-01-C & 0.349 & 0.100 & & 0.008 & 0.094 & 0.111 & 0.337 & & \\
\hline AMBG-02-C & 0.730 & 0.178 & & 0.010 & 0.217 & 0.189 & 0.667 & & \\
\hline AMBG-03-C & 1.384 & 0.305 & & 0.007 & 0.455 & 0.315 & 1.389 & & \\
\hline AMBG-04-C & 3.291 & 0.545 & & & 2.143 & 0.577 & 3.313 & & \\
\hline AMBG-05-C & 0.408 & 0.143 & & 0.008 & 0.121 & 0.137 & 0.475 & & \\
\hline AMBG-06-C & 0.502 & 0.147 & 0.178 & 0.005 & 0.119 & 0.157 & 0.455 & & 0.025 \\
\hline AMBG-07-C & 0.953 & 0.230 & & 0.005 & 0.294 & 0.215 & 0.970 & & \\
\hline AMBG-08-C & 0.504 & 0.228 & 0.278 & 0.007 & 0.246 & 0.233 & 0.876 & & 0.025 \\
\hline AMBG-09-C & 1.173 & 0.250 & & 0.010 & 0.362 & 0.249 & 1.240 & & \\
\hline AMBG-10-C & 0.862 & 0.259 & & 0.006 & 0.241 & 0.198 & 0.903 & & \\
\hline AMBG-11-C & 0.900 & 0.219 & & 0.007 & 0.280 & 0.208 & 1.026 & & \\
\hline AMBG-12-C & 0.979 & 0.268 & & 0.012 & & 0.234 & 1.017 & & \\
\hline AMBG-13-C & 0.410 & 0.140 & 0.289 & 0.028 & 0.321 & 0.134 & 0.324 & & 0.050 \\
\hline AMBG-14-C & 0.361 & 0.128 & 0.178 & 0.008 & 0.121 & 0.117 & 0.283 & & 0.050 \\
\hline AMBG-15-C & 0.438 & 0.147 & 0.279 & 0.008 & 0.196 & 0.145 & 0.350 & & 0.050 \\
\hline AMBG-16-C & 0.245 & 0.090 & 0.169 & 0.008 & 0.105 & 0.090 & 0.182 & & 0.050 \\
\hline
\end{tabular}




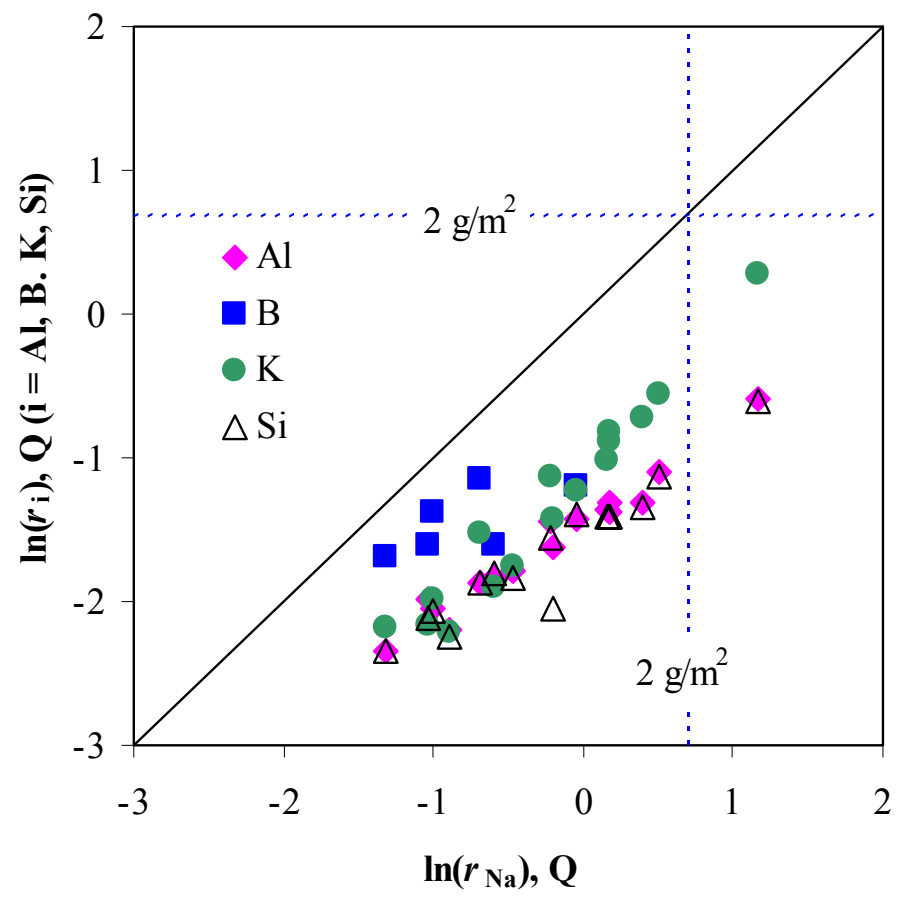

Figure 3.3. Comparison of PCT Elemental Releases of Various Components from Quenched Samples $\left(r\right.$ in $\left.\mathrm{g} / \mathrm{m}^{2}\right)$ with Na Release (dotted lines indicate $2 \mathrm{~g} / \mathrm{m}^{2}$ limit)

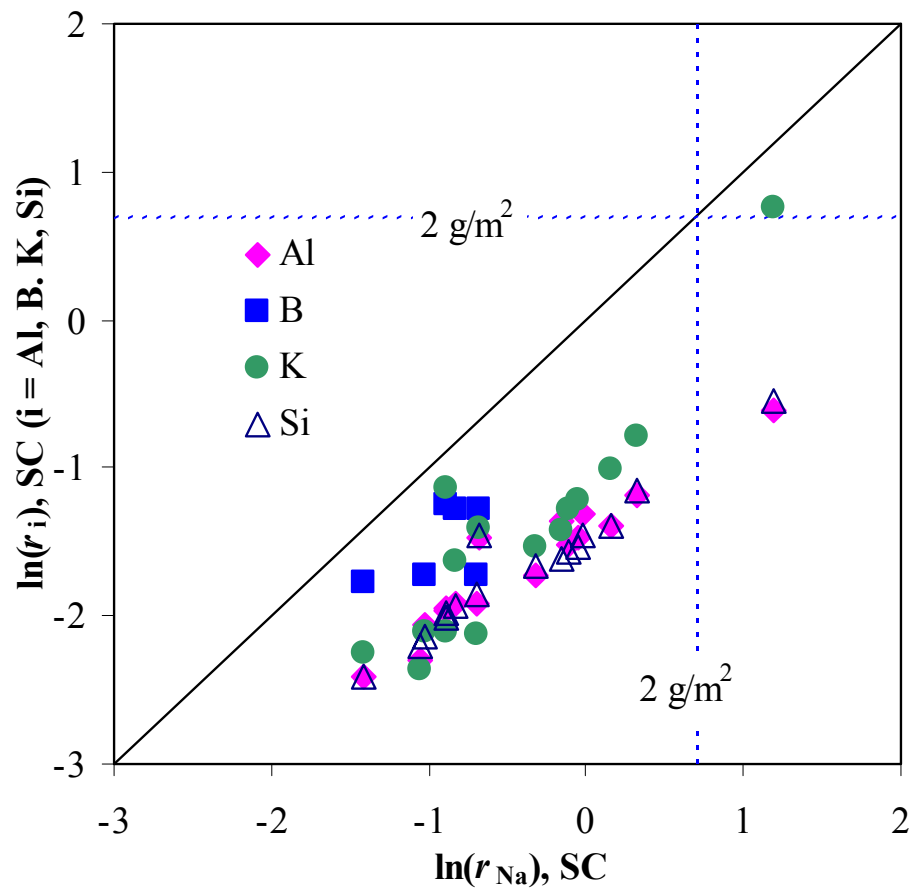

Figure 3.4. Comparison of PCT Normalized Releases of Various Components from SC Samples with Normalized Na Release $\left(r_{\mathrm{i}}\right.$ in $\mathrm{g} / \mathrm{m}^{2}$ ) (dotted lines indicate $2 \mathrm{~g} / \mathrm{m}^{2}$ limit) 


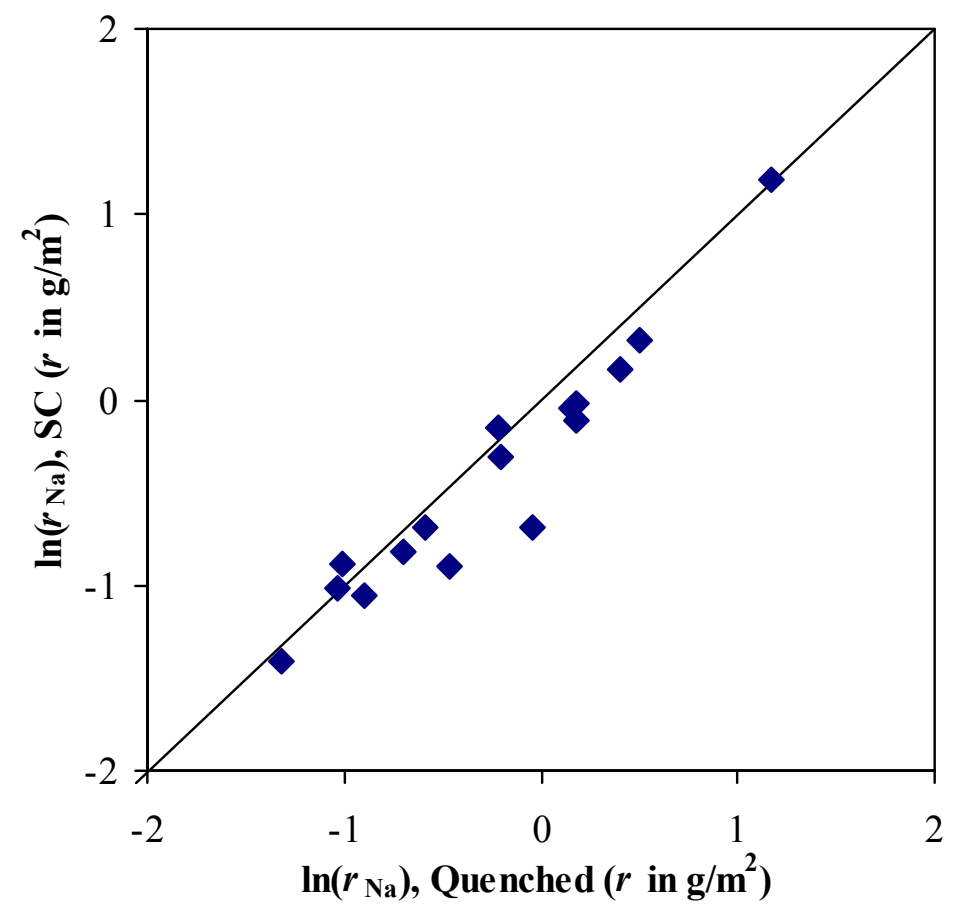

Figure 3.5. Effect of Slow Cooling Treatment on Normalized Na Release

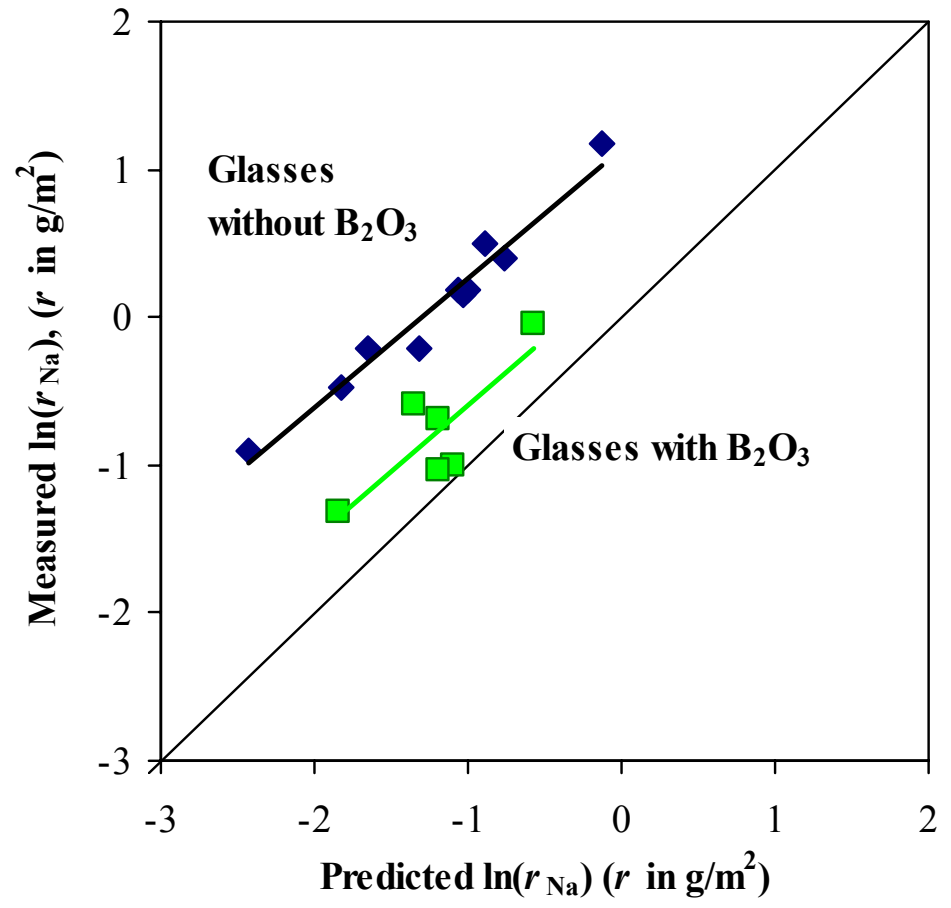

Figure 3.6. Measured vs. Predicted Normalized Na Release 


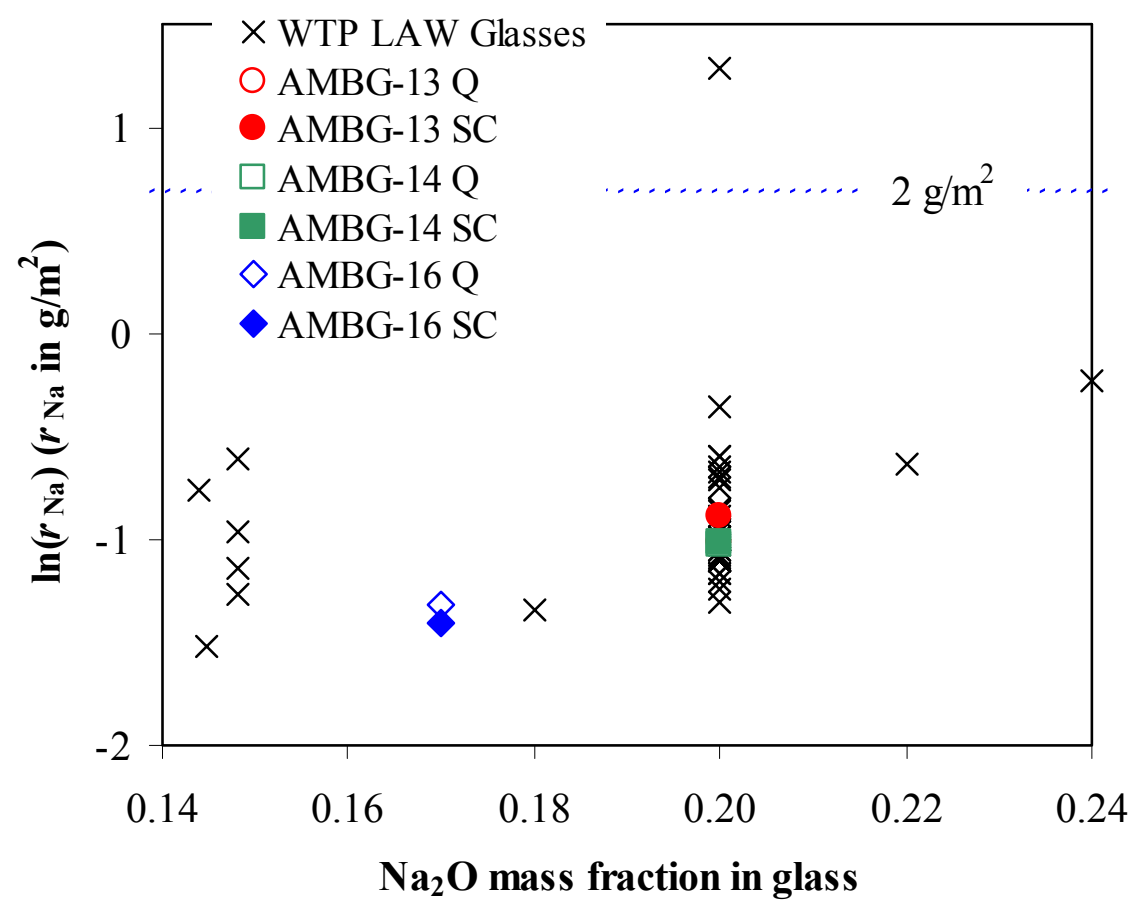

Figure 3.7. Comparison of PCT Responses for AMBG-13, 14, and 16 Glasses with those from Typical WTP LAW Glasses and a LAWABP1 Glass

\subsection{Vapor Hydration Test}

Table 3.10 lists the $200^{\circ} \mathrm{C}$ VHT responses of 16 AMBG glasses. Both quenched and SC-treated samples of AMBG-01 to 04, 07, 08, and 10 to 12 and quenched 06 completely corroded after 14-day tests. The values shown in Table 3.10 for these glasses (in highlighted cells) represent the "minimum possible" $m$ and $r_{\mathrm{a}}$; i.e., the actual $m$ and $r_{\mathrm{a}}$ would be equal to or greater than these values. Table 3.11 summarizes the average corrosion rates in quenched and $\mathrm{SC}$-treated samples of AMBG glasses. Figure 3.8 shows the VHT mass loss as a function of time for the glasses with defined corrosion-rate data, AMBG-05, 06, 09, and 13 to 16 .

As shown in Table 3.10, Table 3.11, and Figure 3.8, the glasses AMBG-13, 14, and 16 had average corrosion rates lower than $50 \mathrm{~g} /\left(\mathrm{m}^{2} \cdot \mathrm{d}\right)$ for quenched and SC samples and for all durations tested. The VHT responses of these three glasses are compared to data from literature in Figure 3.9. The LAW-A33 glass, with two different test sets shown, form the basis for the $50 \mathrm{~g} /\left(\mathrm{m}^{2} \cdot \mathrm{d}\right)$ limit imposed by ORP. The LAW-ABP1 glass is the basis of the 2001 Performance Assessment (PA) (Mann et al. 2001), which concluded that the site-performance objectives could easily be met. The WTP glasses are the data reported by Muller et al. (2001), which represent current baseline compositions for the various waste subenvelopes. Muller et al. (2001) reported their data as rates (in $\left.\mathrm{g} /\left[\mathrm{m}^{2} \cdot \mathrm{d}\right]\right)$ and stated that they typically tested at a single time of roughly 24 days; these data were converted to $\mathrm{m}$ values by multiplying the reported rate by 24 days. Based on this comparison, it can be concluded that the VHT response of the better-performing ICV glass samples (AMBG-13, 14, and 16) performed:

- much better than those used to set the constraint on acceptable glasses 
- better than the glass that formed the basis of the $2001 \mathrm{PA}$

- at least as well as typical WTP glasses.

Figure 3.10 compares average corrosion rates of quenched and SC-treated samples. There is no clear trend in the effect of SC treatment; the quenched versus SC difference in glass corrosion depends on the glass and test duration. The large scatter for the glasses with low corrosion rates (AMBG-13, 14, and 16) is exaggerated by using a logarithmic scale for the values approaching zero.

Table 3.10. $200^{\circ} \mathrm{C}-\mathrm{VHT}$ Response of AMBG Glasses

\begin{tabular}{|c|c|c|c|c|c|c|c|}
\hline Test Number & $\begin{array}{c}\text { Duration } \\
\text { (days) }\end{array}$ & $\begin{array}{c}m \\
\left(g / m^{2}\right)\end{array}$ & $\begin{array}{c}r_{\mathrm{a}} \\
\left(\mathrm{g} /\left[\mathrm{m}^{2} \cdot \mathrm{d}\right]\right)\end{array}$ & Test Number & $\begin{array}{c}\text { Duration } \\
\text { (days) }\end{array}$ & $\begin{array}{c}m \\
\left(g / m^{2}\right)\end{array}$ & $\begin{array}{c}r_{\mathrm{a}} \\
\left(\mathrm{g} /\left[\mathrm{m}^{2} \cdot \mathrm{d}\right]\right)\end{array}$ \\
\hline AMBG-01-Q & 13.8 & 1889.4 & 136.48 & AMBG-10-Q & 13.9 & 2007.0 & 144.23 \\
\hline AMBG-01-SC & 13.9 & 1976.3 & 141.94 & AMBG-10-SC & 13.9 & 2067.0 & 148.30 \\
\hline AMBG-02-Q & 13.8 & 1809.6 & 130.72 & AMBG-11-Q & 13.9 & 1971.2 & 141.66 \\
\hline AMBG-02-SC & 13.9 & 2008.0 & 144.22 & AMBG-11-SC & 13.9 & 1960.2 & 140.64 \\
\hline AMBG-03-Q & 13.9 & 1977.2 & 142.09 & AMBG-12-Q & 13.9 & 2023.1 & 145.41 \\
\hline AMBG-03-SC & 13.9 & 1982.1 & 142.36 & AMBG-12-SC & 13.9 & 2014.3 & 144.52 \\
\hline AMBG-04-Q & 13.8 & 1892.7 & 136.72 & AMBG-13-Q & 6.9 & 6.7 & 0.96 \\
\hline AMBG-04-SC & 13.9 & 2041.6 & 146.47 & AMBG-13-Q & 14.0 & 13.5 & 0.97 \\
\hline AMBG-05-Q & 6.9 & 122.2 & 17.59 & AMBG-13-Q & 28.1 & 223.3 & 7.96 \\
\hline AMBG-05-Q & 13.9 & 1193.3 & 85.75 & AMBG-13-SC & 7.0 & 44.6 & 6.39 \\
\hline AMBG-05-Q & 18.1 & 1449.9 & 80.25 & AMBG-13-SC & 13.9 & 5.2 & 0.37 \\
\hline AMBG-05-Q & 21.0 & 1875.2 & 89.12 & AMBG-13-SC & 28.0 & 96.9 & 3.46 \\
\hline AMBG-05-SC & 6.9 & 118.6 & 17.12 & AMBG-14-Q & 6.9 & 4.0 & 0.58 \\
\hline AMBG-05-SC & 13.9 & 482.9 & 34.68 & AMBG-14(2)-Q & 7.2 & 5.5 & 0.76 \\
\hline AMBG-05-SC & 18.1 & 952.3 & 52.71 & AMBG-14-Q & 14.0 & 0.0 & 0.00 \\
\hline AMBG-05-SC & 21.0 & 1545.7 & 73.53 & AMBG-14(2)-Q & 14.2 & 9.2 & 0.65 \\
\hline AMBG-06-Q & 6.9 & 141.8 & 20.42 & AMBG-14(2)-Q & 28.1 & 2.7 & 0.10 \\
\hline AMBG-06-Q & 9.9 & 1369.5 & 137.83 & AMBG-14(2)-SC & 7.0 & 4.0 & 0.58 \\
\hline AMBG-06-Q & 13.8 & 1930.8 & 139.47 & AMBG-14(2)-SC & 14.0 & 5.3 & 0.38 \\
\hline AMBG-06-SC & 6.9 & 452.4 & 65.30 & AMBG-14(2)-SC & 28.0 & 1.3 & 0.05 \\
\hline AMBG-06-SC & 9.9 & 1276.8 & 128.76 & AMBG-15-Q & 6.9 & 401.1 & 57.74 \\
\hline AMBG-06-SC & 13.9 & 1715.8 & 123.24 & AMBG-15-Q & 10.0 & 684.1 & 68.60 \\
\hline AMBG-07-Q & 13.8 & 1869.3 & 135.03 & AMBG-15-Q & 14.0 & 1050.2 & 75.01 \\
\hline AMBG-07-SC & 13.9 & 2014.1 & 144.76 & AMBG-15-SC & 7.0 & 480.4 & 68.78 \\
\hline AMBG-08-Q & 13.8 & 1947.2 & 140.66 & AMBG-15-SC & 13.9 & 588.2 & 42.17 \\
\hline AMBG-08-SC & 13.9 & 1924.9 & 138.35 & AMBG-15-SC & 21.0 & 630.7 & 30.04 \\
\hline AMBG-09-Q & 6.9 & 87.4 & 12.59 & AMBG-16-Q & 7.1 & 2.7 & 0.38 \\
\hline AMBG-09-Q & 9.9 & 492.2 & 49.54 & AMBG-16-Q & 14.1 & 3.9 & 0.28 \\
\hline AMBG-09-Q & 13.9 & 1655.6 & 118.98 & AMBG-16-Q & 28.1 & 9.2 & 0.33 \\
\hline AMBG-09-SC & 6.9 & 111.6 & 16.11 & AMBG-16-SC & 7.0 & 42.2 & 6.05 \\
\hline AMBG-09-SC & 9.9 & 1056.5 & 106.54 & AMBG-16-SC & 13.9 & 14.2 & 1.02 \\
\hline AMBG-09-SC & 13.9 & 1901.3 & 136.66 & AMBG-16-SC & 28.0 & 2.7 & 0.10 \\
\hline
\end{tabular}


Table 3.11. VHT Average Corrosion Rates of AMBG Glasses

\begin{tabular}{|c|c|c|c|c|c|c|}
\hline Test duration & 7-day & 10-day & 14-day & 18-day & 21-day & 28-day \\
\hline \multicolumn{7}{|c|}{ VHT $r_{\mathrm{a}}$ for Quenched Glasses, $\mathrm{g} /\left(\mathrm{m}^{2} \cdot \mathrm{d}\right)$} \\
\hline AMBG-05-Q & 17.59 & & 85.75 & 80.25 & 89.12 & \\
\hline AMBG-06-Q & 20.42 & 137.83 & & & & \\
\hline AMBG-09-Q & 12.59 & 49.54 & 118.98 & & & \\
\hline AMBG-13-Q & 0.96 & & 0.97 & & & 7.96 \\
\hline AMBG-14-Q ${ }^{(a)}$ & 0.67 & & 0.33 & & & 0.10 \\
\hline AMBG-15-Q & 57.74 & 68.60 & 75.01 & & & \\
\hline AMBG-16-Q & 0.38 & & 4.55 & & & 0.33 \\
\hline \multicolumn{7}{|c|}{ VHT $\boldsymbol{r}_{\mathrm{a}}$ for SC Glasses, $\mathrm{g} /\left(\mathrm{m}^{2} \cdot \mathrm{d}\right)$} \\
\hline AMBG-05-SC & 17.12 & & 34.68 & 52.71 & 73.53 & \\
\hline AMBG-06-SC & 65.30 & 128.76 & 123.24 & & & \\
\hline AMBG-09-SC & 16.11 & 106.54 & 136.66 & & & \\
\hline AMBG-13-SC & 6.39 & & 0.37 & & & 3.46 \\
\hline AMBG-14-SC $^{(\mathrm{a})}$ & 0.58 & & 0.38 & & & 0.05 \\
\hline AMBG-15-SC & 68.78 & & 42.17 & & 30.04 & \\
\hline AMBG-16-SC & 6.05 & & 1.02 & & & 0.10 \\
\hline \multicolumn{7}{|c|}{$\begin{array}{l}\text { (a) Average value from AMBG-14 and AMBG-14(2) glasses for } 7 \text { and } 14 \text { day results on quenched } \\
\text { glasses and from AMBG-14(2) only for all other results }\end{array}$} \\
\hline
\end{tabular}
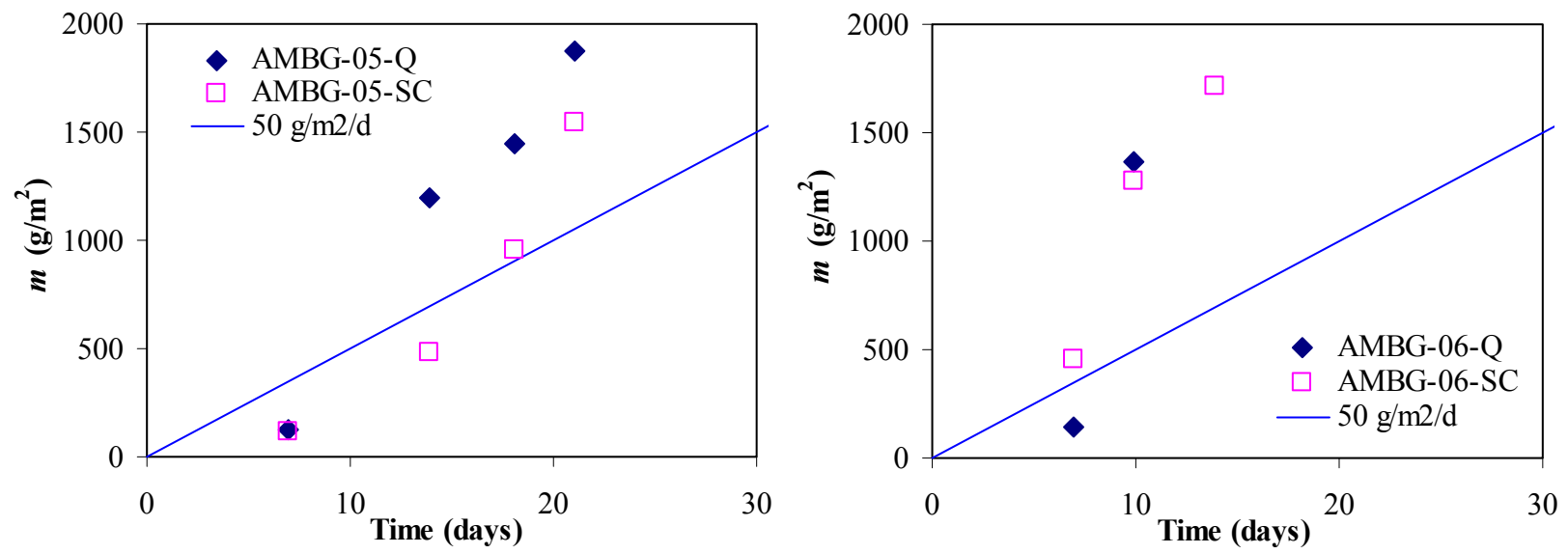

Figure 3.8. VHT Mass Loss a Function of Time for AMBG-05, -06, -09, and -13 to -16 Glasses 

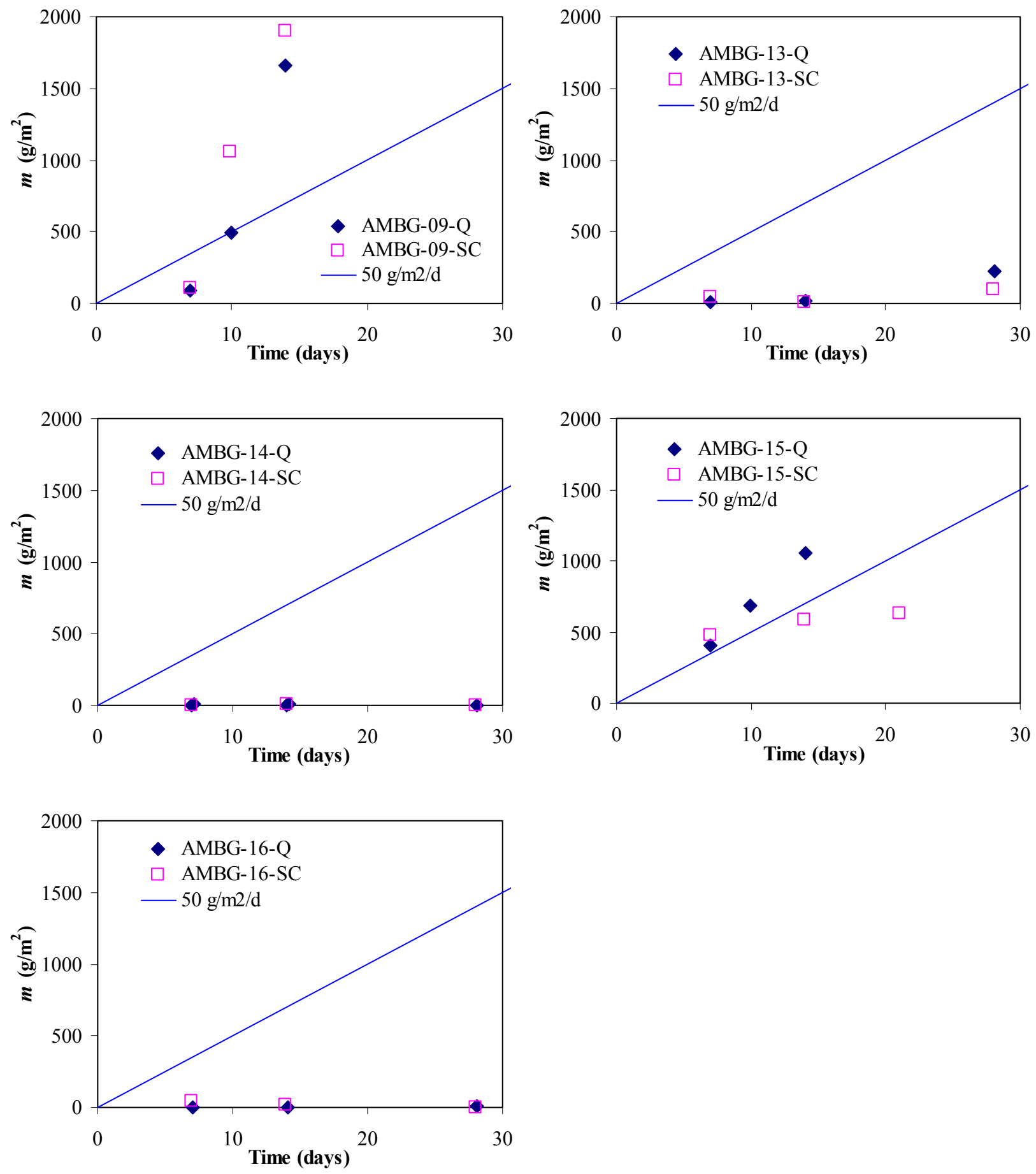

Figure 3.8 (cont'd) 


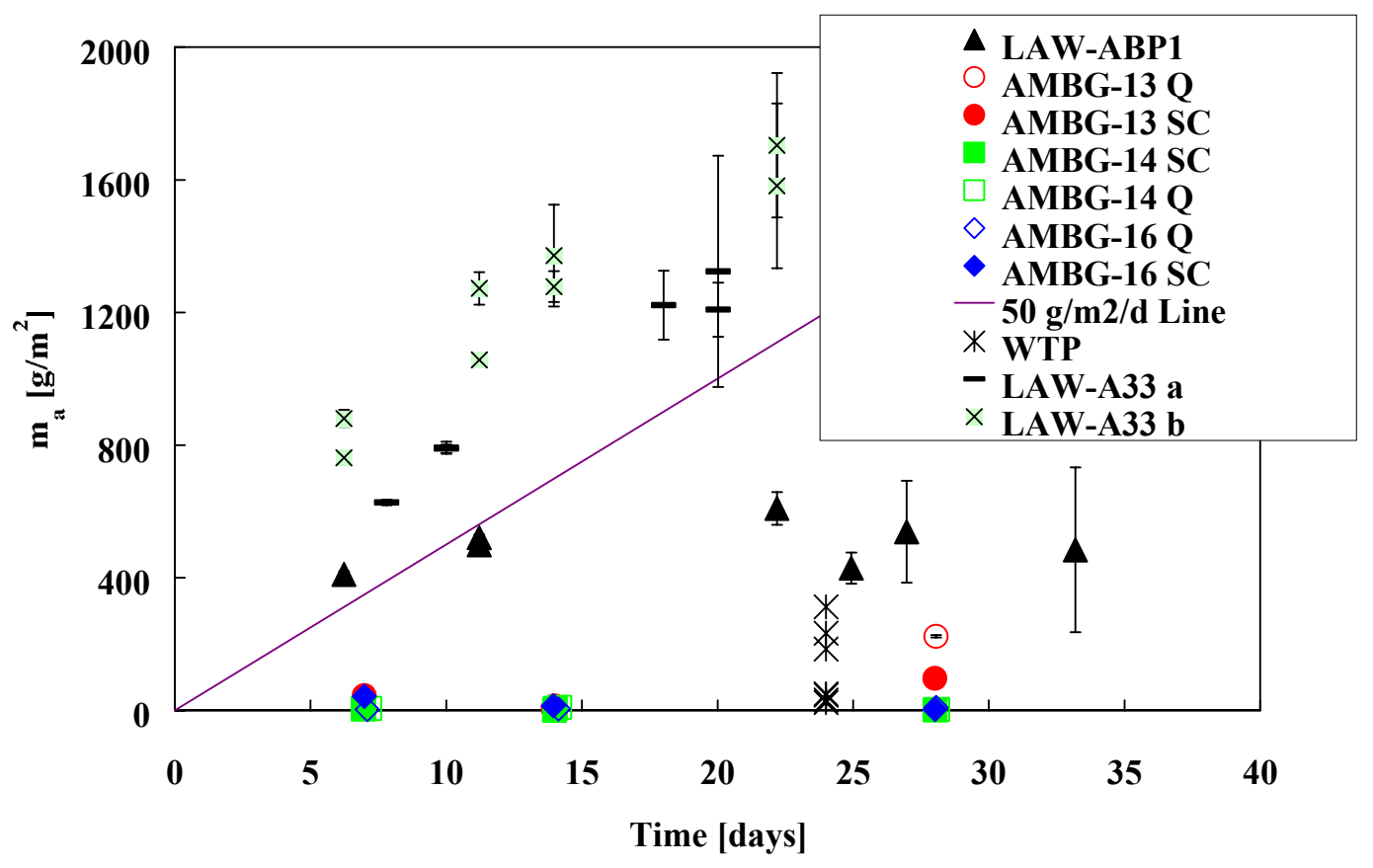

Figure 3.9. Comparison of VHT Responses for AMBG-13, -14, and -16 with those from LAW-A33, LAW-ABP1, and Typical WTP Glasses

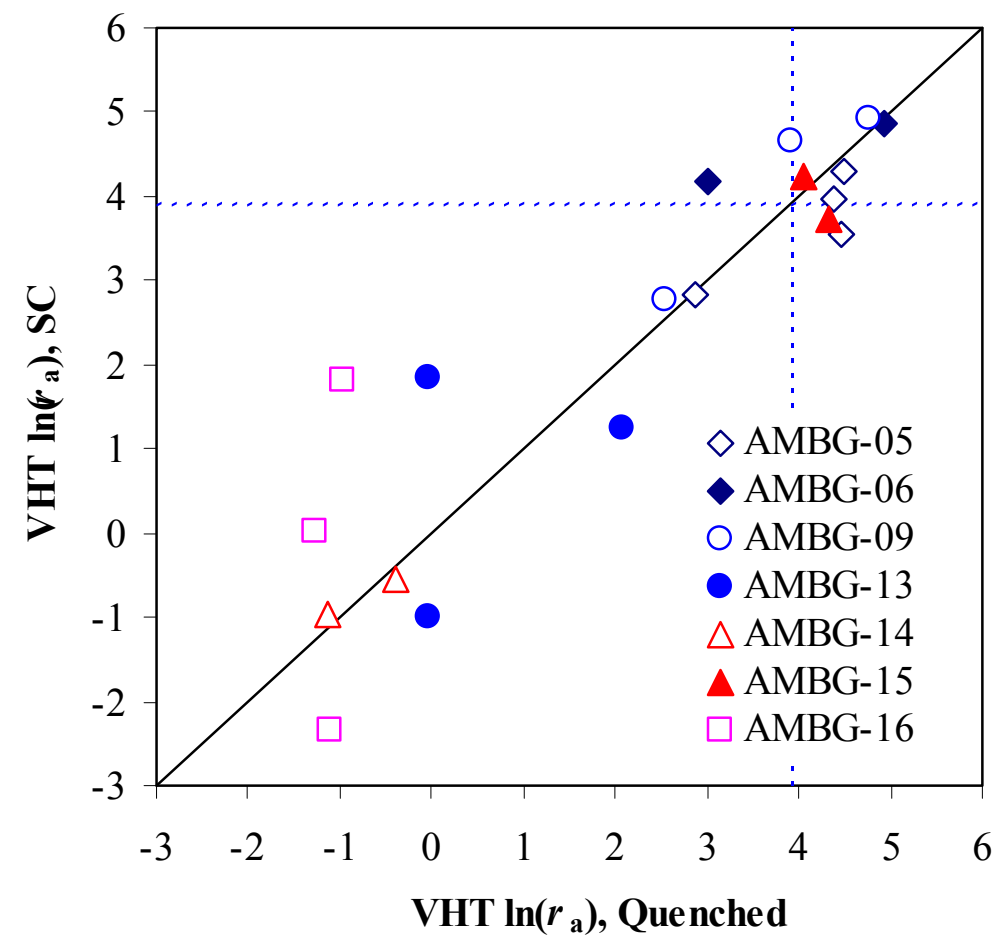

Figure 3.10. Comparison of VHT Corrosion Rates in Quenched and SC Samples 
The crystalline alteration products were identified for a selected set of samples by XRD. These phases are listed in Table 3.12. It should be noted that the phases were identified by crystal structure and not chemical analyses, so, other minerals or compositions with the structure of those identified may be present. For example, $\mathrm{SrZrO}_{3}$ is unlikely while $\mathrm{CaZrO}_{3}$ may have formed.

Table 3.12. Crystalline Alteration Product Summary

\begin{tabular}{||l|c|c|l||}
\hline \hline Sample ID & $\begin{array}{c}\text { Heat } \\
\text { Treatment }\end{array}$ & $\begin{array}{c}\text { VHT } \\
\text { Time }\end{array}$ & Crystalline Phases \\
\hline AMBG-05 & Q & $21 \mathrm{~d}$ & $\begin{array}{l}\text { Cancrinite }-\mathrm{Na}_{6} \mathrm{CaAl}_{6} \mathrm{Si}_{6}\left(\mathrm{CO}_{3}\right) \mathrm{O}_{24} \cdot 2 \mathrm{H}_{2} \mathrm{O} \\
\text { Analcime } \mathrm{O}-\mathrm{Na}\left(\mathrm{Si}_{2} \mathrm{Al}_{2}\right)_{6} \cdot \mathrm{H}_{2} \mathrm{O}\end{array}$ \\
\hline AMBG-05 & SC & $21 \mathrm{~d}$ & Analcime $-\mathrm{Na}_{15.92} \mathrm{Al}_{15.84} \mathrm{Si}_{32.16} \mathrm{O}_{96} \cdot 16 \mathrm{H}_{2} \mathrm{O}$ \\
\hline AMBG-11 & Q & $14 \mathrm{~d}$ & $\begin{array}{l}\text { Hydroxycancrinite }-\mathrm{Na}_{8} \mathrm{Al}_{6} \mathrm{Si}_{6} \mathrm{O}_{24}(\mathrm{OH})_{2} \cdot 2 \mathrm{H}_{2} \mathrm{O} \\
\text { Lithium Titanium } \mathrm{Oxxide}_{-1} \mathrm{LiTiO}_{2}\end{array}$ \\
\hline AMBG-11 & SC & $14 \mathrm{~d}$ & Hydroxycancrinite $-\mathrm{Na}_{8} \mathrm{Al}_{6} \mathrm{Si}_{6} \mathrm{O}_{24}(\mathrm{OH})_{2} \cdot 2 \mathrm{H}_{2} \mathrm{O}$ \\
\hline AMBG-13 & Q & $28 \mathrm{~d}$ & Analcime $-\mathrm{Na}\left(\mathrm{AlSi}_{2} \mathrm{O}_{6}\right) \cdot \mathrm{H}_{2} \mathrm{O}$ \\
\hline AMBG-13 & SC & $28 \mathrm{~d}$ & Analcime $-\mathrm{Na}\left(\mathrm{AlSi}_{2} \mathrm{O}_{6}\right) \cdot \mathrm{H}_{2} \mathrm{O}$ \\
\hline AMBG-15 & Q & $14 \mathrm{~d}$ & $\begin{array}{l}\text { Analcime }-\mathrm{Na}\left(\mathrm{AlSi}_{2} \mathrm{O}_{6}\right) \cdot \mathrm{H}_{2} \mathrm{O} \\
\text { Nosean }-\mathrm{Na}\left(\mathrm{SO}_{4}\right)\left(\mathrm{Al}_{6} \mathrm{Si}_{6} \mathrm{O}_{24}\right)\end{array}$ \\
\hline AMBG-15 & Q & $14 \mathrm{~d}$ & $\begin{array}{l}\text { Sodalite }-\mathrm{Na}_{8}\left(\mathrm{AlSiO}_{4}\right)_{6}\left(\mathrm{ClO}_{3}\right)_{1.91}(\mathrm{OH})_{0.09} \\
\text { Analcime }-\mathrm{Na}\left(\mathrm{AlSi}_{2} \mathrm{O}_{6}\right) \cdot \mathrm{H}_{2} \mathrm{O} \\
\text { Strontium Zirconium } \mathrm{Oxide}_{2}-\mathrm{SrZrO}_{3}\end{array}$ \\
\hline
\end{tabular}

\subsection{Toxicity Characteristic Leach Procedure}

Table 3.13 summarizes the TCLP responses for quenched samples of AMBG-04 and 13 glasses and SCtreated samples of AMBG-10 and 13 glasses. AMBG-13 was tested for TCLP response because it was selected as the baseline composition for next set of glass formulation tests and AMBG-04 and 10 were tested to check the effect of $\mathrm{Na}_{2} \mathrm{O}$ concentration on TCLP releases in general. The measured releases of $\mathrm{B}$ and $\mathrm{Cr}\left(c_{\mathrm{B}}\right.$ and $\left.c_{\mathrm{Cr}}\right)$ are compared with those predicted by the first-order model (Kim and Vienna 2002). The $\mathrm{Cr}$ is the only regulated component in these glasses. The $\mathrm{B}$ release is included because the normalized B release $\left(r_{\mathrm{B}}\right)$ is used as a representative measure of glass dissolution in the TCLP condition. This $r_{\mathrm{B}}$ is modeled as a function of glass composition, and the release of each hazardous element is calculated from the following relations, assuming that glass dissolution is congruent:

$$
\begin{gathered}
c_{i}=r_{B} f_{i} \\
r_{B}=\frac{c_{B}}{f_{B}}
\end{gathered}
$$

where $c_{i}(\mathrm{mg} / \mathrm{L})$ is the TCLP release of $i$-th element, and $f_{i}$ is the mass fraction of the $i$-th element in glass. As expected from low $\mathrm{Cr}_{2} \mathrm{O}_{3}$ in glass ( 0.09 to 0.12 mass\%), all the glasses, even the glass with 26 mass $\%$ $\mathrm{Na}_{2} \mathrm{O}$ (AMBG-04), resulted in Cr release well below the EPA's UTS limit of $0.6 \mathrm{mg} / \mathrm{L}$. There was poor correlation between measured and predicted $\mathrm{Cr}$ releases in quenched samples-measured $\mathrm{Cr}$ releases 
were much lower than predicted values. This lack of agreement can be attributed to two reasons: the low concentration of $\mathrm{Cr}$ that approaches the analytical limit and the fact that $\mathrm{Cr}$ is an incongruent element, i.e. its release is typically less than that predicted from Equation 3.1 as discussed by Kim and Vienna (2002).

Table 3.13. TCLP Responses of Selected Glasses Compared to the Predicted Values

\begin{tabular}{|c|c|c|c|c|c|}
\hline & $\begin{array}{c}\text { UTS Limit } \\
(\mathrm{mg} / \mathrm{L})\end{array}$ & AMBG-04-Q & AMBG-10-SC & AMBG-13-Q & AMBG-13-SC \\
\hline$c_{\mathrm{B}}(\mathrm{mg} / \mathrm{L})^{(\mathrm{a})}$ & NA & No B in glass & No B in glass & 0.43 & 0.52 \\
\hline$c_{\mathrm{Cr}}(\mathrm{mg} / \mathrm{L})^{(\mathrm{a})}$ & 0.6 & 0.0071 & 0.07 & 0.011 & 0.0059 \\
\hline \multicolumn{6}{|c|}{ Predicted TCLP Releases } \\
\hline$r_{\mathrm{B}}(\mathrm{mg} / \mathrm{L})$ & NA & 148.2 & $58.9^{(\mathrm{b})}$ & 69.4 & $69.4^{(\mathrm{b})}$ \\
\hline$c_{\mathrm{B}}(\mathrm{mg} / \mathrm{L})$ & NA & No B in glass & No B in glass & 1.08 & $1.08^{(\mathrm{b})}$ \\
\hline$c_{\mathrm{Cr}}(\mathrm{mg} / \mathrm{L})$ & 0.6 & 0.123 & $0.043^{(\mathrm{b})}$ & 0.043 & $0.043^{(b)}$ \\
\hline \multicolumn{6}{|c|}{$\begin{array}{l}\text { (a) The italicized values in highlighted cells are estimated results because they are below the reporting } \\
\text { limits }{ }^{(a)}(0.5 \text { and } 0.25 \mathrm{mg} / \mathrm{L} \text { for } \mathrm{B} \text { and } \mathrm{Cr} \text { respectively). } \\
\text { (b) Predicted values for quenched glasses. }\end{array}$} \\
\hline
\end{tabular}

The relative performance of different glasses under TCLP leach conditions can be assessed by comparing normalized releases, generally, by comparing the normalized boron release. Figure 3.11 compares the TCLP normalized B releases from quenched and SC treated AMBG-13 glasses with the data from literature. The WTP LAW glasses are from Muller et al. (2001) and Muller and Pegg (1998), which measured the TCLP releases for selected glasses. Normalized Zn release was included because B releases were not reported. $\mathrm{ZnO}$ was one of major glass components in these glasses, and $\mathrm{Zn}$ is a congruent element that behaves similarly with B in representing glass dissolution in TCLP conditions (Kim and Vienna 2002). The normalized B releases from WTP HLW glasses (Kot and Pegg 2001) are included to provide general information on TCLP responses of typical waste glasses. Figure 3.11 shows that the ICV glasses had lower normalized B releases than typical WTP LAW glasses. This result implies that the ICV glasses can contain higher concentrations of regulated toxic elements without failing the TCLP requirements

(a) The reporting limit is defined as the level (concentration) to which data are reported for a specific test method and/or sample. The reporting limit is typically 2 to 5 times the method detection limit, depending on the individual analyte performance, stability, and laboratory's judgment. 


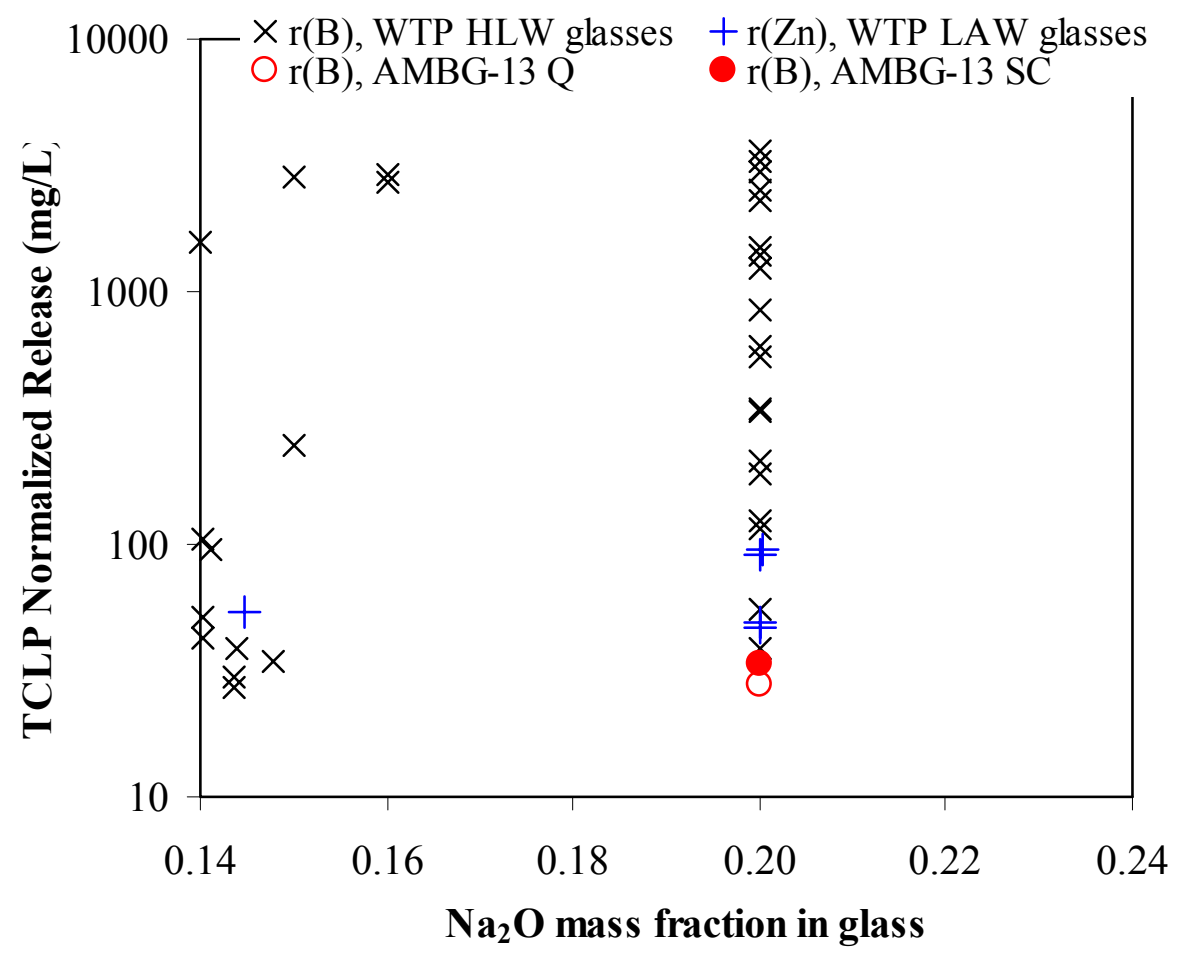

Figure 3.11. Comparison of TCLP Normalized Releases for AMBG-13 Glasses with Those from Typical WTP LAW and HLW Glasses

\subsection{Viscosity and Electrical Conductivity}

Viscosity and electrical conductivity were measured for AMBG-13 and 16 glasses. AMBG-13 was chosen because it was selected as the baseline composition for next set of glass formulation tests and AMBG-16 was tested to provide necessary data for one of the large-scale melter tests, which will use similar composition as AMBG-16. Note that since viscosity and electrical conductivity are properties of the molten glass, there is no distinction between quenched and SC-treated glases. Table 3.14 lists the viscosity-temperature data for AMBG-13 and 16 glasses. Figure 3.12 shows the $\ln (\eta)$ versus $1 / T(T$ in $\mathrm{K})$ plots for viscosities measured, fitted by the Arrhenius relation and predicted by the first-order model (Vienna et al. 2002). Figure 3.13 shows the viscosity versus temperature (in ${ }^{\circ} \mathrm{C}$ ) plots for the same data as in Figure 3.12. Figure 3.13 shows that the first-order model predicts the viscosity of these glasses reasonably well. The differences in measured and predicted temperatures at 10 and $5 \mathrm{~Pa} \cdot \mathrm{s}$ were 26 and $18^{\circ} \mathrm{C}$ for AMBG-13 and 5 and $3^{\circ} \mathrm{C}$ for AMBG-16.

Table 3.14. Viscosity Results for AMBG-13 and 16 Glasses

\begin{tabular}{||c|c||c|c||}
\hline \multicolumn{2}{||c||}{ AMBG-13 } & \multicolumn{2}{c||}{ AMBG-16 } \\
\hline$T\left({ }^{\circ} \mathrm{C}\right)$ & $\eta(\mathrm{Pa} \cdot \mathrm{s})$ & $T\left({ }^{\circ} \mathrm{C}\right)$ & $\eta(\mathrm{Pa} \cdot \mathrm{s})$ \\
\hline 1095 & 51.116 & 1094 & 91.603 \\
\hline 1145 & 27.831 & 1144 & 47.481 \\
\hline 1195 & 16.039 & 1194 & 27.442 \\
\hline
\end{tabular}




\begin{tabular}{||l|l||c|c||}
1245 & 9.237 & 1244 & 14.871 \\
\hline 1294 & 5.795 & 1293 & 9.153 \\
\hline 1343 & 3.840 & 1294 & 8.611 \\
\hline 1344 & 3.646 & 1343 & 5.439 \\
\hline 1344 & 3.680 & 1343 & 6.124 \\
\hline 1393 & 2.254 & 1343 & 6.437 \\
\hline 1394 & 2.132 & 1393 & 3.993 \\
\hline
\end{tabular}

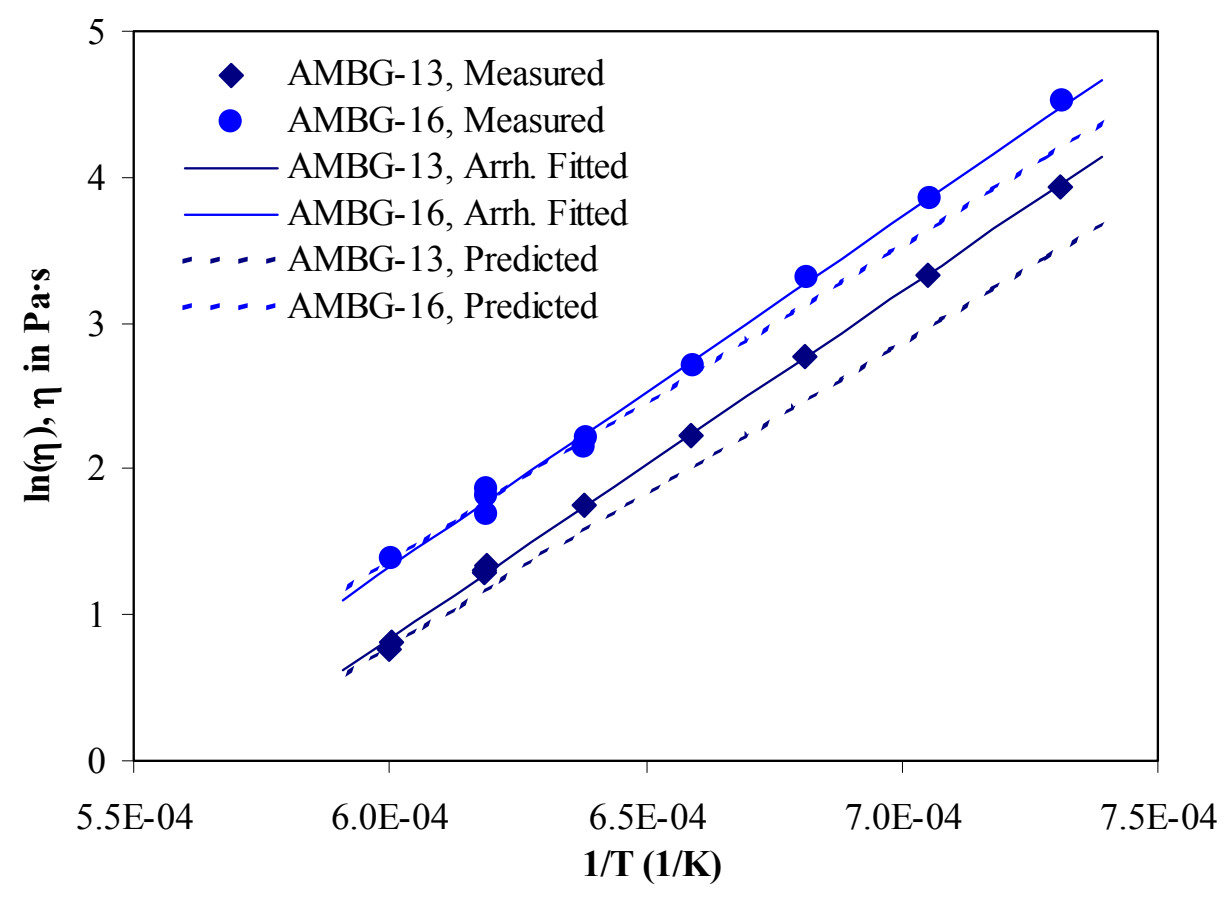

Figure 3.12. $\ln (\eta)$ Versus $1 / T(T$ in $\mathrm{K})$ Plot for AMBG-13 and 16 Glasses (the Lines for Arrhenius fit of measured data and for model prediction are also included) 


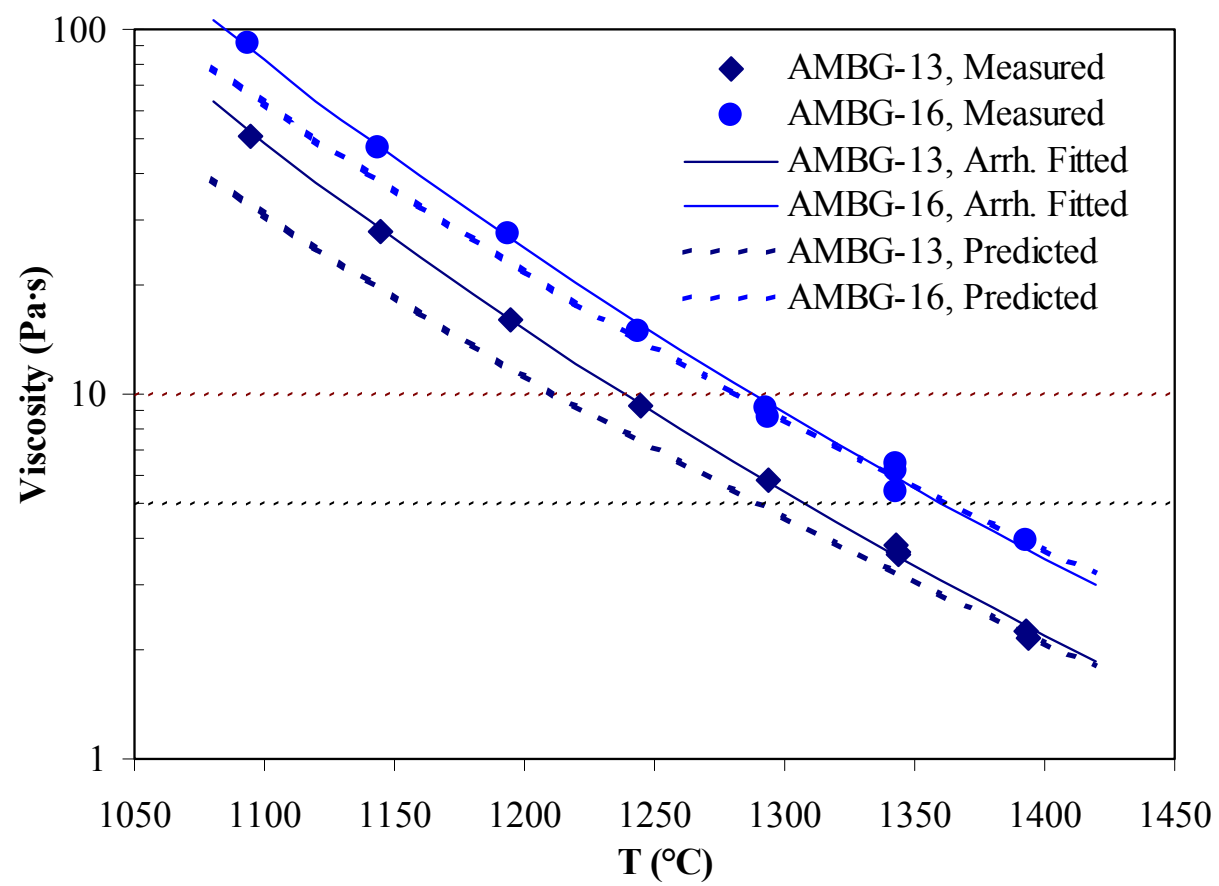

Figure 3.13. Viscosity Versus Temperature (in ${ }^{\circ} \mathrm{C}$ ) Plot for AMBG-13 and 16 Glasses (the curves for Arrhenius fit of measured data and for model prediction are also included)

Table 3.15 lists the electrical conductivity-temperature data for AMBG-13 and 16 glasses. Figure 3.14 shows the $\varepsilon$ versus $T$ (in ${ }^{\circ} \mathrm{C}$ ) plots for electrical conductivity measured at four different frequencies.

Figure 3.15 shows the $\ln (\varepsilon)$ versus $1 / T$ ( $T$ in $\mathrm{K}$ ) plots for electrical conductivity measured, fitted by the Arrhenius relation and predicted by the first-order model (Hrma et al. 1994). The measured value at 1 $\mathrm{kHz}$ is included in Figure 3.15 because the model by Hrma et al. (1994) used this frequency. Figure 3.15 shows that the first-order model predicts the electrical conductivity of these glasses very well. The measured electrical conductivity at temperatures at which the measured viscosity is 10 and $5 \mathrm{~Pa} \cdot \mathrm{s}$ were 39.67 and $49.53 \mathrm{~S} / \mathrm{m}$ for AMBG-13 and 30.20 and $36.93 \mathrm{~S} / \mathrm{m}$ for AMBG-16. The differences in measured and predicted electrical conductivity at temperatures at which the measured viscosity is 10 and $5 \mathrm{~Pa} \cdot \mathrm{s}$ were 3.24 and 4.00 for AMBG-13 and 2.11 and 3.92 S/m for AMBG-16.

Table 3.15. Electrical Conductivity Results for AMBG-13 and 16 Glasses

\begin{tabular}{|c|c|c|c|c|c|c|c|c|c|}
\hline \multicolumn{5}{|c|}{$\varepsilon$ of $A M B G-13(\mathrm{~S} / \mathrm{m})$} & \multicolumn{5}{|c|}{$\varepsilon$ of $A M B G-16(\mathrm{~S} / \mathrm{m})$} \\
\hline$T\left({ }^{\circ} \mathrm{C}\right)$ & $100 \mathrm{~Hz}$ & $1 \mathrm{kHz}$ & $10 \mathrm{kHz}$ & $100 \mathrm{kHz}$ & $T\left({ }^{\circ} \mathrm{C}\right)$ & $100 \mathrm{~Hz}$ & $1 \mathrm{kHz}$ & $10 \mathrm{kHz}$ & $100 \mathrm{kHz}$ \\
\hline 1391 & 48.22 & 63.29 & 69.85 & 69.38 & 1392 & 38.57 & 39.75 & 39.55 & 39.35 \\
\hline 1294 & 36.11 & 47.15 & 51.97 & 51.88 & 1295 & 28.82 & 30.89 & 30.38 & 30.41 \\
\hline 1195 & 26.13 & 34.13 & 37.25 & 37.25 & 1195 & 20.65 & 23.05 & 22.33 & 22.25 \\
\hline 1095 & 18.10 & 23.47 & 25.23 & 25.27 & 1096 & 14.05 & 16.02 & 15.44 & 15.37 \\
\hline
\end{tabular}




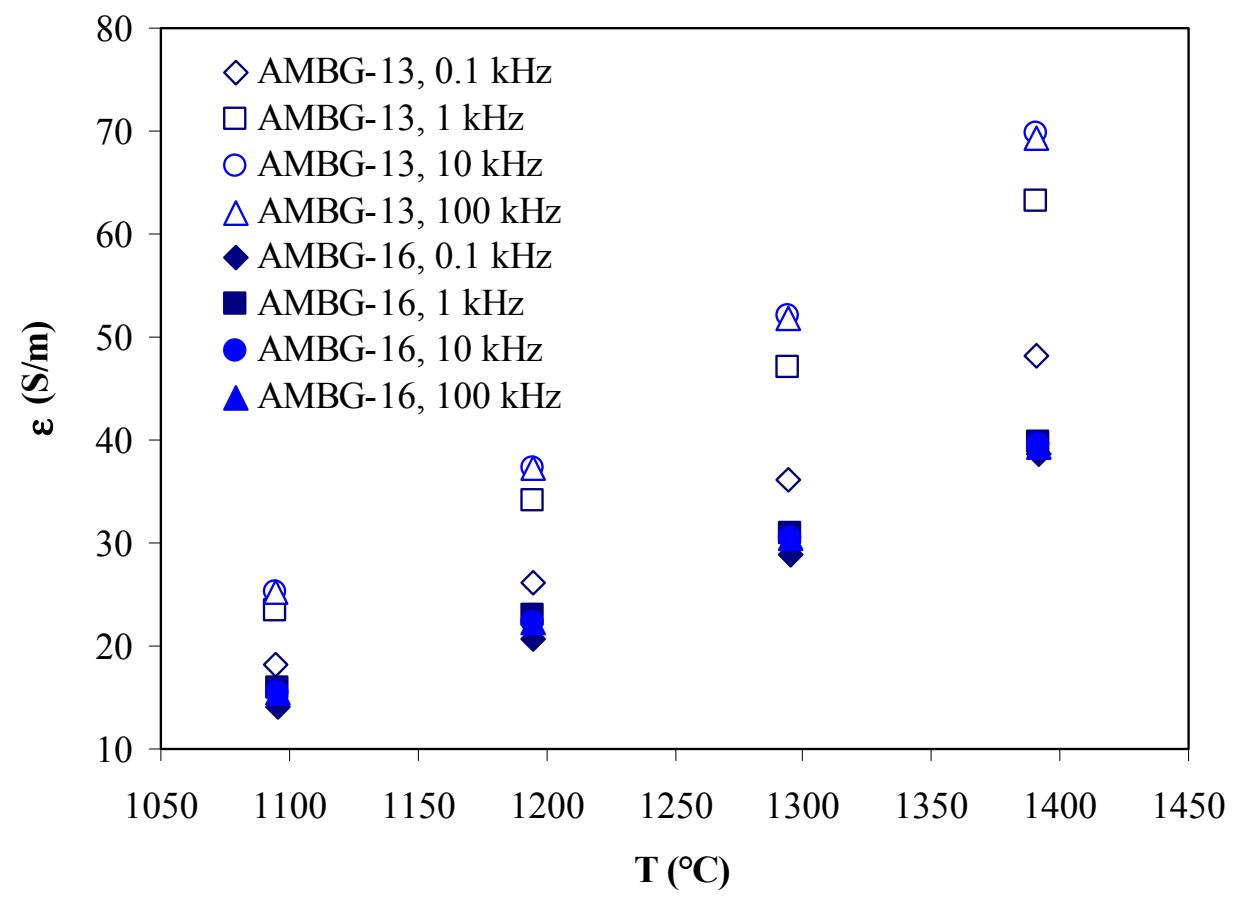

Figure 3.14. Electrical Conductivity versus Temperature for AMBG-13 and 16 Glasses

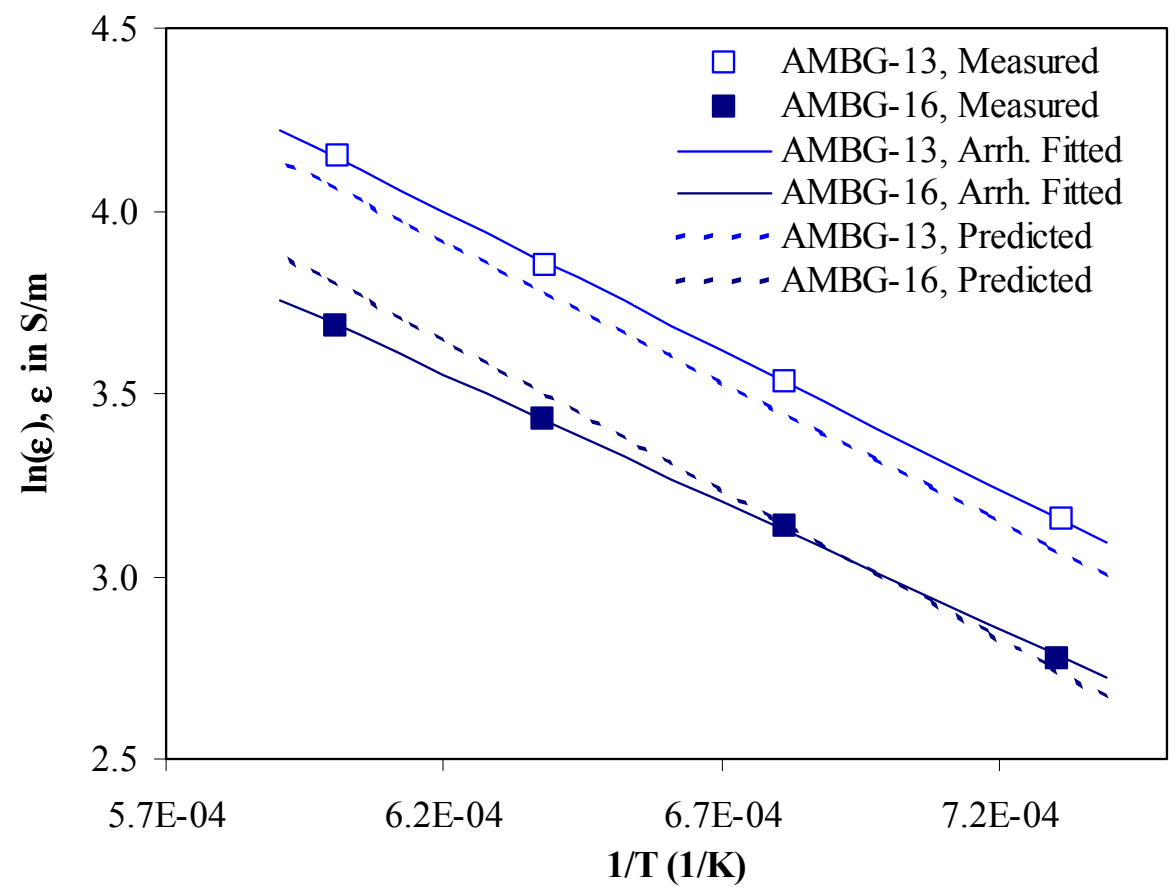

Figure 3.15. $\ln (\varepsilon)$ Versus $1 / T(T$ in $K)$ Plot for AMBG-13 and 16 Glasses at $1 \mathrm{kHz}$ (the lines for Arrhenius fit of measured data and for model prediction are also included) 


\subsection{Secondary Phase Identification}

The SC heat-treatment schedule was developed by AMEC using a simulation and is thought to be conservative. Table 3.7 shows the cooling schedule used. Only glasses AMBG-04, 10, 12, and 14 showed signs of phase changes upon SC. In glasses AMBG-04, -10, and -12, large numbers of crystals appeared at the SC sample surfaces within $\sim 1.5 \mathrm{~mm}$ from the Pt-Glass interface. A few crystals, below the detection limit of XRD, were seen in the bulk glass. Table 3.16 lists mass fractions of crystalline phases identified in this $\sim 1.5$-mm layer. The phases identified were nepheline $\left[\mathrm{NaAlSiO}_{4}\right]$, combeite $\left[\mathrm{Na}_{4} \mathrm{Ca}_{4}\left(\mathrm{Si}_{6} \mathrm{O}_{18}\right)\right]$, and baddeleyite $\left[\mathrm{ZrO}_{2}\right]$. Figure 3.16 is an example SEM micrograph with nepheline and baddeleyite in the AMBG-10-SC sample. AMBG-14 formed $\mathrm{ZrO}_{2}$ within the melt, which was probable because of the relatively high $\mathrm{Zr}$ addition. These crystals partially settled to an $\sim 5$-mm layer at the crucible bottom. Mass fractions of a $\mathrm{ZrO}_{2}$ phase in the bulk sample and the crucible bottom area are also included in Table 3.16. Figure 3.17 show optical micrographs of baddeleyite crystals formed and settled at the bottom of the SC-treated AMBG-14 glass. Figure 3.18 shows the SEM micrographs of baddeleyite crystals formed in SC-treated AMBG-14 glass. Dendritic growth patterns and agglomerates of irregular shapes with well defined edges were observed. Appendix B shows the XRD patterns of AMBG-04, 10, 12, and 14 glasses in the bulk of the glass and at the Pt-glass interface (AMBG-04, 10, 12) or crucible bottom (AMBG-14). Only internal-standard peaks appear in the bulk samples of the slowcooled AMBG-04, 10, and 12 glasses.

Table 3.16. Crystalline Phases, in Mass\%, Determined by XRD in SC Samples within $\sim 1.5-\mathrm{mm}$ at Pt-Glass Interface

\begin{tabular}{|c|c|c|c|}
\hline Glass & $\begin{array}{c}\text { Nepheline } \\
\left(\mathrm{NaAlSiO}_{4}\right) \\
\text { Mass } \%\end{array}$ & $\begin{array}{c}\text { Combeite } \\
{\left[\mathrm{Na}_{4} \mathrm{Ca}_{4}\left(\mathrm{Si}_{6} \mathrm{O}_{18}\right)\right]} \\
\mathrm{Mass} \%\end{array}$ & $\begin{array}{c}\text { Baddeleyite } \\
\left(\mathrm{ZrO}_{2}\right) \\
\text { Mass\% }\end{array}$ \\
\hline AMBG-04-SC, Pt-glass interface area & 1.15 & 0 & 0 \\
\hline AMBG-10-SC, Pt-glass interface area & 6.90 & 1.95 & 0.35 \\
\hline AMBG-12-SC, Pt-glass interface area & 0.35 & 0 & 0.27 \\
\hline AMBG-14B2-SC, bulk glass & 0 & 0 & 0.49 \\
\hline AMBG-14B2-SC, crucible bottom area & 0 & 0 & 5.36 \\
\hline
\end{tabular}




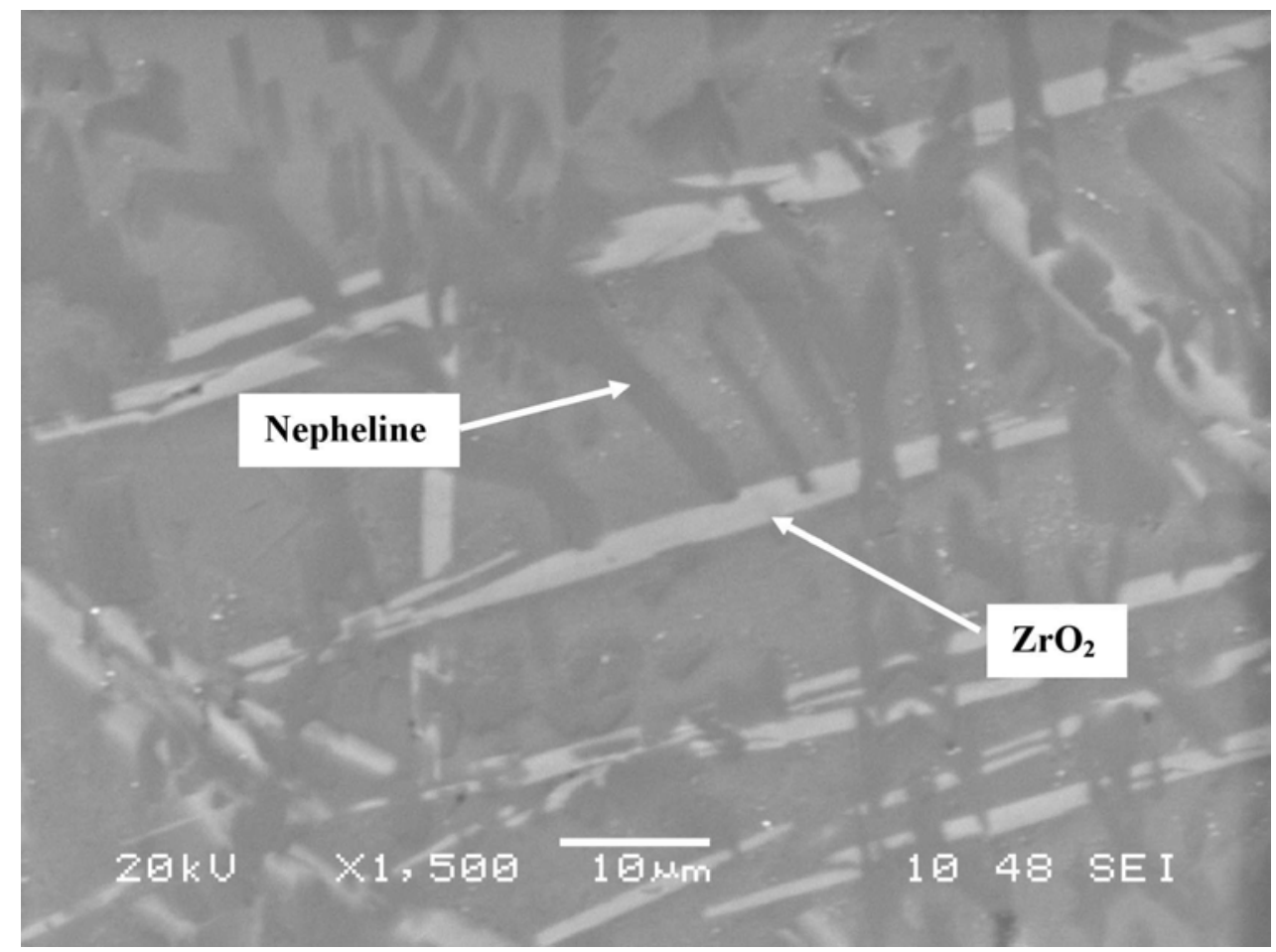

Figure 3.16. SEM Micrograph Showing Nepheline and Zirconia Crystals Formed at the Surface Layer of the SC Treated AMBG-10 Glass

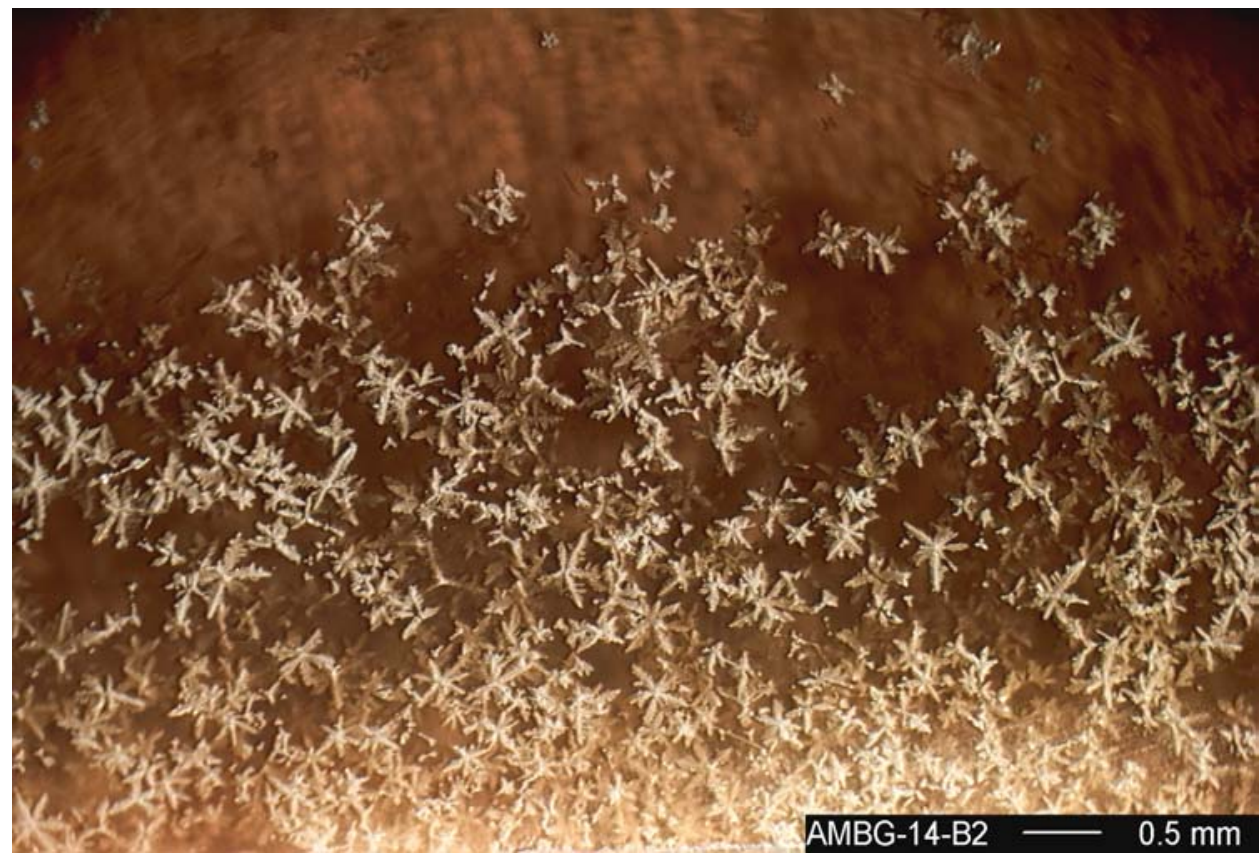

Figure 3.17. Optical Micrographs Showing Baddeleyite Crystals Formed and Settled at the Bottom of the SC Treated AMBG-14 Glass 

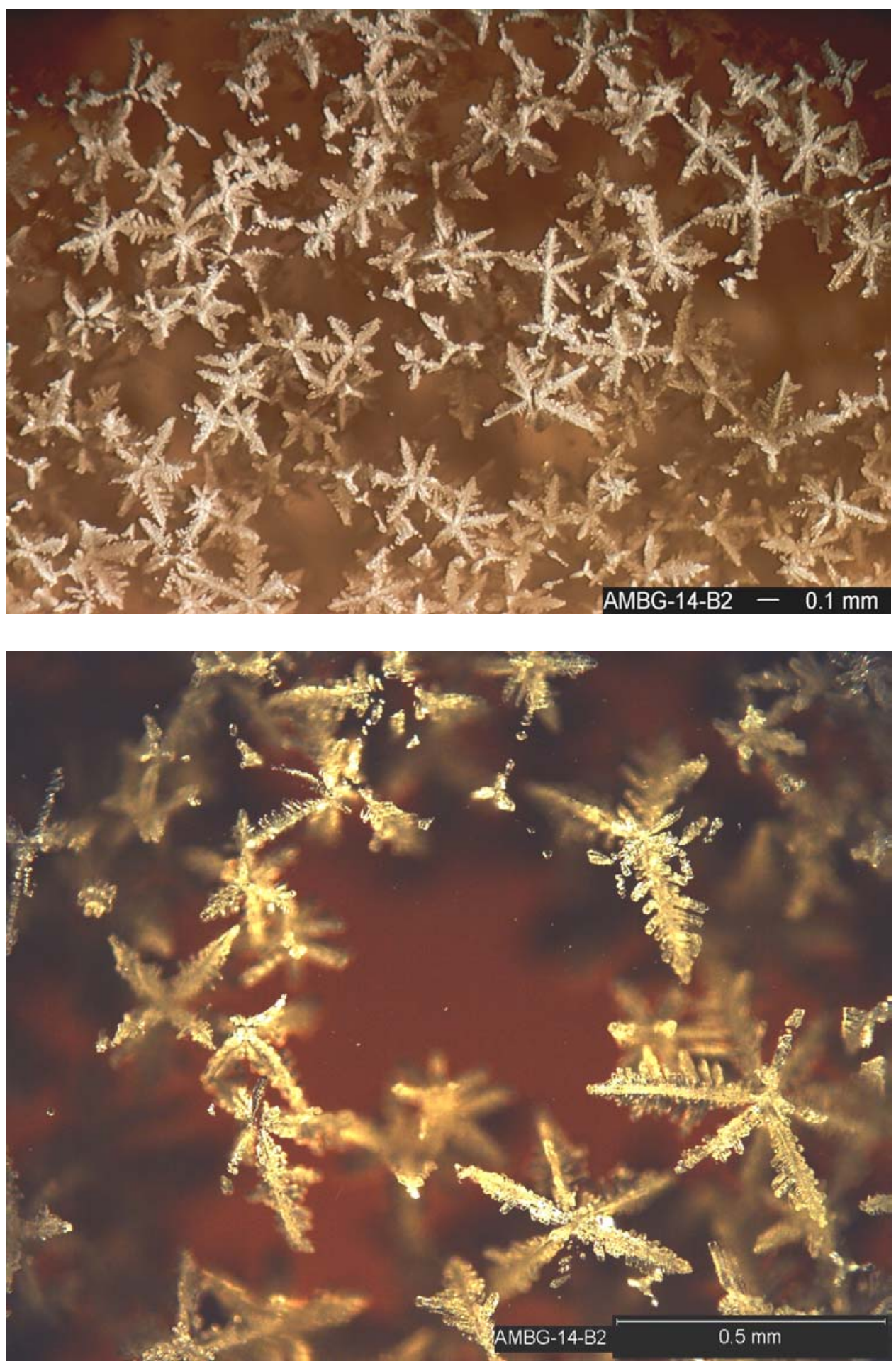

Figure 3.17 (Contd) 


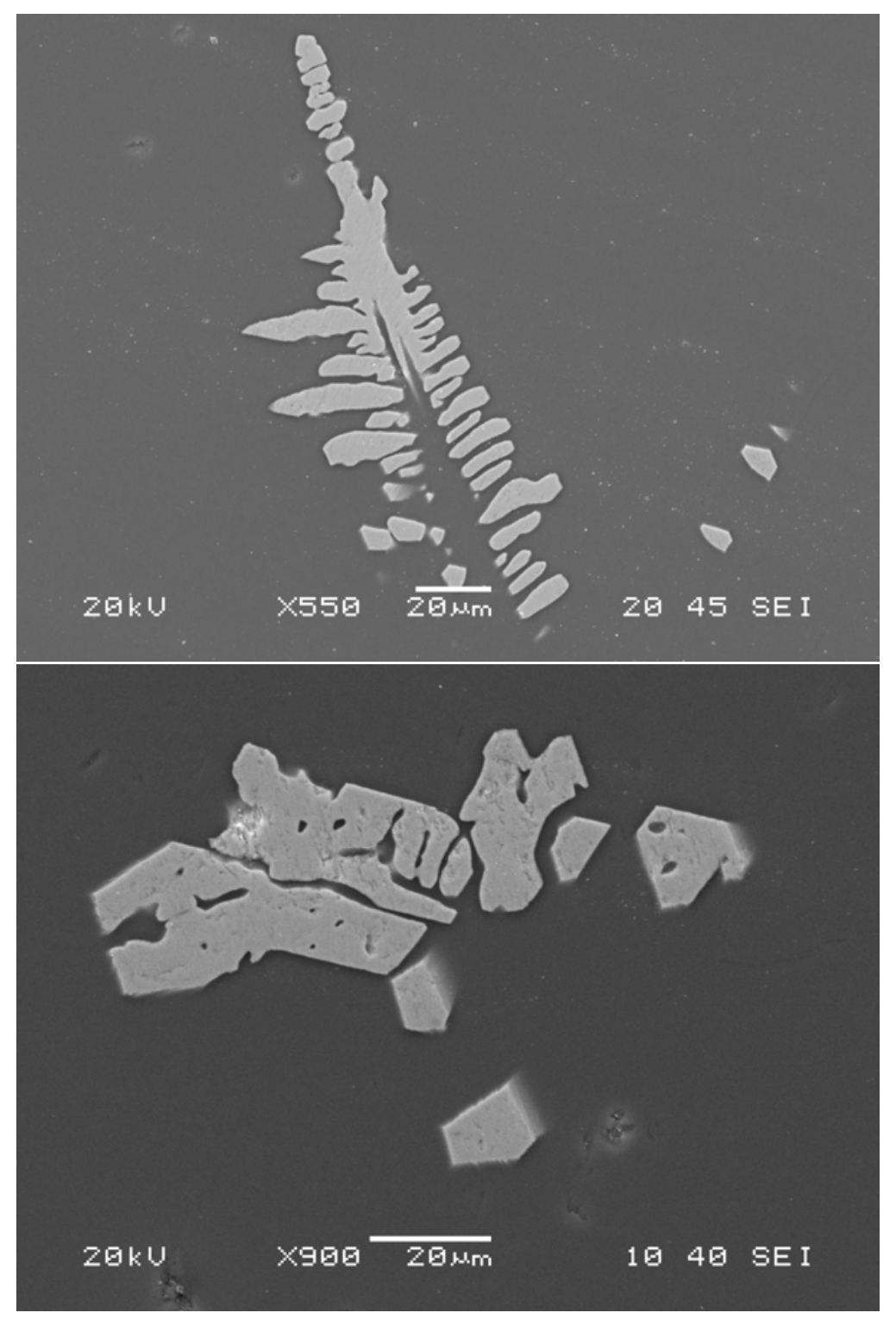

Figure 3.18. SEM Micrographs of Baddeleyite Crystals in Slow-Cooled AMBG-14 Glass

\subsection{Baseline Glass Selection}

Based on the results of the preliminary glass formulation testing presented above, it is clear that a number of AMBG glasses will make a suitable baseline glass for testing. The glass that appears to have the best mix of properties is AMBG-13 because it has outstanding PCT and VHT responses, does not contain any crystals after $\mathrm{SC}$ heat treatment, and has 20 mass $\% \mathrm{Na}_{2} \mathrm{O}$. Therefore, AMBG-13 was selected as a glass suitable for scale-up and radioactive testing of the ICV process. It should be noted that this glass is by no means optimized, and further work is recommended to develop an optimum glass for the ICV process with Hanford LAW, including a study of alternative soils, bounding conditions, and potential effects of variability. 


\subsection{Simulant and Actual Waste-Crucible Tests}

This section describes the glass formulation and sample fabrication for simulant and actual waste-crucible tests, the results on glass composition analysis, PCT, VHT, density, redox, and secondary phase identification, and the comparison of properties between glasses from simulant and actual LAW.

\subsection{Simulant and Actual Waste-Crucible Glass Formulation and Sample Fabrication}

The results from preliminary crucible melts using raw chemicals were used to identify a baseline glass formulation (AMBG-13) as described in Section 3.7. Simulant and actual waste-crucible melts were formulated based on this AMBG-13 glass and fabricated for testing. Five melts (AMEC simulant crucible melt [ASCM]-01 to 05), involving samples of simulated saltcake and the one melt, AMEC radioactive crucible melt (ARCM)-01, with an actual radioactive tank LAW were used for validation purposes. The five ASCM glasses varied the waste loading and the concentrations of additives around the baseline glass. The goal of these glasses is to identify the effect of waste (i.e., $\mathrm{Na}_{2} \mathrm{O}$ ) loading on the product quality for this particular baseline glass. Table 4.1 lists the compositions of these glasses on a dry LAW and additive basis. These glasses range in $\mathrm{Na}_{2} \mathrm{O}$ content from 17 mass\% (ASCM-02 and 03) to 24 mass\% (ASCM-05). The ARCM-01 glass had the same target composition as ASCM-01 glass.

Table 4.1. ASCM Target Glass Formulations in Mass\% of Components

\begin{tabular}{||l|c|c|c|c|c||}
\hline & ASCM-01 & ASCM-02 & ASCM-03 & ASCM-04 & ASCM-05 \\
\hline Soil & 68.2 & 68.5 & 71.6 & 65.9 & 63.6 \\
\hline Waste & 19.8 & 16.5 & 16.4 & 22.1 & 24.4 \\
\hline $\mathrm{B}_{2} \mathrm{O}_{3}$ & 5.0 & 5.0 & 5.0 & 5.0 & 5.0 \\
\hline $\mathrm{ZrO}_{2}$ & 7.0 & 7.0 & 7.0 & 7.0 & 7.0 \\
\hline $\mathrm{SiO}_{2}$ & 0.0 & 3.0 & 0.0 & 0.0 & 0.0 \\
\hline
\end{tabular}

Rather than using the reagent-grade oxide and carbonate chemicals used for preliminary melts (Section 3.1.2), actual soil supplied by AMEC from their site in Richland, WA, and LAW simulant supplied by CHG (Rassat et al. 2003) were used. The composition of the soil is listed in Table 3.1. Table 4.2 shows the reagents and the masses used to prepare $1 \mathrm{~L}$ of non-radioactive dissolved saltcake simulant matching the composition specified in Table 4.3 (Rassat et al. 2003). The mass of water was estimated to achieve the expected solution density of $1.24 \mathrm{~g} / \mathrm{mL}$. Reagents were added in the order listed, except that a fraction of the water was reserved for dilution to final volume. Table 4.3 summarizes the concentrations of analytes in the dissolved saltcake solution simulant and shows the measured concentration of analytes in the pretreated actual waste (Rassat et al. 2003). Finally, Table 4.4 shows the concentration of glass components in $\mathrm{g} / \mathrm{L}$ and mass fractions for saltcake simulant and actual waste. 
Table 4.2. Concentrations of Reagents in Saltcake Solution Simulant

\begin{tabular}{||l|c|l||}
\hline Reagent & \multicolumn{1}{|c|}{ /L } & Mole/L \\
\hline $\mathrm{H}_{2} \mathrm{O}$ & 860 & \\
\hline $\mathrm{Na}_{2} \mathrm{C}_{2} \mathrm{O}_{4}$ & 1.58 & 0.0118 \\
\hline $\mathrm{CH}_{3} \mathrm{COONa}_{2}$ & 10.79 & 0.132 \\
\hline $\mathrm{NaNO}_{3}$ & 196.11 & 2.308 \\
\hline $\mathrm{KNO}_{3}$ & 1.25 & 0.0124 \\
\hline $\mathrm{NaOH}$ & 29.58 & 0.740 \\
\hline $\mathrm{Al}\left(\mathrm{NO}_{3}\right)_{3} \cdot 9 \mathrm{H}_{2} \mathrm{O}$ & 23.90 & 0.0637 \\
\hline $\mathrm{Na}_{2} \mathrm{CO}_{3}$ & 50.35 & 0.475 \\
\hline $\mathrm{Na}_{2} \mathrm{SO}_{4}$ & 12.78 & 0.0900 \\
\hline $\mathrm{Na}_{2} \mathrm{CrO}_{4}$ & 1.68 & 0.0104 \\
\hline $\mathrm{Na}_{3} \mathrm{PO}_{4} \cdot 12 \mathrm{H}_{2} \mathrm{O}$ & 18.70 & 0.0492 \\
\hline $\mathrm{NaCl}_{\mathrm{NaF}}$ & 2.56 & 0.0438 \\
\hline $\mathrm{NaF}_{\mathrm{NaNO}}$ & 1.33 & 0.0316 \\
\hline $\mathrm{CsNO}$ & 29.26 & 0.424 \\
\hline
\end{tabular}

Table 4.3. Analyte Concentrations in Saltcake Solution Simulant and in Actual Waste

\begin{tabular}{|c|c|c|}
\hline \multirow[b]{2}{*}{ Component } & \multicolumn{2}{|c|}{ "Concentration in mole/L } \\
\hline & $\begin{array}{l}\text { Cold Simulant, } \\
\text { As-formulated }\end{array}$ & $\begin{array}{c}\text { Pretreated Actual Waste, } \\
\text { Measured }\end{array}$ \\
\hline $\mathrm{Al}$ & 0.0637 & $0.208 \pm 0.0025$ \\
\hline $\mathrm{B}$ & 0 & $0.0021 \pm 0.000057$ \\
\hline $\mathrm{Ca}$ & 0 & $0.0014 \pm 0.00024$ \\
\hline $\mathrm{Cr}$ & 0.0104 & $0.0186 \pm 0.00015$ \\
\hline $\mathrm{K}$ & 0.0124 & $0.0090 \pm 0.00054$ \\
\hline $\mathrm{Na}$ & 5.00 & $5.10 \pm 0.11$ \\
\hline $\mathrm{Si}$ & 0 & $0.0039 \pm 0.00043$ \\
\hline \multicolumn{3}{|l|}{ Anions/Other } \\
\hline $\mathrm{Cl}$ & 0.0438 & $0.0415 \pm 0.0$ \\
\hline $\mathrm{CO}_{3}\left(\right.$ or $\left.\mathrm{TIC}^{(\mathrm{a})}\right)$ & 0.475 & $0.533 \pm 0.0017$ \\
\hline $\mathrm{F}$ & 0.0316 & $0.018 \pm 0.00026$ \\
\hline $\mathrm{NO}_{2}$ & 0.424 & $0.414 \pm 0.0046$ \\
\hline $\mathrm{NO}_{3}$ & 2.51 & $2.44 \pm 0.011$ \\
\hline $\mathrm{PO}_{4}$ & 0.0492 & $0.0515 \pm 0.0014$ \\
\hline $\mathrm{SO}_{4}$ & 0.0900 & $0.0932 \pm 0.000074$ \\
\hline $\mathrm{C}_{2} \mathrm{O}_{4}$ (oxalate) & 0.0118 & $0.0105 \pm 0.000032$ \\
\hline Other soluble TOC ${ }^{(\mathrm{b})}$ (e.g., acetate) & 0.263 & $\mathrm{n} / \mathrm{a}$ \\
\hline TOC (direct measure) & 0.287 & $0.233 \pm 0.0049$ \\
\hline Free $\mathrm{OH}$ & 0.485 & $0.51 \pm 0.0035$ \\
\hline \multicolumn{3}{|l|}{$\begin{array}{l}\text { (a) TIC = total inorganic carbon } \\
\text { (b) } \mathrm{TOC}=\text { total organic carbon }\end{array}$} \\
\hline
\end{tabular}


Table 4.4. Glass Component Concentration in Saltcake Solution Simulant and Actual Waste

\begin{tabular}{|c|c|c|c|c|}
\hline \multirow[b]{2}{*}{ Glass component } & \multicolumn{2}{|c|}{ Target Saltcake Simulant } & \multicolumn{2}{|c|}{ Actual Waste } \\
\hline & $\begin{array}{c}\text { Concentration } \\
\mathrm{g} / \mathrm{L}\end{array}$ & $\begin{array}{c}\text { Mass } \\
\text { fraction }\end{array}$ & $\begin{array}{c}\text { Concentration } \\
\mathrm{g} / \mathrm{L}\end{array}$ & $\begin{array}{c}\text { Mass } \\
\text { fraction }\end{array}$ \\
\hline $\mathrm{Al}_{2} \mathrm{O}_{3}$ & 3.25 & 0.0188 & 10.60 & 0.0577 \\
\hline $\mathrm{B}_{2} \mathrm{O}_{3}$ & & & 0.07 & 0.0004 \\
\hline $\mathrm{CaO}$ & & & 0.08 & 0.0004 \\
\hline $\mathrm{Cl}$ & 1.55 & 0.0090 & 1.47 & 0.0080 \\
\hline $\mathrm{Cr}_{2} \mathrm{O}_{3}$ & 0.79 & 0.0046 & 1.41 & 0.0077 \\
\hline F & 0.60 & 0.0035 & 0.34 & 0.0019 \\
\hline $\mathrm{K}_{2} \mathrm{O}$ & 0.58 & 0.0034 & 0.42 & 0.0023 \\
\hline $\mathrm{Na}_{2} \mathrm{O}$ & 154.99 & 0.8983 & 158.05 & 0.8599 \\
\hline $\mathrm{P}_{2} \mathrm{O}_{5}$ & 3.49 & 0.0202 & 3.66 & 0.0199 \\
\hline $\mathrm{SiO}_{2}$ & & & 0.23 & 0.0013 \\
\hline $\mathrm{SO}_{3}$ & 7.21 & 0.0418 & 7.46 & 0.0406 \\
\hline Total & 172.46 & 1.0000 & 183.80 & 1.0000 \\
\hline
\end{tabular}

The glass-oxide fractions that would result from the target mixtures of soil, LAW/LAW simulant, and additives are listed in Table 4.5. Table 4.6 lists predicted properties of ASCM and ARCM glasses.

Table 4.5. Compositions of ASCM and ARCM Glasses (in mass fractions)

\begin{tabular}{||l|c|c|c|c|c|c||}
\hline & ASCM-01 & ASCM-02 & ASCM-03 & ASCM-04 & ASCM-05 & ARCM-01 \\
\hline $\mathrm{Al}_{2} \mathrm{O}_{3}$ & 0.0989 & 0.0988 & 0.1031 & 0.0961 & 0.0933 & 0.1059 \\
\hline $\mathrm{B}_{2} \mathrm{O}_{3}$ & 0.0500 & 0.0500 & 0.0500 & 0.0500 & 0.0500 & 0.0501 \\
\hline $\mathrm{CaO}$ & 0.0375 & 0.0377 & 0.0394 & 0.0362 & 0.0350 & 0.0371 \\
\hline $\mathrm{Cl}$ & 0.0018 & 0.0015 & 0.0015 & 0.0020 & 0.0022 & 0.0017 \\
\hline $\mathrm{Cr}_{2} \mathrm{O}_{3}$ & 0.0009 & 0.0008 & 0.0008 & 0.0010 & 0.0011 & 0.0016 \\
\hline $\mathrm{F}$ & 0.0007 & 0.0006 & 0.0006 & 0.0008 & 0.0009 & 0.0004 \\
\hline $\mathrm{Fe}_{2} \mathrm{O}_{3}$ & 0.0633 & 0.0636 & 0.0665 & 0.0611 & 0.0590 & 0.0624 \\
\hline $\mathrm{K}_{2} \mathrm{O}$ & 0.0176 & 0.0176 & 0.0183 & 0.0171 & 0.0166 & 0.0172 \\
\hline $\mathrm{MgO}$ & 0.0097 & 0.0098 & 0.0102 & 0.0094 & 0.0091 & 0.0096 \\
\hline $\mathrm{Na}_{2} \mathrm{O}$ & 0.2000 & 0.1700 & 0.1700 & 0.2200 & 0.2400 & 0.2000 \\
\hline $\mathrm{P}_{2} \mathrm{O}_{5}$ & 0.0060 & 0.0053 & 0.0054 & 0.0064 & 0.0068 & 0.0061 \\
\hline $\mathrm{ReO}_{2}$ & 0.0001 & 0.0001 & 0.0001 & 0.0001 & 0.0001 & \\
\hline $\mathrm{SiO}_{2}$ & 0.4255 & 0.4575 & 0.4471 & 0.4111 & 0.3966 & 0.4199 \\
\hline $\mathrm{SO}_{3}$ & 0.0083 & 0.0069 & 0.0068 & 0.0093 & 0.0102 & 0.0084 \\
\hline $\mathrm{TiO}_{2}$ & 0.0097 & 0.0098 & 0.0102 & 0.0094 & 0.0091 & 0.0096 \\
\hline $\mathrm{ZrO}_{2}$ & 0.0700 & 0.0700 & 0.0700 & 0.0700 & 0.0700 & 0.0700 \\
\hline $\mathrm{Total}$ & 1.0000 & 1.0000 & 1.0000 & 1.0000 & 1.0000 & 1.0000 \\
\hline $\mathrm{Soil}$ & 0.6817 & 0.6852 & 0.7164 & 0.6586 & 0.6355 & 0.6725 \\
\hline $\mathrm{Waste}^{\mathrm{Additive}}$ & 0.1983 & 0.1648 & 0.1636 & 0.2214 & 0.2445 & 0.2075 \\
\hline $\mathrm{Na}_{2} \mathrm{O}$ from Soil & 0.1200 & 0.1500 & 0.1200 & 0.1200 & 0.1200 & 0.1200 \\
\hline $\mathrm{Na}_{2} \mathrm{O}$ from Waste & 0.1781 & 0.0220 & 0.0230 & 0.0211 & 0.0204 & 0.0216 \\
\hline & & 0.1480 & 0.1470 & 0.1989 & 0.2196 & 0.1784 \\
\hline
\end{tabular}


Table 4.6. Predicted Properties of ASCM and ARCM Glasses

\begin{tabular}{|c|c|c|c|c|c|c|c|c|c|}
\hline Property & Symbol & Unit & Reference & $\begin{array}{c}\text { ASCM- } \\
01\end{array}$ & $\begin{array}{c}\text { ASCM- } \\
02\end{array}$ & $\begin{array}{c}\text { ASCM- } \\
03\end{array}$ & $\begin{array}{c}\text { ASCM- } \\
04\end{array}$ & $\begin{array}{c}\text { ASCM- } \\
05\end{array}$ & $\begin{array}{c}\text { ARCM- } \\
01\end{array}$ \\
\hline \multirow{2}{*}{ Viscosity } & $T_{\eta=5 \text { Pa's }}$ & ${ }^{\circ} \mathrm{C}$ & Vienna et al. 2002 & 1290 & 1364 & 1357 & 1246 & 1203 & 1297 \\
\hline & $T_{\eta=10 \text { Pa:s }}$ & ${ }^{\circ} \mathrm{C}$ & Vienna et al. 2002 & 1213 & 1282 & 1276 & 1171 & 1130 & 1219 \\
\hline \multirow{2}{*}{$\begin{array}{l}\text { Electrical } \\
\text { Conductivity }\end{array}$} & $\varepsilon_{\eta}=5$ Pa.s & $\mathrm{S} / \mathrm{m}$ & Hrma et al. 1994 & 43 & 41 & 41 & 45 & 47 & 44 \\
\hline & $\mathcal{E}_{\eta=10 \text { Pa:s }}$ & $\mathrm{S} / \mathrm{m}$ & Hrma et al. 1994 & 33 & 32 & 31 & 35 & 37 & 34 \\
\hline \multirow{3}{*}{ PCT } & $r_{\mathrm{B}}$ & $\mathrm{g} / \mathrm{m}^{2}$ & Vienna et al. 2002 & 0.16 & 0.08 & 0.08 & 0.25 & 0.41 & 0.14 \\
\hline & $r_{\mathrm{Li}}$ & $\mathrm{g} / \mathrm{m}^{2}$ & Vienna et al. 2002 & 0.16 & 0.09 & 0.08 & 0.24 & 0.37 & 0.14 \\
\hline & $r_{\mathrm{Na}}$ & $\mathrm{g} / \mathrm{m}^{2}$ & Vienna et al. 2002 & 0.33 & 0.16 & 0.15 & 0.57 & 0.96 & 0.30 \\
\hline TCLP & $c_{\mathrm{Cr}}$ & $\mathrm{mg} / \mathrm{L}$ & Kim and Vienna 2002 & 0.043 & 0.018 & 0.019 & 0.074 & 0.126 & 0.072 \\
\hline Density & $\rho$ & $\mathrm{g} / \mathrm{mL}$ & Vienna et al. 2002 & 2.704 & 2.682 & 2.688 & 2.716 & 2.727 & 2.701 \\
\hline $\mathrm{S} /(\mathrm{S}+\mathrm{A}+\mathrm{N})^{(\mathrm{a})}$ & & & & 0.587 & 0.630 & 0.621 & 0.565 & 0.543 & 0.579 \\
\hline
\end{tabular}

(a) $\mathrm{S} /(\mathrm{S}+\mathrm{A}+\mathrm{N})$ stands for the $\mathrm{SiO}_{2}$ fraction in the $\mathrm{SiO}_{2}-\mathrm{Na}_{2} \mathrm{O}-\mathrm{Al}_{2} \mathrm{O}_{3}$ submixture.

For the batch made from the simulant, the first step was measuring the total content of glass components in the simulant solution. The overall concentration of glass-components in the simulated saltcake solution could not be measured by simple calcination because the calcine would be highly hydroscopic.

Therefore, calcination was carried out with an addition of silica. Exactly $10.00 \mathrm{~g}$ of pure silica were placed in a platinum crucible. While the saltcake solution was thoroughly stirred with a motor and impeller, an approximately 10-mL sample was removed with a pipette added into the crucible by draining it over the surface of the silica. The crucible was weighed and placed into an oven preheated to $105 \pm 5^{\circ} \mathrm{C}$ for 24 hours for drying. The crucible was then transferred into a furnace preheated at $200^{\circ} \mathrm{C}$. In a process that lasted more than an hour, the temperature was slowly increased to $650^{\circ} \mathrm{C}$ and held for $60 \pm 15$ minutes. When $\mathrm{NO}_{\mathrm{x}}$ evolution was no longer visible, the temperature was slowly raised to $1050^{\circ} \mathrm{C}$ to complete calcination.

The concentration of glass-forming components in the saltcake solution, $c_{G}$, is given by:

$$
c_{G}=\left(m_{C}-m_{S}\right) / V
$$

where $m_{C}$ is the mass of calcine in the crucible, $m_{S}$ is the mass of silica in the crucible, and $V$ is the solution volume.

The next step was reducing the volume of saltcake solution. The saltcake solution was weighed and then evaporated until its volume was reduced to roughly one half of the original. Then the mass-reduction coefficient, defined as

$$
\alpha=m_{\text {final }} / m_{\text {original }}
$$

was calculated, obtaining $\alpha=0.595$ from $m_{\text {original }}=48.92 \mathrm{~kg}$ and $m_{\text {final }}=29.11 \mathrm{~kg}$. 
When the volume reduction was completed, Re was added to the saltcake solution as an ostensible Tc surrogate. The target $\mathrm{ReO}_{2}$ concentration was 0.01 mass $\%$, which was deemed to be a minimum comfortable amount for accurate measurements by chemical analysis. It was added in the form of $\operatorname{Re}_{2} \mathrm{O}_{7}$. The mass ( $w_{\mathrm{Re} 2 \mathrm{O} 7}$ in $\mathrm{g}_{2} \mathrm{Re}_{2} \mathrm{O}_{7}$ per $\mathrm{g}$ solution) was calculated using the formula:

$$
w_{\mathrm{Re}_{2} \mathrm{O}_{7}}=\frac{w_{G} g_{\mathrm{ReO}_{2}} M_{\mathrm{Re}_{2} \mathrm{O}_{7}}}{2 \alpha W M_{\mathrm{ReO}_{2}}}
$$

where

$$
\begin{aligned}
w_{G} & =\text { total mass of glass components per a mass unit of the original saltcake solution } \\
g_{\mathrm{ReO} 2} & =\text { mass fraction of } \mathrm{ReO}_{2} \text { in the baseline glass (ASCM-01) } \\
M_{\mathrm{ReO} 2} & =\text { molecular mass of } \mathrm{ReO}_{2} \\
M_{\mathrm{Re} 2 \mathrm{O} 7} & =\text { molecular mass of } \mathrm{Re}_{2} \mathrm{O}_{7} \\
W & =\text { baseline glass (ASCM-01) waste loading } \\
\alpha & =\text { mass reduction coefficient. }
\end{aligned}
$$

The $w_{G}$ is given by

$$
w_{G}=c_{G} / \rho_{S}
$$

\begin{tabular}{|c|c|c|c|c|c|}
\hline & 01 & 02 & 03 & 04 & 05 \\
\hline $\mathrm{W}$ & 0.1983 & 0.1648 & 0.1636 & 0.2214 & 0.2445 \\
\hline Mass $\% \mathrm{ReO}_{2}$ in glass & 0.010 & 0.008 & 0.008 & 0.011 & 0.012 \\
\hline
\end{tabular}

where $\rho_{S}$ is the density of saltcake solution $\left(\rho_{S}=1.24 \mathrm{~g} / \mathrm{mL}\right)$. By Table $4.4, c_{G}=172.46 \mathrm{~g} / \mathrm{L}$ so $w_{G}=139.08 \mathrm{~g} / \mathrm{kg}$ solution and by Table $4.5, W=0.1983$. For $g_{\mathrm{ReO} 2}=0.0001$ and $\alpha=0.595$, we obtain $w_{\mathrm{Re} 207}=0.131 \mathrm{~g} / \mathrm{kg}$ solution.

$\mathrm{Re}_{2} \mathrm{O}_{7}$ was added to all the saltcake solution available at the concentration calculated for the baseline glass ASCM-01, i.e., $w_{\mathrm{Re} 2 \mathrm{O} 7}=0.131 \mathrm{~g} / \mathrm{kg}$ solution for all glasses. This created a small change in the target mass $\% \mathrm{ReO}_{2}$ in the other ASCM glasses (see Table 4.7).

Table 4.7. Rhenium Addition to Saltcake Solution for ASCM Glasses

The total mass of $\operatorname{Re}_{2} \mathrm{O}_{7}\left(m_{\mathrm{Re} 2 \mathrm{O} 7}\right)$ to be dissolved in the solution was calculated as $3.813 \mathrm{~g}$ using the formula:

$$
m_{\mathrm{Re}_{2} O_{7}}=w_{\operatorname{Re}_{2} O_{7}} m_{W}
$$

where $m_{W}$ is the saltcake-solution mass, $29.11 \mathrm{~kg}$. The solution was stirred with a motor and impeller until all $\mathrm{Re}_{2} \mathrm{O}_{7}$ dissolved. Out of $29.11 \mathrm{~kg}$ of saltcake-solution with Re addition, $24.30 \mathrm{~kg}$ was reserved for the first engineering-scale (ES-1) test and the rest of $4.81 \mathrm{~kg}$ was used for the simulant crucible tests and sample analyses. 
When these operations were completed, batch preparation was performed for glasses defined in the Table 4.5 test matrix. Apart from the major ingredients (the saltcake, the soil, $\mathrm{H}_{3} \mathrm{BO}_{3}, \mathrm{ZrO}_{2}$, and $\mathrm{SiO}_{2}$ ), sugar was also added to adjust the redox to the reduced condition of the typical ICV product glass. Table 4.8 contains the manufacturer, lot number, and LOI information for the materials used. The LOIs account for additional water in the source chemicals.

Table 4.8. Information on Dry Soil and Source Chemicals

\begin{tabular}{||l|l|l|c||}
\hline Component & Manufacture & $\begin{array}{l}\text { Lot } \\
\text { Number }\end{array}$ & $\begin{array}{c}\text { LOI }^{(\mathbf{a})} \\
\text { (mass\%) }\end{array}$ \\
\hline Dry Soil & N/A & N/A & 0.80 \\
\hline $\begin{array}{l}\text { Saltcake } \\
\text { solution }\end{array}$ & Noah & $120451 / 1.1$ & 78.26 \\
\hline $\mathrm{H}_{3} \mathrm{BO}_{3}$ & Noah & $20032 / 2.1$ & 44.26 \\
\hline $\mathrm{ZrO}_{2}$ & Noah & $18151 / 1.1$ & 0 \\
\hline $\mathrm{SiO}_{2}$ & Fisher & 016166 & 0 \\
\hline
\end{tabular}

(a) LOI is loss on ignition at $1050^{\circ} \mathrm{C}$ for 2 hours.

(b) After water evaporation with a mass reduction coefficient $\alpha=0.595$.

The same limitations on weighing and cross-contamination precautions were applied as for the preliminary glasses (Section 3.1.3). Equation 3.1 was used to obtain the masses of batch components for $500 \mathrm{~g}$ of ASCM glasses from mass fractions listed in Table 4.5. For chemically identical batch and glass components, as in the case of $\mathrm{ZrO}_{2}$ or soil, Equation 3.1 reduces to

$$
m_{i}=\frac{x_{i} m_{G}}{1-\lambda_{i}}
$$

The amounts of chemicals thus obtained are listed in Table 4.9.

Table 4.9. Masses (g) of Batch Materials to Make 500-g ASCM Glasses

\begin{tabular}{|c|c|c|c|c|c|c|}
\hline & & ASCM-01 & ASCM-02 & ASCM-03 & ASCM-04 & $\overline{\text { ASCM-05 }}$ \\
\hline Dry Soil & $\mathrm{g}$ & 343.60 & 345.36 & 361.09 & 331.96 & 320.31 \\
\hline Saltcake solution $^{(a)}$ & $\mathrm{g}$ & 456.07 & 379.02 & 376.26 & 509.20 & 562.33 \\
\hline $\mathrm{H}_{3} \mathrm{BO}_{3}$ & $\mathrm{~g}$ & 44.85 & 44.85 & 44.85 & 44.85 & 44.85 \\
\hline $\mathrm{ZrO}_{2}$ & $\mathrm{~g}$ & 35.00 & 35.00 & 35.00 & 35.00 & 35.00 \\
\hline $\mathrm{SiO}_{2}$ & $\mathrm{~g}$ & 0 & 15.00 & 0 & 0 & 0 \\
\hline Total & $\mathrm{g}$ & 879.52 & 819.24 & 817.20 & 921.01 & 962.49 \\
\hline
\end{tabular}

Two batches, $500 \mathrm{~g}$ each, of ASCM-01 glass were prepared. For the final melt, the ground glass was mixed together and melted as a single batch. Table 4.10 shows the amount of chemicals and actual waste for $500 \mathrm{~g}$ of ARCM glass. The density of actual waste was measured before preparation of the batch. Similar to ASCM-01, two batches of $500 \mathrm{~g}$ of ARCM-01 were prepared. 


\section{Table 4.10. Masses (g) of Batch Materials and Volume of Actual Waste to Make 500-g ARCM Glass}

\begin{tabular}{||l|c|c||}
\hline \hline Materials & & ARCM-01 \\
\hline Dry Soil & g & 338.96 \\
\hline $\mathrm{H}_{3} \mathrm{BO}_{3}$ & $\mathrm{~g}$ & 44.85 \\
\hline $\mathrm{ZrO}_{2}$ & $\mathrm{~g}$ & 35.00 \\
\hline $\mathrm{SiO}_{2}$ & $\mathrm{~g}$ & 0 \\
\hline Subtotal & $\mathrm{g}$ & 418.81 \\
\hline Actual Waste Volume & $\mathrm{mL}$ & 564.47 \\
\hline
\end{tabular}

As described above, an additional step was performed before melting glasses from the simulant or actual waste. Before adding sugar, the batch was dried at $100 \pm 20^{\circ} \mathrm{C}$ in a PTFE beaker, which allowed for easy removal of the dried material. The dried material was then transferred to a Pt-alloy crucible and calcined at $700 \pm 30^{\circ} \mathrm{C}$ to remove as much $\mathrm{NO}_{\mathrm{x}}$ as possible.

During drying of one of the two ARCM-01 batches, the PTFE beaker was accidentally placed too close to a furnace heating element and melted (as shown in Figure 4.1). Because of the intimate mixture of batch and crucible, the affected ARCM-01 batch was discarded, leaving only one batch.

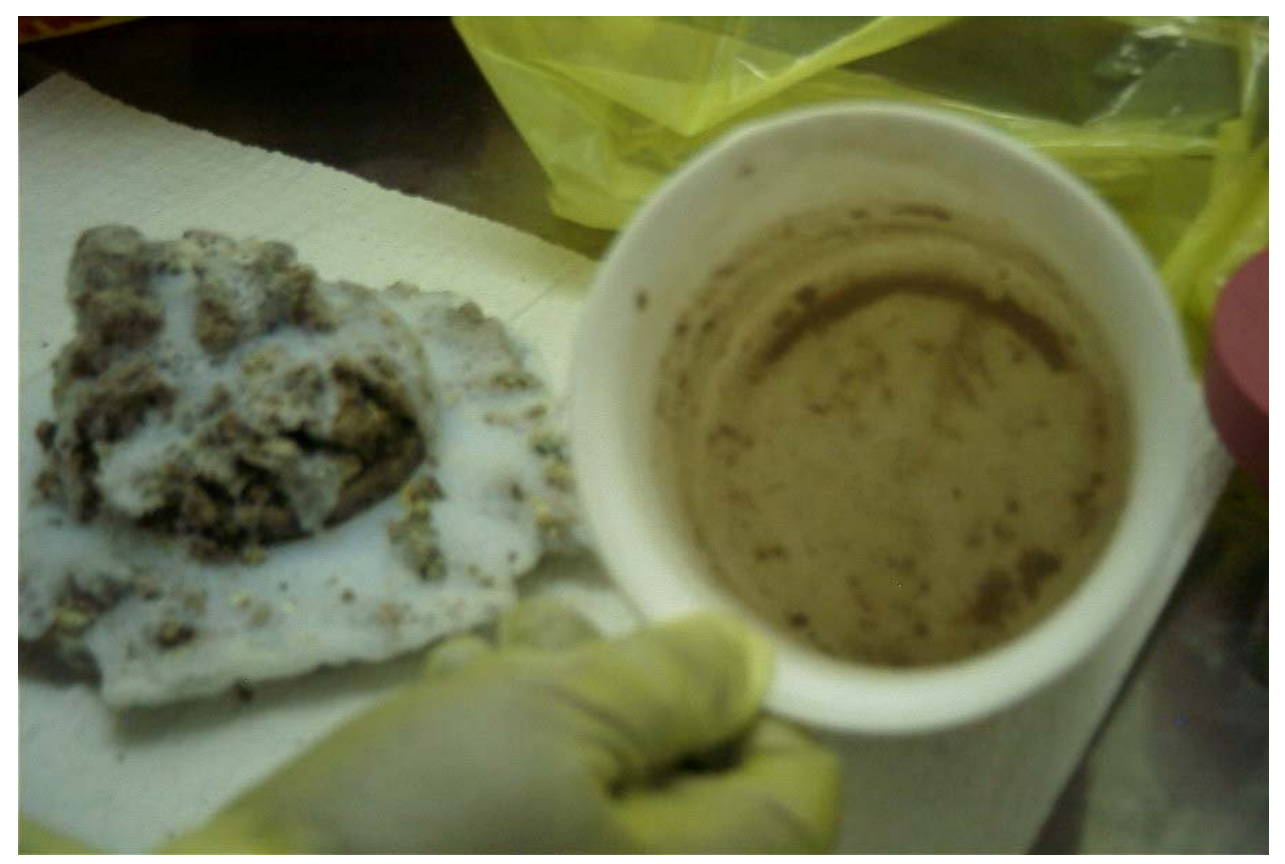

Figure 4.1. Photograph of Melted and Unmelted PTFE Crucibles Used to Dry ARCM-01 Batches

Because nitrates and aluminosilicates react, producing a sodium aluminosilicate-nitrite, $\mathrm{Na}_{8}\left(\mathrm{AlSiO}_{4}\right)_{6}\left(\mathrm{NO}_{2}\right)_{2}$, a compound that has a sodalite structure and decomposes at high temperatures 
(possibly up to $1450^{\circ} \mathrm{C}$ ), not all $\mathrm{NO}_{\mathrm{x}}$ could be removed in the calcining step. As a result, some sugar would react with the nitrate from sodalite instead of with $\mathrm{Fe}_{2} \mathrm{O}_{3}$. Additional sugar was added to compensate for some losses due to reaction with sodalite and combustion with atmospheric oxygen.

It was assumed that the $\mathrm{Fe}(\mathrm{II})$ from the soil was oxidized to $\mathrm{Fe}(\mathrm{III})$ by nitrates from the saltcake during calcining. The amount of sugar to reduce Fe(III) to Fe(II) was estimated according to the scheme:

$$
\mathrm{C}_{12} \mathrm{H}_{22} \mathrm{O}_{11}+24 \mathrm{Fe}_{2} \mathrm{O}_{3} \rightarrow 48 \mathrm{FeO}+12 \mathrm{CO}_{2}+11 \mathrm{H}_{2} \mathrm{O}
$$

By this reaction, the amount of sugar $\left(m_{\text {sugar }}\right)$ is

$$
m_{\text {sugar }}=\frac{m_{G} g_{\mathrm{Fe}_{2} \mathrm{O}_{3}} M_{\mathrm{C}_{12} \mathrm{H}_{22} \mathrm{O}_{11}}}{24 M_{\mathrm{Fe}_{2} \mathrm{O}_{3}}}
$$

where $m_{G}$ is the glass mass, $g_{\mathrm{Fe} 2 \mathrm{O} 3}$ is the $\mathrm{Fe}_{2} \mathrm{O}_{3}$ fraction in the glass, and $M_{\mathrm{Fe} 2 \mathrm{O} 3}$ and $M_{\mathrm{C} 12 \mathrm{H} 22 \mathrm{O} 11}$ are the molecular masses of $\mathrm{Fe}_{2} \mathrm{O}_{3}$ and sugar, respectively. According to Equation 4.7, the amount of sugar to be added to the calcine to make $m_{G}=500 \mathrm{~g}$ of ASCM- 01 glass $\left(g_{\mathrm{Fe} 2 \mathrm{O} 3}=0.0633\right)$ is $m_{\text {sugar }}=2.83 \mathrm{~g}$. This corresponds to $c_{\text {sugar }}=5.65 \mathrm{~g}$ sugar $/ \mathrm{kg}$ glass. The $m_{\text {sugar }}$ values (in $\mathrm{g}$ of sugar per $500 \mathrm{~g}$ of glass) are listed in Table 4.11.

Table 4.11. Calculated Reductant Required to Reduce all $\mathrm{Fe}_{2} \mathrm{O}_{3}$ to $\mathrm{FeO}$ for $\mathrm{ASCM}_{\text {Glasses }}{ }^{(a)}$

\begin{tabular}{||c|c|l|l|l|l|l||}
\hline & Unit & \multicolumn{1}{|c|}{$\mathbf{0 1}$} & \multicolumn{1}{|c|}{$\mathbf{0 2}$} & \multicolumn{1}{|c|}{$\mathbf{0 3}$} & \multicolumn{1}{|c|}{$\mathbf{0 4}$} & \multicolumn{1}{|c||}{$\mathbf{0 5}$} \\
\hline$g_{\mathrm{Fe} 2 \mathrm{O} 3}$ & & 0.0633 & 0.0636 & 0.0665 & 0.0611 & 0.0590 \\
\hline$m_{\text {sugar }}$ & $\mathrm{g}$ & 2.827 & 2.840 & 2.970 & 2.728 & 2.635 \\
\hline$c_{\text {sugar }}$ & $\mathrm{g} / \mathrm{kg}$ glass & 5.653 & 5.680 & 5.939 & 5.457 & 5.269 \\
\hline (a) The two ARCM glasses have compositions similar to ASCM-01 glass. \\
\hline
\end{tabular}

Sugar would also react with sodalite by the reaction:

$$
\mathrm{C}_{12} \mathrm{H}_{22} \mathrm{O}_{11}+12 \mathrm{Na}_{8}\left(\mathrm{AlSiO}_{4}\right)_{6}\left(\mathrm{NO}_{2}\right)_{2} \rightarrow 72 \mathrm{NaAlSiO}_{4}+12 \mathrm{CO}_{2}+24 \mathrm{NO}+11 \mathrm{H}_{2} \mathrm{O}+12 \mathrm{Na}_{2} \mathrm{O}
$$

This may require extra sugar $\left(c_{\text {sugar/sodalite }}\right)$, which is calculated by the following relation:

$$
c_{\text {sugar } / \text { sodalite }}=\frac{\beta \xi W x_{N} M_{C_{12} H_{22} O_{11}}}{12 c_{G}}
$$

where $x_{N}$ is molar concentration of nitrogen in the solution, $\beta$ is the fraction of nitrogen from the waste that forms sodalite, and $\xi$ is the $\mathrm{C}: \mathrm{N}$ ratio for the sugar-sodalite reaction. Using the values $x_{N}=2.934$ mole $/ \mathrm{L}$ (from Table 4.3), $\beta \approx 0.1, \xi=0.5, c_{G}=172.46 \mathrm{~g} / \mathrm{L}$, and $W=0.1983$ (for ASCM-01), we obtain $c_{\text {sugar } / \text { sodalite }}=4.81 \mathrm{~g}$ sugar $/ \mathrm{kg}$ glass. This amount is not much different from $5.65 \mathrm{~g}$ sugar $/ \mathrm{kg}$ glass needed for $\mathrm{Fe}(\mathrm{III}) \rightarrow \mathrm{Fe}(\mathrm{II})$ reduction, even though the value of $\beta \approx 0.1$ is probably exaggerated. 
Some sugar may also be lost by oxidation when the crucible is exposed to air. Therefore, a constant $11 \mathrm{~g}$ of sugar per kg glass were used for the tests, except for the ARCM glasses for which the sugar addition was doubled. This corresponds to the theoretical amount of sugar required to reduce all $\mathrm{Fe}_{2} \mathrm{O}_{3}$ to $\mathrm{FeO}$, and the sodalite of about 10 mass\% nitrogen from the waste (or simulant) is assumed to participate in the sodalite formation (assuming no air-sugar reactions occur).

Pieces of the calcine were removed from the crucible to a beaker. Sugar (110 g) was dissolved in $500 \mathrm{~mL}$ of water, and $25 \mathrm{~mL}$ of this solution was slowly poured over the calcine in the beaker while stirring the mixture with a rod. The mixture was dried at $110^{\circ} \mathrm{C}$ for 1 hour. A portion of the dry mixture was returned to the crucible to fill about half of its volume and placed in the furnace preheated at temperatures from $1200^{\circ} \mathrm{C}$ to $1360^{\circ} \mathrm{C}$, which correspond to $T_{\eta=5}$ Pas. The remaining batch was added in one or two portions. The content was kept under argon atmosphere at the melt temperature for 1 hour. The glass was poured on a stainless steel plate (as shown in Figure 4.2), crushed in the tungsten carbide mill, and remelted under argon for 1 hour at the same temperature. The same pouring procedure was followed as for the preliminary glasses (as shown in Figure 4.3 and Figure 4.4).

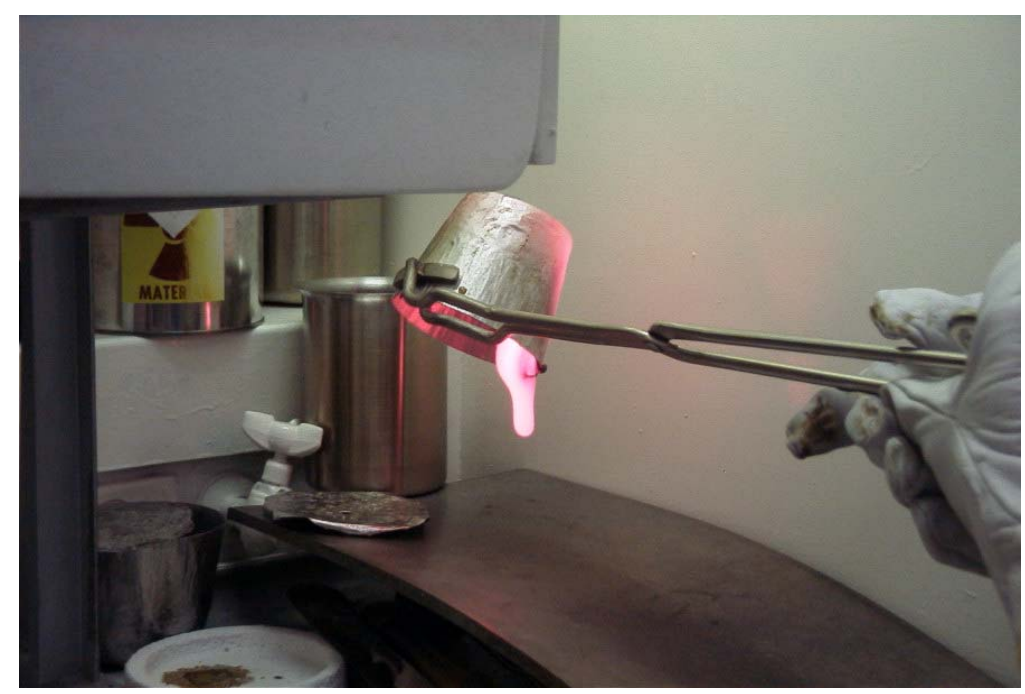

Figure 4.2. Photograph of ARCM-01 Melt Being Poured Onto Stainless Steel Plate 


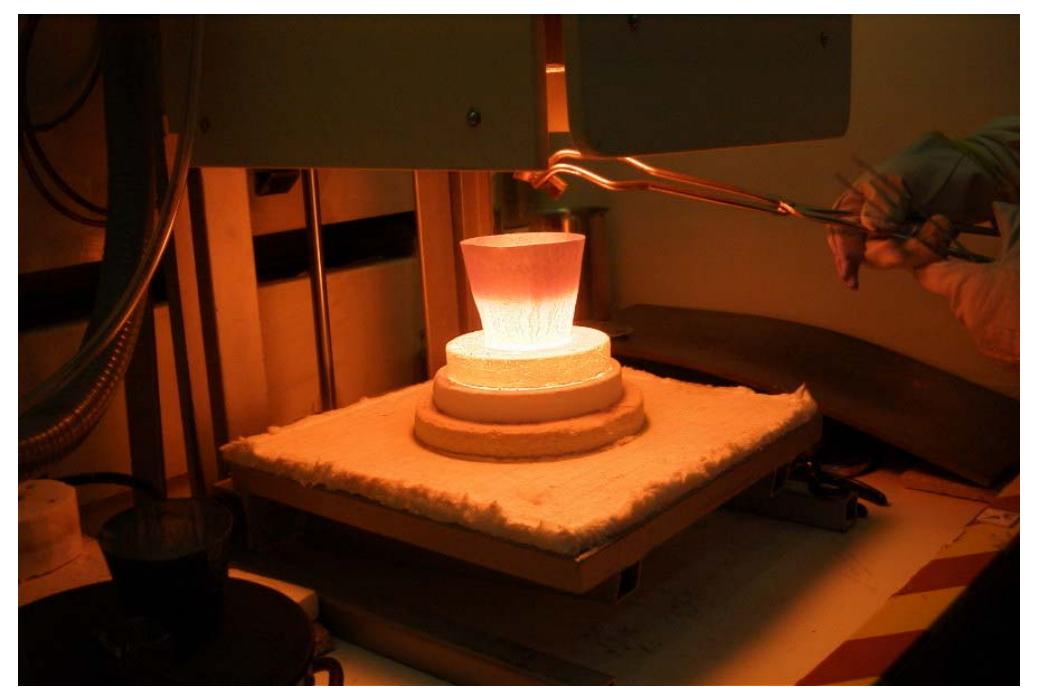

Figure 4.3. Photograph of ARCM-01 Sample at the Completion of the Second Melt

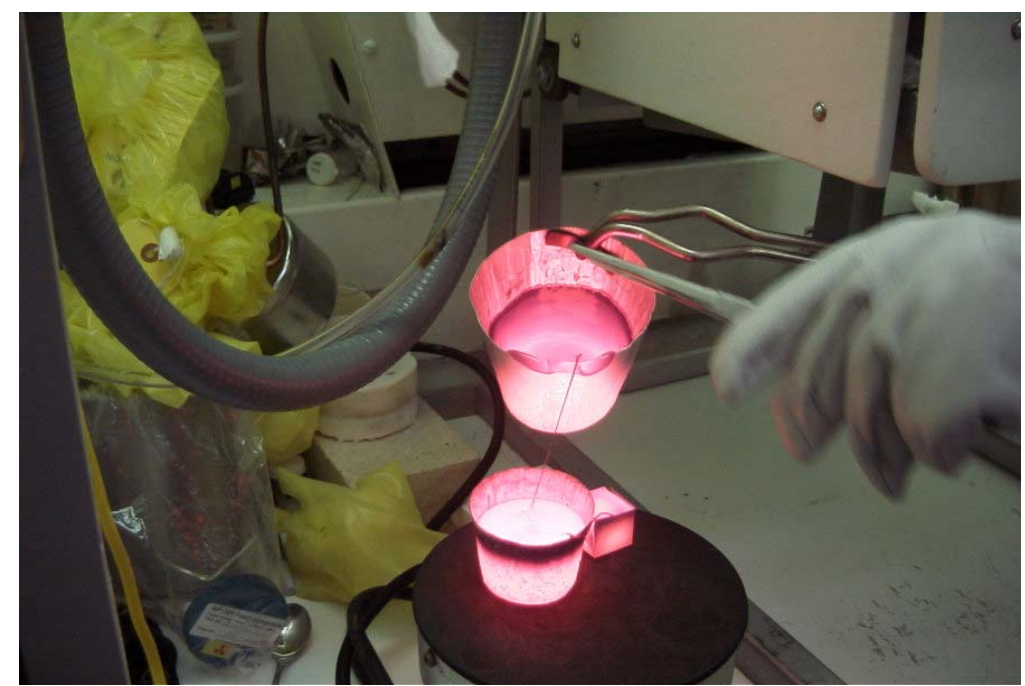

Figure 4.4. Photograph of ARCM-01 Melt Being Cast into Two Molds for VHT (small cube) and SC Heat Treatment (crucible)

\subsection{Glass-Composition Analysis}

Each set of glass composition analyses included the analysis of LRM-1 glass (Wolf et al. 1998) for the purpose of bias-correcting the analytical results based on known reference values for LRM glass. The methodology developed by Weier and Piepel (2003) was followed. The uncertainties for major glass components in LRM glass were obtained from the standard deviation values and number of measurements given in the literature (Wolf et al. 1998). A 10\% relative analytical uncertainty was used for all glass components for measured values at PNNL and SRTC. The analytical glass composition data presented in this report are all those bias-corrected using LRM glass analyses.

Table 4.12 summarizes the results of glass-composition analysis for five ASCM glasses and a sample of ARCM glass. Figure 4.5 shows the comparison of measured and target concentrations as a function of 
$\mathrm{Na}_{2} \mathrm{O}$ concentration in glass (directly proportional to waste loading) for the components with a target mass fraction higher than 0.03 . The measured concentrations were higher than the targets for $\mathrm{Na}_{2} \mathrm{O}$ and $\mathrm{SiO}_{2}$ and lower for $\mathrm{Al}_{2} \mathrm{O}_{3}, \mathrm{~B}_{2} \mathrm{O}_{3}, \mathrm{CaO}, \mathrm{Fe}_{2} \mathrm{O}_{3}$, and $\mathrm{ZrO}_{2}$. These differences were within roughly $15 \%$ of target concentrations except for $\mathrm{CaO}$ and $\mathrm{Fe}_{2} \mathrm{O}_{3}$, which showed a 30 to $50 \%$ difference. There was no trend in the measured-to-target ratio affected by the glass composition. The source for these differences could be a combined effect of analytical biases involved in soil, waste, and glass analyses as well as possible variation of soil compositions. The calculated retentions of $\mathrm{SO}_{3}$ in $\mathrm{ASCM}$ glasses ranged from 62 to $76 \%$.

Table 4.12. Analyzed Compositions of ASCM and ARCM Glasses (in mass fractions) ${ }^{(a)}$

\begin{tabular}{|c|c|c|c|c|c|c|}
\hline בComponent & ASCM-01 & ASCM-02 & ASCM-03 & ASCM-04 & ASCM-05 & ARCM-01 \\
\hline $\mathrm{Al}_{2} \mathrm{O}_{3}$ & 0.0912 & 0.0915 & 0.0947 & 0.0872 & 0.0852 & 0.0939 \\
\hline $\mathrm{B}_{2} \mathrm{O}_{3}$ & 0.0465 & 0.0447 & 0.0454 & 0.0465 & 0.0474 & 0.0457 \\
\hline $\mathrm{CaO}$ & 0.0262 & 0.0266 & 0.0269 & 0.0250 & 0.0247 & 0.0257 \\
\hline $\mathrm{Cr}_{2} \mathrm{O}_{3}$ & 0.0010 & 0.0009 & 0.0009 & 0.0011 & 0.0012 & 0.0016 \\
\hline $\mathrm{Fe}_{2} \mathrm{O}_{3}$ & 0.0300 & 0.0306 & 0.0317 & 0.0286 & 0.0272 & 0.0288 \\
\hline $\mathrm{K}_{2} \mathrm{O}$ & 0.0125 & 0.0119 & 0.0119 & 0.0114 & 0.0118 & 0.0117 \\
\hline $\mathrm{MgO}$ & 0.0165 & 0.0164 & 0.0171 & 0.0156 & 0.0148 & 0.0128 \\
\hline $\mathrm{Na}_{2} \mathrm{O}$ & 0.2137 & 0.1793 & 0.1757 & 0.2297 & 0.2546 & 0.1866 \\
\hline $\mathrm{P}_{2} \mathrm{O}_{5}$ & 0.0049 & 0.0044 & 0.0043 & 0.0053 & 0.0058 & 0.0062 \\
\hline $\mathrm{ReO}_{2}$ & $\mathrm{ND}^{(\mathrm{b})}$ & $\mathrm{ND}^{(\mathrm{b})}$ & $\mathrm{ND}^{(\mathrm{b})}$ & $\mathrm{ND}^{(\mathrm{b})}$ & $\mathrm{ND}^{(\mathrm{b})}$ & $\mathrm{NA}^{(\mathrm{c})}$ \\
\hline $\mathrm{SiO}_{2}$ & 0.4679 & 0.4969 & 0.4846 & 0.4433 & 0.4252 & 0.4774 \\
\hline $\mathrm{SO}_{3}$ & 0.0052 & 0.0044 & 0.0042 & 0.0058 & 0.0077 & $\mathrm{NA}^{(\mathrm{c})}$ \\
\hline $\mathrm{TiO}_{2}$ & 0.0092 & 0.0093 & 0.0100 & 0.0090 & 0.0085 & 0.0062 \\
\hline $\mathrm{ZrO}_{2}$ & 0.0609 & 0.0652 & 0.0623 & 0.0601 & 0.0609 & 0.0594 \\
\hline Total & 0.9859 & 0.9821 & 0.9697 & 0.9686 & 0.9753 & 0.9560 \\
\hline
\end{tabular}

(a) Average from duplicate measurements.

(b) Below the detection limit of 0.0001 .

(c) Not analyzed - the analytical instruments used for the radioactive glasses were not capable of detecting these components. 


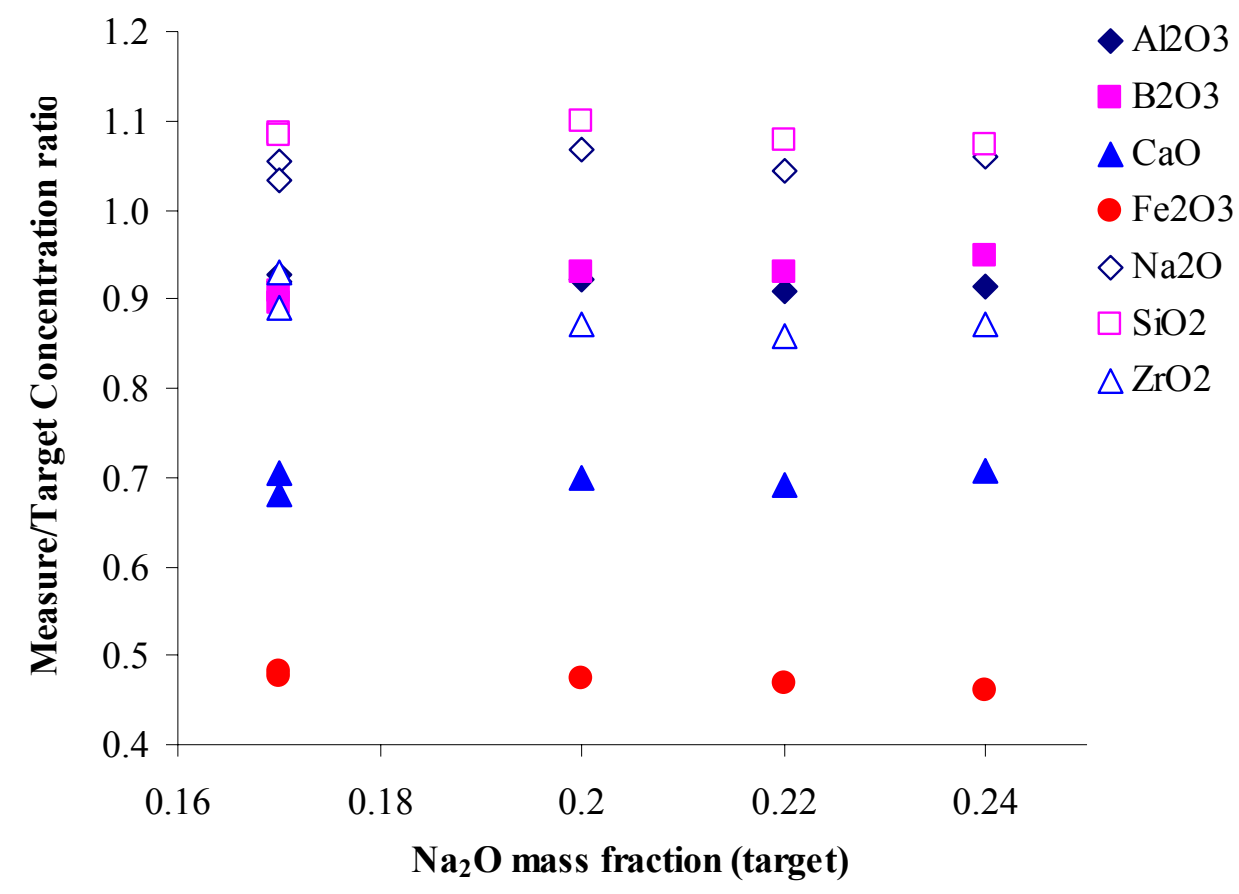

Figure 4.5. The Ratio of Measured to Target Concentrations for Selected Major Components in ASCM Glasses

Table 4.13 lists the radionuclide concentrations in ARCM-01 glass. Also included in Table 4.13 are the concentrations of radionuclides measured in the saltcake solution used to prepare ARCM-01 glass and corresponding concentrations in ARCM-01 glass calculated based on the amount of saltcake used, 564.47 $\mathrm{ml}$ saltcake for $500 \mathrm{~g}$ glass, given in Table 4.10 . 
Table 4.13. Concentration of Radioactive Components in Actual Waste and in ARCM-01 glass

\begin{tabular}{|c|c|c|c|c|c|}
\hline & In Actual V & iste (from & Rapko et al. 2003) & $\begin{array}{c}\text { Calculated in } \\
\text { ARCM-01 Glass }\end{array}$ & $\begin{array}{c}\text { Measured }^{(b)} \text { in } \\
\text { ARCM-01 Glass }\end{array}$ \\
\hline Analyte & Method & Units & Average (SD) & $\mu \mathrm{Ci} / \mathrm{g}$ glass & $\begin{array}{c}\mu \mathrm{Ci} / \mathrm{g} \text { (1-sigma } \\
\text { error) }\end{array}$ \\
\hline${ }^{7} \mathrm{Be}$ & & & NA & & $0.000274( \pm 15 \%)$ \\
\hline${ }^{60} \mathrm{Co}$ & $\gamma$-spectroscopy & $\mu \mathrm{Ci} / \mathrm{mL}$ & $0.00681(0.00025)$ & 0.00769 & $0.00816( \pm 2 \%)$ \\
\hline${ }^{99} \mathrm{Tc}$ & ICP-MS & $\mu \mathrm{Ci} / \mathrm{mL}$ & $0.0412(0.0002)$ & 0.0465 & NA \\
\hline${ }^{99} \mathrm{TcO}_{4}$ & Sep/LSC & $\mu \mathrm{Ci} / \mathrm{mL}$ & $0.0339(0.0025)$ & 0.0383 & NA \\
\hline${ }^{127} \mathrm{I}$ & ICP-MS & $\mu \mathrm{g} / \mathrm{L}$ & $899(22)$ & $1015^{(a)}$ & NA \\
\hline${ }^{129} \mathrm{I}$ & ICP-MS & $\mu \mathrm{Ci} / \mathrm{mL}$ & $0.0000585(0.0000024)$ & $6.604 \mathrm{E}-05$ & $\mathrm{NA}$ \\
\hline${ }^{137} \mathrm{Cs}$ & $\gamma$-spectroscopy & $\mu \mathrm{Ci} / \mathrm{mL}$ & $0.00121(0.00020)$ & 0.00137 & $0.00184( \pm 3 \%)$ \\
\hline${ }^{152} \mathrm{Eu}$ & $\gamma$-spectroscopy & $\mu \mathrm{Ci} / \mathrm{mL}$ & $0.000171(0.000006)$ & 0.000193 & $0.000208( \pm 5 \%)$ \\
\hline${ }^{154} \mathrm{Eu}$ & $\gamma$-spectroscopy & $\mu \mathrm{Ci} / \mathrm{mL}$ & $0.00889(0.00039)$ & 0.0100 & $0.0109( \pm 2 \%)$ \\
\hline${ }^{155} \mathrm{Eu}$ & $\gamma$-spectroscopy & $\mu \mathrm{Ci} / \mathrm{mL}$ & $0.00466(0.00029)$ & 0.00526 & $0.00541( \pm 5 \%)$ \\
\hline${ }^{79} \mathrm{Se}$ & $\mathrm{Sep} / \mathrm{LSC}$ & $\mu \mathrm{Ci} / \mathrm{mL}$ & $<9 \mathrm{E}-05$ & & NA \\
\hline${ }^{90} \mathrm{Sr}$ & Sep/LSC & $\mu \mathrm{Ci} / \mathrm{mL}$ & $<0.15$ & & NA \\
\hline${ }^{95} \mathrm{Nb}$ & & & NA & & $<2 . \mathrm{E}-5$ \\
\hline${ }^{125} \mathrm{Sb}$ & & & NA & & $<4 . \mathrm{E}-5$ \\
\hline${ }^{126} \mathrm{Sn} /{ }^{126} \mathrm{Sb}$ & $\gamma$-spectroscopy & $\mu \mathrm{Ci} / \mathrm{mL}$ & $<6 \mathrm{E}-03$ & & $0.000383( \pm 2 \%)$ \\
\hline${ }^{133} \mathrm{Cs}$ & ICP-MS & $\mu \mathrm{g} / \mathrm{L}$ & $<0.013$ & & $\mathrm{NA}$ \\
\hline${ }^{134} \mathrm{Cs}$ & & & NA & & $<2 . \mathrm{E}-5$ \\
\hline${ }^{137} \mathrm{Cs}$ & ICP-MS & $\mu \mathrm{Ci} / \mathrm{mL}$ & ND & & NA \\
\hline${ }^{237} \mathrm{~Np}$ & ICP-MS & $\mu \mathrm{Ci} / \mathrm{mL}$ & $<0.027$ & & NA \\
\hline${ }^{238} \mathrm{Pu}$ & $\alpha$-spectroscopy & $\mu \mathrm{Ci} / \mathrm{mL}$ & $<0.01$ & & $\mathrm{NA}$ \\
\hline${ }^{239} \mathrm{Pu}$ & ICP-MS & $\mu \mathrm{Ci} / \mathrm{mL}$ & $<3.0 \mathrm{E}-02$ & & NA \\
\hline${ }^{240} \mathrm{Pu}$ & ICP-MS & $\mu \mathrm{Ci} / \mathrm{mL}$ & $<1.0 \mathrm{E}-02$ & & NA \\
\hline${ }^{239,240} \mathrm{Pu}$ & $\alpha$-spectroscopy & $\mu \mathrm{Ci} / \mathrm{mL}$ & $<0.03$ & & $\mathrm{NA}$ \\
\hline${ }^{241} \mathrm{Pu} /{ }^{241} \mathrm{Am}$ & ICP-MS & $\mu \mathrm{g} / \mathrm{L}$ & $<8.7 \mathrm{E}-03$ & & NA \\
\hline${ }^{241} \mathrm{Am}$ & $\gamma$-spectroscopy & $\mu \mathrm{Ci} / \mathrm{mL}$ & $<0.03$ & & $0.00753( \pm 4 \%)$ \\
\hline${ }^{242} \mathrm{Cm}$ & $\alpha$-spectroscopy & $\mu \mathrm{Ci} / \mathrm{mL}$ & $<0.15$ & & NA \\
\hline${ }^{243,244} \mathrm{Cm}$ & $\alpha$-spectroscopy & $\mu \mathrm{Ci} / \mathrm{mL}$ & $<0.015$ & & NA \\
\hline Sum of $\alpha$ & $\alpha$-spectroscopy & $\mu \mathrm{Ci} / \mathrm{mL}$ & $0.00715(0.00020)$ & & NA \\
\hline $\mathrm{U}$ & ICP-AES & $\mu \mathrm{g} / \mathrm{mL}$ & $<600$ & & NA \\
\hline $\mathrm{U}$ & $\mathrm{LF}$ & $\mu \mathrm{g} / \mathrm{mL}$ & $<780$ & & $\mathrm{NA}$ \\
\hline
\end{tabular}
(a) $\mu \mathrm{g} / \mathrm{g}$ glass
(b) by $\gamma$-spectroscopy 


\subsection{Glass Characterization Results}

Table 4.14 summarizes the results of properties measured for five ASCM glasses and an ARCM glass, including 7-day PCT, 14-day VHT, and TCLP responses, density, and iron redox. The results are presented as functions of $\mathrm{Na}_{2} \mathrm{O}$ concentration in glass. As discussed in Section 4.1, ASCM glasses have the same additive concentration of 7 mass $\% \mathrm{ZrO}_{2}$ and 5 mass $\% \mathrm{~B}_{2} \mathrm{O}_{3}$. The ASCM- 02 and -03 glasses have $\sim 3 \%$ less waste loading than the baseline glass, ASCM-01. ASCM-03 makes up the 3\% difference with additional soil but ASCM-02 uses $3 \% \mathrm{SiO}_{2}$ to mitigate the detrimental effects that the additional $\mathrm{Al}_{2} \mathrm{O}_{3}$ in soil tends to have on the glass durability.

Table 4.14. Summary of Properties for Simulant and Actual Waste Crucible Test Glasses

\begin{tabular}{|c|c|c|c|c|c|c|}
\hline Component & ASCM-01 & ASCM-02 & ASCM-03 & ASCM-04 & ASCM-05 & ARCM-01 \\
\hline \multicolumn{7}{|c|}{ 7-Day PCT Leachate Concentration (mg/L) ${ }^{(\mathrm{a})}$} \\
\hline$c_{N a}, \mathrm{Q}$ & 133.78 & 69.67 & 69.70 & 218.51 & 343.28 & 121.50 \\
\hline$c_{A l}, \mathrm{Q}$ & 12.44 & 8.59 & 9.15 & 15.52 & 19.35 & 14.00 \\
\hline$c_{B}, \mathrm{Q}$ & 6.83 & 4.30 & 4.52 & 9.33 & 12.94 & 6.88 \\
\hline$c_{C a}, \mathrm{Q}$ & 0.313 & 0.226 & 0.189 & 0.250 & 0.216 & 0.300 \\
\hline$c_{K}, \mathrm{Q}$ & 3.52 & 1.91 & 2.21 & 4.96 & 7.76 & 4.35 \\
\hline$c_{S i}, \mathrm{Q}$ & 54.37 & 43.11 & 42.01 & 64.99 & 79.48 & 62.65 \\
\hline$c_{N a}, \mathrm{SC}$ & 120.47 & 70.68 & 67.13 & 199.82 & 305.58 & 110.00 \\
\hline$c_{A l}, \mathrm{SC}$ & 11.80 & 8.17 & 8.78 & 14.31 & 17.49 & 13.80 \\
\hline$c_{B}, \mathrm{SC}$ & 6.40 & 4.01 & 4.18 & 8.64 & 11.85 & 4.84 \\
\hline$c_{C a}, \mathrm{SC}$ & 0.215 & 0.239 & 0.199 & 0.241 & 0.221 & 0.330 \\
\hline$c_{K}, \mathrm{SC}$ & 2.86 & 1.64 & 1.93 & 4.17 & 6.18 & 3.45 \\
\hline$c_{S i}, \mathrm{SC}$ & 52.36 & 41.27 & 41.12 & 62.57 & 75.58 & 60.30 \\
\hline
\end{tabular}


Table 4.13 (Contd)

\begin{tabular}{|c|c|c|c|c|c|c|}
\hline Component & ASCM-01 & "ASCM-02 & בASCM-03 & ASCM-04 & בASCM-05 & ARCM-01 \\
\hline \multicolumn{7}{|c|}{ 7-Day PCT Normalized Release $\left(\mathrm{g} / \mathrm{m}^{2}\right)$} \\
\hline$r_{N a}, \mathrm{Q}$ & 0.451 & 0.276 & 0.276 & 0.669 & 0.964 & 0.409 \\
\hline$r_{A l}, \mathrm{Q}$ & 0.119 & 0.082 & 0.084 & 0.153 & 0.196 & 0.125 \\
\hline$r_{B}, \mathrm{Q}$ & 0.220 & 0.139 & 0.146 & 0.301 & 0.417 & 0.221 \\
\hline$r_{C a}, \mathrm{Q}$ & 0.006 & 0.004 & 0.003 & 0.005 & 0.004 & 0.006 \\
\hline$r_{K}, \mathrm{Q}$ & 0.121 & 0.065 & 0.073 & 0.175 & 0.281 & 0.152 \\
\hline$r_{S i}, \mathrm{Q}$ & 0.137 & 0.101 & 0.101 & 0.169 & 0.214 & 0.160 \\
\hline$r_{N a}, \mathrm{SC}$ & 0.406 & 0.280 & 0.266 & 0.612 & 0.858 & 0.371 \\
\hline$r_{A l}, \mathrm{SC}$ & 0.113 & 0.078 & 0.080 & 0.141 & 0.177 & 0.123 \\
\hline$r_{B}, \mathrm{SC}$ & 0.206 & 0.129 & 0.135 & 0.278 & 0.381 & 0.155 \\
\hline$r_{C a}, \mathrm{SC}$ & 0.004 & 0.004 & 0.004 & 0.005 & 0.004 & 0.006 \\
\hline$r_{K}, \mathrm{SC}$ & 0.098 & 0.056 & 0.064 & 0.147 & 0.224 & 0.121 \\
\hline$r_{S i}, \mathrm{SC}$ & 0.132 & 0.096 & 0.098 & 0.163 & 0.204 & 0.154 \\
\hline \multicolumn{7}{|c|}{ 14-Day VHT Mass Loss $\left(\mathrm{g} / \mathrm{m}^{2}\right)$} \\
\hline$m, \mathrm{Q}$ & 5.16 & 16.59 & 5.16 & 221.16 & 1389.03 & 0.00 \\
\hline$m, \mathrm{SC}$ & 13.11 & 4.00 & 3.96 & 9.15 & 935.44 & 11.69 \\
\hline \multicolumn{7}{|c|}{ 14-Day VHT Average Corrosion Rate $\left(g /\left[\mathrm{m}^{2} \cdot \mathrm{d}\right]\right)$} \\
\hline$r_{a}, \mathrm{Q}$ & 0.37 & 1.19 & 0.37 & 15.82 & 99.34 & 0.00 \\
\hline$r_{a}, \mathrm{SC}$ & 0.94 & 0.28 & 0.28 & 0.65 & 67.13 & 0.83 \\
\hline \multicolumn{7}{|c|}{ TCLP Releases (concentration in $\mathrm{mg} / \mathrm{L})^{(\mathrm{a})}$} \\
\hline$c_{B}, \mathrm{Q}$ & 0.51 & 0.40 & 0.46 & 0.68 & 0.77 & 1.00 \\
\hline$c_{C r}, \mathrm{Q}$ & 0.022 & 0.015 & 0.011 & 0.021 & 0.015 & 0.007 \\
\hline$c_{B}, \mathrm{SC}$ & 0.60 & 0.52 & 0.86 & 0.47 & 0.92 & 1.20 \\
\hline$c_{C r}, \mathrm{SC}$ & ND & 0.005 & 0.033 & 0.015 & 0.059 & 0.030 \\
\hline \multicolumn{7}{|c|}{ TCLP Normalized B Releases (mg/L) } \\
\hline$r_{B}, \mathrm{Q}$ & 32.8 & 25.8 & 29.6 & 43.8 & 49.6 & 64.4 \\
\hline$r_{B}, \mathrm{SC}$ & 38.6 & 33.5 & 55.4 & 30.3 & 59.2 & 77.3 \\
\hline \multicolumn{7}{|c|}{ Density $\left(\mathrm{g} / \mathrm{cm}^{3}\right)$} \\
\hline$\rho, \mathrm{Q}$ & 2.649 & 2.635 & 2.654 & 2.655 & 2.655 & 2.645 \\
\hline$\rho, \mathrm{SC}$ & 2.666 & 2.651 & 2.655 & 2.671 & 2.672 & 2.651 \\
\hline \multicolumn{7}{|c|}{ Iron Redox [Fe(II)/Fe(total)] } \\
\hline $\mathrm{Fe}(\mathrm{II}) / \mathrm{Fe}$ & 0.09 & 0.13 & 0.16 & 0.07 & 0.14 & \\
\hline $\begin{array}{l}\text { (a) The italici } \\
\text { limits }(0.2 \\
\text { glass, resp }\end{array}$ & $\begin{array}{l}\mathrm{d} \text { values in } \mathrm{h} \\
\mathrm{mg} / \mathrm{L} \text { for } \mathrm{Cr} \text { i } \\
\text { tively). }\end{array}$ & $\begin{array}{l}\text { ghlighted cells } \\
\mathrm{n} \text { all glasses; } 0\end{array}$ & $\begin{array}{l}\text { are estimated } \\
5 \text { and } 1.2 \mathrm{mg} / \mathrm{L}\end{array}$ & $\begin{array}{l}\text { esults because } \\
\text { for B in ASC }\end{array}$ & $\begin{array}{l}\text { they are below } \\
\mathrm{M} \text { glasses and }\end{array}$ & $\begin{array}{l}\text { he reporting } \\
\text { RCM- } 01\end{array}$ \\
\hline
\end{tabular}

\subsection{Product Consistency Test}

Each set of PCT tests included the LRM-1 glass (Wolf et al. 1998) so that the reproducibility of each set of data can be validated. Table 4.15 summarizes the PCT leachate concentration data on LRM glass measured when ASCM and ARCM glasses were analyzed to the standard reference data in the literature 
(Ebert and Wolf 2000). Also included in Table 4.15 are the LRM glass data obtained when ES-1 glasses were analyzed, which will be discussed later in Section 6.5. Table 4.15 shows that all the leachate data obtained in this study are well within the reproducibility range of the standard reference data, which provides the validity of the PCT data presented in this report.

Table 4.15. Comparison of PCT Leachate Concentrations in LRM Glass Measured in this Study to the Standard Reference Data (Ebert and Wolf 2000)

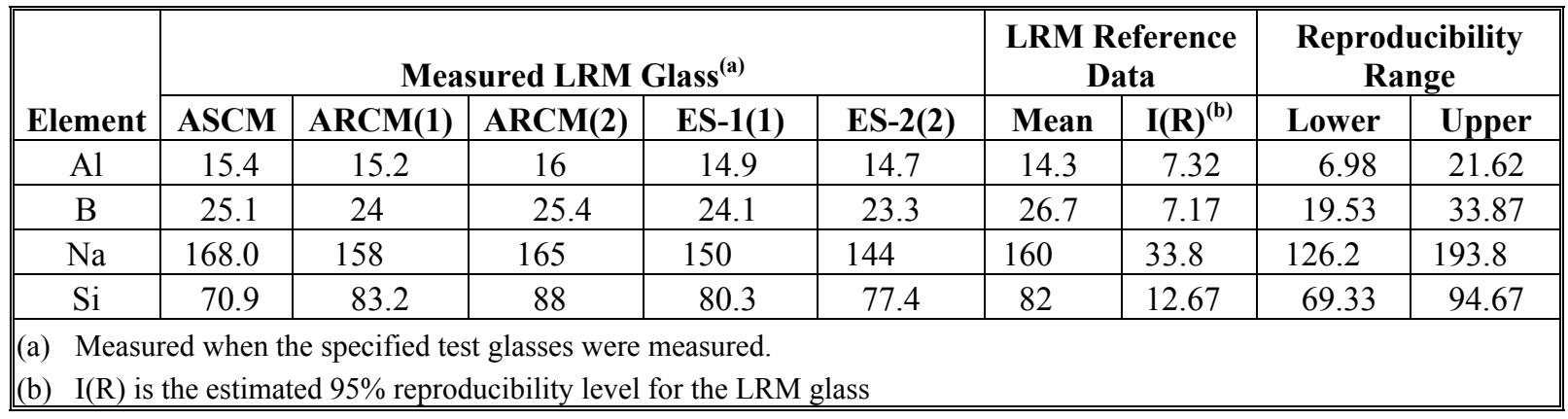

Figure 4.6 and Figure 4.7 show the 7-day PCT normalized sodium releases from quenched and SC-treated samples of ASCM glasses as a function of $\mathrm{Na}_{2} \mathrm{O}$ concentration in glass, Figure 4.6 for $r_{N a}$ and Figure 4.7 for $\ln \left(r_{\mathrm{Na}}\right)$. All ASCM glasses, even ASCM-05 with 24 mass $\% \mathrm{Na}_{2} \mathrm{O}$, passed the $2-\mathrm{g} / \mathrm{m}^{2}$ requirement. The data show that $\mathrm{SC}$ treatment slightly decreased the $r_{\mathrm{Na}}$ for glasses with 20 mass $\% \mathrm{Na}_{2} \mathrm{O}$ or higher. It is likely that this effect of $\mathrm{SC}$ was caused by partial oxidation of $\mathrm{FeO}$ to $\mathrm{Fe}_{2} \mathrm{O}_{3}$ discussed in Section 3.2 even though ASCM glasses were not as reduced as expected (see Table 4.14 and Figure 4.15) because of oxidation that occurred during melting. Further oxidation was possible during the SC treatment that proceeds at lower temperature than that at which the glass was processed. The slight increase in glass density due to SC heat treatment may also have contributed to the differences. There was no noticeable difference between ASCM-02 and 03, indicating that the effect of 3 mass $\% \mathrm{SiO}_{2}$ replacing soil had a negligible effect on PCT release. Predicted $r_{\mathrm{Na}}$ values for quenched glasses are included in Figure 4.6 and Figure 4.7 for comparison. The measured releases for quenched glasses are equal to or slightly higher than the predicted releases for all ASCM glasses, showing reasonably good predictability of the firstorder model for these glasses. Figure 4.8 and Figure 4.9 compare PCT $r_{i}$ values for Al, B, K, and Si with $r_{N a}$ values for quenched and SC-treated samples of ASCM glasses showing consistent results with the preliminary crucible test glasses discussed in Section 3.2. 


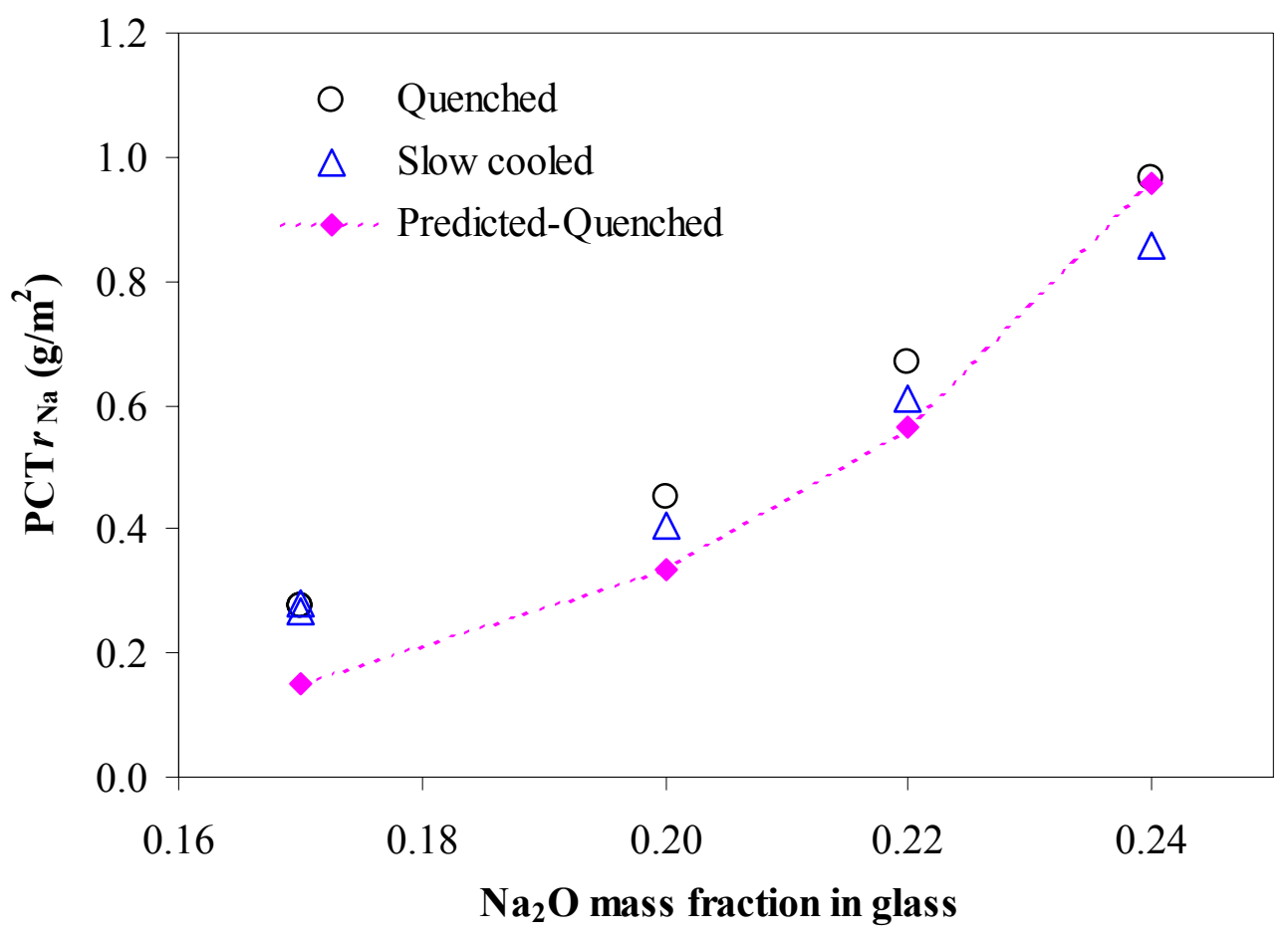

Figure 4.6. 7-Day PCT $r_{N a}$ as a Function of $\mathrm{Na}_{2} \mathrm{O}$ Concentration in ASCM Glasses

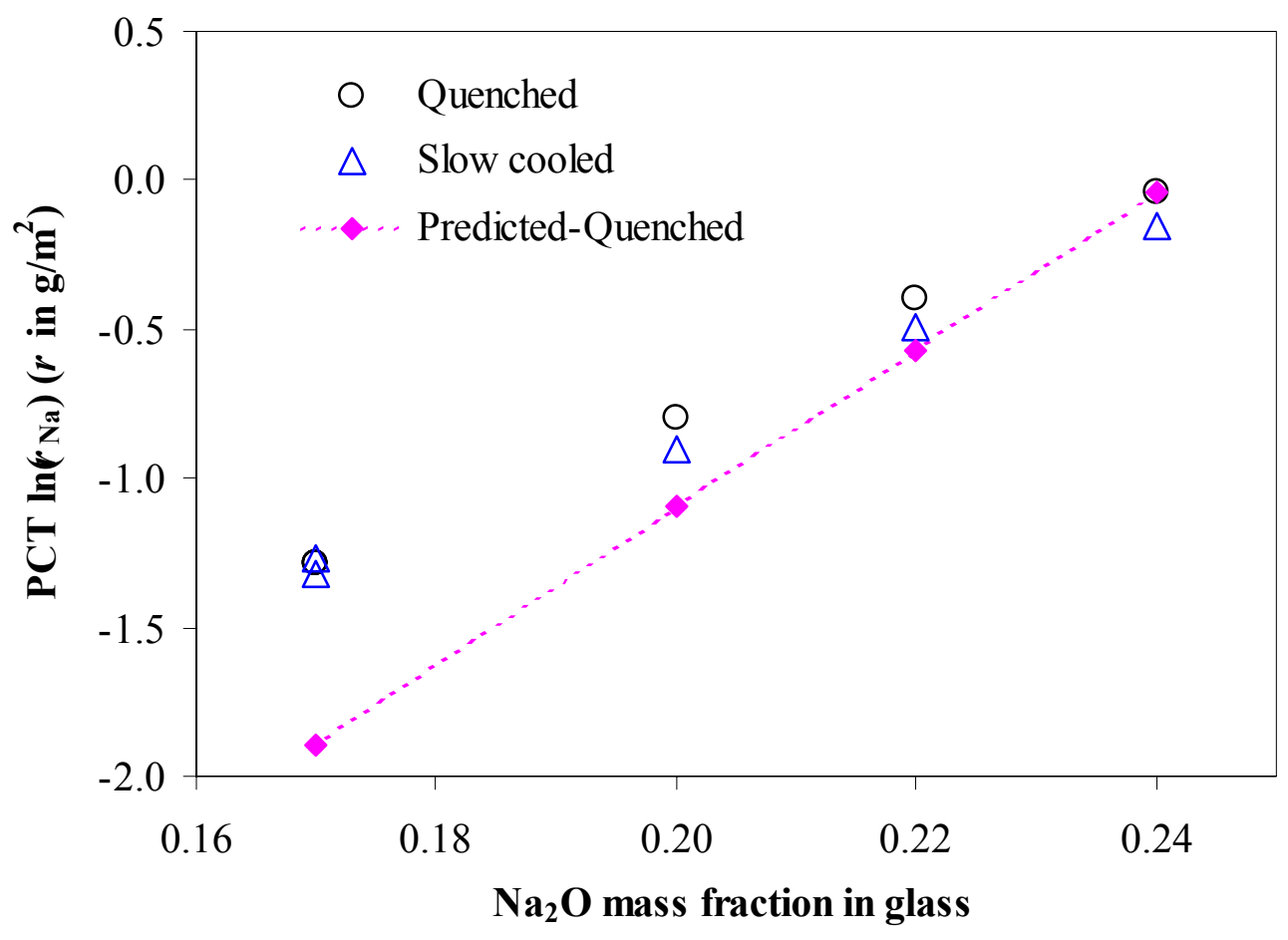

Figure 4.7. 7-Day PCT $\ln \left(r_{N a}\right)$ as a Function of $\mathrm{Na}_{2} \mathrm{O}$ Concentration in ASCM Glasses 


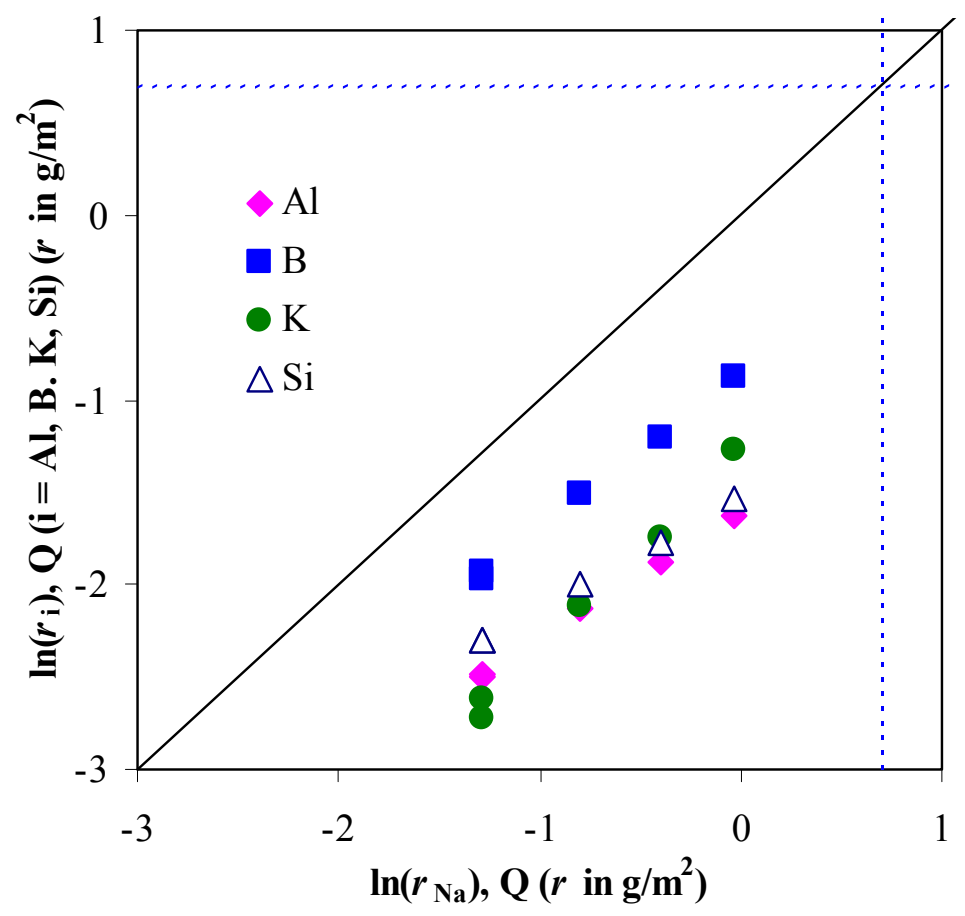

Figure 4.8. Comparison of PCT Elemental Releases of Various Components from Quenched ASCM Glasses with Na Release

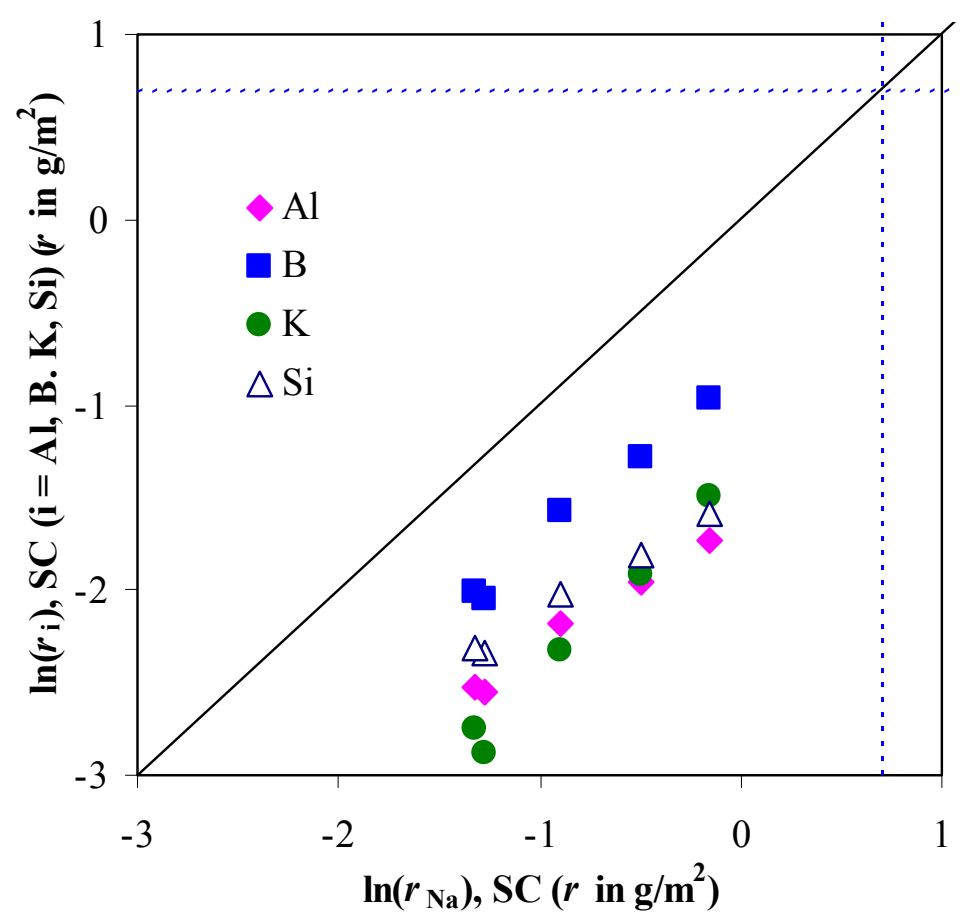

Figure 4.9. Comparison of PCT Elemental Releases of Various Components from SC Treated ASCM Glasses with Na Release 


\subsection{Vapor Hydration Test}

Figure 4.10 and Figure 4.11 (same as Figure 4.10 but using log scale) show 14-day VHT average corrosion rates from quenched and SC-treated samples of ASCM glasses as a function of $\mathrm{Na}_{2} \mathrm{O}$ concentration in glass. Except for ASCM-05 with 24 mass $\% \mathrm{Na}_{2} \mathrm{O}$, ASCM glasses passed the $50 \mathrm{~g} /\left(\mathrm{m}^{2} \cdot \mathrm{d}\right)$ requirement. The corrosion rate is decreased by $\mathrm{SC}$ treatment, at least for glasses with 22 mass $\% \mathrm{Na}_{2} \mathrm{O}$ or higher. For glasses with 20 mass $\% \mathrm{Na}_{2} \mathrm{O}$ or lower, the corrosion rate is too small to detect a difference. Figure 4.11 shows a non-linear behavior between $\ln \left(r_{a}\right)$ and $\mathrm{Na}_{2} \mathrm{O}$ concentration deviating from the linearmodel prediction.

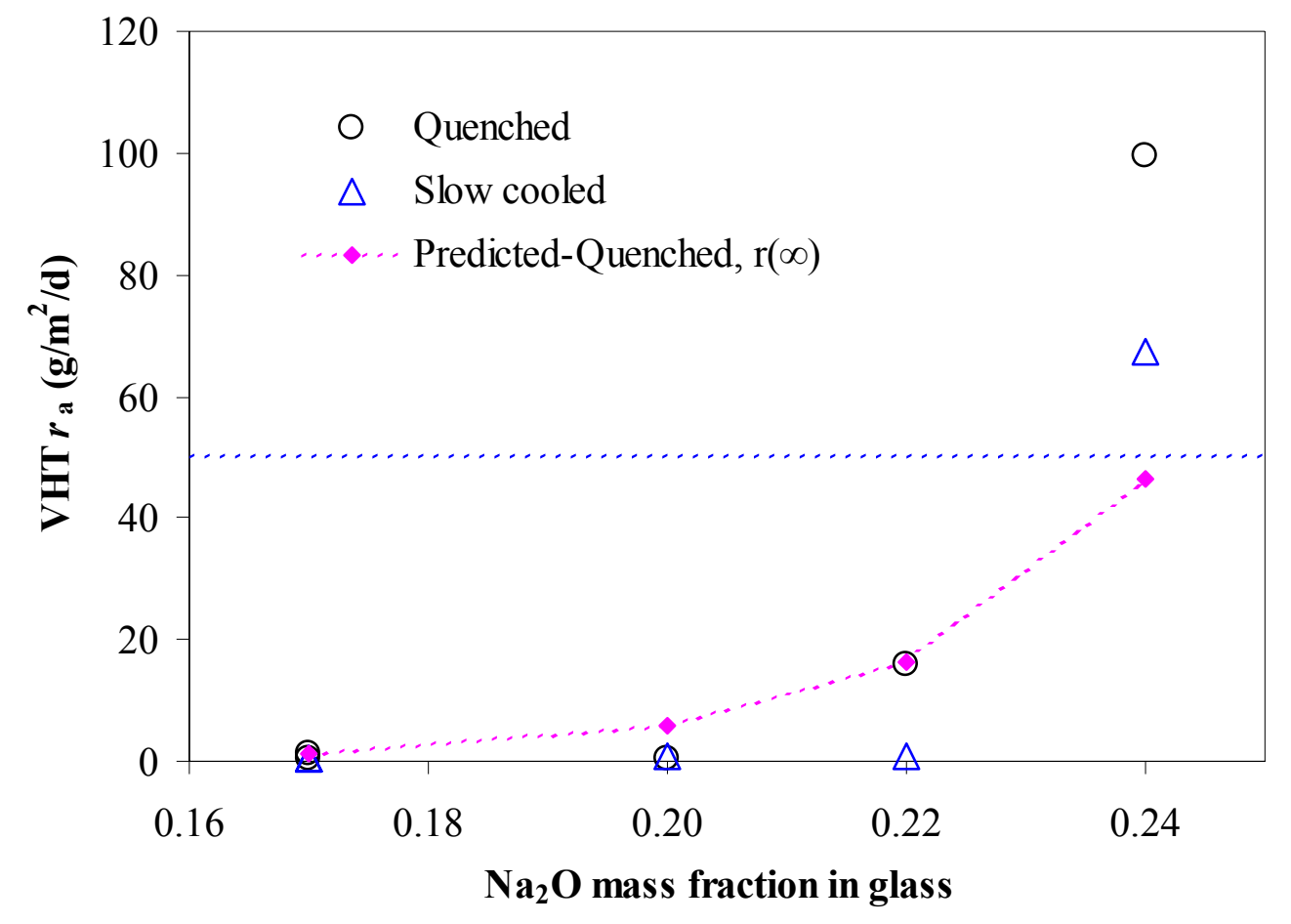

Figure 4.10. 14-day VHT $r_{a}$ as a Function of $\mathrm{Na}_{2} \mathrm{O}$ Concentration in ASCM Glasses 


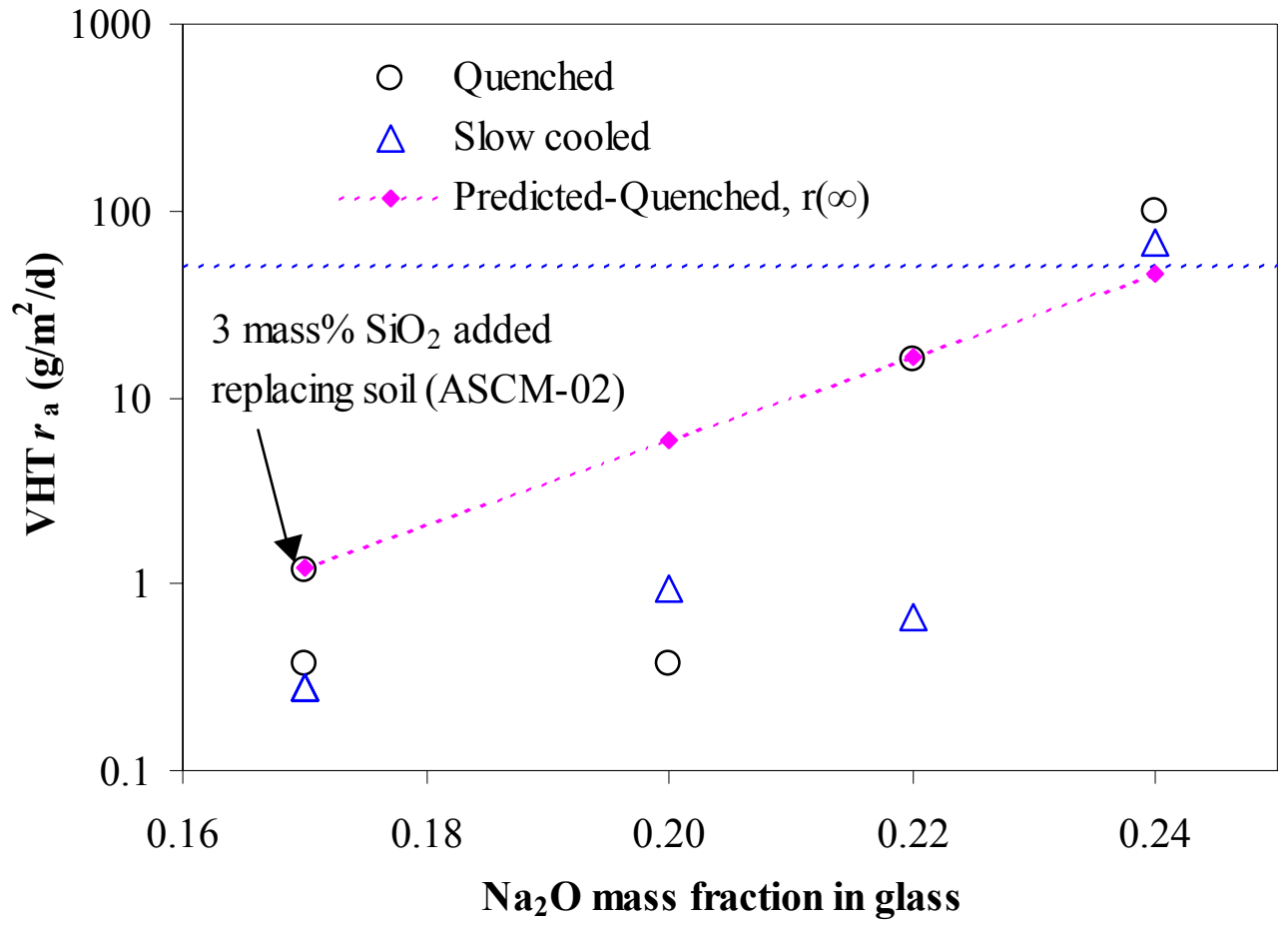

Figure 4.11. 14-day VHT $r_{a}$ as a Function of $\mathrm{Na}_{2} \mathrm{O}$ Concentration in ASCM Glasses (shown in Log Scale)

The crystalline alteration products were identified for a selected set of samples by XRD. Only ASCM-04 and -05 contained enough alteration to identify the crystalline phases. These phases are listed in Table 3.16. It should be noted that the phases were identified by crystal structure and not chemical analyses, so, other minerals or compositions with the structure of those identified may be present. For example, $\mathrm{SrZrO}_{3}$ is unlikely while $\mathrm{CaZrO}_{3}$ may have formed.

Table 4.16. Crystalline Alteration Product Summary

\begin{tabular}{||l|c|c|l||}
\hline \hline Sample ID & $\begin{array}{c}\text { Heat } \\
\text { Treatment }\end{array}$ & $\begin{array}{c}\text { VHT } \\
\text { Time }\end{array}$ & Crystalline Phases \\
\hline ASCM-04 & Q & $14 \mathrm{~d}$ & $\begin{array}{l}\text { Analcime }-\mathrm{Na}_{16.08} \mathrm{Al}_{15.84} \mathrm{Si}_{32.16} \mathrm{O}_{96} \cdot 16 \mathrm{H}_{2} \mathrm{O} \\
\text { Strontium Zirconium Oxide }-\mathrm{SrZrO}_{3} \\
\text { Lithium Iron Oxide -- } \mathrm{LiFeO}_{2}\end{array}$ \\
\hline ASCM-05 & Q & $14 \mathrm{~d}$ & $\begin{array}{l}\text { Sodalite - } \mathrm{Na}_{8}\left(\mathrm{AlSiO}_{4}\right)_{6}\left(\mathrm{ClO}_{3}\right)_{1.91}(\mathrm{OH})_{0.09} \\
\text { Lithium Iron Oxide -- } \mathrm{LiFeO}_{2}\end{array}$ \\
\hline
\end{tabular}

\subsection{Toxicity Characteristic Leaching Procedure}

Figure 4.12 shows the TCLP normalized B releases from quenched and SC-treated samples of ASCM glasses as a function of $\mathrm{Na}_{2} \mathrm{O}$ concentration in glass. The $\mathrm{Cr}$ releases for these glasses are in Figure 4.13. Figure 4.13 shows that the $\mathrm{Cr}$ releases in all the glasses, even for ASCM- 05 with 24 mass $\% \mathrm{Na}_{2} \mathrm{O}$, pass the UTS limit of the $0.6 \mathrm{mg} / \mathrm{L}$ requirement by at least an order of magnitude. As shown in Figure 4.12 
and Figure 4.13, normalized B releases were slightly increased after SC treatment except for one glass (ASCM-04), whereas the Cr release did not show a consistent effect of SC treatment. Figure 4.12 and Figure 4.13 also show that there is poor correlation between measured and predicted TCLP releases. The measured $\mathrm{Cr}$ release is much smaller than predicted mainly because of conservatism involved in the model prediction (Kim and Vienna 2002), as discussed in Section 3.4. However, the lack of agreement for normalized B release is not currently understood. These glasses, except for the glass with 24 mass $\%$ $\mathrm{Na}_{2} \mathrm{O}$ (ASCM-05), are within the model-validity region.

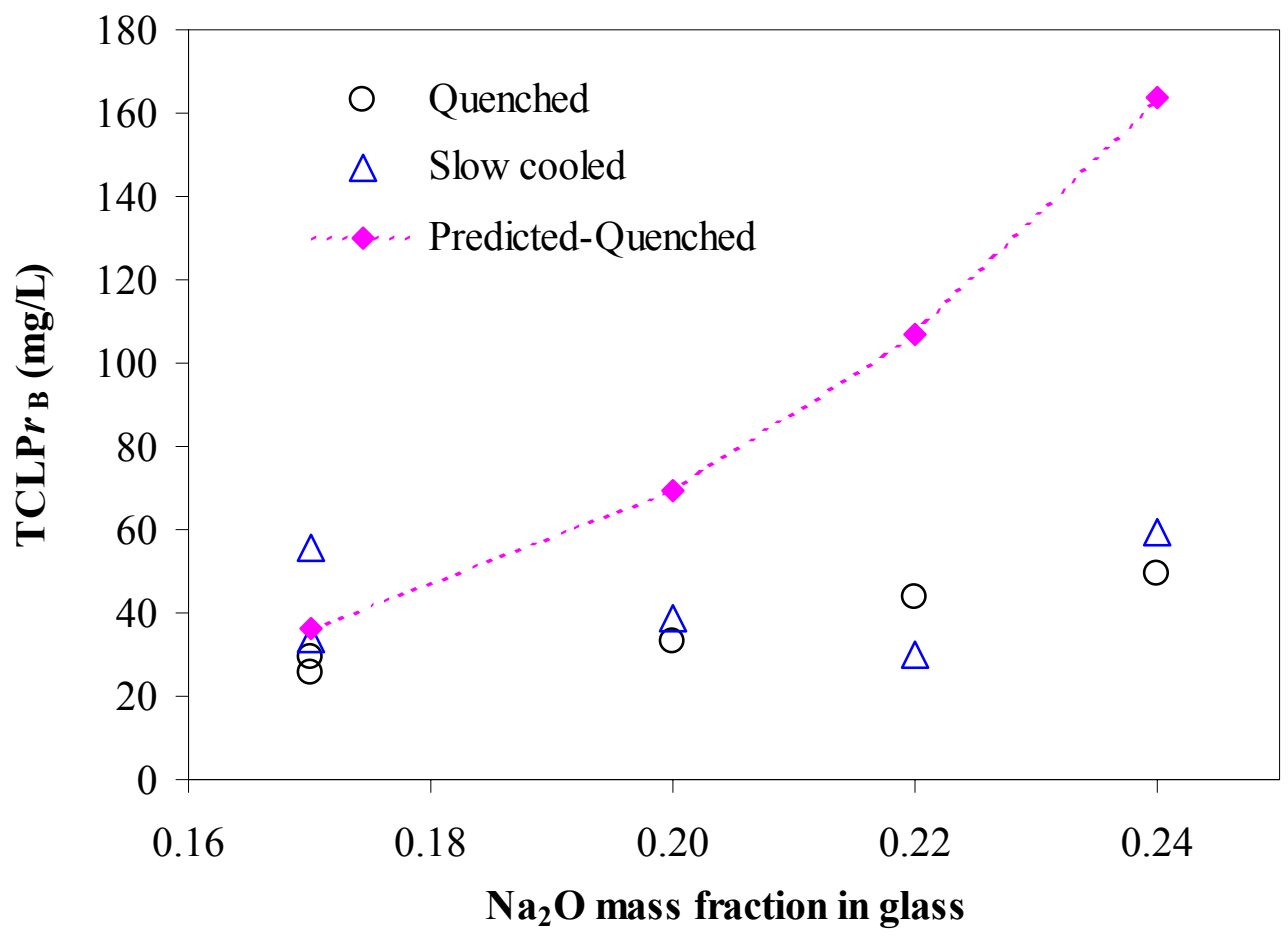

Figure 4.12. TCLP $r_{B}$ as a Function of $\mathrm{Na}_{2} \mathrm{O}$ Concentration in ASCM Glasses 


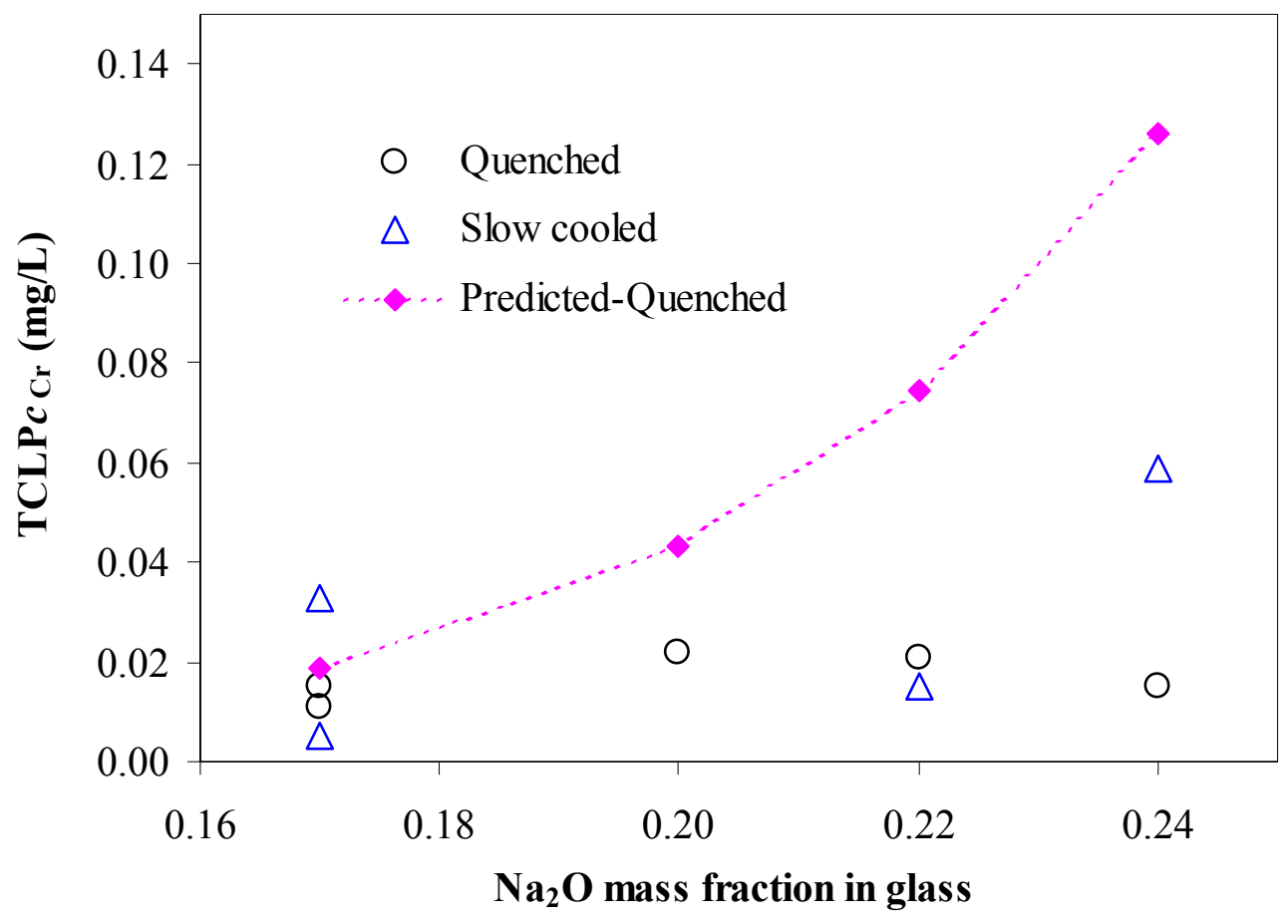

Figure 4.13. TCLP $c_{C r}$ as a Function of $\mathrm{Na}_{2} \mathrm{O}$ Concentration in ASCM Glasses

\subsection{Density}

Figure 4.14 shows the glass density for quenched and SC-treated samples of ASCM glasses as a function of $\mathrm{Na}_{2} \mathrm{O}$ concentration in glass. The $\mathrm{SC}$ treatment increased the density, as expected, from the effect of annealing during SC without any crystallization. The current model slightly over-predicted the density with a $2.0 \%$ difference on average between measured and predicted density values. 


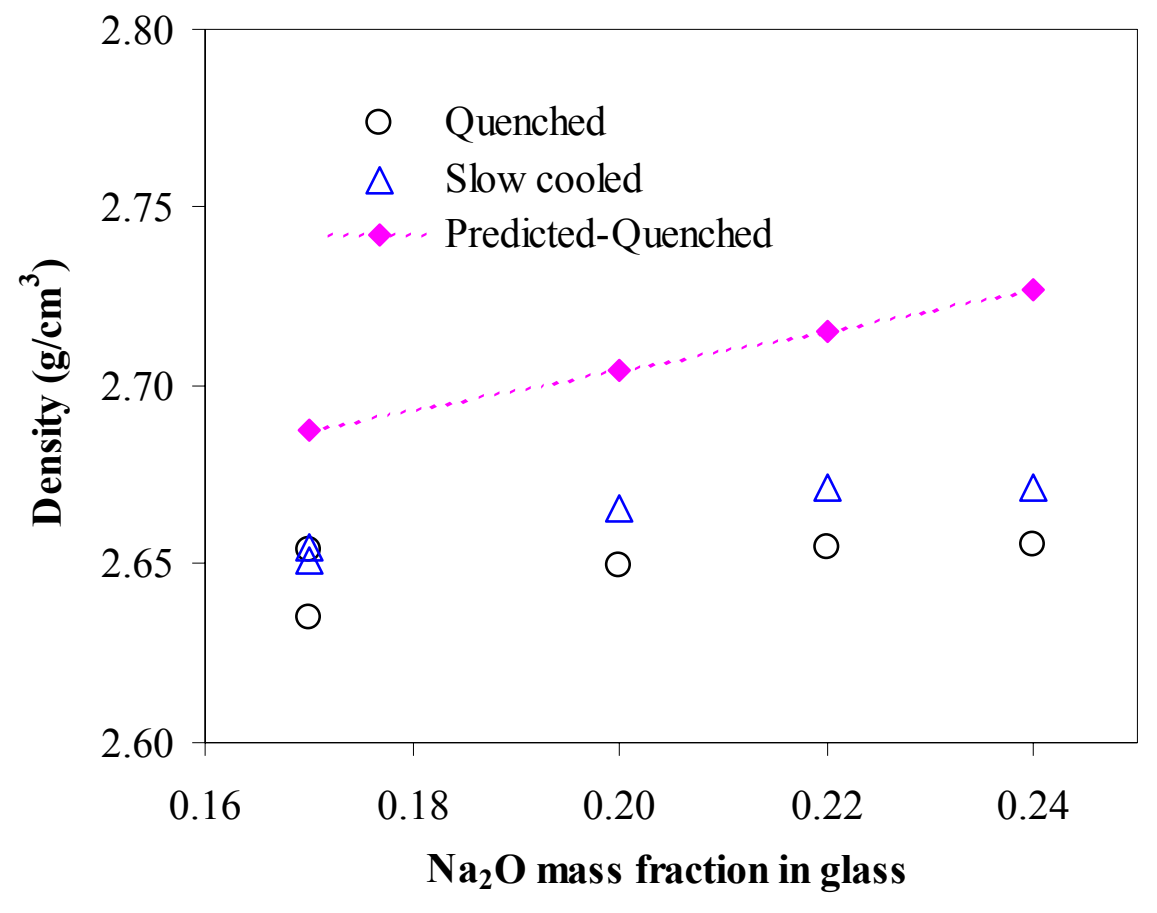

Figure 4.14. Density as a Function of $\mathrm{Na}_{2} \mathrm{O}$ Concentration in ASCM Glasses

\subsection{Redox}

Figure 4.15 shows the iron redox for the quenched samples of ASCM glasses as a function of $\mathrm{Na}_{2} \mathrm{O}$ concentration in glass. The $\mathrm{Fe}(\mathrm{II}) / \mathrm{Fe}$ (total) fraction varied between 9 and $16 \%$ with a minimum at 22 mass $\% \mathrm{Na}_{2} \mathrm{O}$. These simulant crucible test glasses were prepared with sufficient sugar that can "theoretically" reduce most of the iron in the simulant and soil. However, as Figure 4.15 shows, ASCM glasses were oxidized either because of excessive sodalite formation or atmospheric oxygen that could consume the reducing agent to an unforeseen extent. This influx of atmospheric oxygen can occur during initial melting when the constant flow of Ar cannot be maintained. The impact of redox on the VHT response (the most limiting glass constraint) is reported in Section 5.0. 


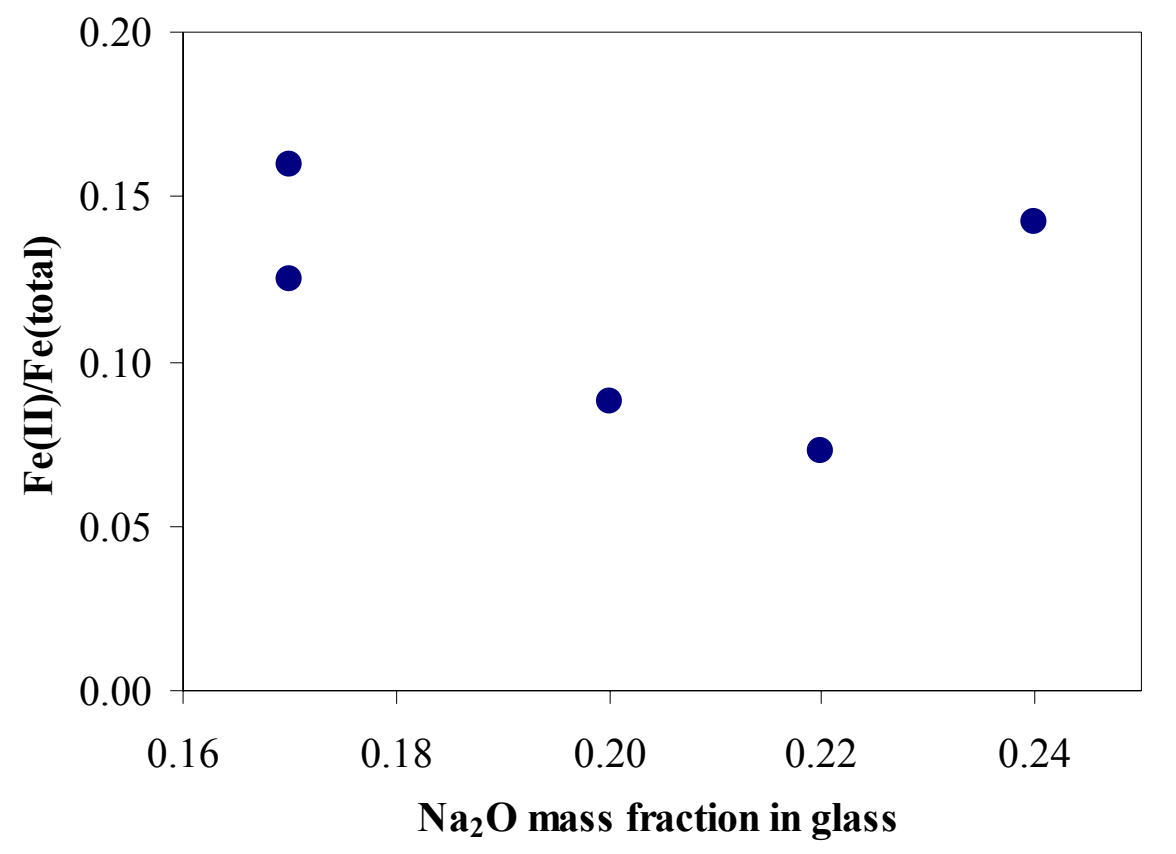

Figure 4.15. Iron Redox [ $\mathrm{Fe}(\mathrm{II}) / \mathrm{Fe}\left(\right.$ total)] as a Function of $\mathrm{Na}_{2} \mathrm{O}$ Concentration in ASCM Glasses

\subsection{Secondary Phase identification}

Glasses with greater than 17 mass $\% \mathrm{Na}_{2} \mathrm{O}$ did not form any secondary phases after being subjected to the $\mathrm{SC}$ heat treatment. However, in ASCM-02 and 03 glasses with 17 mass $\% \mathrm{Na}_{2} \mathrm{O}$, scattered spots or holes covered with deposits of composition different from the surrounding glass were observed as shown in Figure 4.16 and Figure 4.17. Spherical inclusions containing elemental Fe, Cr, and Ti were scattered in Glasses ASCM-02 and -03 (Figure 4.16 through Figure 4.18).

Current test methods (PCT, VHT, and TCLP) do not show any impact of the presence of metallic inclusions and cavities on the product performance. However, caution is necessary when these test methods are applied to waste products that contain inclusions embedded in the amorphous phase. Inclusions embedded in a durable-glass phase are exposed to the corrosion medium only when the glass that separates them from the environment is corroded away. Therefore, their effect on glass-corrosion behavior can only be determined with aggressive tests that use mechanically cut surfaces. Fracture surfaces of crushed glass do not expose the inclusions to the corrosion medium in the same proportions at which they are present in the bulk. Also, the tests that do not dissolve enough material as compared to the scale of the size and distribution of the inclusions may be affected by the method of the sample surface treatment before the corrosion test. Because the inclusions were not observed in the glasses of current interest with greater than 17 mass $\% \mathrm{Na}_{2} \mathrm{O}$, further studies to identify the effect of these inclusions were not attempted in this study. 


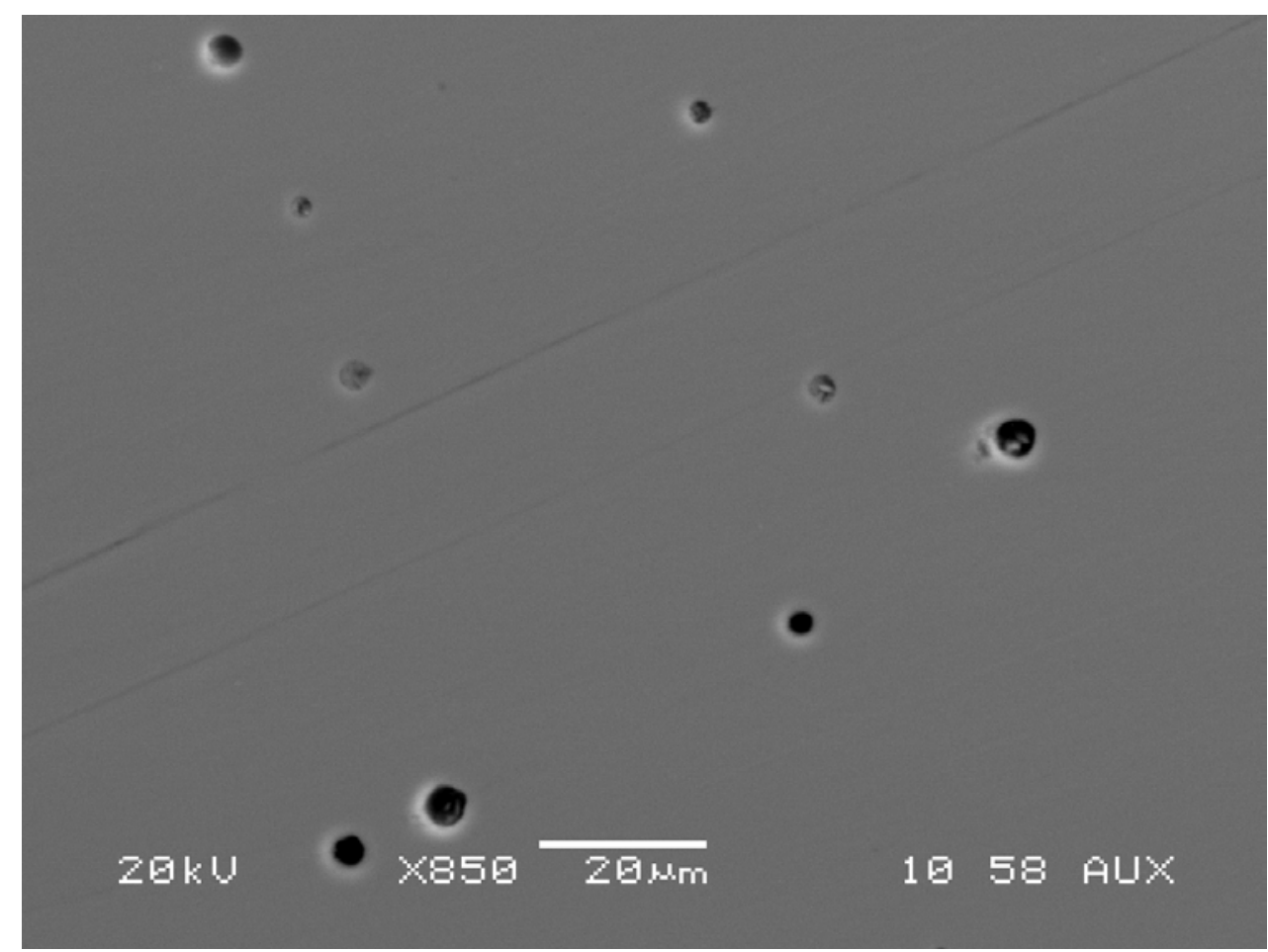

Figure 4.16. SEM Micrograph of Inclusions in SC-Treated ASCM-02 Glass

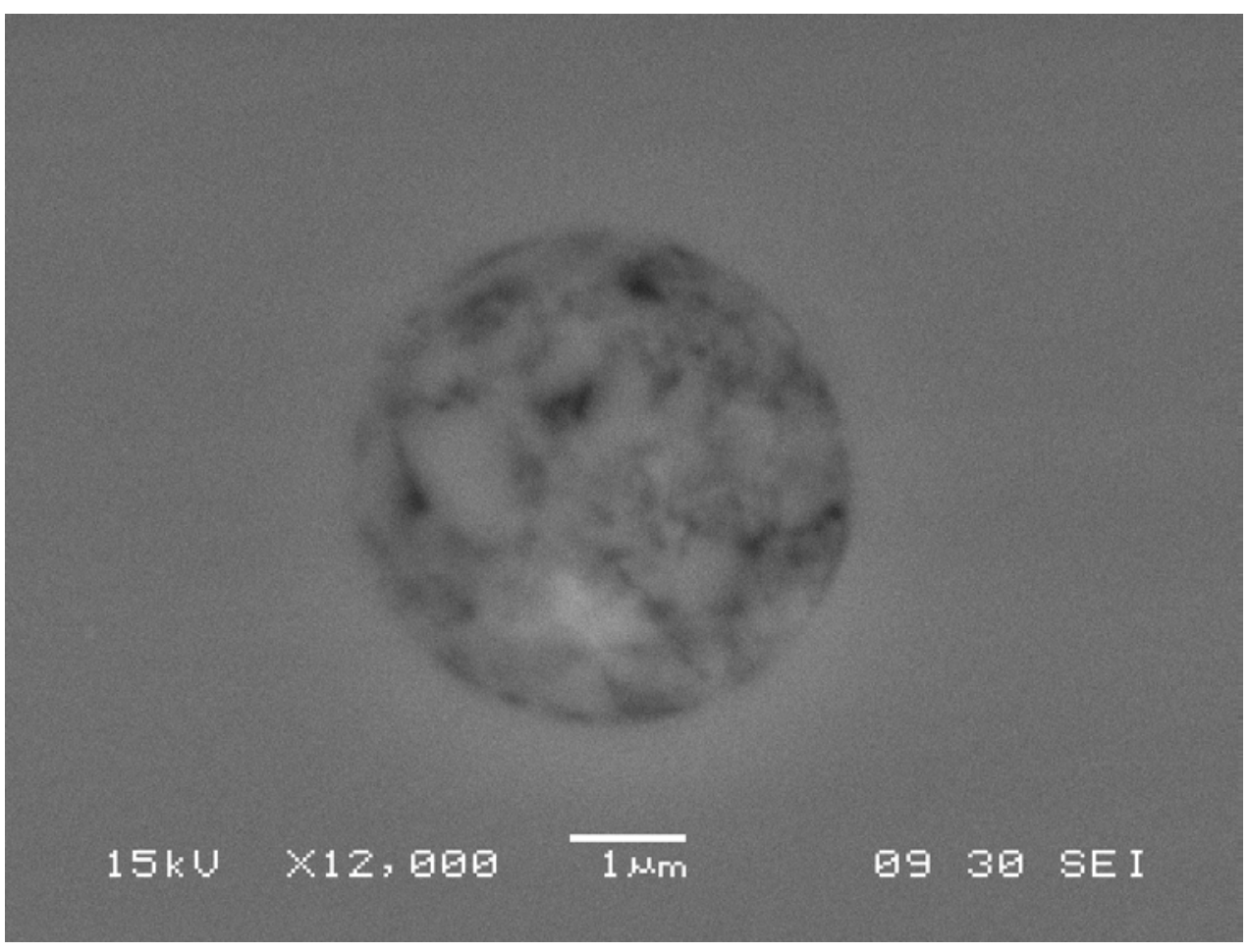

Figure 4.17. SEM Image of an Inclusion in SC-Treated ASCM-02 Glass 



$\mathrm{O}$

Figure 4.18. SEM EDS Dot Map of SC-Treated ASCM-02 Glass 


\subsection{Comparison of Simulant and Actual LAW Glass Properties}

The formulation of simulant and actual waste-crucible melts is based on AMBG-13 glass composition. Five ASCM melts (from 17 to 24 mass $\% \mathrm{Na}_{2} \mathrm{O}$ ) were made with varied waste loading (Table 4.1) of the simulated saltcake (Table 4.2 through Table 4.4) and one melt, ARCM- 01 of the same $\mathrm{Na}_{2} \mathrm{O}$ content as ASCM-01 (20 mass\%) was made with an actual radioactive tank LAW_-see Table 4.1 and Table 4.3 through Table 4.5. The results of compositional analyses are summarized in Table 4.12 and Figure 4.5.

Figure 4.19 compares the target compositions of glasses (based on soil, waste, and simulant analytical compositions), showing that overall bulk composition of ASCM-01 and ARCM-01 are virtually identical despite minor differences in the compositions of the waste simulant and the actual waste. Ratios of target mass fractions for ASCM-01 and ARCM-01 components with more than 0.5 mass\% in ARCM-01 glass are within 0.93 to 1.02 limits. The corresponding analytical compositions are in Figure 4.20. The differences between analytical compositions of ASCM-01 and ARCM-01 are larger than those of target compositions. These differences can be attributed to several possible sources of errors: 1) analyses of the wastes, 2) analyses of the glasses, 3) variation in soil composition, and 4) differences in the redox states of $\mathrm{Fe}$. Because compositions of both batch materials and the final product are subjected to analytical uncertainties, it is not certain which compositions, whether target or analytical, are more accurate. The $\mathrm{Fe}(\mathrm{II}) / \mathrm{Fe}$ fraction was measured only for ASCM-01, but not for ARCM-01 glass.

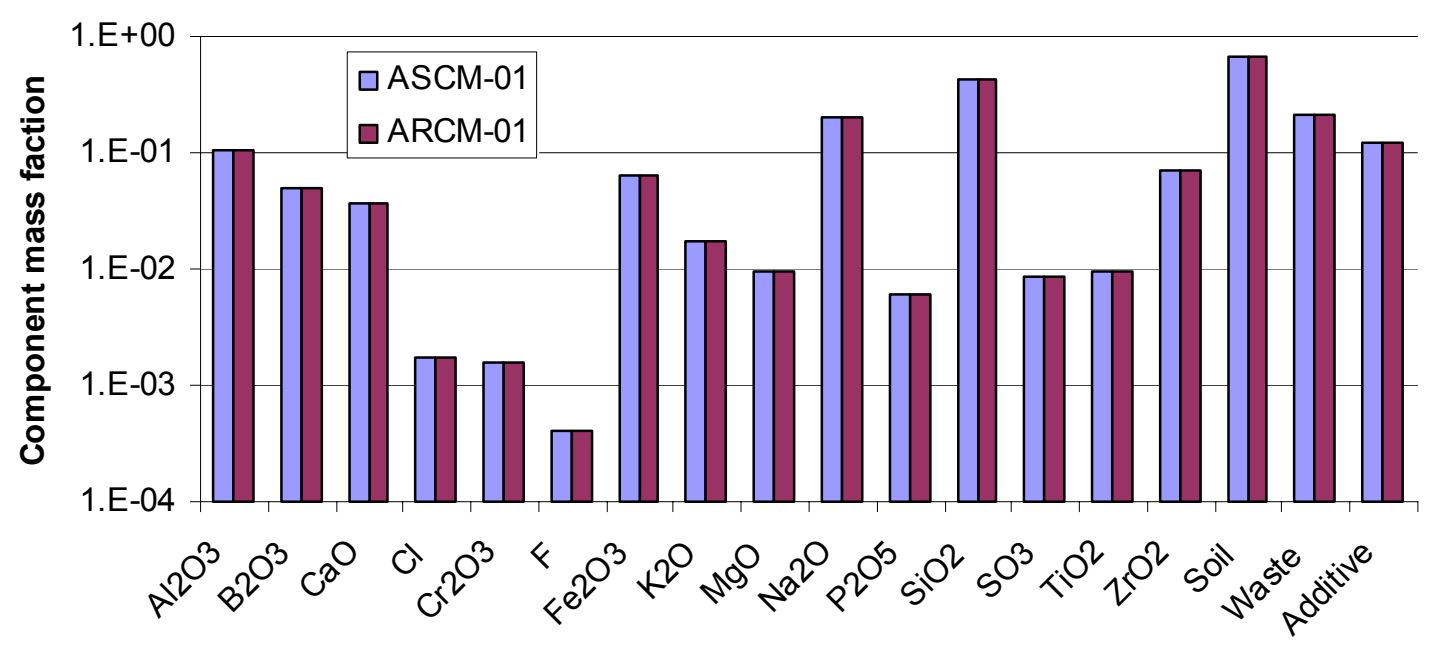

Figure 4.19. Targeted Mass Fractions of Components in Simulated (ASCM-01) and Radioactive (ARCM-01) Glasses 


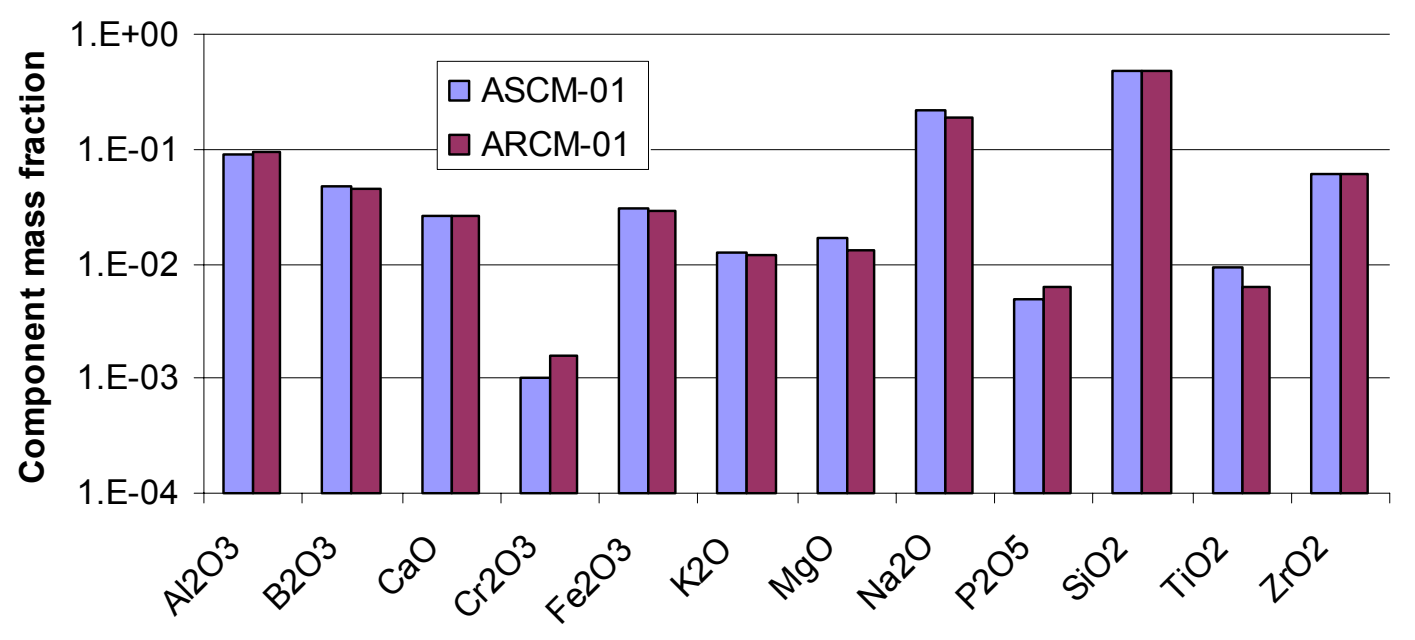

Figure 4.20. Analytical Mass Fractions of Components in Simulated (ASCM-01) and Radioactive (ARCM-01) Glasses

The behavior of ASCM-01 and ARCM-01 glasses is characterized in Table 4.14 and Figure 4.6 through Figure 4.18. The glass characteristics tested include the results the 7-day PCT, the 14-day VHT, TCLP responses, density, and phase behavior in response to quenching and slow cooling. Figure 4.21 through Figure 4.24 compare leachate concentrations and normalized releases of several elements ( $\mathrm{Na}, \mathrm{Al}, \mathrm{B}, \mathrm{Ca}$, $\mathrm{K}$, and $\mathrm{Si}$ ) from the 7-day PCT. The Na concentration in the ASCM-01 leachate is $10 \%$ higher than that from the ARCM-01 leachate regardless of whether the samples were quenched or subjected to the SCtreatment. This $10 \%$ difference is also seen when the releases are normalized using the target mass fractions of elements in the glasses. Boron concentrations in the ASCM-01 and ARCM-01 leachates and the corresponding normalized releases differ by $1 \%$ for the quenched glasses and by $33 \%$ for the SC glasses. This unusually large difference is restricted to a single case of the release data. It is not expected that quenched and SC treated ASCM-01 and ARCM-01 glasses would be different beyond the mild impact of structural relaxation because neither quenched and nor SC-treated ASCM glasses with more than 17 mass $\% \mathrm{Na}_{2} \mathrm{O}$ formed secondary phases. This $33 \%$ difference in PCT B release is attributed to analytical error that would be eliminated if the tests were duplicated or triplicated. 


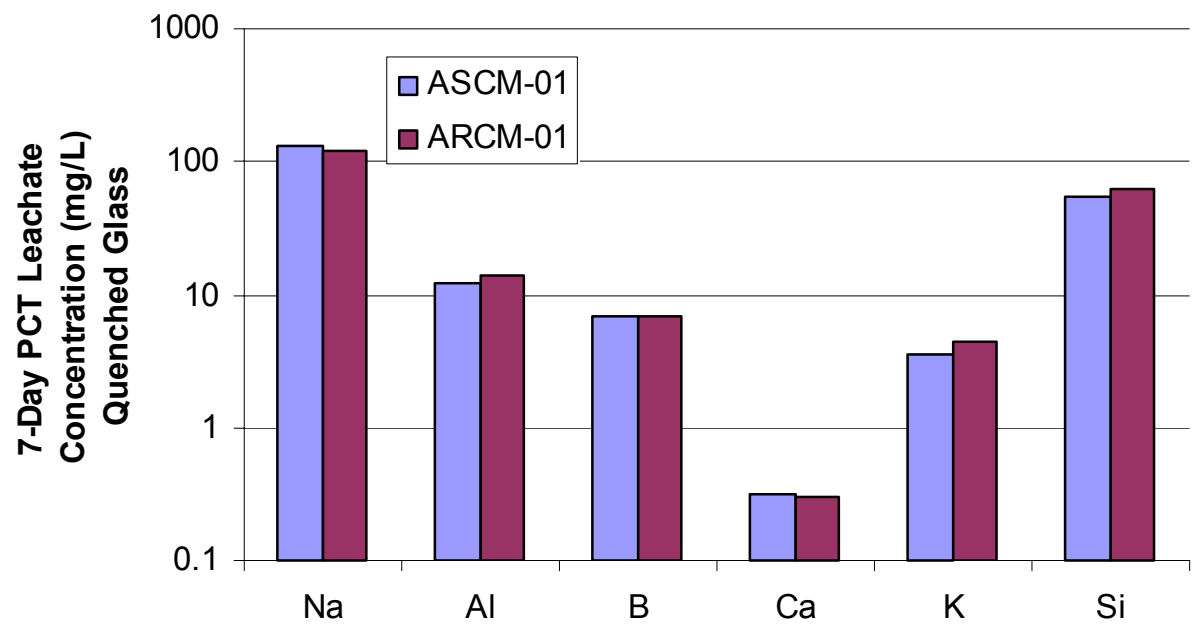

Figure 4.21. 7-Day PCT Leachate Concentrations from Simulated (ASCM-01) and Radioactive (ARCM-01) Quenched Glasses

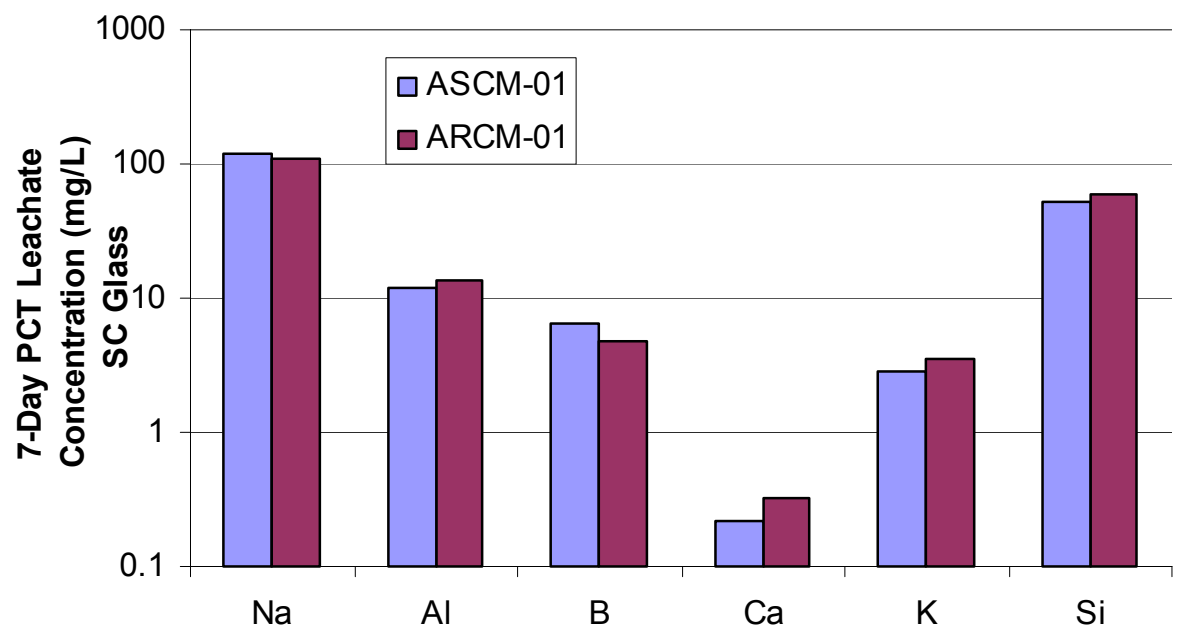

Figure 4.22. 7-Day PCT Leachate Concentrations from Simulated (ASCM-01) and Radioactive (ARCM-01) SC Glasses 


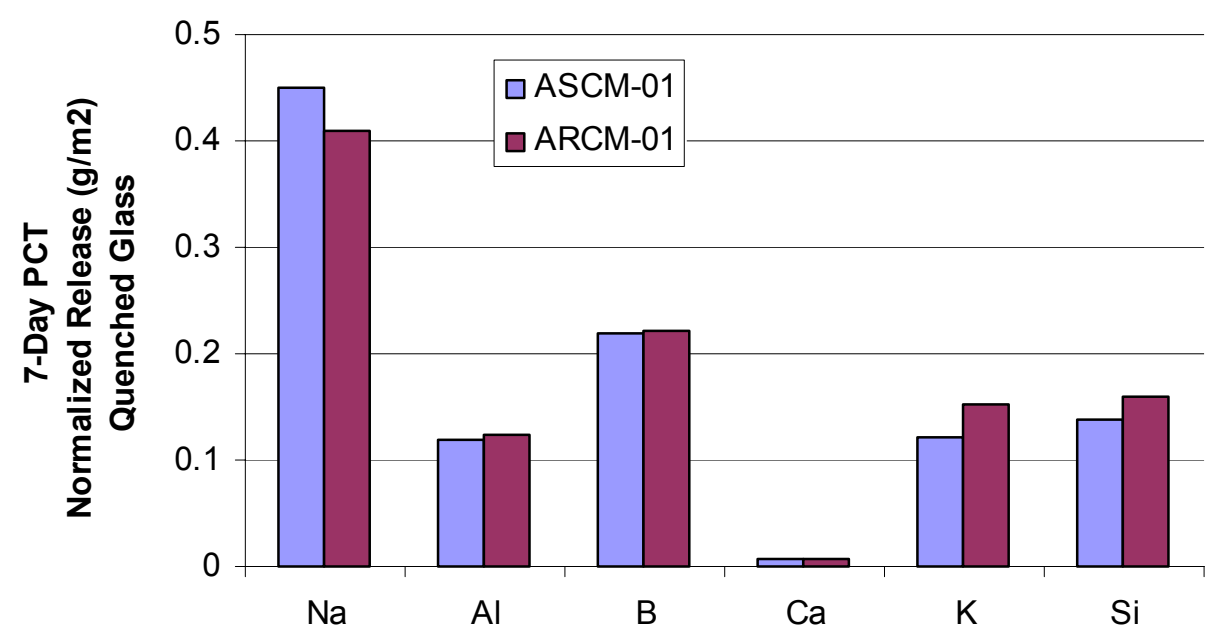

Figure 4.23. 7-Day PCT Normalized Releases from Simulated (ASCM-01) and Radioactive (ARCM-01) Quenched Glasses

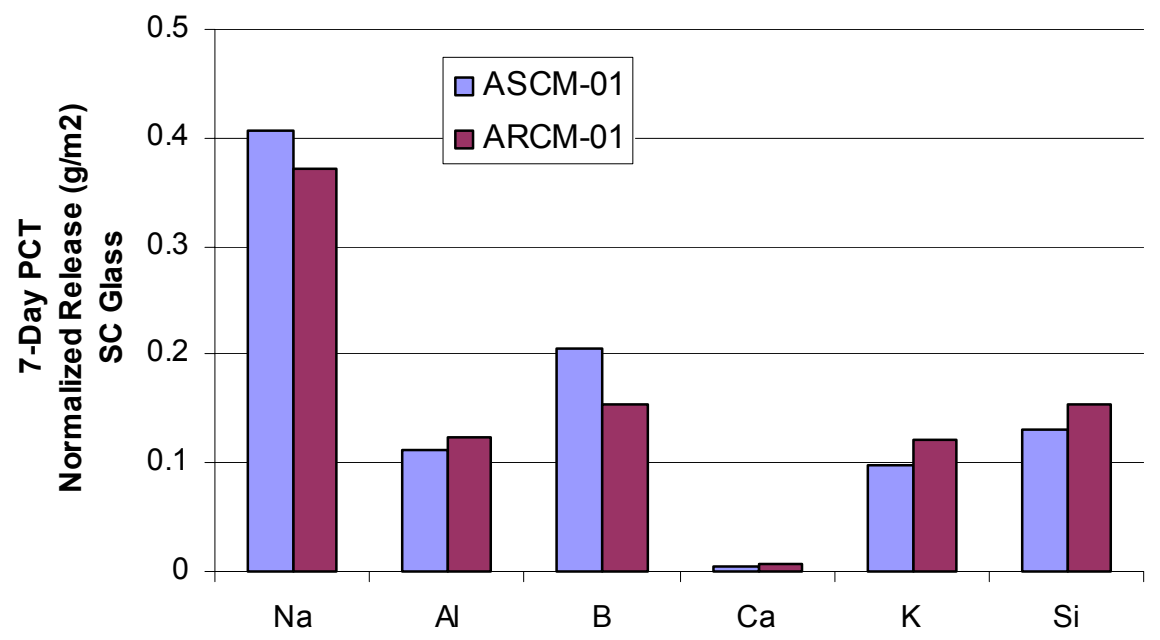

Figure 4.24. 7-Day PCT Normalized Releases from Simulated (ASCM-01) and Radioactive (ARCM-01) SC Glasses

The PCT solutions from ARCM-01 glasses were also analyzed for Tc and Re concentrations by ICP-MS and summarized in Table 4.17 (Re was not detected in any of the samples). The concentration of Tc in the ARCM-01 glass, calculated from the amount of actual waste used, $1.129 \mathrm{~mL} / \mathrm{g}$ glass (from Table 4.10), and the analyzed concentration of Tc in the actual waste, $2.43 \mathrm{mg} / \mathrm{L}$ (Rapko et al. 2003), was 2.74E-06 (in mass fraction). The normalized Tc releases shown in Table 4.17 were calculated assuming there was no Tc lost during glass preparation. These normalized Tc releases are several times lower than normalized $\mathrm{Na}$ or B releases given in Table 4.14, which are typically used to represent glass dissolution. This result suggests that there is no selective leaching of Tc under a PCT condition 
Table 4.17. Concentration of Tc in PCT Solutions from ARCM-01 Glasses and Normalized Tc Releases

\begin{tabular}{||c|c|c||}
\hline \hline Glass & $\boldsymbol{c}_{\mathbf{T}}, \mathbf{m g} / \mathbf{L}$ & $\boldsymbol{r}_{\mathbf{T}}, \mathbf{g} / \mathbf{m}^{\mathbf{2}}$ \\
\hline ARCM-1-Q(1) & $2.96 \mathrm{E}-04$ & 0.054 \\
\hline ARCM-1-Q(2) & $2.94 \mathrm{E}-04$ & 0.054 \\
\hline ARCM-1-SC(1) & $2.06 \mathrm{E}-04$ & 0.038 \\
\hline ARCM-1-SC(2) & $2.15 \mathrm{E}-04$ & 0.039 \\
\hline
\end{tabular}

As Figure 4.11 shows, the average VHT corrosion rate of ASCM- 01 glass was less than $1 \mathrm{~g} / \mathrm{m}^{2} / \mathrm{d}$ based on 14-day tests. According to Table 4.14, no measurable corrosion was detected by the 14-day VHT for ARCM-01 quenched glass and a barely detectable corrosion was measured for ARCM-01 SC glass.

These differences are within the limits of variations expected for repeated experiments with an identical composition.

The TCLP B release is twice as high from ARCM-01 samples, both quenched and SC-treated, than from ASCM-01 samples (Table 4.14). However, low B concentrations that are very close to or below reporting limits and extremely low $\mathrm{Cr}$ concentrations well below reporting limit do not allow reasonable comparison. Because ASCM-01 and ARCM-01 glasses passed the test requirement with a large margin, no attempt was made to check if the differences in the TCLP release are repeatable.

The densities of quenched and SC-treated ASCM-01 and ARCM-01 glasses are the same within 1\%.

Based on these comparisons, it appears that the salt cake simulant gives an adequate likeness to the actual LAW as far as glass property responses are concerned. The relatively small differences in glass properties can be attributed to experimental uncertainties and the difference in composition between simulant and actual LAW (e.g., the difference in Al concentrations). This conclusion is significant, since, the cost and worker dose increments to working with actual waste can be avoided by the use of simulant waste for a large fraction of glass property testing. 


\subsection{Redox Effect Study}

This section describes the fabrication of samples for redox effect study and the results of the redox measurements and VHTs.

\subsection{Redox Effect Study Sample Fabrication}

The testing of preliminary glasses (Section 3.3) suggested that the VHT response was the most limiting property for the ICV product with Hanford LAW. It was shown by Vienna et al. (2001) that iron redox can significantly affect the VHT response measured at a single point in time, so it was decided that a small study would be performed to measure the impact of redox on the VHT performance of a typical ICV glass over a sufficient time period to discern the effect of iron redox on the final rate of corrosion. Three glasses, AMOG-01 to 03 (Table 5.1), were formulated for this study. These glasses have the same composition as ASCM-04 glass shown in Table 4.5, except that the iron redox varies from glass to glass. ASCM-04 was selected (rather than the baseline composition) because its 14-day VHT corrosion extent was large enough to obtain measurable VHT responses to iron redox while the glass still passed the VHT response limit for Hanford LAW forms. The baseline glass (ASCM-01) did not have measurable corrosion after 14 days, and thus would require rather long test durations to evaluate the effect of redox.

Table 5.1 lists the sources of iron and atmospheres for three AMOG glasses. Glass AMOG-01 was heat treated under Ar with 2.84 vol\% $\mathrm{H}_{2}$. Glass AMOG-02 was heat treated under a $\mathrm{CO}_{2}-\mathrm{CO}$ gas mixture. The oxidized glass, AMOG-03, was heat treated under pure oxygen.

Table 5.1. Fe Sources and Gas Compositions for Glasses with Varied Iron Redox Melted at $1270^{\circ} \mathrm{C}$

\begin{tabular}{||l|c|c|c||}
\hline \hline & ID & Source & Atmosphere \\
\hline Fully reduced & AMOG-01 & $\mathrm{FeO}$ & $2.84 \% \mathrm{H}_{2}$ in $\mathrm{Ar}$ \\
\hline Half-reduced & AMOG-02 & $0.763 \mathrm{Fe}_{3} \mathrm{O}_{4}+0.237 \mathrm{FeO}$ & $3.26 \% \mathrm{CO}_{\text {in } \mathrm{CO}_{2}}$ \\
\hline Fully oxidized & AMOG-03 & $\mathrm{Fe}_{2} \mathrm{O}_{3}$ & $\mathrm{O}_{2}$ \\
\hline
\end{tabular}

Theoretical redox values were calculated using the following relationship between the $\mathrm{Fe}(\mathrm{II}) / \mathrm{Fe}(\mathrm{III})$ molar ratio

$$
\ln \frac{[F e(I I)]}{[F e(I I I)]}=a-b \ln \left(p_{O_{2}}\right)+\frac{\Delta H^{\prime}}{R T}
$$

where $\Delta H^{\prime}=-101 \mathrm{~kJ} / \mathrm{mol}, a=7.01, b=0.17$, and $p_{\mathrm{O} 2}$ is in $\mathrm{Pa}$. It was estimated that $50 \%$ of $\mathrm{Fe}$ would be reduced at $1270^{\circ} \mathrm{C}$ at equilibrium with a $\mathrm{CO}_{2}+\mathrm{CO}$ mixture with $3.26 \% \mathrm{CO}$ (i.e., at $p_{\mathrm{O} 2}=6.26 \times 10^{-3} \mathrm{~Pa}$ ). However, the iron-redox ratio of AMOG-02 glass equilibrated with a $p_{\mathrm{O} 2}$ calculated from Equation (5.1) may somewhat differ from the intended value of $\mathrm{Fe}(\mathrm{II}) / \mathrm{Fe}$ because the coefficient values in Equation (5.1) are based on an experimental study performed with the MS-7 generic glass (Hrma et al. 2002) and their applicability to the ICV glass is uncertain. 
To shorten the time to reach equilibrium, the AMOG-02 glass batch was made with a mixture of $\mathrm{Fe}_{3} \mathrm{O}_{4}$ and $\mathrm{FeO}$ containing 76.32 mass $\%(50 \mathrm{~mol} \%) \mathrm{Fe}_{3} \mathrm{O}_{4}$. The "fully" oxidized AMOG-03 glass would have, by Equation (5.1), $\mathrm{Fe}(\mathrm{II}) / \mathrm{Fe}=0.056$, i.e., $5.6 \%$ of $\mathrm{Fe}$ would be reduced at $1270^{\circ} \mathrm{C}$ in equilibrium with pure oxygen (i.e., at $p_{\mathrm{O} 2}=10^{5} \mathrm{~Pa}$ ). The AMOG-03 glass batch was made with $\mathrm{Fe}_{2} \mathrm{O}_{3}$ as the source chemical. The oxygen in excess to $p_{\mathrm{O} 2}=10^{5} \mathrm{~Pa}$ escapes by the reaction

$$
\mathrm{Fe}_{2} \mathrm{O}_{3} \rightarrow 2 \mathrm{FeO}+1 / 2 \mathrm{O}_{2}
$$

This reaction is a fining reaction used in commercial glass technology to remove tiny carbonate bubbles from the glass. The bubbles escape from the melt into the surrounding atmosphere.

Chemicals listed in Table 5.2 were used for the redox study. The amounts of chemicals for $100 \mathrm{~g}$ of AMOG glasses were calculated and are listed in Table 5.3.

Table 5.2. Information on Source Chemicals

\begin{tabular}{|c|c|c|c|}
\hline Component & Manufacture & $\begin{array}{c}\text { Lot } \\
\text { Number }\end{array}$ & $\begin{array}{c}\text { LOD }^{(a)} \\
(\operatorname{mass} \%)\end{array}$ \\
\hline $\mathrm{Al}_{2} \mathrm{O}_{3}$ & Fisher & 006627 & 0.000 \\
\hline $\mathrm{H}_{3} \mathrm{BO}_{3}$ & Noah & $20032 / 2.1$ & 0.989 \\
\hline $\mathrm{Cr}_{2} \mathrm{O}_{3}$ & Fisher & 851377 & 0.000 \\
\hline $\mathrm{FeO}$ & Alfa products & & 0.208 \\
\hline $\mathrm{K}_{2} \mathrm{CO}_{3}$ & Fisher & 005661 & 0.763 \\
\hline $\mathrm{Na}_{2} \mathrm{CO}_{3}$ & Fisher & 025436 & 0.000 \\
\hline $\mathrm{SiO}_{2}$ & Fisher & 016166 & 0.000 \\
\hline $\mathrm{ZrO}_{2}$ & Noah & $18151 / 1.1$ & 0.000 \\
\hline $\mathrm{CaCO}_{3}$ & Fisher & 007112 & 0.372 \\
\hline $\mathrm{NaCl}$ & Sigma & 74H1061 & 0.272 \\
\hline $\mathrm{NaF}$ & Mallinckrodt & WBXZ & 0.000 \\
\hline $\mathrm{MgO}$ & Fisher & 700694 & 0.904 \\
\hline $\mathrm{NaPO}_{3}$ & J.T. Baker & X09610 & 0.371 \\
\hline $\mathrm{ReO}_{2}$ & Alfa products & & \\
\hline $\mathrm{Na}_{2} \mathrm{SO}_{4}$ & J.T. Baker & 22102 & 0.086 \\
\hline $\mathrm{TiO}_{2}$ & J.T. Baker & 525355 & 0.273 \\
\hline
\end{tabular}


Table 5.3. Masses of Batch Chemicals to Make 100-g AMOG Glass

\begin{tabular}{||l|c|c|c||}
\hline & AMOG-01 & AMOG-02 & AMOG-03 \\
\hline $\mathrm{Al}_{2} \mathrm{O}_{3}$ & 9.61 & 9.61 & 9.61 \\
\hline $\mathrm{H}_{3} \mathrm{BO}_{3}$ & 8.97 & 8.97 & 8.97 \\
\hline $\mathrm{CaCO}_{3}$ & 6.46 & 6.46 & 6.46 \\
\hline $\mathrm{NaCl}$ & 0.330 & 0.330 & 0.330 \\
\hline $\mathrm{Cr}_{2} \mathrm{O}_{3}$ & 0.10 & 0.10 & 0.10 \\
\hline $\mathrm{NaF}$ & 0.177 & 0.177 & 0.177 \\
\hline $\mathrm{FeO}$ & 5.509 & 1.377 & \\
\hline $\mathrm{Fe}_{3} \mathrm{O}_{4}$ & & 4.430 & \\
\hline $\mathrm{Fe}_{2} \mathrm{O}_{3}$ & & & 6.11 \\
\hline $\mathrm{K}_{2} \mathrm{CO}_{3}$ & 2.528 & 2.528 & 2.528 \\
\hline $\mathrm{MgO}_{\mathrm{g} O}$ & 0.944 & 0.944 & 0.944 \\
\hline $\mathrm{Na}_{2} \mathrm{CO}_{3}$ & 35.49 & 35.49 & 35.49 \\
\hline $\mathrm{NaPO}_{3}$ & 0.919 & 0.919 & 0.919 \\
\hline $\mathrm{ReO}_{2}$ & 0.0101 & 0.0101 & 0.0101 \\
\hline $\mathrm{SiO}_{2}$ & 41.26 & 41.26 & 41.26 \\
\hline $\mathrm{Na}_{2} \mathrm{SO}_{4}$ & 1.650 & 1.650 & 1.650 \\
\hline $\mathrm{TiO}_{2}$ & 0.941 & 0.941 & 0.941 \\
\hline $\mathrm{ZrO}_{2}$ & 7.02 & 7.02 & 7.02 \\
\hline $\mathrm{Total}$ & 121.92 & 122.22 & 122.52 \\
\hline \hline
\end{tabular}

The same procedure as for AMBG batches (Section 3.1.3) was followed for glass fabrication. The batches were melted at $1270^{\circ} \mathrm{C}$ in a reaction vessel. Figure 5.1 shows an experimental setup used to control the atmosphere when melting the AMOG glasses. A platinum crucible with the sample is inserted in the alumina tube placed in the furnace. The alumina tube is sealed with a Teflon sealant and a stainless steel lid with three openings, one for inlet gas tube, one for outlet gas tube, and the other for the thermocouple in a protective sheath. Gases from cylinders are mixed in desired proportions in the gas mixer and introduced into the alumina tube at the flow rate $1.6 \mathrm{~L} / \mathrm{min}$. The outlet gas goes to the water bath to absorb CO and maintain a constant overpressure in the alumina tube. The whole assembly is kept in a fume hood. After 1 hour of melting, glasses were poured onto a clean stainless steel quench plate and then ground and remelted in the same crucible at the same temperature as the first melt.

Melts were poured onto two small stainless steel molds $(15 \times 15 \times 20 \mathrm{~mm}[0.6 \times 0.6 \times 0.8 \mathrm{in}]$.$) and heated on a$ hot plate for the VHT sample of the quenched glass. One of the samples was transferred into a preheated oven for annealing. Another sample was prepared in a Pt boat $(15 \times 15 \times 20 \mathrm{~mm}[0.6 \times 0.6 \times 0.8 \mathrm{in}$.] $)$ using crushed quenched glass and used for the SC heat-treatment under protective atmosphere. 


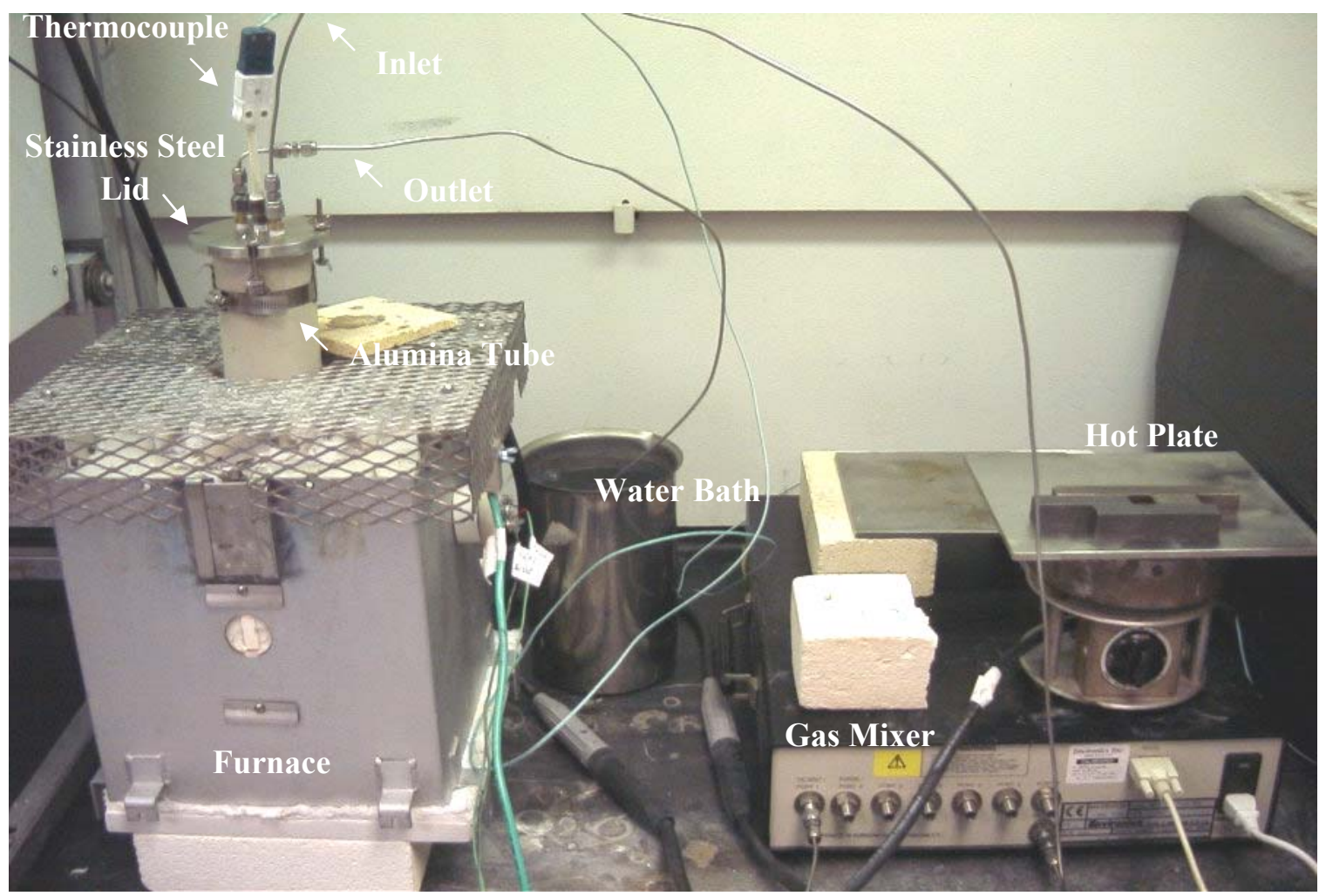

Figure 5.1. Experimental Setup Used to Control Atmospheres for Preparation of AMOG Glasses

\subsection{Redox and Vapor Hydration Test}

Table 5.4 lists the measured glass-redox values for AMOG glasses. The measured $\mathrm{Fe}(\mathrm{II}) / \mathrm{Fe}(\mathrm{total})$ ratios for quenched glasses agree reasonably well with the target (theoretical) values.

Table 5.4. Measured Redox Ratio for AMOG Samples

\begin{tabular}{||c|c|c|c||}
\hline & \multicolumn{3}{|c||}{ Fe(II)/Fe } \\
\hline Glass ID & Target & $\begin{array}{c}\text { Measured, } \\
\text { SRTC }\end{array}$ & $\begin{array}{c}\text { Measured, } \\
\text { PNNL }\end{array}$ \\
\hline AMOG-01 & 0.90 & 0.87 & 0.82 \\
\hline AMOG-02 & 0.50 & 0.40 & 0.39 \\
\hline AMOG-03 & 0.056 & 0.00 & 0.00 \\
\hline
\end{tabular}

Table 5.5 lists the VHT mass losses from the AMOG glasses at 7-, 14-, and 28-days. These results are plotted as functions of time in Figure 5.2. Figure 5.3 shows that the VHT mass loss decreased linearly with the increasing fraction of Fe(II). This result implies that Fe(III) tends to increase the VHT mass loss - an effect similar to that of Al. Both Al and Fe(III) are glass formers in high-alkali borosilicate glasses and both need alkali ions for charge compensation. Both $\mathrm{Al}$ and $\mathrm{Fe}$ (III) decrease the initial rate of corrosion (in Stages I and II), but hasten the transition (Stage III) to the final stage of corrosion (Stage IV). These corrosion stages were identified by Vienna et al. (2001) who also showed that the final corrosion rate $\left(r_{\infty}\right)$ decreased with increasing $\mathrm{Fe}(\mathrm{II}) / \mathrm{Fe}$ fraction. This effect of $\mathrm{Fe}(\mathrm{II}) / \mathrm{Fe}$ on $r_{\infty}$ was 
measured for only one glass and no attempt was made to demonstrate if it applies to more than one composition. Longer test duration (beyond the deadline for this report) would be needed to establish the final corrosion rate $\left(r_{\infty}\right)$ for AMOG glasses.

Table 5.5. Summary of $200^{\circ} \mathrm{C}$ VHT Results

\begin{tabular}{||l|c|r|c||}
\hline Time (days) & $\mathbf{7}$ & $\mathbf{1 4}$ & $\mathbf{2 8}$ \\
\hline Mass Loss, $\boldsymbol{m} \mathbf{( g / \mathbf { m } ^ { 2 } )}$ \\
\hline AMOG-01 & 4.1 & 45.4 & 150.7 \\
\hline AMOG-02 & 2.7 & 149.3 & 303.7 \\
\hline AMOG-03 & 2.7 & 159.3 & 564.5 \\
\hline Average Mass Loss Rate, $\boldsymbol{r}_{\mathbf{a}}\left(\mathbf{g} / \mathbf{m}^{\mathbf{2}} / \mathbf{d}\right)$ \\
\hline AMOG-01 & 0.58 & 3.24 & 5.38 \\
\hline AMOG-02 & 0.37 & 10.56 & 10.82 \\
\hline AMOG-03 & 0.38 & 11.42 & 20.18 \\
\hline
\end{tabular}

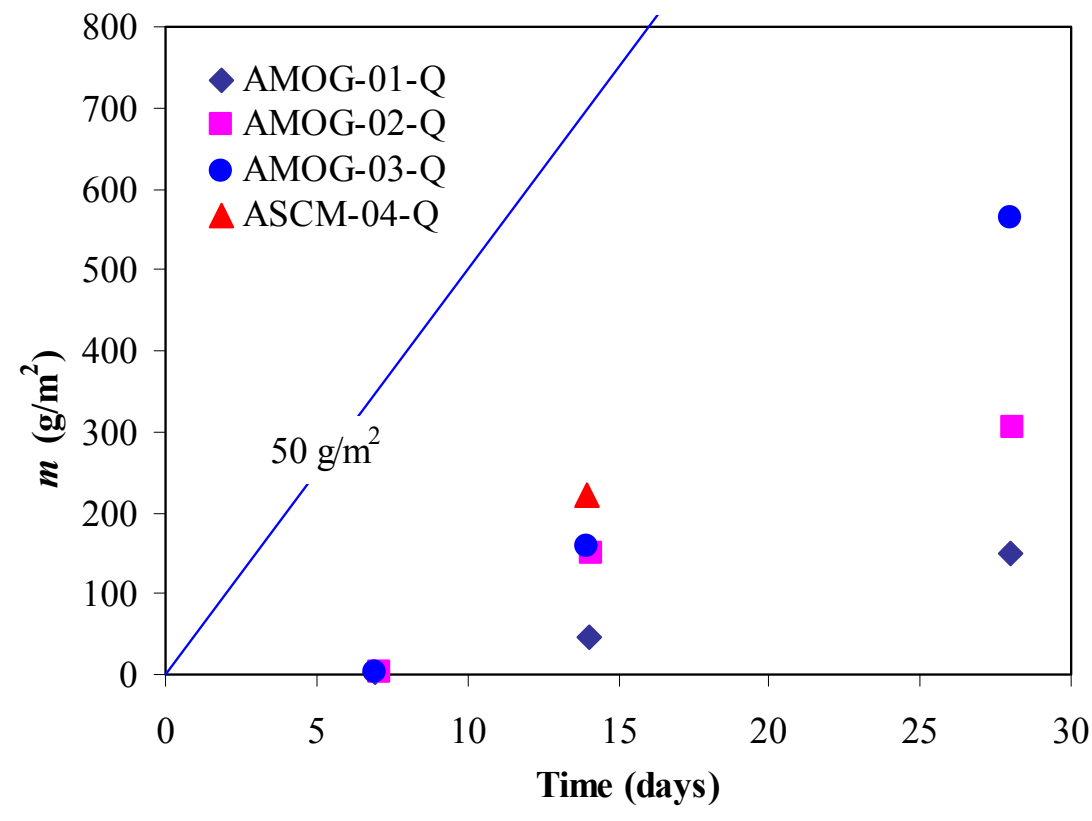

Figure 5.2. VHT $200^{\circ} \mathrm{C}$ Mass Losses versus Time for AMOG Samples 


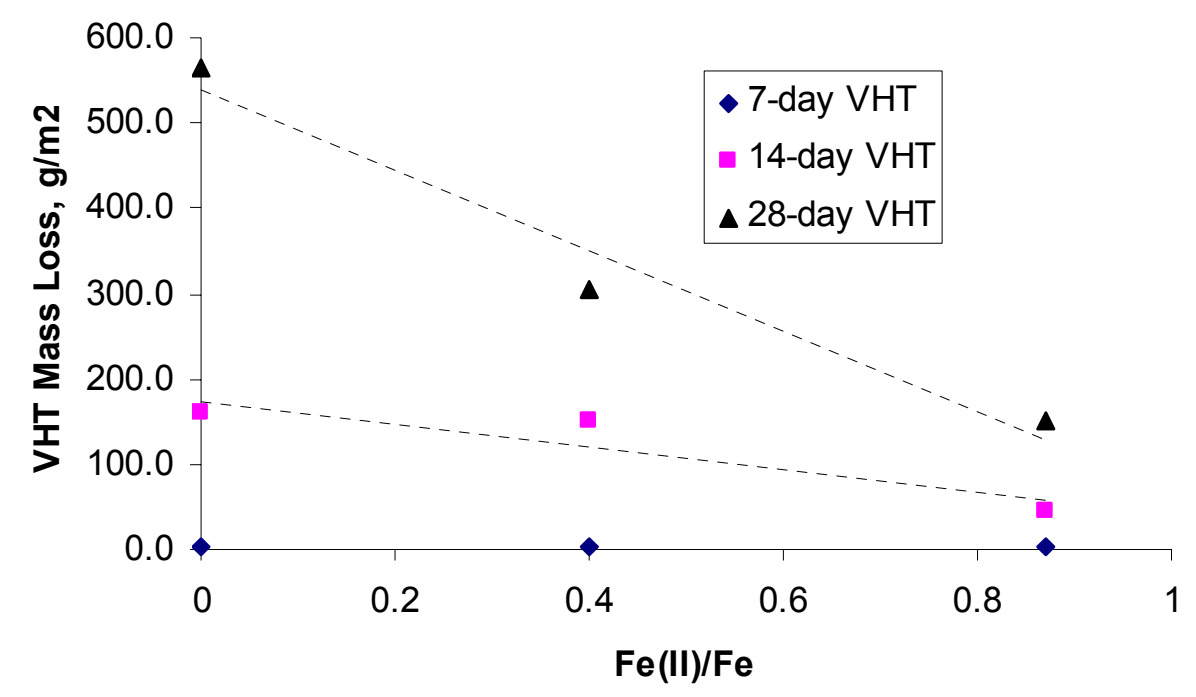

Figure 5.3. VHT Effect of the Oxidation-Reduction State of Iron on the VHT Mass Loss for AMOG Glasses 


\subsection{Engineering-Scale Simulant and Te Tracer Tests}

This section describes the feed preparation for two engineering scale tests (ES-1 and ES-2), the results of composition analysis for ES-1 and ES-2, and glass characterization on PCT, the VHT, the TCLP response, density, and secondary phase identification for ES-1. Details are provided for the sample position and identification for glass-composition analyses as well as glass characterization.

\subsection{Engineering-Scale Simulant and Tc Tracer Tests Feed Preparation}

The engineering-scale study was performed with a glass of the same composition as ASCM-01 glass shown in Table 4.5. For this engineering study, the first step was measuring the content of glass components in the saltcake solution and reducing the saltcake volume as described in Section 4.0. Of the two tests performed, the first (ES-1) used Re as a Tc surrogate, and the second (ES-2) used both Re and Tc. A separate batch of simulant solution was received for each engineering-scale test from $\mathrm{CHG}$. A waste calcine test was performed for the first solution only.

Adding Re as an ostensible Tc surrogate for ES-1 proceeded as described above in Section 4.1 for the simulant crucible tests. For adding $\mathrm{Re}$ for ES-2, the mass of $\mathrm{Re}_{2} \mathrm{O}_{7}$ was calculated for the as-received simulant solution before volume reduction. Thus, $\alpha=1$ for ES-2; other values of parameters were the same as for ES-1; using $w_{G}=139.08 \mathrm{~g} / \mathrm{kg}$ solution, $W=0.1983, g_{\mathrm{ReO} 2}=0.0001$, and $\alpha=1$ gives $w_{\mathrm{Re} 2 \mathrm{O} 7}=$ $0.0779 \mathrm{~g} / \mathrm{kg}$ solution. The mass of $\mathrm{Re}_{2} \mathrm{O}_{7}\left(m_{\mathrm{Re} 2 \mathrm{O} 7}\right)$ to be dissolved in the $39.05 \mathrm{~kg}$ of solution was $m_{\mathrm{Re} 207}=$ $3.04 \mathrm{~g} \mathrm{Re}_{2} \mathrm{O}_{7}$. This amount was stirred into the solution.

\subsubsection{Engineering-Scale 1 (ES-1) Test Preparation}

The volume of the container in which the ES-1 batch was converted to glass was $28.3 \mathrm{~L}\left(1 \mathrm{ft}^{3}\right)$. With the batch density of $1.40 \mathrm{~kg} / \mathrm{L}$, the total mass of the batch was $39.64 \mathrm{~kg}$. This batch was dried at $105^{\circ} \mathrm{C}$, but some of the batch was heated much higher than this, especially where the batch came in contact with the container where the heating elements were present.

Table 6.1 shows glass composition in terms of the sources used. This table is based on the ASCM-01 glass composition listed in Table 4.1 .

Table 6.1. ES-1 Glass Composition in Terms of Mass Fractions from Source Materials

\begin{tabular}{||l|c||}
\hline Component & Fraction \\
\hline Soil & 0.6817 \\
\hline Waste & 0.1983 \\
\hline $\mathrm{B}_{2} \mathrm{O}_{3}$ & 0.0500 \\
\hline $\mathrm{ZrO}_{2}$ & 0.0700 \\
\hline Total & 1.0000 \\
\hline
\end{tabular}


The soil was dried at $200^{\circ} \mathrm{C}$ before batching. The soil lost 0.80 mass $\%$ from LOI at $1050 \mathrm{C}$ for $2 \mathrm{hr}$ (due to organic residues). Hence, for $1 \mathrm{~kg}$ glass, the mass of the soil is $0.6817 /(1-0.0080)=0.6872 \mathrm{~kg}$.

The LOI for the boric acid is 0.989 mass \% in addition to the stoichiometric water. Therefore, the mass of boric acid for $1 \mathrm{~kg}$ glass is $0.05^{*}\left(2 M_{\mathrm{H} 3 \mathrm{BO} 3} / M_{\mathrm{B} 2 \mathrm{O} 3}\right) /(1-0.00989)=0.0897 \mathrm{~kg}$. There is no measurable LOI for the zirconia. The amount of zirconia for $1 \mathrm{~kg}$ glass is $0.070 \mathrm{~kg}$. Finally, the saltcake solution (after its volume has been reduced) contains 21.74 mass $\%$ glass components. Consequently, the mass of the saltcake solution per $1 \mathrm{~kg}$ glass is $0.1983 / 0.2174=0.9120 \mathrm{~kg}$. These amounts add to $w_{B W}=1.7589 \mathrm{~kg}$ of materials that are batched to make $1 \mathrm{~kg}$ glass. This batch was dried at $105^{\circ} \mathrm{C}$.

When these materials are mixed and dried at $105^{\circ} \mathrm{C}$, the loss of excess water evaporated from the saltcake solution is 52.93 mass\%. The corresponding mass of the saltcake solution for $1 \mathrm{~kg}$ glass after drying is $0.9120 *(1-0.5293)=0.4293 \mathrm{~kg}$ per $\mathrm{kg}$ glass, and the total mass of the dried batch is $w_{B D}=1.2762 \mathrm{~kg}$ per kg glass.

To fill $28.3 \mathrm{~L}\left(1 \mathrm{ft}^{3}\right)$ with dried batch, $m_{B D}=39.64 \mathrm{~kg}$ of dry batch are needed, estimated using the bulk density value of $1.4 \mathrm{~g} / \mathrm{cc}$, which was measured on a sample of dry batch. For this, the amount of each ingredient is given by the formula

$$
m_{i W}=\frac{w_{B W}}{w_{B D}} m_{B D}
$$

These amounts are shown in the second column of Table 6.2.

Table 6.2. Masses of Batch Materials for ES-1

\begin{tabular}{||l|c|c||}
\hline & \multicolumn{2}{|c||}{ Mass per batch (kg) } \\
\hline & $\begin{array}{c}\text { Required to fill 18.3-L } \\
\text { container (Estimated) }\end{array}$ & $\begin{array}{c}\text { Actually Used } \\
\text { in ES-1 }\end{array}$ \\
\hline Dry soil & 21.35 & 18.31 \\
\hline Saltcake (reduced volume) & 28.33 & 24.30 \\
\hline $\mathrm{H}_{3} \mathrm{BO}_{3}$ & 2.79 & 2.39 \\
\hline $\mathrm{ZrO}_{2}$ & 2.17 & 1.86 \\
\hline Total & 54.64 & 46.86 \\
\hline
\end{tabular}

Approximately $40 \mathrm{~L}$ of saltcake were received from $\mathrm{CHG}$ (48.92 $\mathrm{kg}$ before condensing the solution). After condensation was complete, the mass of the solution was $29.11 \mathrm{~kg}$. Because a portion of the solution (4.81 kg) was used for simulant crucible tests as described in Section 4.1, 24.30 kg was left for ES-1. This amount was somewhat smaller than the $28.33 \mathrm{~kg}$ needed for filling a $28.32-\mathrm{L}\left(1-\mathrm{ft}^{3}\right)$ container with the feed, so it was compensated by using the proportionally smaller actual amounts shown in the last column in Table 6.2. At least $1 \mathrm{~cm}$ (0.4 in.) of undissolved solids settled at the bottom of the concentrated saltcake solution. By vigorously stirring the solution, the solids were easily suspended.

The prescribed amount of boric acid $(2.39 \mathrm{~kg})$ was dissolved in $24.30 \mathrm{~kg}$ of the saltcake solution. The saltcake solution volume was further reduced by evaporating more water from it (using a heat lamp, 
flowing air, and a motorized agitator). Half of the solution was poured into a black iron pan placed in a water bath. The corresponding amounts of soil and $\mathrm{ZrO}_{2}$ in two batches (listed in Table 6.2 as the total amount, $18.31 \mathrm{~kg}$ of soil dried at $200^{\circ} \mathrm{C}$ and $1.86 \mathrm{~kg} \mathrm{ZrO}_{2}$ ) were each mixed in a $\mathrm{V}$-blender for 30 to 60 minutes. The soil $+\mathrm{ZrO}_{2}$ mixture was added to the solution in the black iron pan. The paste was thoroughly homogenized with a rod while heating the pan with heat lamps and flowing compressed air. Continued periodic agitation helped avoid crusting over much of the batch surface. Care was taken to prevent splattering of the batch outside the pan, caking on the bottom, and the separation of the ingredients. After the two batches were dried, they were combined into a large plastic bag and mixed. The total weight of the dried batch was $32.40 \mathrm{~kg}$ after a $307 \mathrm{~g}$ of sample was removed. The batch was divided into 10 plastic bags that were stacked on each other and filled the $28.3 \mathrm{~L}\left(1 \mathrm{ft}^{3}\right)$ melt cavity before being processed in the ES ICV container.

Following the ES-1 run, the block of glass was removed from the ICV container to characterize for glasscomposition distribution and glass properties. Figure 6.1 shows the ES-1 glass block after it was taken to the laboratory for evaluation.

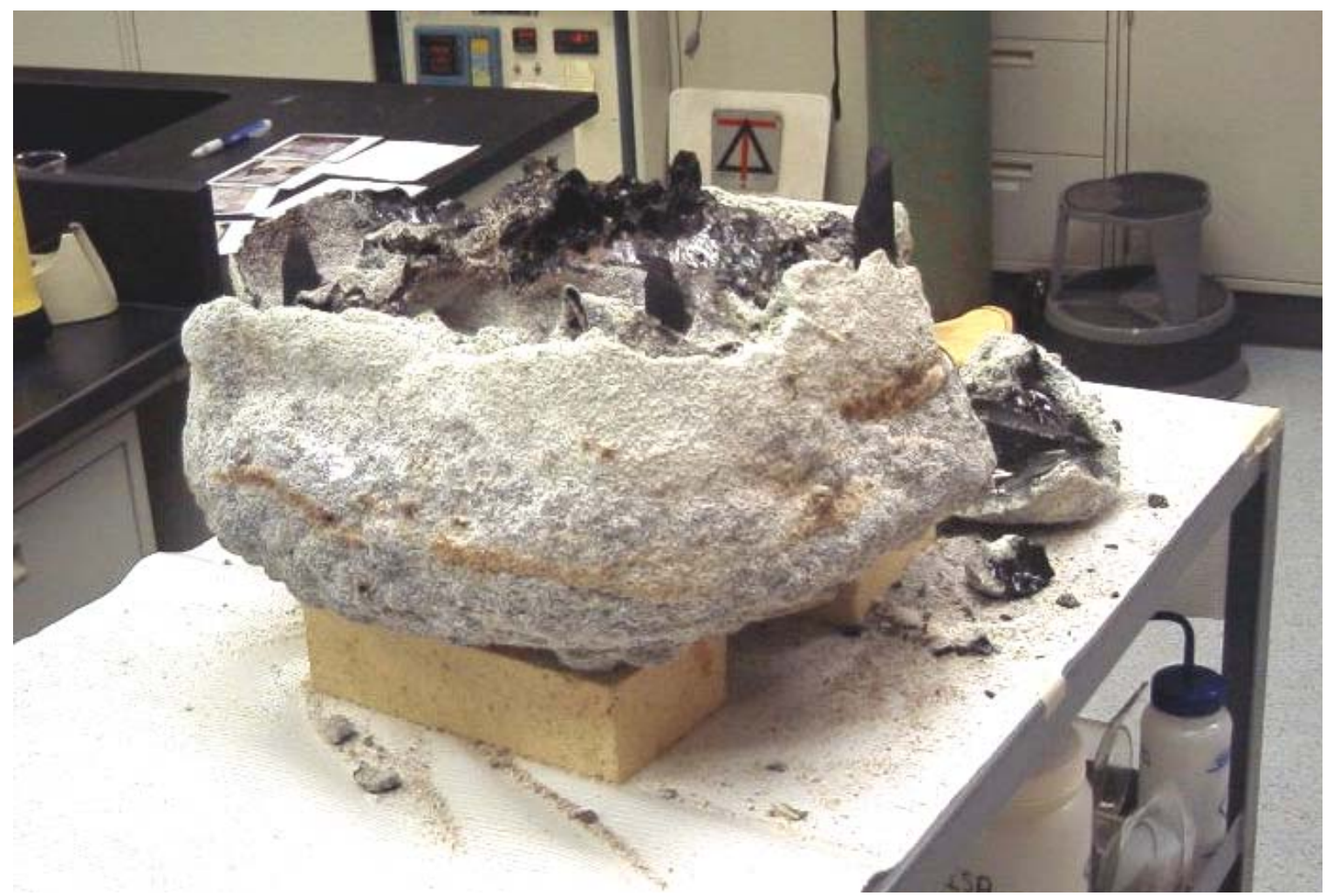

Figure 6.1. Glass Block from the ES-1 Run

\subsubsection{Engineering-Scale 2 (ES-2) Test Preparation}

The amounts of Hanford soil, $\mathrm{H}_{3} \mathrm{BO}_{3}$, and $\mathrm{ZrO}_{2}$ batched to make $1 \mathrm{~kg}$ glass for ES-2 were the same as in ES-1. The mass of as-received (no volume reduction) saltcake solution to make $1 \mathrm{~kg}$ glass was $1.4257 \mathrm{~kg}$ $\left(=1000 \mathrm{~W} / w_{G}\right)$. From $39.05 \mathrm{~kg}$ of saltcake solution for ES-2, $27.39 \mathrm{~kg}\left[=m_{W} w_{G}, /(1000 \mathrm{~W})\right]$ of glass would be produced. The batch amount for Hanford soil, $\mathrm{H}_{3} \mathrm{BO}_{3}$, and $\mathrm{ZrO}_{2}$ was obtained by multiplying this 
amount of glass by the amount of each material required to make $1 \mathrm{~kg}$ glass. These amounts are shown in Table 6.3.

Table 6.3. Masses of Batch Materials Required for ES-2

\begin{tabular}{|l|c||}
\hline \multicolumn{1}{|c|}{ Materials } & Mass (kg) \\
\hline Dry soil & 18.82 \\
\hline Saltcake with $\mathrm{Re}$ & 39.05 \\
\hline $\mathrm{H}_{3} \mathrm{BO}_{3}$ & 2.46 \\
\hline $\mathrm{ZrO}_{2}$ & 1.92 \\
\hline Total & 62.25 \\
\hline
\end{tabular}

The amount of ${ }^{99} \mathrm{Tc}$ available for use in ES-2 was $1.46 \mathrm{mCi}$, which corresponds to $0.0885 \mathrm{~g}$ of ${ }^{99} \mathrm{Tc}$ at a specific activity of $16.95 \mathrm{mCi} / \mathrm{g}$. This amount of Tc was added to the saltcake solution for ES-2. The corresponding mass fraction of $\mathrm{TcO}_{2}$ in glass, $g_{\mathrm{TcO} 2}$, is given by the formula

$$
g_{\mathrm{TcO}_{2}}=\frac{m_{\mathrm{Tc}} W M_{\mathrm{TcO}_{2}}}{m_{W} w_{G} M_{\mathrm{Tc}}}
$$

where $M_{\mathrm{Tc}}$ and $M_{\mathrm{TcO} 2}$ are the molecular masses of $\mathrm{Tc}$ and $\mathrm{TcO}_{2}$, and $m_{\mathrm{Tc}}$ is the Tc mass. Using $m_{\mathrm{Tc}}=0.0885 \mathrm{~g}, W=0.1983, m_{W}=39.05 \mathrm{~kg}$, and $w_{G}=139.08 \mathrm{~g} / \mathrm{kg}$ solution results in $g_{\mathrm{TcO} 2}=4.28 \mathrm{E}-6$ (or 0.000428 mass $\%)$.

The volume of the $39.05 \mathrm{~kg}$ of as-received saltcake-solution was reduced by evaporating water while stirring it with a motor and impeller and heating with an infrared heat lamp. When the volume reduction of the saltcake solution reached approximately $50 \%$, the prescribed $2.46 \mathrm{~kg}$ of boric acid was dissolved in the solution. Next, $3.04 \mathrm{~g}$ of $\mathrm{Re}_{2} \mathrm{O}_{7}$ was added into the agitated mix. The dry (at $\left.200^{\circ} \mathrm{C}\right)$ soil $(18.82 \mathrm{~kg}$ ) and $\mathrm{ZrO}_{2}(1.92 \mathrm{~kg})$ were mixed in a V-blender for 30 to 60 minutes.

In a radioactive laboratory, the Tc solution (containing $\mathrm{NH}_{4} \mathrm{TcO}_{4}$ ) was added to the saltcake solution and stirred in by hand. The batch was divided into half, and the sand mixture was homogenized into the saltcake solution by stirring with a spatula as shown in Figure 6.2. This mixture was transferred to a black-iron container in a heated waterbath (as shown in Figure 6.3), and the feed was dried as shown in Figure 6.4. The dried feed was divided into ten plastic containers that fit the configuration of the $28.3 \mathrm{~L}$ $\left(1 \mathrm{ft}^{3}\right)$ melt cavity and transferred to the engineering-scale ICV container for the ES-2 run. The weight of dried feed used in ES-2 was $35.47 \mathrm{~kg}$ after taking $446 \mathrm{~g}$ of sample for analysis.

Figure 6.5 shows the ES-2 glass block tilted on end inside of the cavity of the melter. The long, thin black glass layer (approximately 3.5 to $4 \mathrm{~cm}$ thick) is observed in the lower center of the photo with a white sandy bottom with several black thermocouple wires crossing the bottom. 


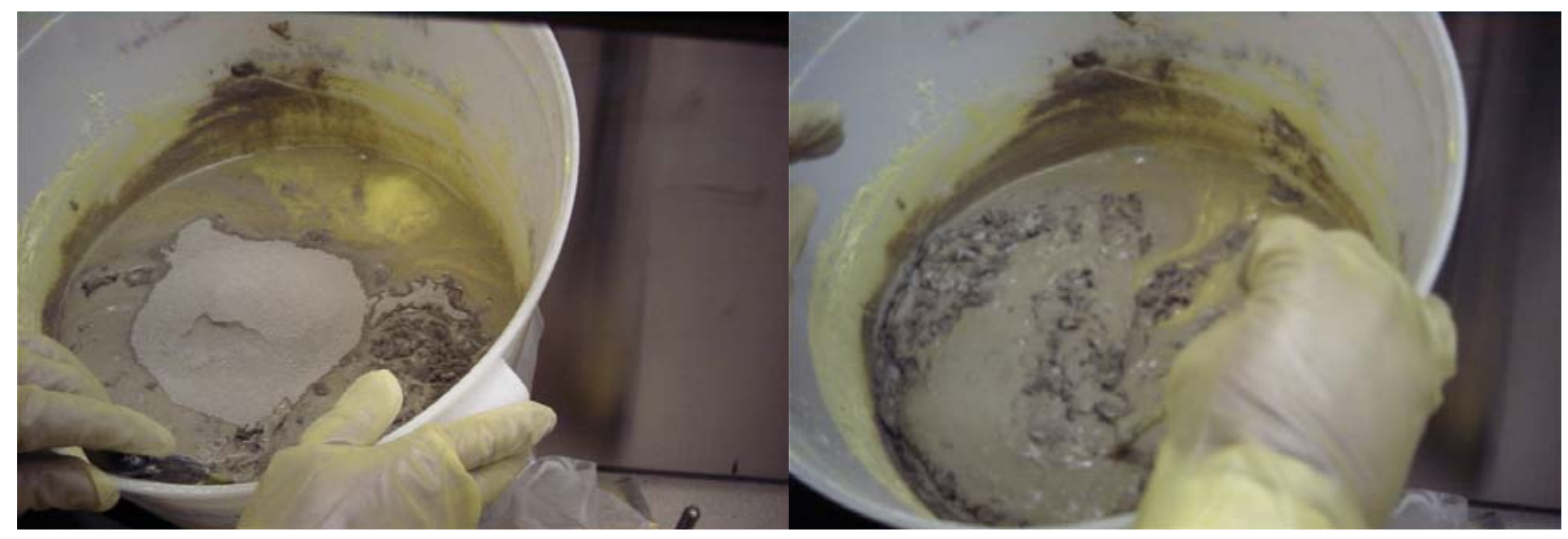

Figure 6.2. Addition of Soil and $\mathrm{ZrO}_{2}$ Mixture to $\mathrm{LAW}$ Simulant for ES-2

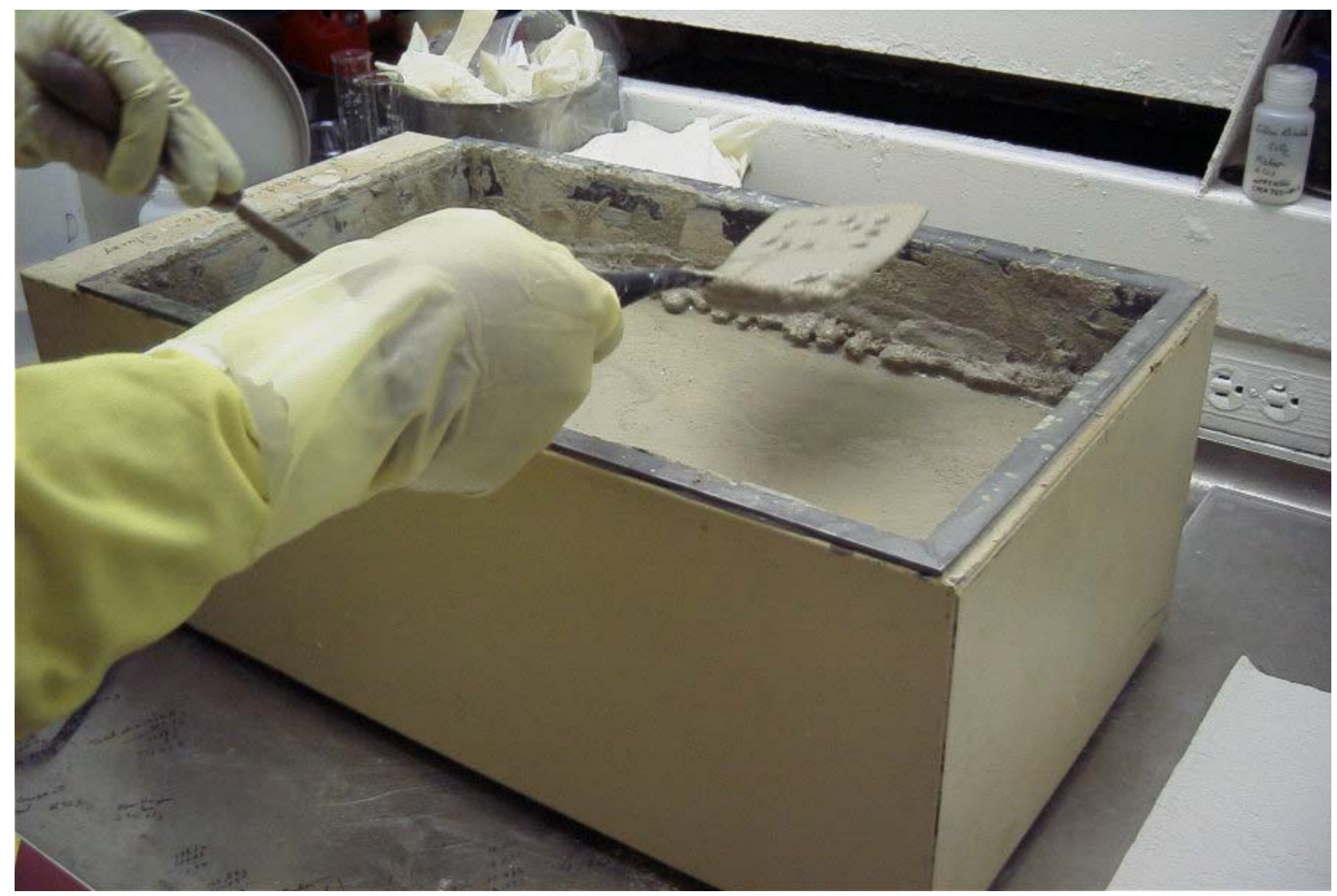

Figure 6.3. ES-2 Feed after Transfer into Water Bath 


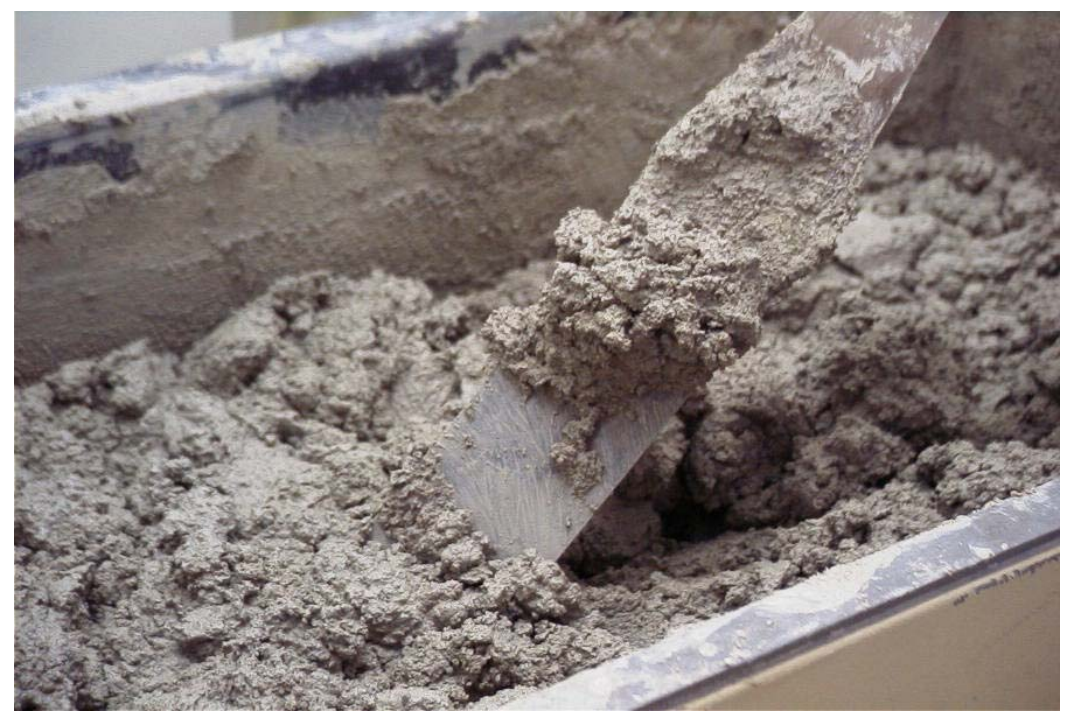

Figure 6.4. ES-2 Feed During Drying

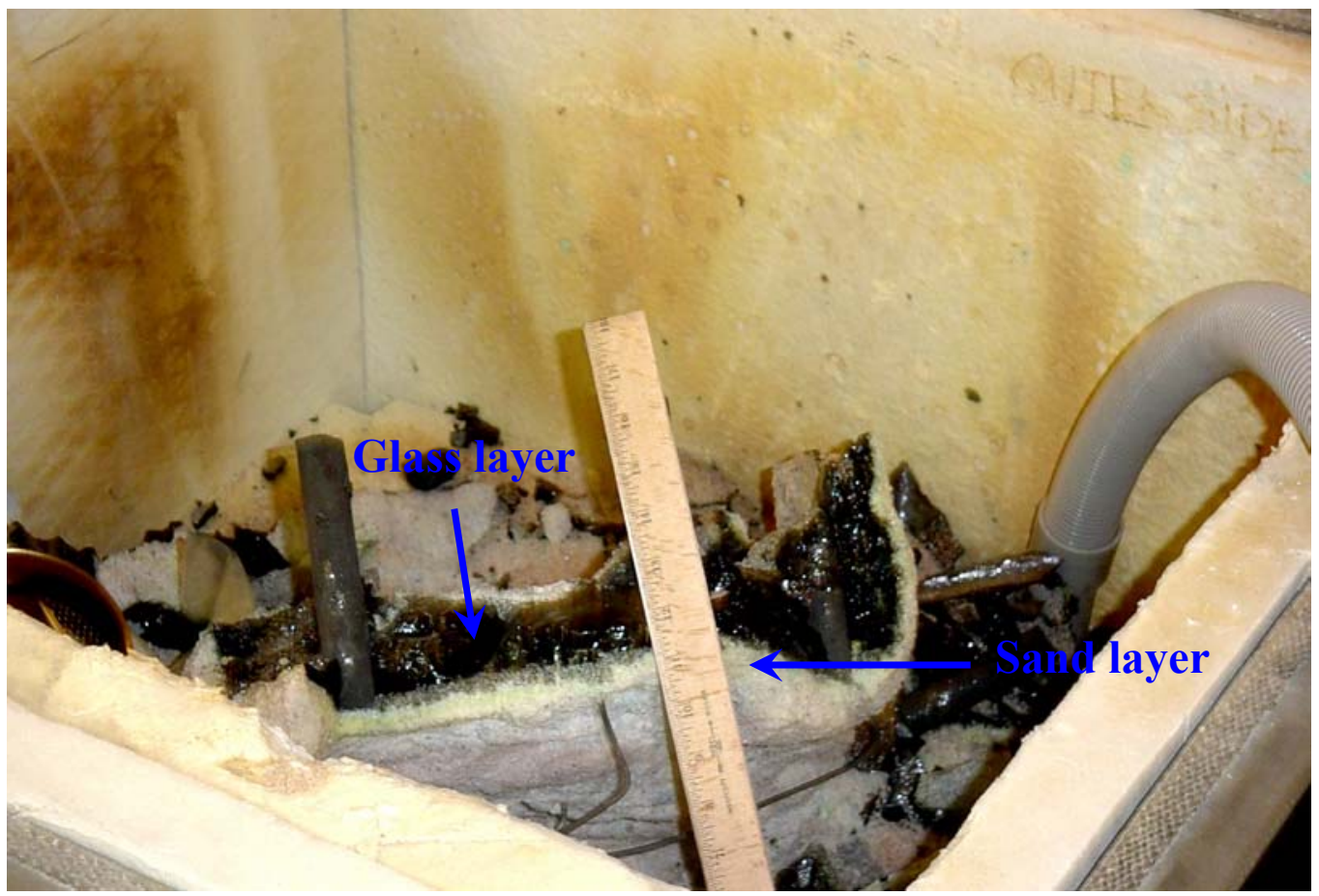

Figure 6.5. ES-2 Glass Block Inside of the Cavity of the Melter

\subsubsection{Flux Materials in ES-1 and ES-2}

In both engineering-scale tests, an extra amount of flux materials was added to the top of the dried feed in the starter region of the melt. Table 6.4 summarizes the amount of flux materials used in each ES test. The oxide concentration of flux materials is given in Table 6.5. The flux was basically the glass composition without the waste component. It was used to help ensure a smooth startup of the melting process. 
Table 6.4. Amount of Flux Materials Used in Each ES Test

\begin{tabular}{||c|r|r||}
\hline & ES-1 & ES-2 \\
\hline Hanford soil & 5.995 & 5.624 \\
\hline $\mathrm{NaNO}_{3}$ & 4.110 & 3.855 \\
\hline $\mathrm{ZrO}_{2}$ & 0.598 & 0.561 \\
\hline $\mathrm{B}_{2} \mathrm{O}_{3}$ & 0.419 & 0.393 \\
\hline Total & 11.122 & 10.433 \\
\hline oxide mass & 8.511 & 7.983 \\
\hline
\end{tabular}

Table 6.5. Oxide Concentration of Flux Materials Used in ES Tests (ES-1 and 2)

\begin{tabular}{||c|c||}
\hline Oxide & Mass Fraction \\
\hline $\mathrm{Al}_{2} \mathrm{O}_{3}$ & 0.0983 \\
\hline $\mathrm{B}_{2} \mathrm{O}_{3}$ & 0.0493 \\
\hline $\mathrm{CaO}$ & 0.0387 \\
\hline $\mathrm{Fe}_{2} \mathrm{O}_{3}$ & 0.0654 \\
\hline $\mathrm{K}_{2} \mathrm{O}$ & 0.0175 \\
\hline $\mathrm{MgO}$ & 0.0101 \\
\hline $\mathrm{Na}_{2} \mathrm{O}$ & 0.1987 \\
\hline $\mathrm{P}_{2} \mathrm{O}_{5}$ & 0.0020 \\
\hline $\mathrm{SiO}_{2}$ & 0.4397 \\
\hline $\mathrm{TiO}_{2}$ & 0.0101 \\
\hline $\mathrm{ZrO}_{2}$ & 0.0703 \\
\hline $\mathrm{Total}_{2}$ & 1.0000 \\
\hline
\end{tabular}

\subsection{Sample Position and Identification for ES-1 Glass-Composition Analysis}

Figure 6.6 is a schematic of the ES-1 glass block showing positions of glass samples taken for chemicalcomposition analysis. Figure 6.7 through Figure 6.9 are photographs showing the position of each sample as it was taken from the ES-1 glass block. 
Engineering Scale Melt EST-1, Top View

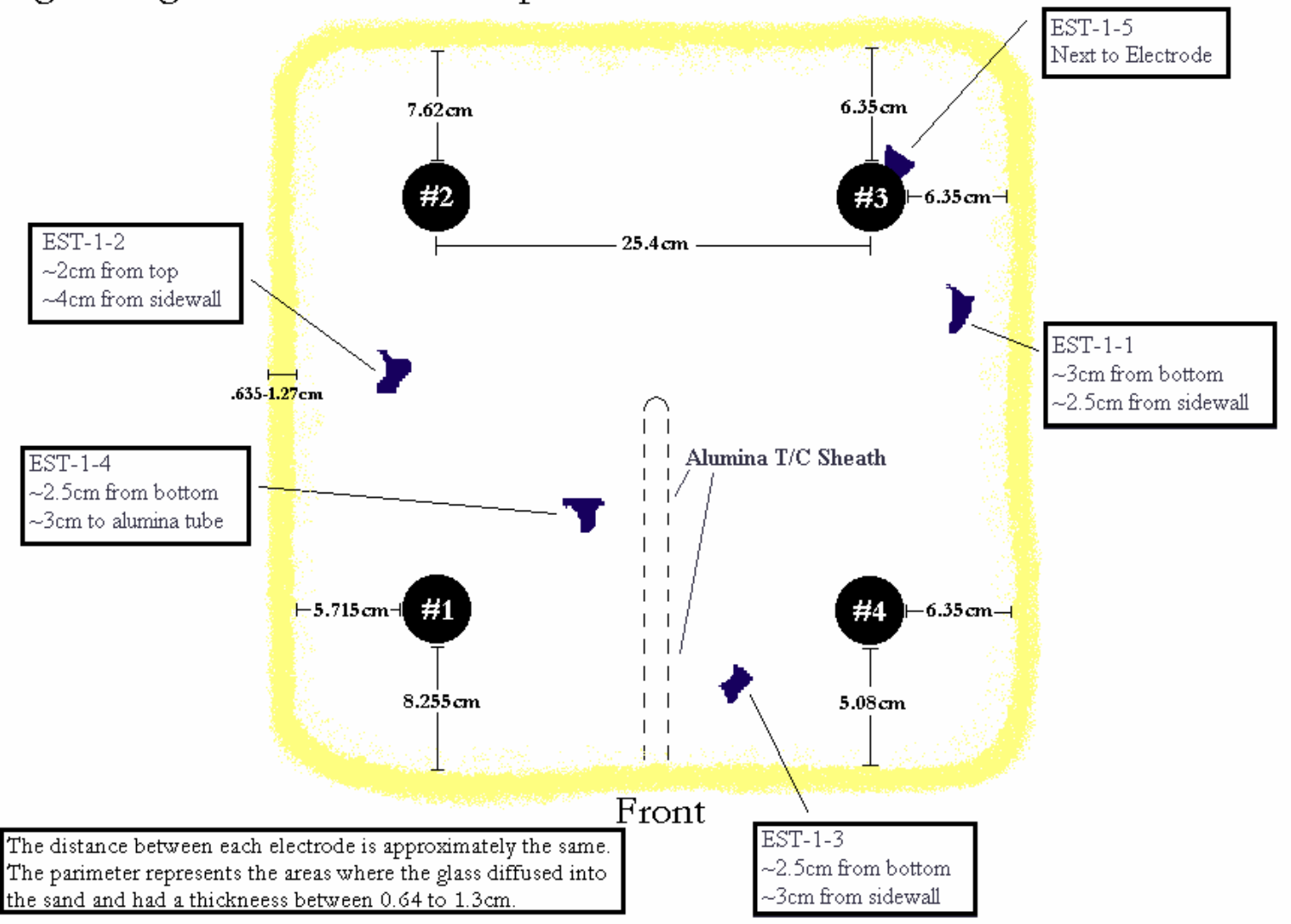

Figure 6.6. Position of Glass Samples Taken for Composition Analysis from the ES-1 Glass Block ${ }^{\text {a }}$

(a) The term "EST" used within the diagram is the same as "ES." 


\section{EST-1 Glass, Cross-Section from Front of Block}

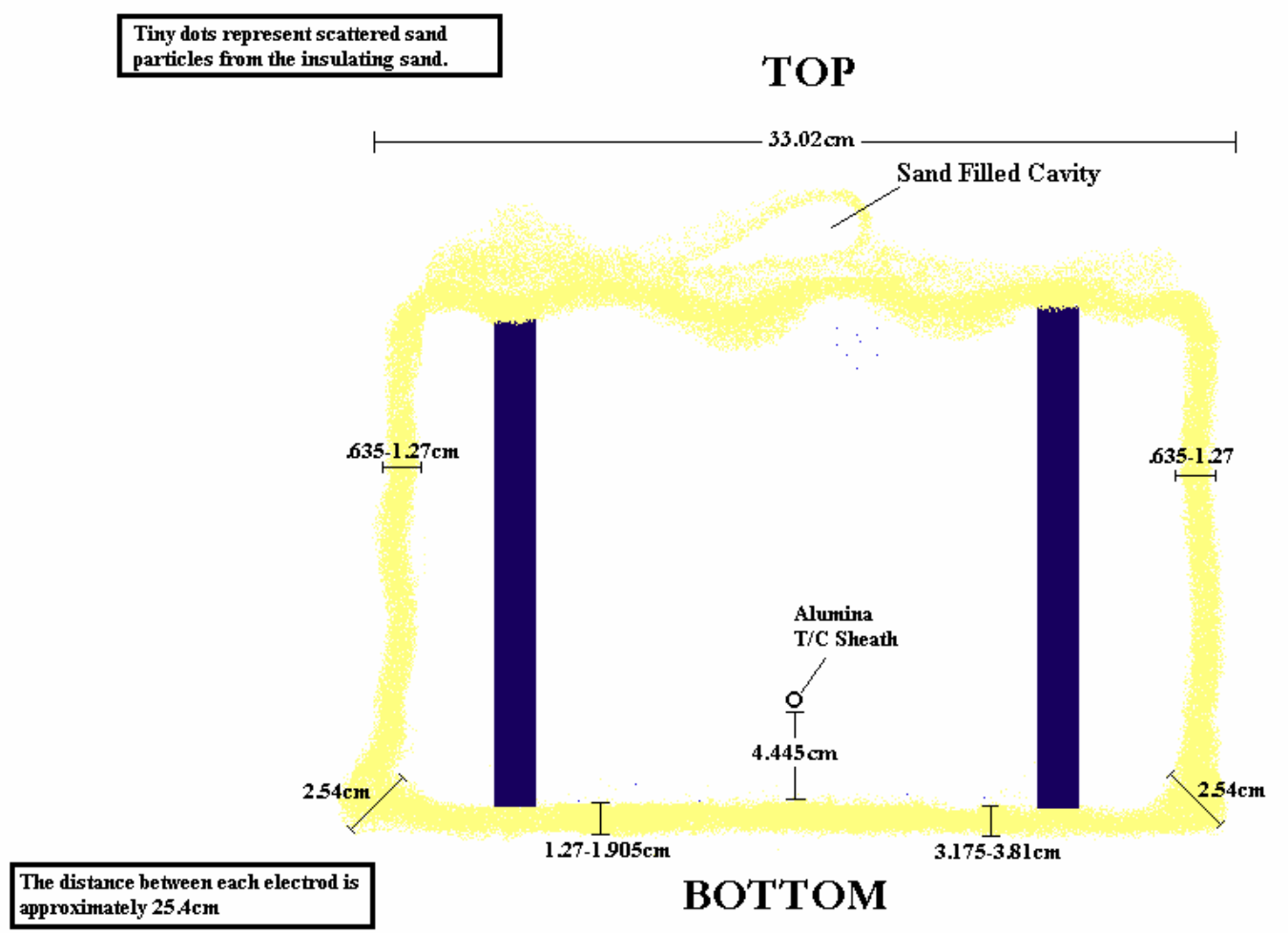

Figure 6.6 Continued

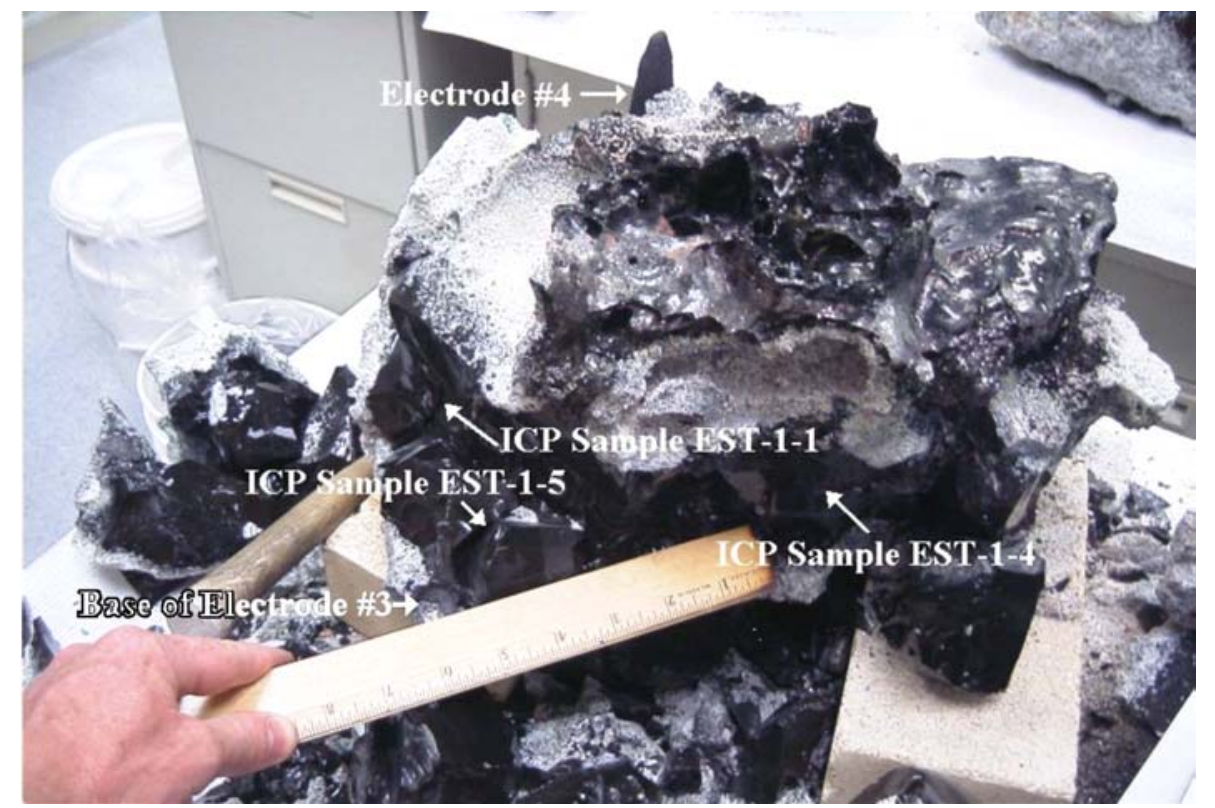

Figure 6.7. ES-1-1, -4, and -5 Samples and their Positions in ES-1 Glass Block ${ }^{(a)}$

(a) The term "EST" used within the picture is the same as "ES." 


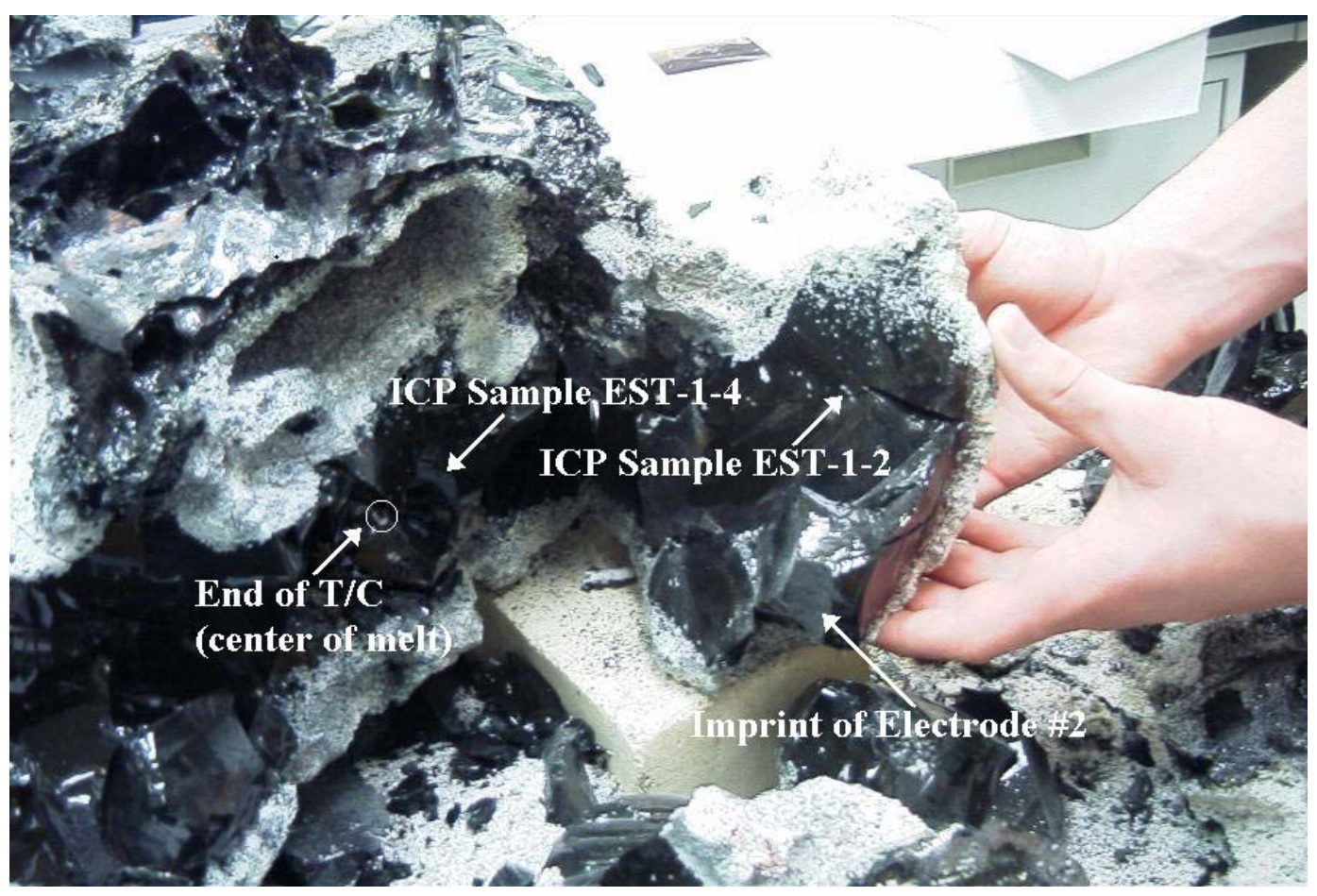

Figure 6.8. ES-1-2, and -4 Samples and their Positions in ES-1 Glass Block

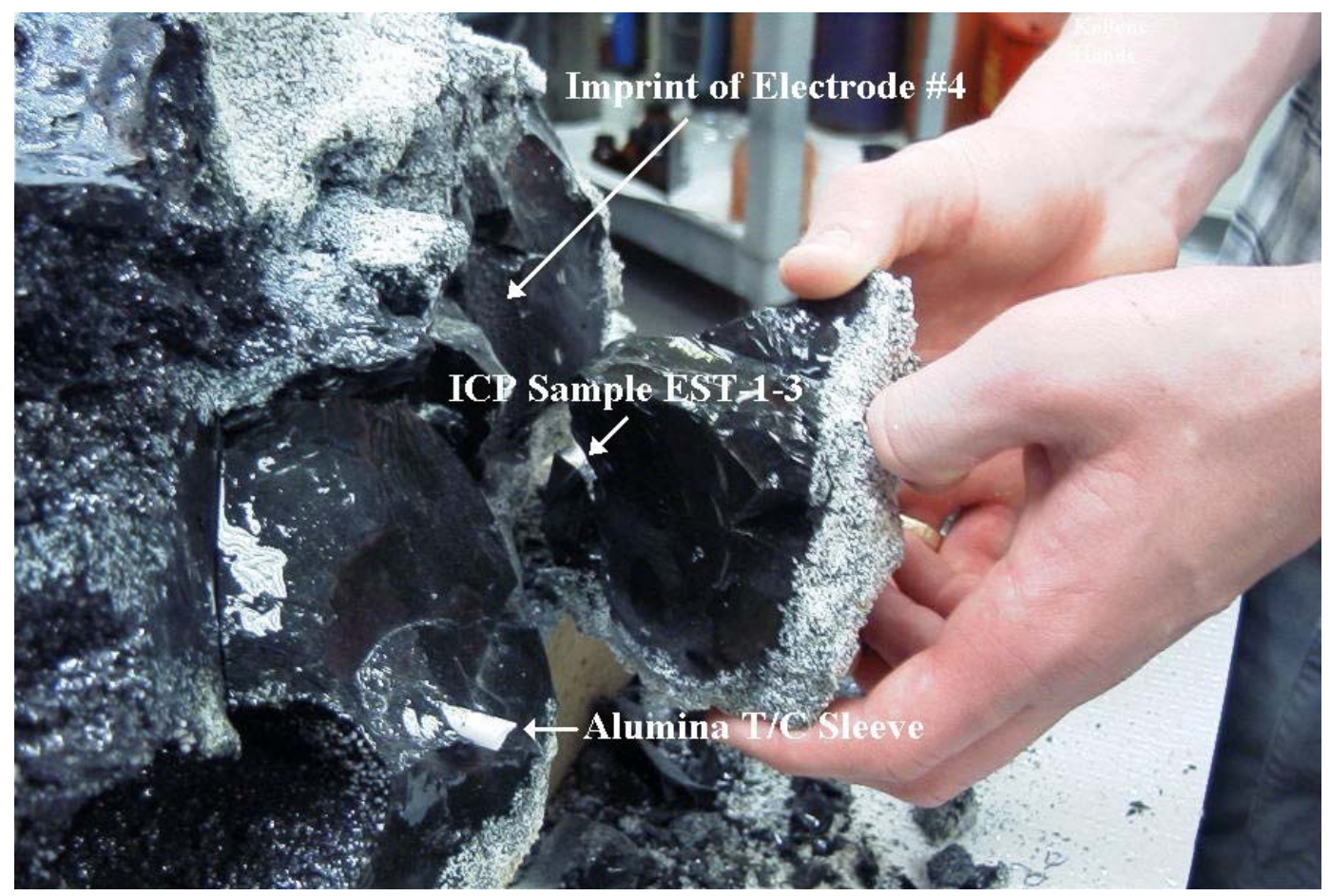

Figure 6.9. ES-1-3 Sample and its Position in ES-1 Glass Block 
Figure 6.10 shows the enlarged area of the bulk glass from ES-1 near the interface of the glass-insulating sand. There are no particles of sand in some areas of the bulk glass while in other areas sand particles in clusters are widely distributed. In most areas, such as on the sides and at the bottom, the convective currents of the molten glass seemed to sweep away loose grains of sand. However, in some areas of the melt top and corners, sand particles seemed to have collected because the flow of the glass leaves particles in these areas, and slightly less dense sand grains float to the uneven surface pockets at the top. When samples were taken for chemical analysis (see Figure 6.4), they were taken several centimeters from the glass-sand interface to avoid including any sand particles that may be captured in the glass samples and therefore bias the chemical analysis. Figure 6.11 and Figure 6.12 are magnified crosssections of the glass-sand interface showing grains of sand in the melt (the square-shaped bracket is a 1 inch square Pt wire).

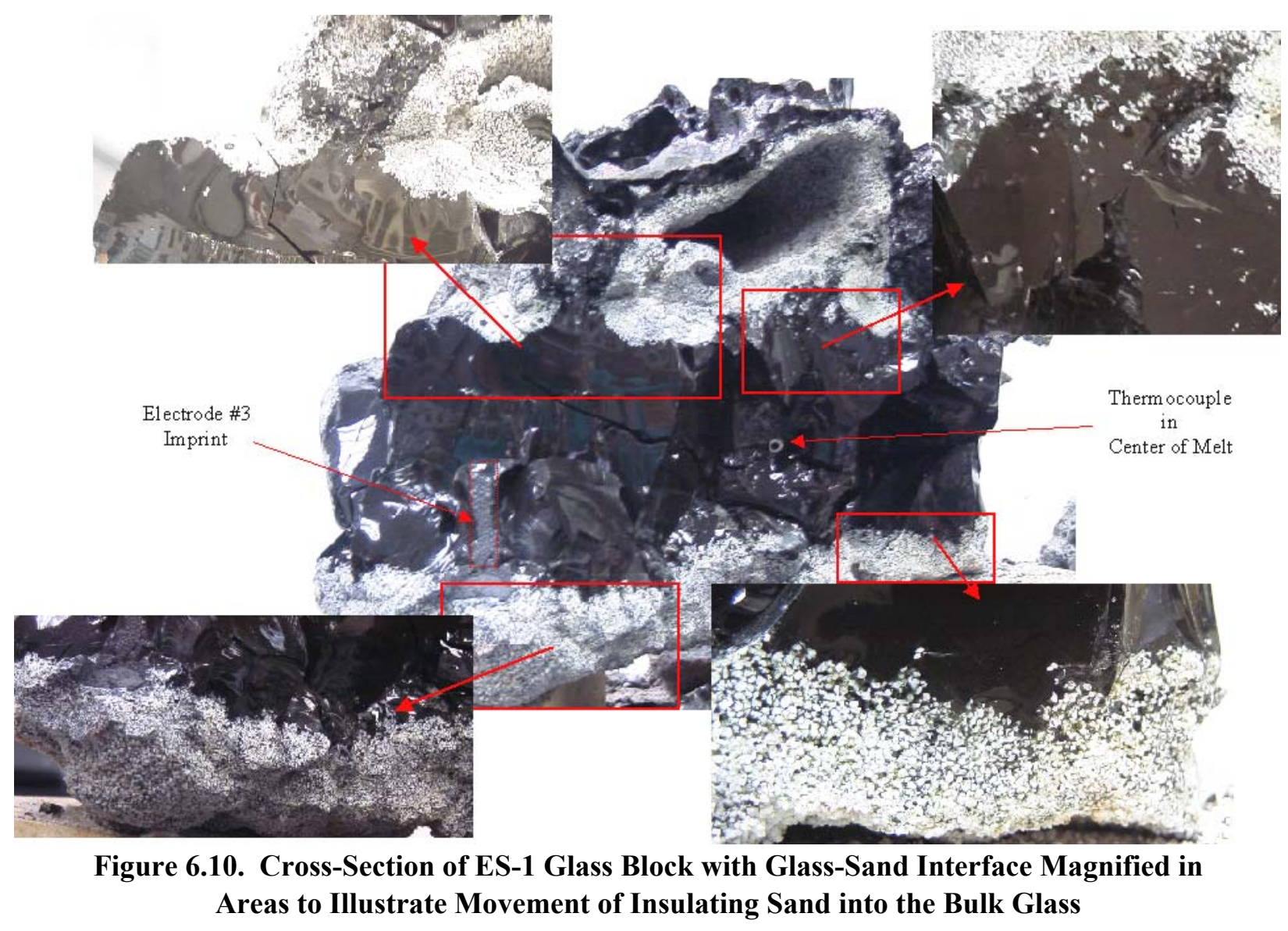




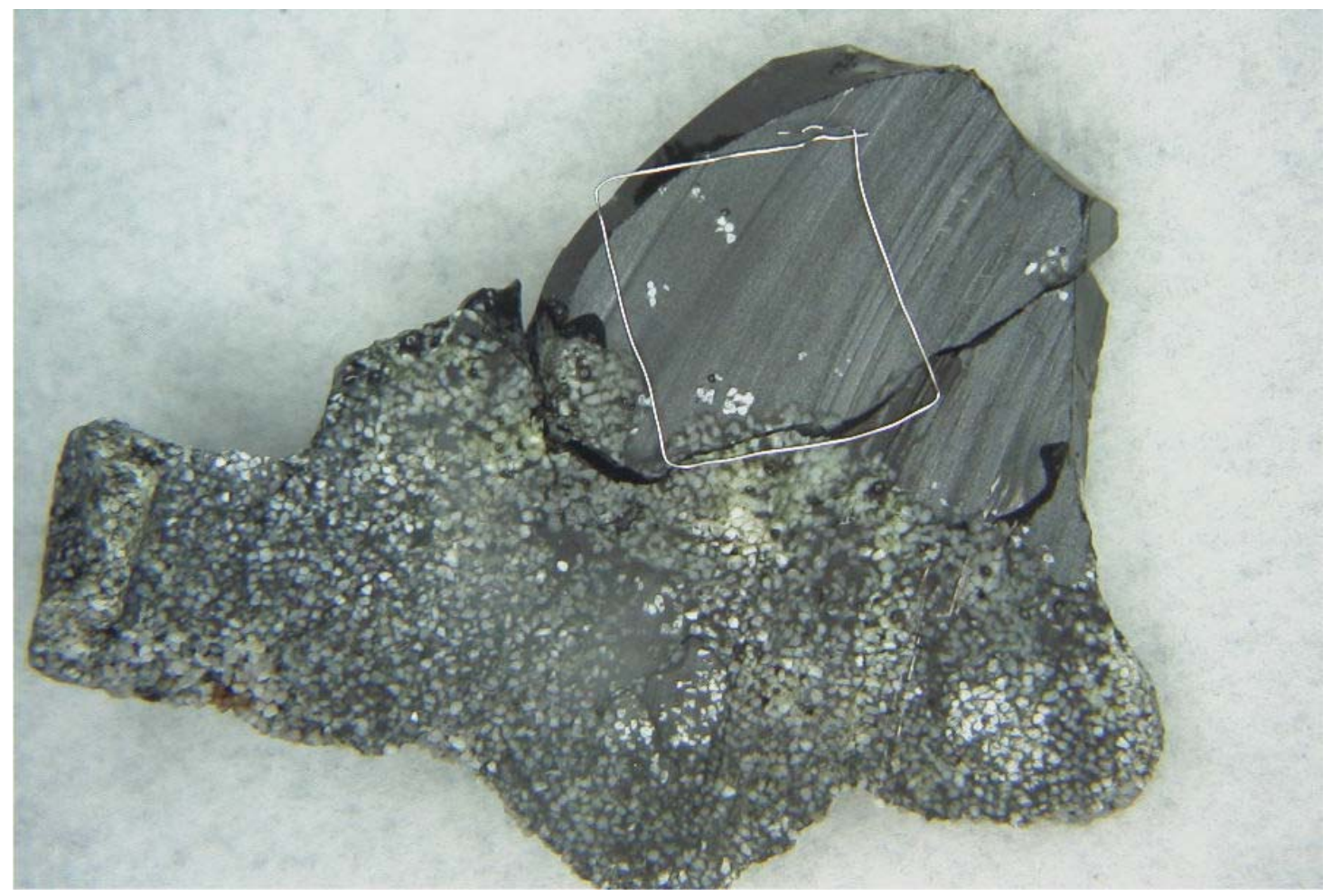

Figure 6.11. Example of Glass-Sand Interface at the Bottom of the Melt

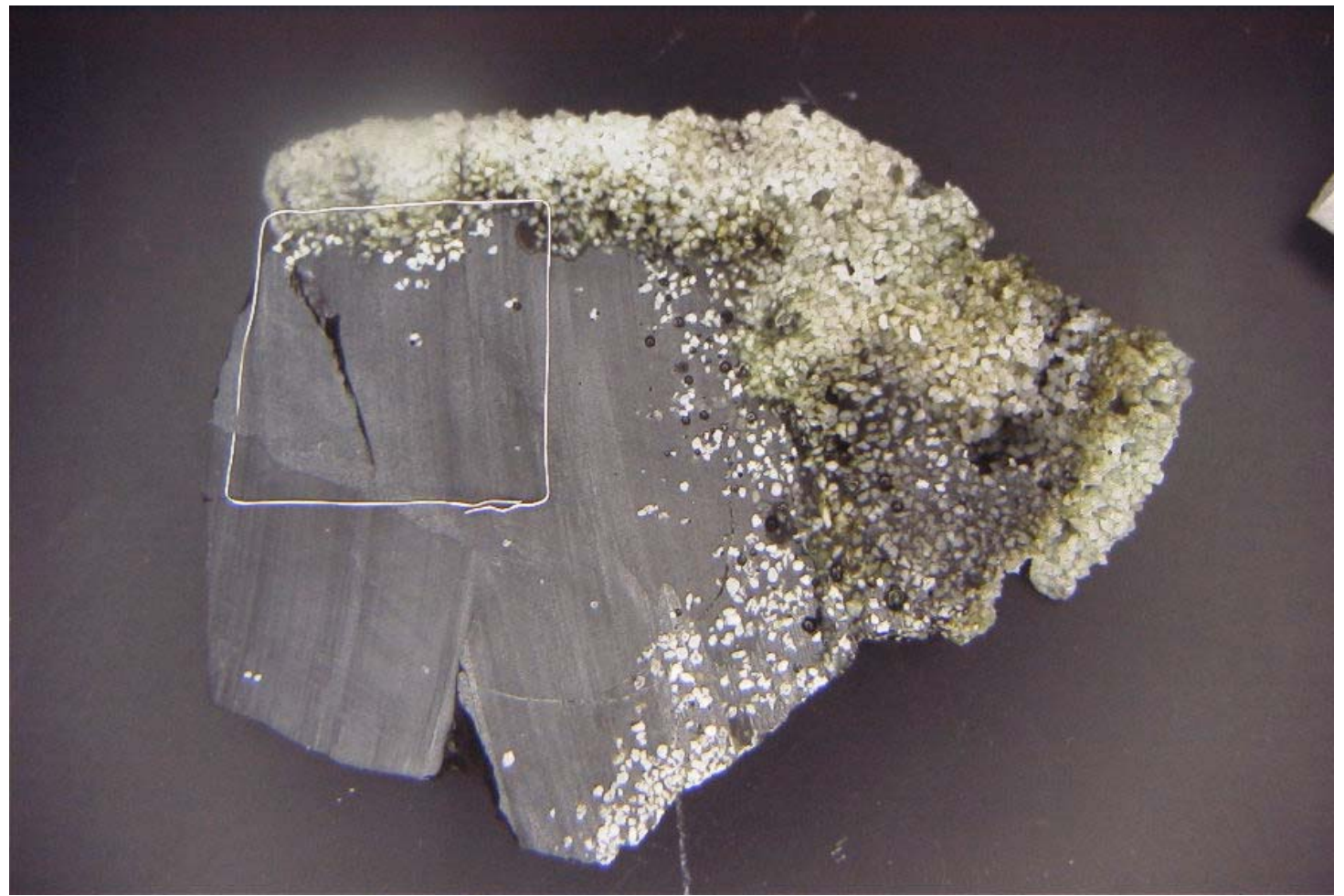

Figure 6.12. Example of Glass-Sand Interface at the Side-Wall and Top of Melt (side-wall is top of this photo) 


\subsection{Glass-Composition Analysis}

Table 6.6 summarizes the results of glass-composition and iron-redox analyses of the five samples taken from different locations in the ES-1 glass block (see Figure 6.6 through Figure 6.9). Figure 6.13 shows the comparison of measured and target concentrations of major glass components (those with a target mass fraction higher than 0.03) in these samples. Measured concentrations were lower than the targets for all components except for $\mathrm{SiO}_{2}$. The difference of measured versus target concentrations ranged from 42 to $55 \%$ for $\mathrm{SiO}_{2}$ and 25 to $60 \%$ for the remaining six major components. The significant increase of $\mathrm{SiO}_{2}$ resulted from the dissolution of silica sand that lined container walls to insulate them from the glass melt. The effects of sand dissolution on glass composition is expected to be significantly higher in engineeringscale tests than larger tests or a prototypic ICV process because of the high melt surface area-to-volume ratio of the engineering-scale test. The decrease in concentrations of other major oxides was a dilution effect caused by the dissolution of silica in the melt.

Figure 6.13 also shows the measured and target concentration ratios for $\mathrm{SO}_{3}$ that is prone to loss by volatilization. The $\mathrm{SO}_{3}$ retention in glass ranged from 16 to $23 \%$ (relative). ES-1 glasses had a lower $\mathrm{SO}_{3}$ retention than the simulant crucible tests performed with ASCM glasses and discussed in Section 4.2. Similar to ASCM glasses, $\mathrm{SO}_{3}$ retention was nearly constant regardless of sample position.

Among five samples taken from different positions, glass composition was reasonably constant except for ES-1-2, which had a slightly higher $\mathrm{SiO}_{2}, \mathrm{Fe}_{2} \mathrm{O}_{3}$, and $\mathrm{ZrO}_{2}$ concentration and a slightly lower $\mathrm{Na}_{2} \mathrm{O}$ concentration than the remaining four glasses. This encouraging result of nearly constant composition indicates that the glass melt was well mixed by convection currents during the melting process.

The iron-redox results listed in Table 6.6 indicate that the glass is highly reduced. There was no noticeable trend in the variation of the redox in relation to the sampling positions. It should be noted that the total electrode surface area-to-melt volume is higher for the engineering-scale tests than it will be in actual production. Therefore, it is likely that the process will produce more oxidized glass than measured in ES-1 samples.

A discrepancy exists between the ratio of measured versus target concentrations of components in simulant crucible test samples and in the ES-1 test samples. Both glasses, those for crucible tests and the ES-1 test, were prepared from the same simulant, soil, and additive materials and in the same ratios. The discrepancy is beyond that which can be expected based on the analytical biases. Figure 6.14 shows the same plot as displayed in Figure 6.13 for seven major components except that the ratios were calculated as fractions of the analyzed concentrations of ASCM-01 glass that had exactly the same target composition as ES-1 glass samples. The effect of sand dissolution during the ES-1 process is clearly evident. The mass fraction of sand dissolved in ES-1 glass, $S$, can be estimated from the mass-balance relation:

$$
g_{i}(1-S)+s_{i} S=G_{i}
$$

where $g_{i}$ and $G_{i}$ are the i-th component mass fraction in the glass before (target) and after (measured) sand dissolution, respectively, and $s_{i}$ is the i-th component mass fraction in sand. The target glass composition needs to be adjusted after accounting for the amount of flux materials added to the top of the dried feed, 
given in Table 6.4. Alternatively, the least-square-regression approach expressed by the following matrix equation can be used to obtain the $\mathbf{S}$ vector:

$$
\mathbf{S}=\left(\mathbf{g}^{\mathrm{T}} \mathbf{g}\right)^{-1} \mathbf{g}^{\mathrm{T}} \mathbf{G}
$$

where the $\mathbf{g}$ matrix represents the target glass and sand compositions, and $\mathbf{G}$ is the measured composition vector.

Table 6.7 lists the $S$ values obtained from Equation 6.4, assuming sand is pure $\mathrm{SiO}_{2}$. Estimated average $S$ values range from 0.30 to 0.39 . This high value of $S$ is attributed to the small scale used in the current ES-1 test as discussed above in this section.

Table 6.6. Analyzed Compositions (in mass fractions) and Redox of ES-1 Glasses

\begin{tabular}{|c|c|c|c|c|c|c|}
\hline Component & ES-1-1 & ES-1-2 & ES-1-3 & ES-1-4 & ES-1-5 & Average \\
\hline $\mathrm{Al}_{2} \mathrm{O}_{3}$ & 0.0719 & 0.0661 & 0.0700 & 0.0695 & 0.0712 & 0.0697 \\
\hline $\mathrm{B}_{2} \mathrm{O}_{3}$ & 0.0336 & 0.0332 & 0.0334 & 0.0341 & 0.0351 & 0.0339 \\
\hline $\mathrm{CaO}$ & 0.0205 & 0.0212 & 0.0216 & 0.0207 & 0.0218 & 0.0212 \\
\hline $\mathrm{Cr}_{2} \mathrm{O}_{3}$ & 0.0006 & 0.0006 & 0.0006 & 0.0006 & 0.0006 & 0.0006 \\
\hline $\mathrm{Fe}_{2} \mathrm{O}_{3}$ & 0.0208 & 0.0232 & 0.0201 & 0.0201 & 0.0206 & 0.0209 \\
\hline $\mathrm{K}_{2} \mathrm{O}$ & 0.0099 & 0.0113 & 0.0115 & 0.0102 & 0.0114 & 0.0109 \\
\hline $\mathrm{MgO}$ & 0.0121 & 0.0113 & 0.0114 & 0.0120 & 0.0114 & 0.0116 \\
\hline $\mathrm{Na}_{2} \mathrm{O}$ & 0.1499 & 0.1233 & 0.1500 & 0.1479 & 0.1503 & 0.1443 \\
\hline $\mathrm{P}_{2} \mathrm{O}_{5}$ & 0.0026 & 0.0022 & 0.0024 & 0.0024 & 0.0025 & 0.0024 \\
\hline $\mathrm{ReO}_{2}$ & $\mathrm{ND}^{(\mathrm{a})}$ & $\mathrm{ND}^{(\mathrm{a})}$ & $\mathrm{ND}^{(\mathrm{a})}$ & $\mathrm{ND}^{(\mathrm{a})}$ & $\mathrm{ND}^{(\mathrm{a})}$ & \\
\hline $\mathrm{SiO}_{2}$ & 0.6136 & 0.6602 & 0.6052 & 0.6127 & 0.6087 & 0.6201 \\
\hline $\mathrm{SO}_{3}$ & 0.0019 & 0.0017 & 0.0017 & 0.0015 & 0.0013 & 0.0016 \\
\hline $\mathrm{TiO}_{2}$ & 0.0072 & 0.0066 & 0.0066 & 0.0069 & 0.0066 & 0.0068 \\
\hline $\mathrm{ZrO}_{2}$ & 0.0471 & 0.0515 & 0.0456 & 0.0467 & 0.0452 & 0.0472 \\
\hline Total & 0.9918 & 1.0124 & 0.9800 & 0.9854 & 0.9867 & 0.9913 \\
\hline \multicolumn{7}{|l|}{ Redox } \\
\hline $\mathrm{Fe}(\mathrm{II}) / \mathrm{Fe}(\text { total })^{(\mathrm{b})}$ & 1 & 1 & 0.87 & 1 & 0.90 & 0.95 \\
\hline \multicolumn{7}{|c|}{$\begin{array}{l}\text { (a) Below the detection limit of } 0.0001 \text {. } \\
\text { (b) } \mathrm{Fe}(\mathrm{II}) / \mathrm{Fe}=1 \text { suggests that a portion of } \mathrm{Fe} \text { was reduced to } \mathrm{Fe} \text { metal inclusions, which was } \\
\text { actually observed. }\end{array}$} \\
\hline
\end{tabular}




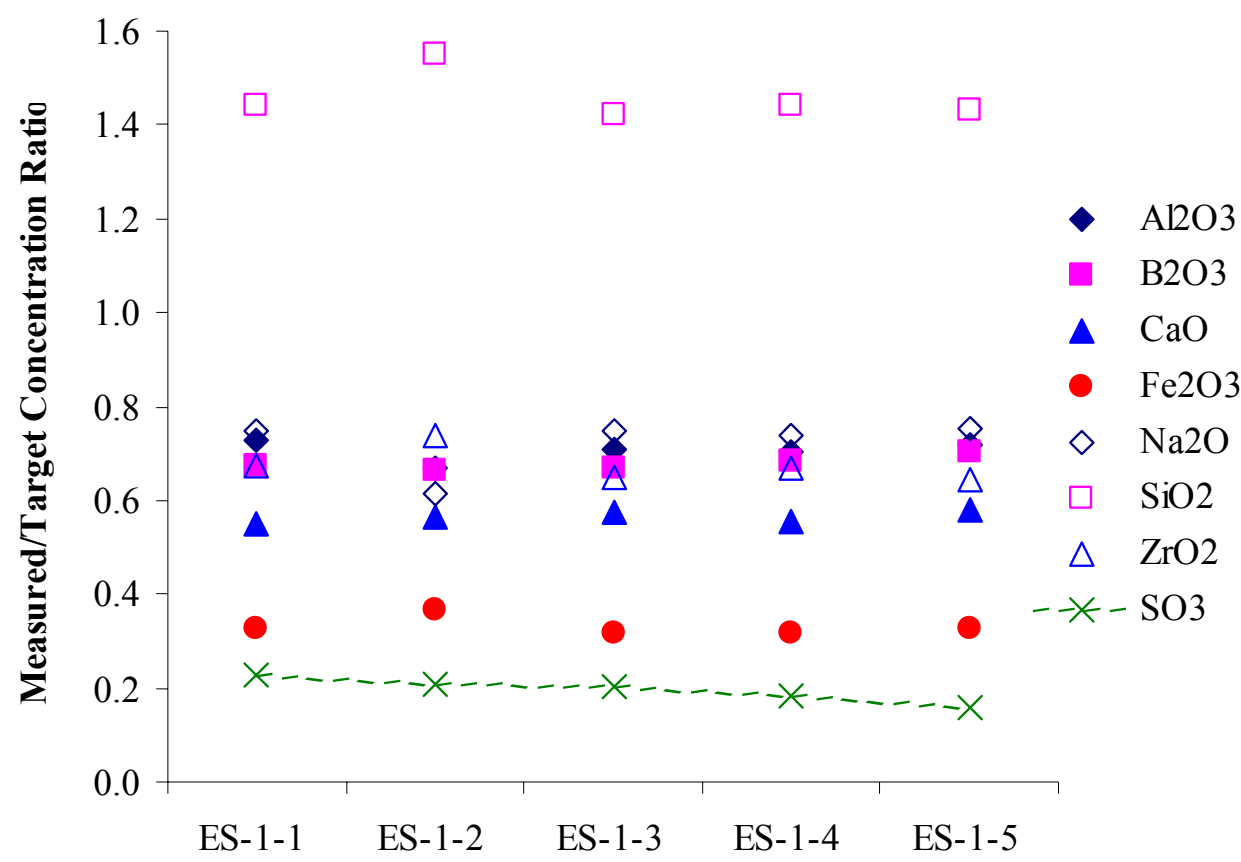

ES-1 Sample ID

Figure 6.13. Ratio of Measured and Target Concentrations of $\mathrm{ReO}_{2}, \mathrm{SO}_{3}$, and Selected Major Components in ES-1 Glasses

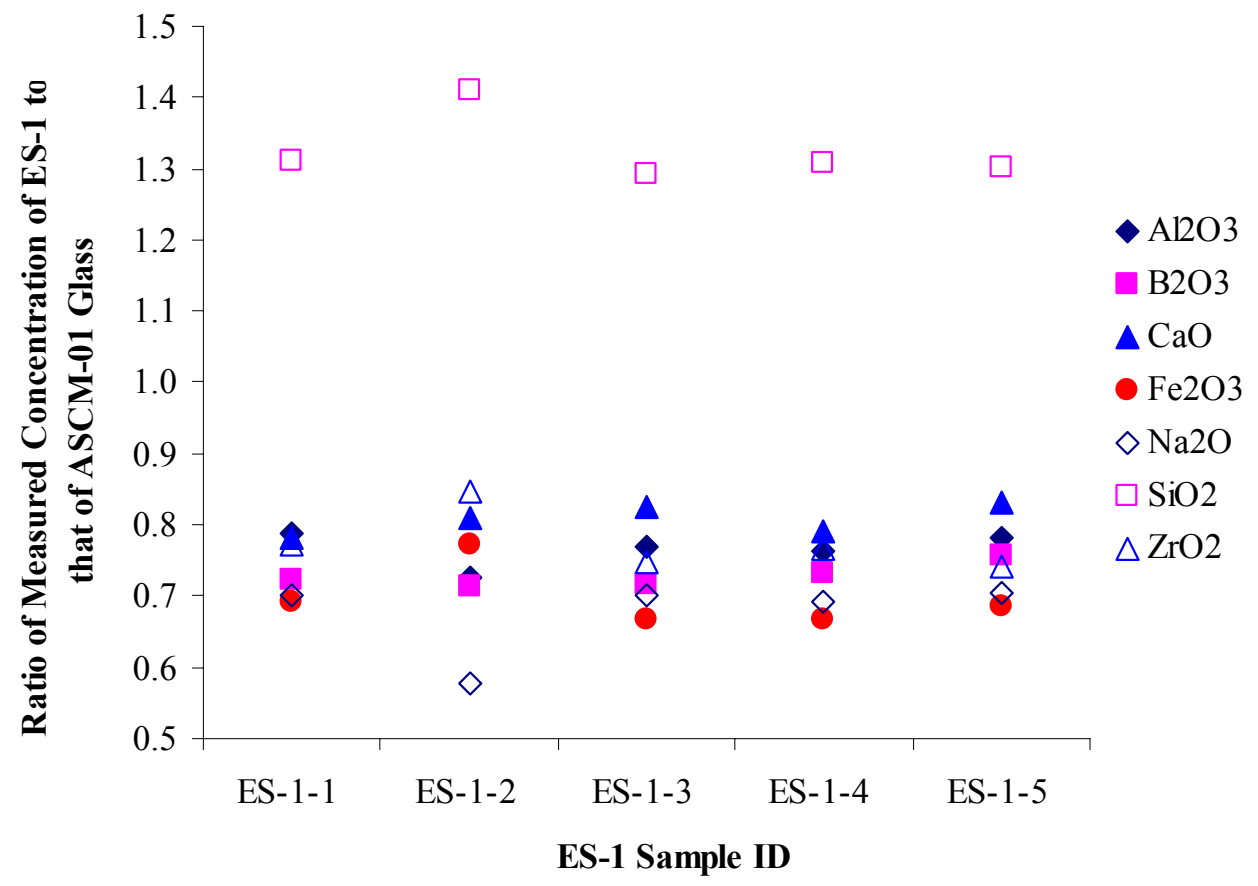

Figure 6.14. Ratio of Measured Concentrations of ES-1 Glasses to that of ASCM-01 Glass for Selected Major Components 
Table 6.7. Estimated Mass Fraction of Sand Dissolved in the ES-1 Glass Samples $(S)$ Calculated from Analyzed Glass Compositions

\begin{tabular}{||c|c|c|c|c|c|c||}
\hline \hline Component & ES-1-1 & ES-1-2 & ES-1-3 & ES-1-4 & ES-1-5 & Average \\
\hline$S$ & 0.31 & 0.39 & 0.30 & 0.31 & 0.31 & 0.33 \\
\hline
\end{tabular}

\subsection{Sample Position and Identification for Glass Characterization}

Figure 6.15 shows schematics of the ES-1 glass block showing positions of glass samples taken for glass characterization for PCT, VHT, TCLP, and density. Figure 6.16 illustrates how the ES-1 through -8 samples for glass characterization were taken from the side-wall area of the ES-1 glass block. The PCT sample came from close to the glass-sand interface. Three samples were taken for VHT: one from the area where glass had soaked into the sand insulation, another from the glass-sand interface so that half of the sample was in the glass and half was in the glass soaked sand, and the third sample was a bulk glass sample near the glass-sand boundary.

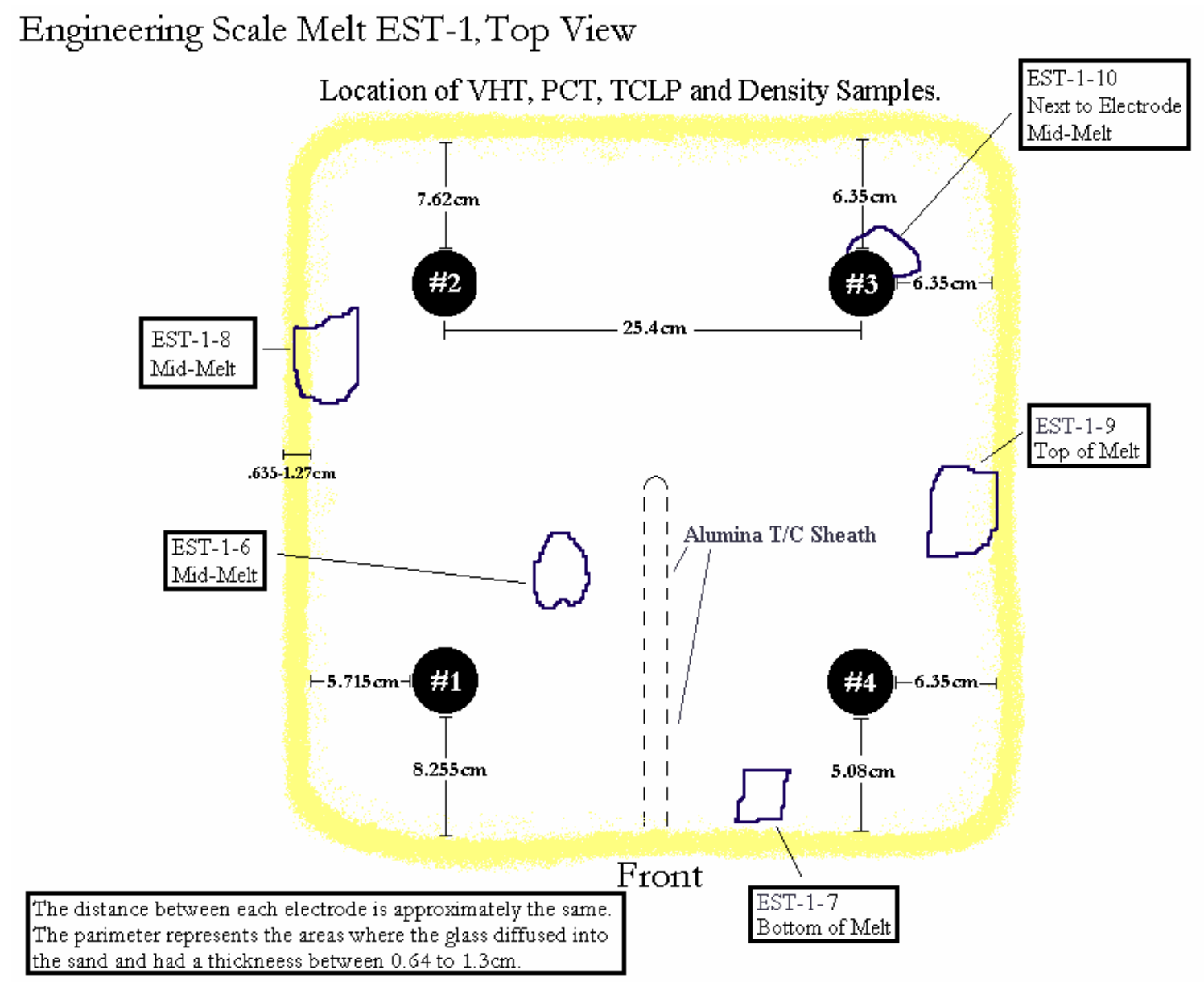

Figure 6.15. ES-1 Glass Block Showing the Areas from Where PCT, VHT, TCLP and Density Samples Were Obtained ${ }^{(a)}$

\footnotetext{
a The term "EST" used within the diagram is the same as "ES".
} 


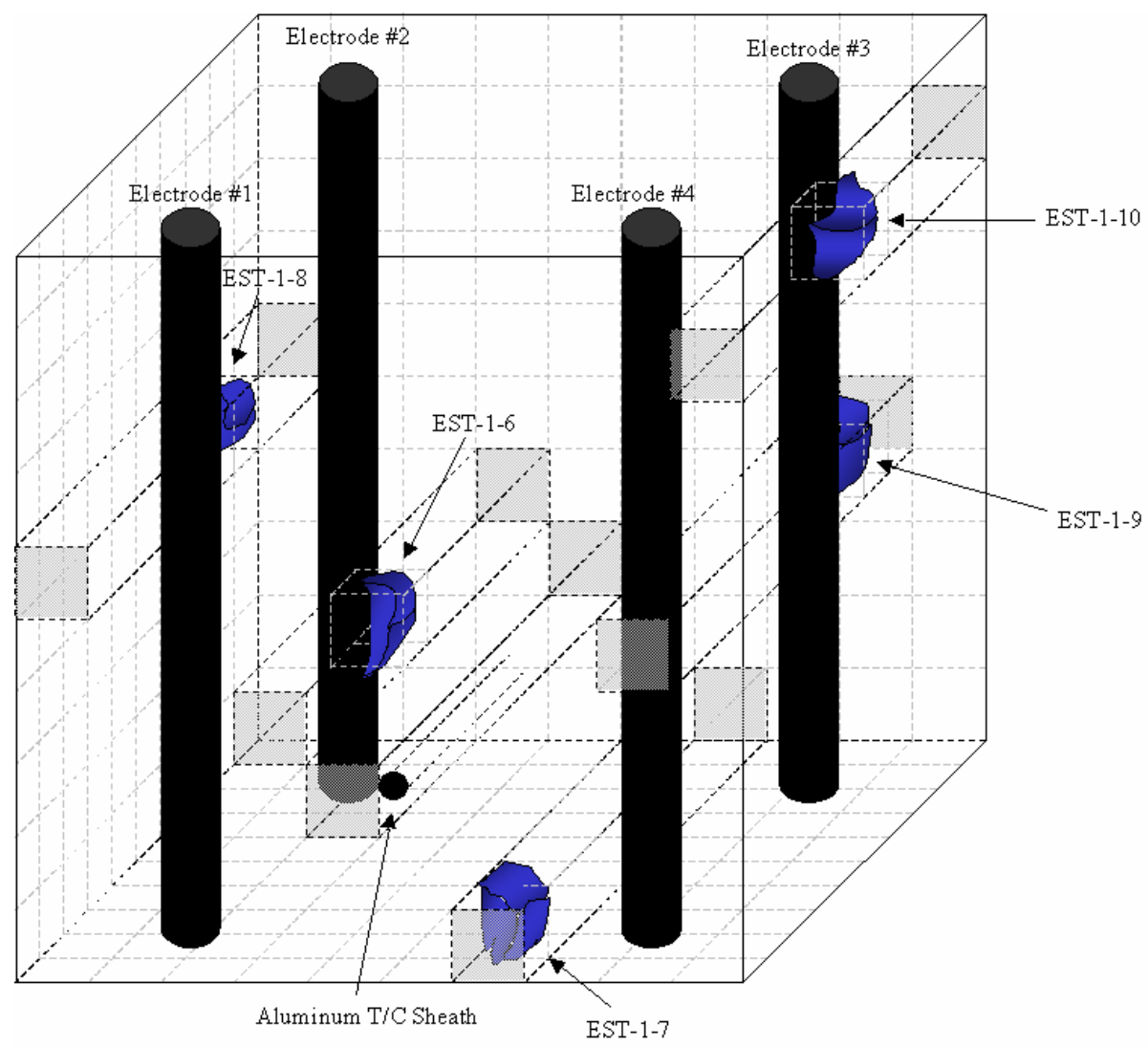

Figure 6.15. (Continued) 


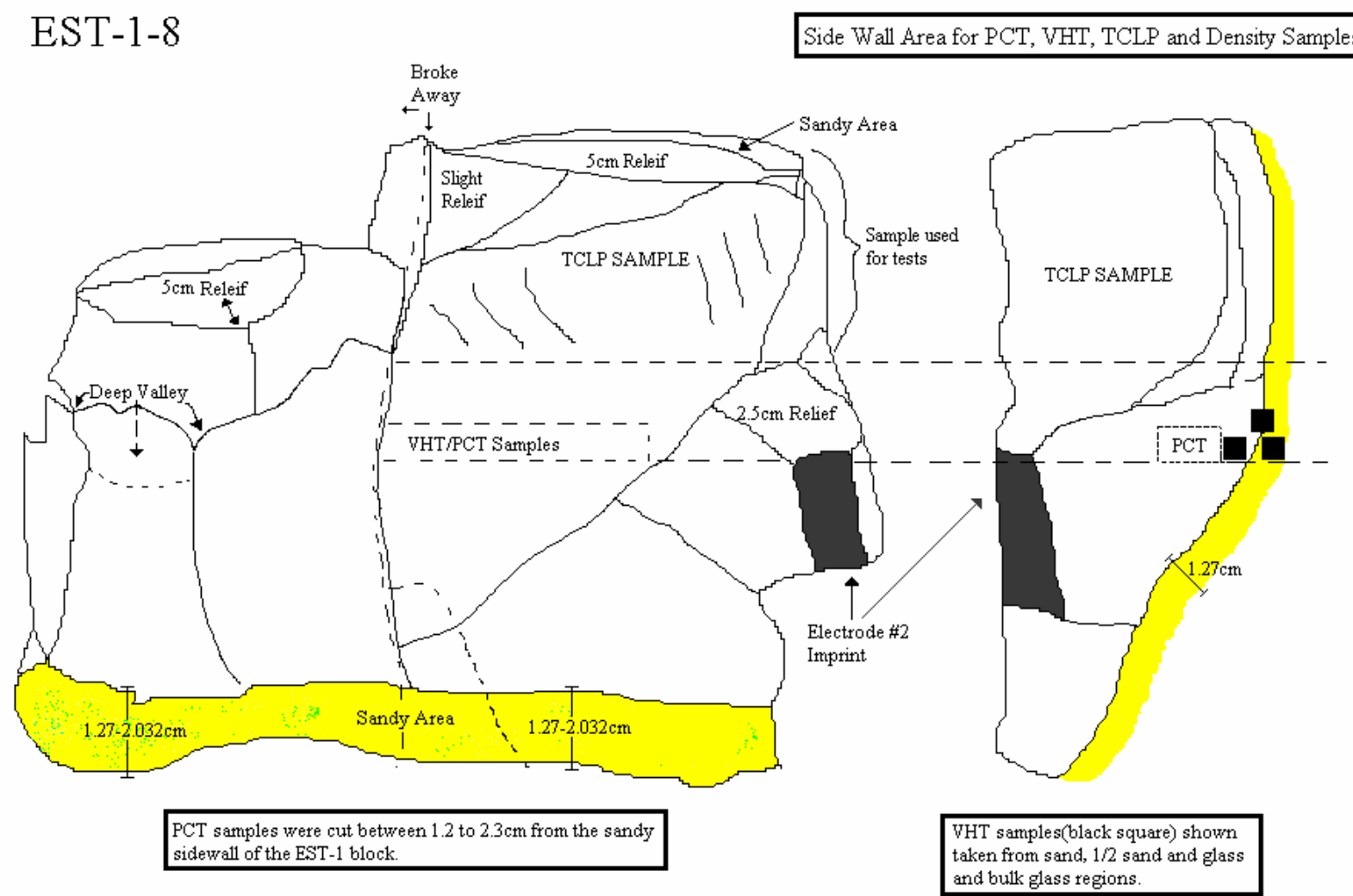

Figure 6.16. Illustration of How the ES-1-8 Samples for Glass Characterization Were Obtained from Side-Wall Area of the ES-1 Glass Block ${ }^{(a)}$

\subsection{Product Consistency Test}

Table 6.8 summarizes the PCT response of ES-1 glass samples. The normalized releases from ES-1 glasses were much lower (roughly 1/3) than both quenched and SC treated ASCM-01 glasses (see Table 4.14) that had the same target composition. This low PCT release can be mainly attributed to the dissolution of silica sand in ES-1. There was no noticeable difference between samples taken at different locations, suggesting that the glass was well homogenized during the melting process. The same conclusion was reached from the analyses of measured glass compositions (see Section 6.3).

(a) The term "EST" used within the diagram is the same as "ES." 
Table 6.8. PCT Responses for ES-1 Glasses

\begin{tabular}{|c|c|c|c|c|c|}
\hline Component & ES-1-6 & ES-1-7 & ES-1-8 & ES-1-9 & ES-1-10 \\
\hline \multicolumn{6}{|c|}{ 7-day PCT leachate concentration (mg/L) } \\
\hline$c_{N a}$ & 45 & 41.6 & 44.6 & 39.2 & 42.4 \\
\hline$c_{A l}$ & 4.93 & 4.87 & 4.81 & 4.13 & 4.8 \\
\hline$c_{B}$ & 2.28 & 2.19 & 2.27 & 1.96 & 2.26 \\
\hline$c_{S i}$ & 50.1 & 47.7 & 51.2 & 50 & 49.3 \\
\hline \multicolumn{6}{|c|}{ 7-day PCT Normalized release $\left(\mathrm{g} / \mathrm{m}^{2}\right)$} \\
\hline$r_{N a}$ & 0.152 & 0.140 & 0.150 & 0.132 & 0.143 \\
\hline$r_{A l}$ & 0.047 & 0.047 & 0.046 & 0.039 & 0.046 \\
\hline$r_{B}$ & 0.073 & 0.071 & 0.073 & 0.063 & 0.073 \\
\hline$r_{S i}$ & 0.126 & 0.120 & 0.129 & 0.126 & 0.124 \\
\hline \multicolumn{5}{|c|}{$\begin{array}{ll}6 \text { center of the glass block } & 7 \text { bottom of the glass block } \\
9 \text { between electrodes \#3 and \#4 } & 10 \text { next to the electrode \#3 }\end{array}$} & odes \#1 a \\
\hline
\end{tabular}

\subsection{Vapor Hydration Test}

Table 6.9 summarizes the 14-day VHT responses of the glass samples taken from different positions of the ES-1 glass block. In an attempt to better understand the full range of VHT responses, several samples were taken to span the sand layer-glass interface (at both the block bottom and side, see Figure 6.16 for a diagram of where samples were taken from the side of the block). For example, Figure 6.17 shows the VHT samples in the sand layer, at the interface, and in the bulk of the glass along with their cross-sections after testing. The samples show no visible corrosion after $200^{\circ} \mathrm{C}$ for 14 days, even in the samples with noticeable inclusions of silica sand particles. Although a more detailed evaluation is not possible from the current results, Table 6.9 suggest that the ES-1 glasses had slower dissolution rate than ASCM-01 glasses of the same target composition because of the increased $\mathrm{SiO}_{2}$ content caused by the sand dissolution as discussed already.

Table 6.9. 14-day VHT Responses for ES-1 Glasses

\begin{tabular}{|c|c|c|c|c|c|c|c|c|c|}
\hline Sample & ES-1-6 & ES-1-7S & ES-1-7M & ES-1-7G & ES-1-8S & ES-1-8M & ES-1-8G & ES-1-9 & ES-1-10 \\
\hline$m\left(\mathrm{~g} / \mathrm{m}^{2}\right)$ & 5.06 & 5.27 & 3.58 & 3.74 & 5.08 & 4.91 & 3.79 & 1.27 & 66.20 \\
\hline$r_{a}\left(\mathrm{~g} / \mathrm{m}^{2} / \mathrm{d}\right)$ & 0.36 & 0.38 & 0.26 & 0.27 & 0.36 & 0.35 & 0.27 & 0.09 & 4.68 \\
\hline $\begin{array}{l}6 \text { center of } \\
9 \text { between }\end{array}$ & $\begin{array}{l}\text { he glass b } \\
\text { lectrodes }\end{array}$ & $\begin{array}{l}\text { lock } \\
43 \text { and \#4 }\end{array}$ & $\begin{array}{l}7 \text { bott } \\
10 \text { ne }\end{array}$ & th of the gl & $\begin{array}{l}\text { ss block } \\
\text { rode \#3 }\end{array}$ & & \multicolumn{3}{|c|}{8 between electrodes $\# 1$ and $\# 2$} \\
\hline
\end{tabular}



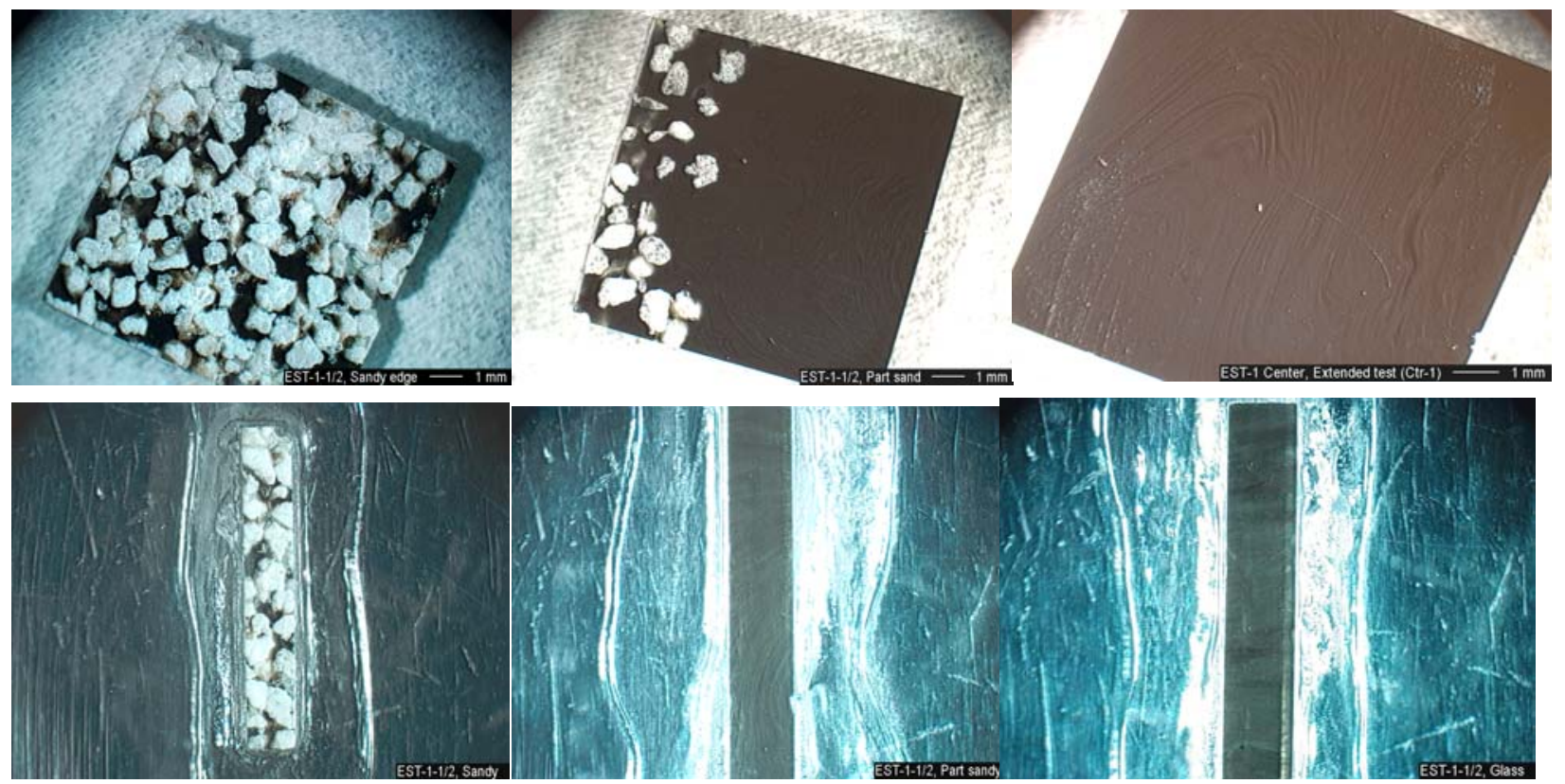

Figure 6.17. Optical Micrographs of VHT Coupons from Sand-Glass Interface Area, ES-1-8 (top view before the test, top, and cross-sections after 14 days at $200^{\circ} \mathrm{C}$, bottom)

Except for the sample taken from the area close to the graphite electrode (ES-1-10) and samples with sand from the bottom (ES-1-7S and 7M), no signs of corrosion were found after the 14-day VHT. The average alteration rates were all below $0.5 \mathrm{~g} /\left(\mathrm{m}^{2} \cdot \mathrm{d}\right)$, the sensitivity limit of the current method. Because of the proximity of the response with the sensitivity limit, the effect of different positions on VHT durability cannot be evaluated. Considering that the ES-1-10 sample was taken from the same position as in the ES-1-5 for glass-composition analysis, which did not show any difference from the other position samples, the slightly higher dissolution rate observed in the ES-1-10 sample is not understood.

The 14-day VHT coupons from the sand-glass interface area (ES-1-7M) had visible reaction products after the 14 day test at $200^{\circ} \mathrm{C}$ (see Figure 6.18, right photo). The reaction products from the ES-1-7S (Figure 6.18 , left photo) were visible only by microscope, where needle-like crystals could be observed on the surface of the sample and numerous small cavities were present inside the sample (see also Figure 6.19). Though analysis of the needle-like crystals was not possible, they are most likely a silica or silicarich phase. Figure 6.18, right photo, Figure 6.20 and Figure 6.21 show the reaction products on coupons from the ES-1-7M glass-sand interface. A more reaction occurred on glass with sand grains than on homogeneous glass (Figure 6.20 and Figure 6.21). The needle-like crystals were also observed on ES-1$7 \mathrm{M}$ coupon (Figure 6.21). As shown in Table 6.9, the 14-day VHT durability was not affected by this small number of crystals. Identifying any possible impact of this crystal formation would require longterm VHT tests and detailed analysis of crystal phases formed, which is beyond the scope of this report. 


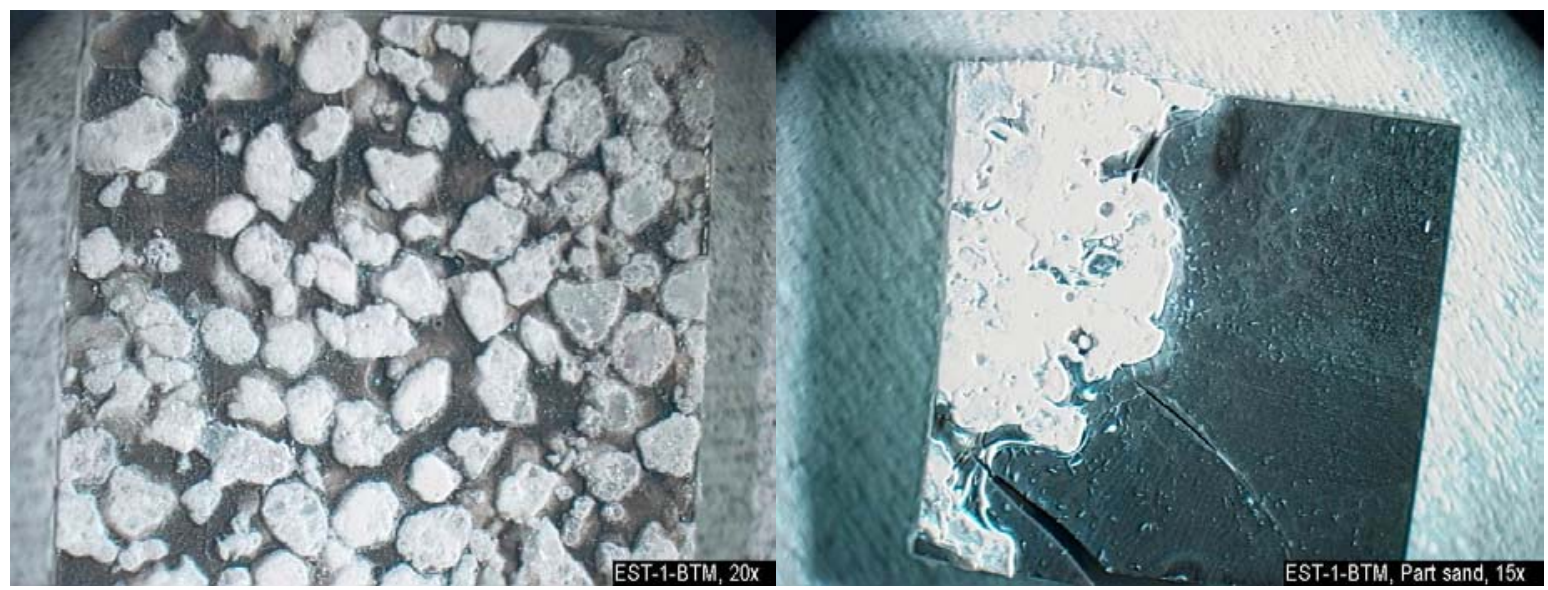

Figure 6.18. Optical Micrographs of VHT Coupons from Sandy Area (ES-1-7S, left) and Sand-Glass Interface Area (ES-1-7M, right) after 14 days at $200^{\circ} \mathrm{C}$ (length and width of coupon are $10 \mathrm{~mm}$ )

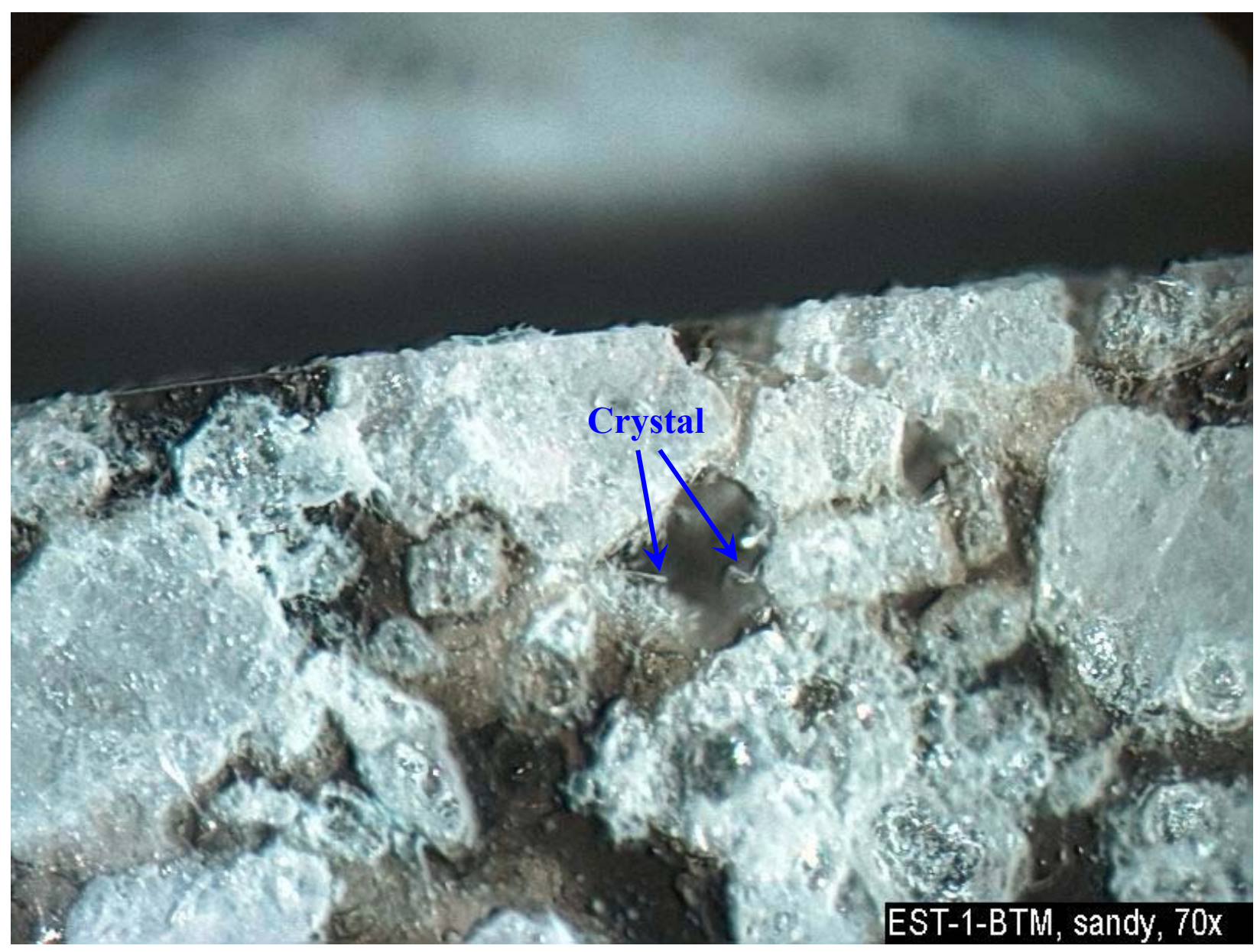

Figure 6.19. Optical Micrograph of VHT Coupon from Sand Area, ES-1-7S after 14 days at $200^{\circ} \mathrm{C}$ (the Cavity in Center of Micrograph Contains Needle-Like Crystals) ${ }^{(a)}$

(a) The term "EST" used within the picture is the same as "ES." 


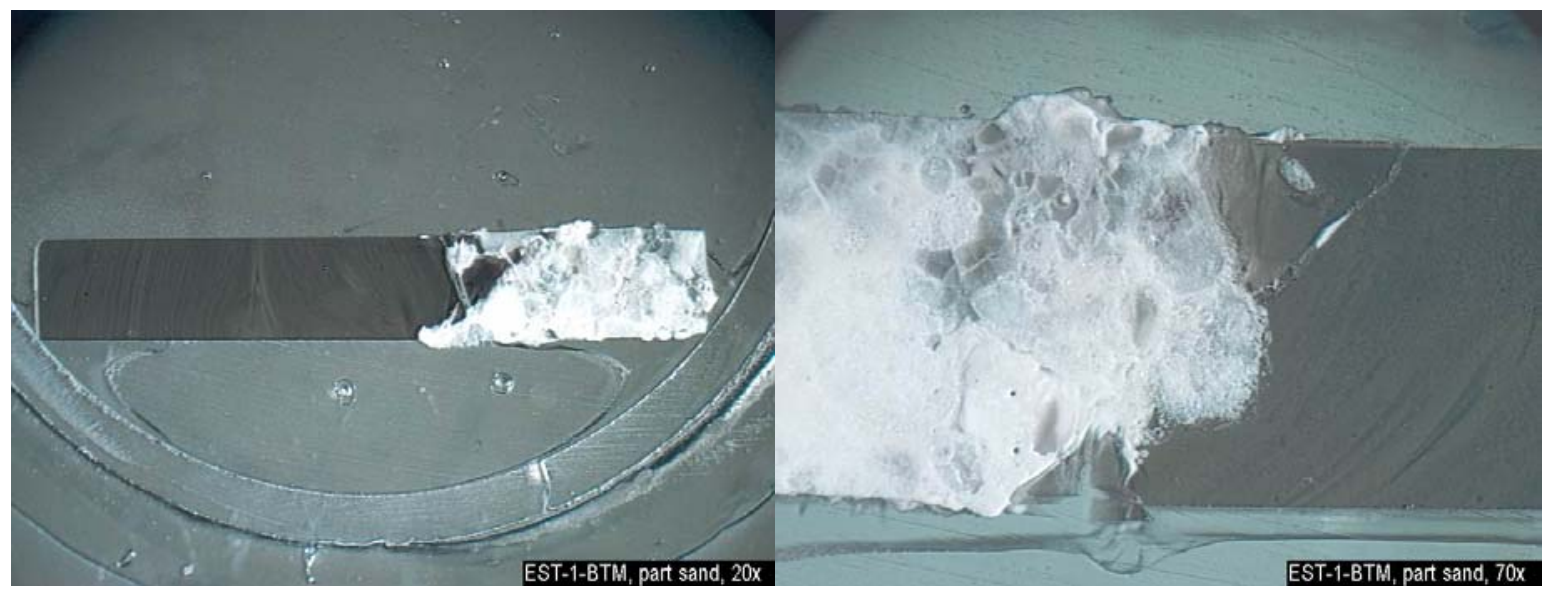

Figure 6.20. Optical Micrographs of VHT Coupon Cross-Section from Sand-Glass Interface Area (ES-1-7M) after 14 days at $200^{\circ} \mathrm{C}$ (length of a coupon is $10 \mathrm{~mm}$ and width is $1.5 \mathrm{~mm}$ )

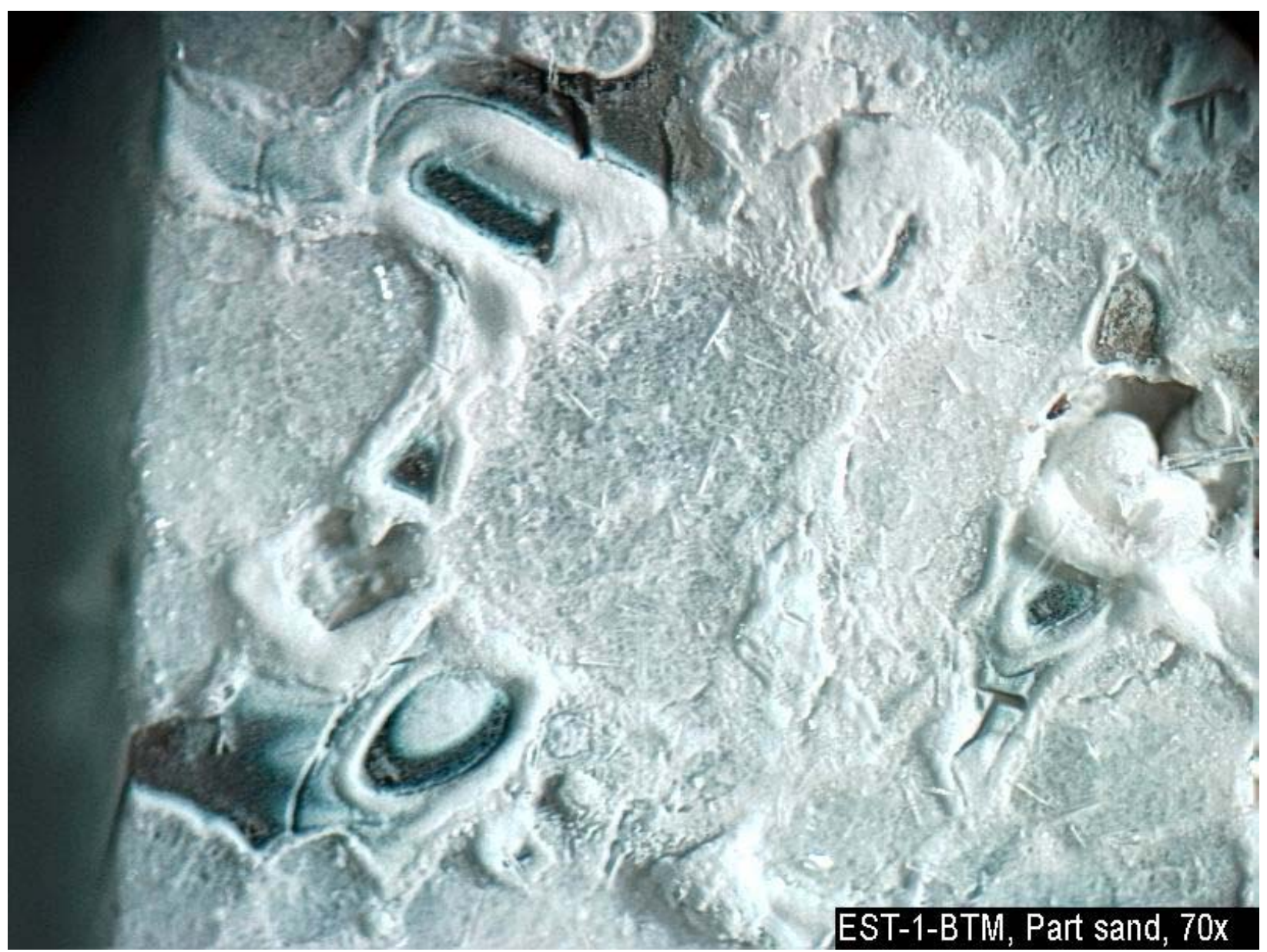

Figure 6.21. Optical Micrograph of the Surface of VHT Coupon from Sand-Glass Interface Area, ES-1-7M, after 14 days at $200^{\circ} \mathrm{C}$. Note the needle-like crystals. ${ }^{(a)}$

(a) The term "EST" used within the picture is the same as "ES." 


\subsection{Toxicity Characteristic Leaching Procedure}

Table 6.10 lists the TCLP responses of the glass samples taken from different positions of the ES-1 glass block. Table 6.10 shows that the Cr releases are at least an order of magnitude lower than the UTS limit of $0.6 \mathrm{mg} / \mathrm{L}$. The ES-1 glasses had lower TCLP B releases compared to quenched and SC treated ASCM-01 glasses, which is consistent with the PCT and VHT results.

Table 6.10. TCLP Responses for ES-1 Glasses

\begin{tabular}{||c|c|c|c|c|c|c||}
\hline $\begin{array}{c}\text { Glass } \\
\text { Sample }\end{array}$ & ES-1-6 & ES-1-7 & ES-1-8 & ES-1-9 & ES-1-10 & ES-1-Foam \\
\hline$c_{B}(\mathrm{mg} / \mathrm{L})$ & 0.23 & 0.36 & 0.33 & 0.2 & 0.24 & 1.1 \\
\hline$c_{C r}(\mathrm{mg} / \mathrm{L})$ & 0.0052 & $\mathrm{ND}$ & $\mathrm{ND}$ & 0.01 & $\mathrm{ND}$ & 0.009 \\
\hline$r_{B}(\mathrm{mg} / \mathrm{L})$ & 14.81 & 23.18 & 21.25 & 12.88 & 15.46 & 70.84 \\
\hline $\begin{array}{l}\text { The italicized values in highlighted cells are estimated results because they are below the reporting limits }(0.25 \mathrm{mg} / \mathrm{L} \text { for } \\
\text { Cr and 0.5 mg/L for B). }\end{array}$ \\
$\begin{array}{l}\text { 6 center of the glass block } \\
9 \text { between electrodes \#3 and \#4 }\end{array}$ \\
\hline
\end{tabular}

\subsection{Density}

Density values for ES-1 samples are listed in Table 6.11. The values span the range of $2.566 \pm 0.006 \mathrm{~g} / \mathrm{mL}$, which is lower than that of the ASCM-01 composition because of the increased silica concentration in the ES-1 glass.

Table 6.11. Density of ES-1 Glass Samples $(\mathrm{g} / \mathrm{mL})$

\begin{tabular}{|r|c|c|c|c|c|c|c||}
\hline \hline Sample & ES-1-6 & ES-1-7 & ES-1-8 & ES-1-9 & ES-1-10 & Mean & ASCM-01 \\
\hline$\rho$ & 2.567 & 2.565 & 2.564 & 2.572 & 2.561 & 2.566 & $2.649-2.666$ \\
\hline
\end{tabular}

6 center of the glass block 7 bottom of the glass block 8 between electrodes \#1 and \#2

9 between electrodes \#3 and \#4 10 next to the electrode \#3

\subsection{Secondary-Phase Identification}

Four types of secondary-phases may occur in the ICV glass: oxide crystals, metals, gas bubbles, and inorganic salts. All these inclusions were observed in crucible melts as discussed in previous sections. A view of the ES-1 block clearly contains a multi-phased material as shown in Figure 6.7, but most of the block mass is single-phased glass. No inclusions were found in the glass at the block exterior. Metallic (mainly Fe) droplets were found near the electrodes, mostly on the electrode surface and at the bottom of the melt. This was not unexpected, due to the highly reducing nature of the graphite electrodes; it is a condition that typically occurs in these kinds of melts. The size of the droplets varied from $1 \mu \mathrm{m}$ to 2 mm. Micrographs of typical droplets and their EDS dot maps are in Figure 6.22 through Figure 6.28. Some droplets contained inclusions of $\mathrm{Cr}$, $\mathrm{Ti}$, and $\mathrm{Zr}$ (Figure 6.25). Most droplets were spherical in shape. Droplets of irregular shape are shown in Figure 6.28. These large droplets $(\sim 0.5 \mathrm{~mm})$ consist of metallic Fe and are often surrounded by irregular metallic precipitates that are rich in $\mathrm{Fe}$ and $\mathrm{Cr}$. Note the irregular inclusions of Ti. 


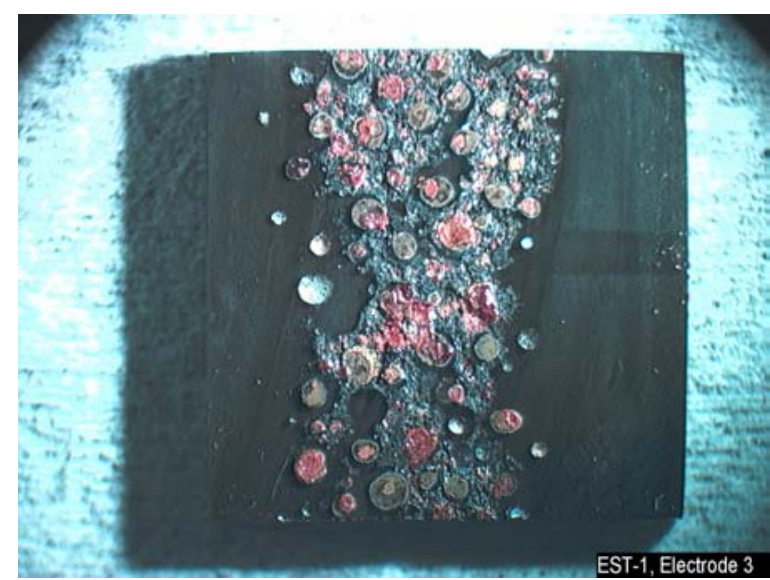

Figure 6.22. VHT Coupon from Glass near Electrode 3 (ES-1-10) with Metallic Droplets Precipitated at the Contact with the Graphite Electrode (iron was oxidized during the 14-days exposure to steam at $200^{\circ} \mathrm{C}$ )

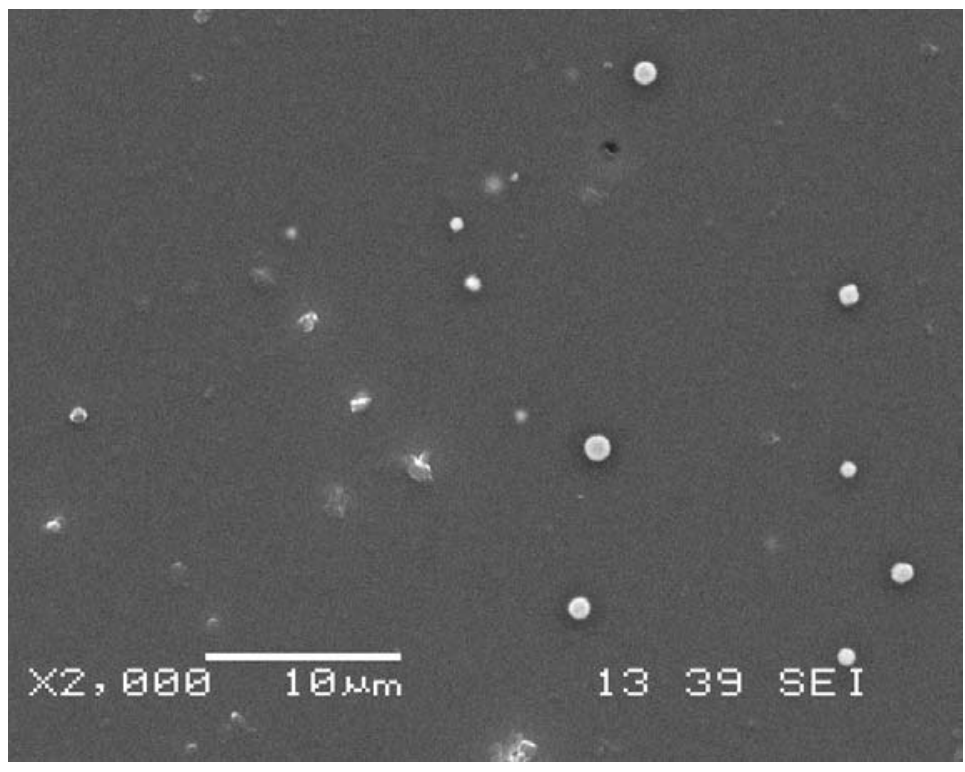

Figure 6.23. A Typical Section of Glass with Metallic Droplets (SEM micrograph) 


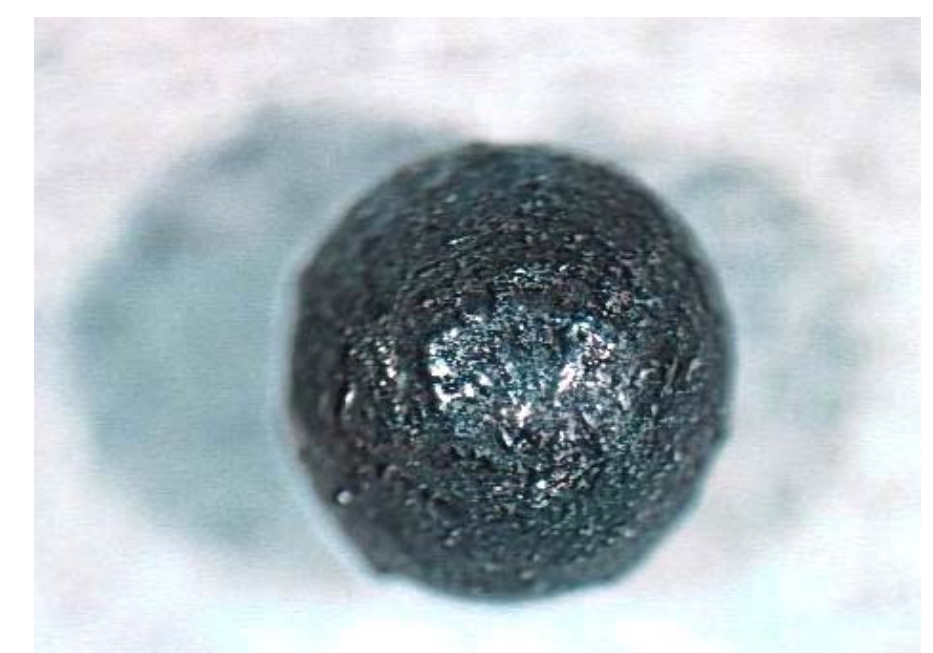

\section{EST-1, "big" metal drop, $25 \mathrm{x}-1 \mathrm{~mm}$}

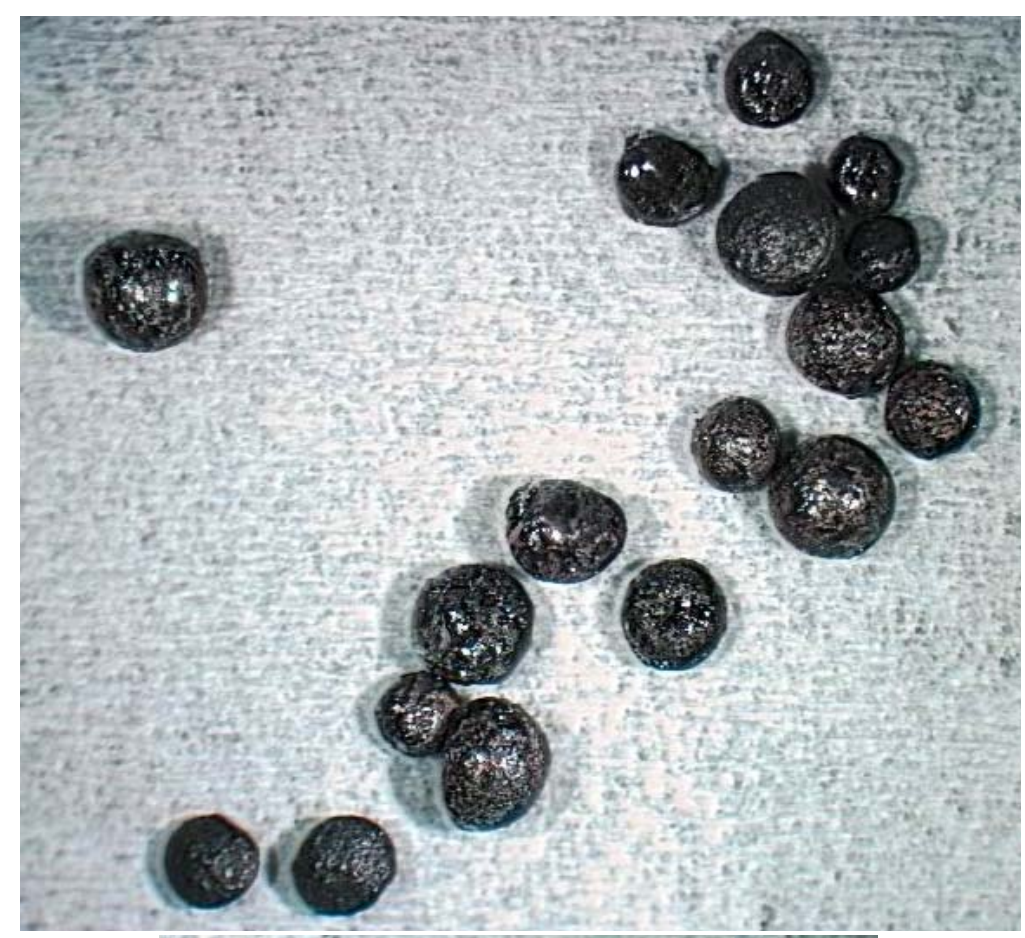

EST-1, "small" drops, 10x $2 \mathrm{~mm}$

Figure 6.24. Metallic Droplets Released from ES-1 Glass Block During Sampling ${ }^{(a)}$

(a) The term "EST" used within the picture is the same as "ES." 

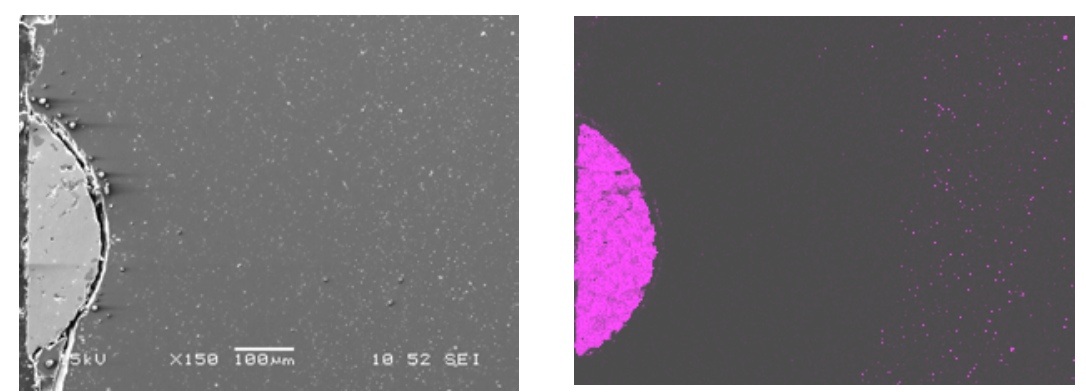

$\mathrm{Fe}$
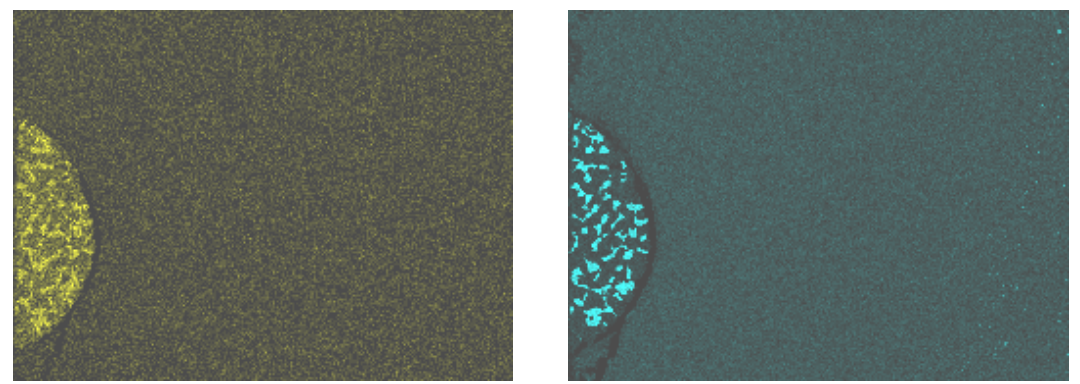

$\mathrm{Cr}$

$\mathrm{Zr}$

Figure 6.25. EDS Dot Map Showing Composition of a Metallic Droplet in ES-1-10

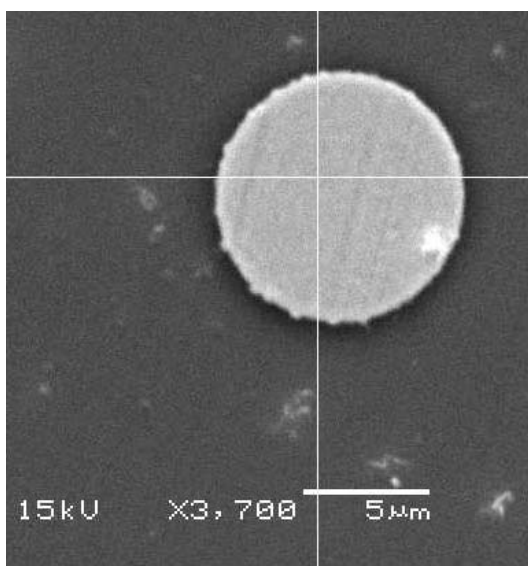

Figure 6.26. A Metallic Droplet in ES-1-10 Sample

Table 6.12. Composition of the Droplet Shown in Figure 6.26

\begin{tabular}{|c|c|c|}
\hline Element & Mass\% & At\% \\
\hline $\mathrm{Fe}$ & 78.0 & 85.3 \\
\hline $\mathrm{Zr}$ & 22.0 & 14.7 \\
\hline
\end{tabular}



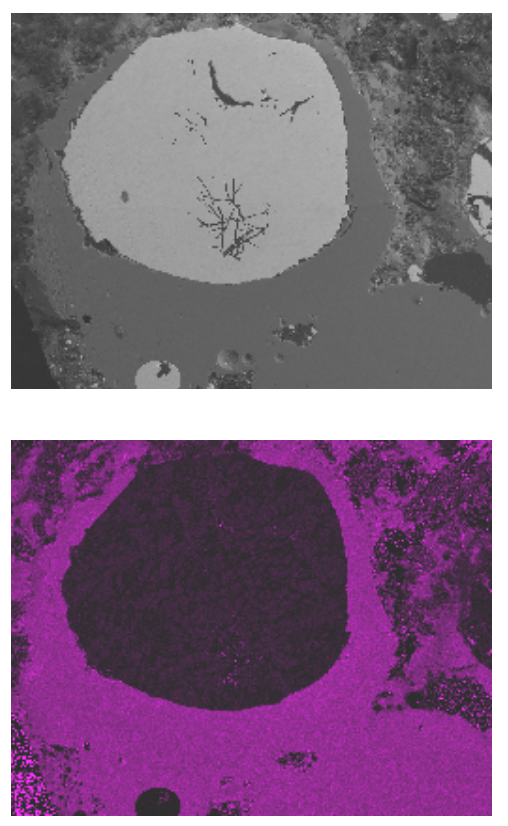

$\mathrm{Si}$

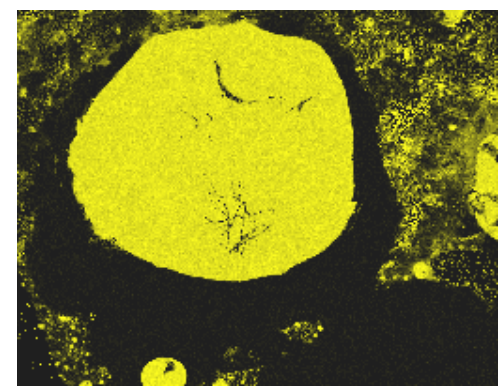

$\mathrm{Fe}$

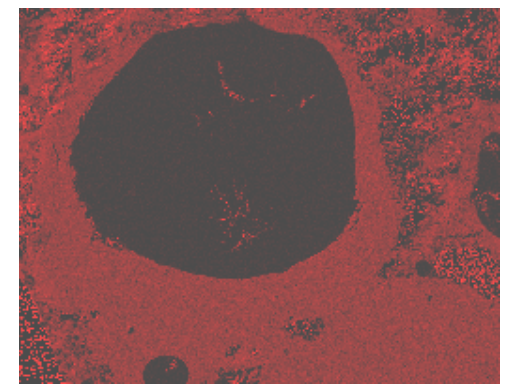

$\mathrm{O}$

Figure 6.27(a). EDS Dot Map of Iron Droplets in ES-1-3
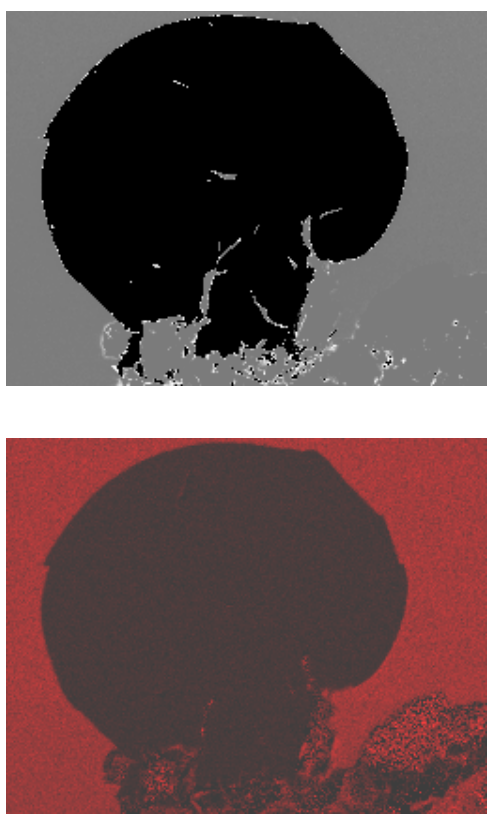

$\mathrm{O}$

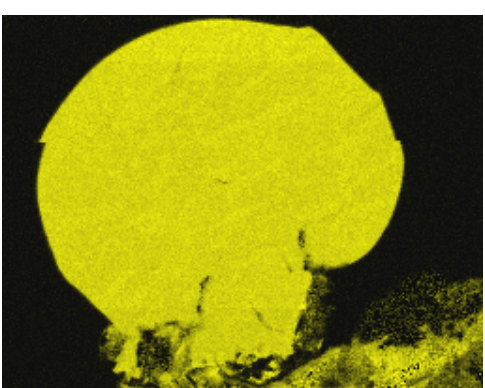

$\mathrm{Fe}$

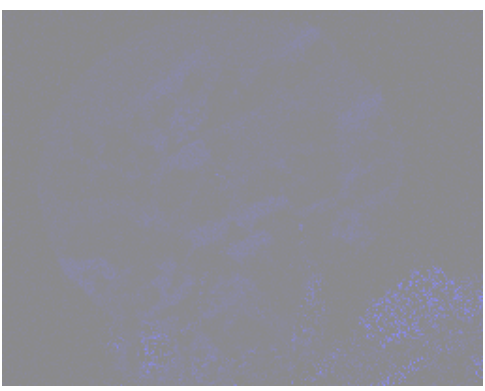

$\mathrm{Cr}$

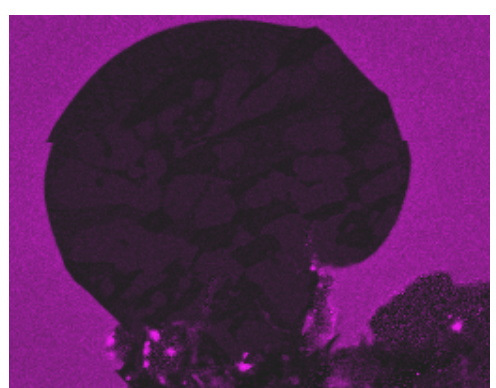

$\mathrm{Si}$

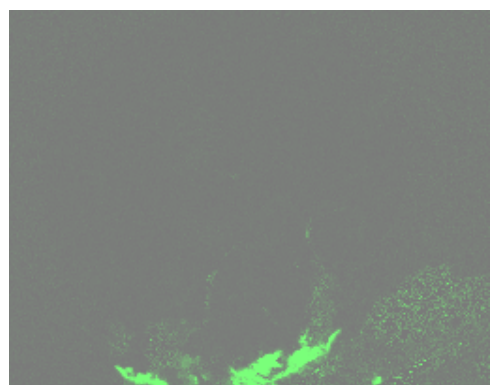

$\mathrm{Ti}$ 


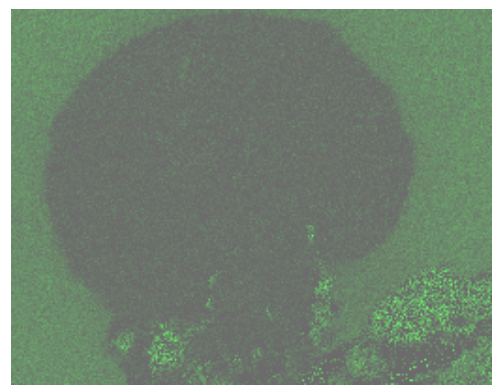

$\mathrm{Na}$

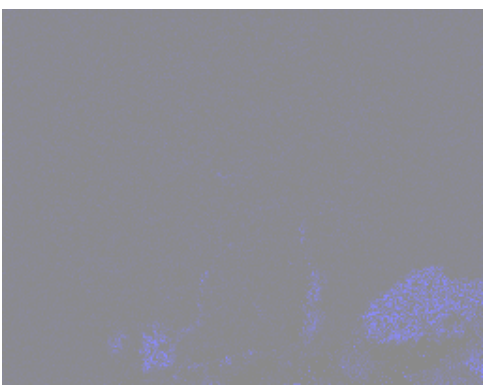

$\mathrm{Mg}$

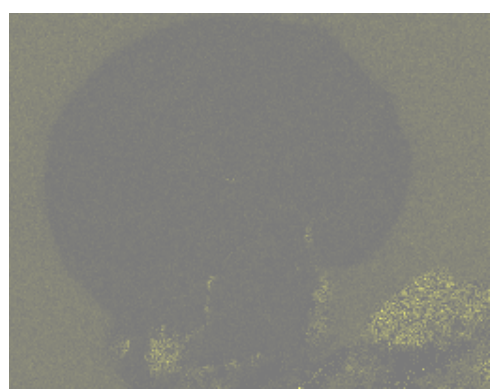

$\mathrm{Al}$

Figure 6.28(b). EDS Dot Map of Iron Droplets in ES-1-3
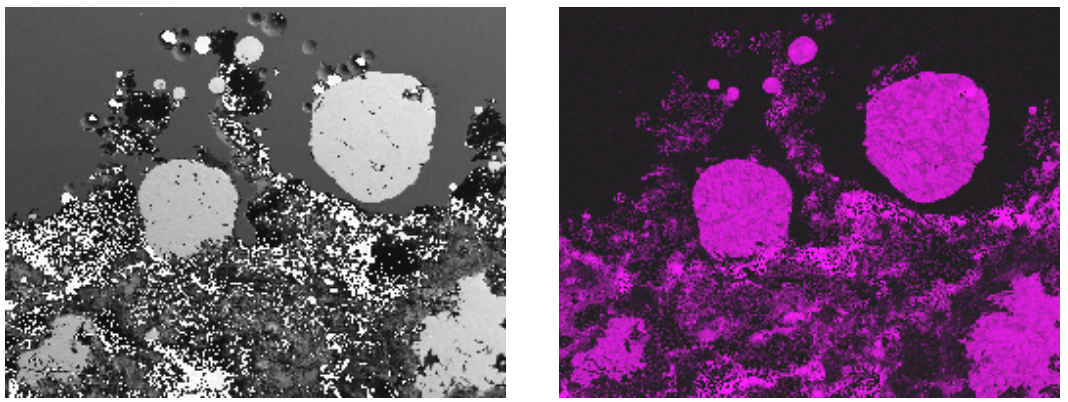

$\mathrm{Fe}$

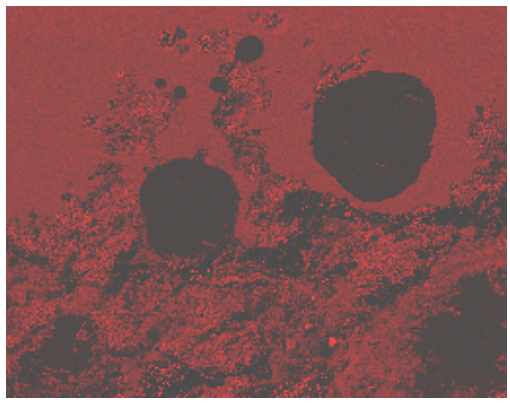

$\mathrm{O}$

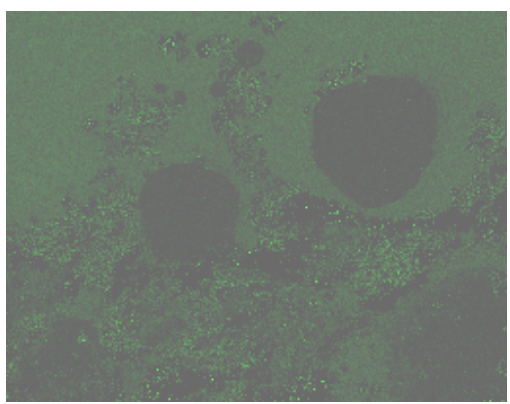

$\mathrm{Na}$

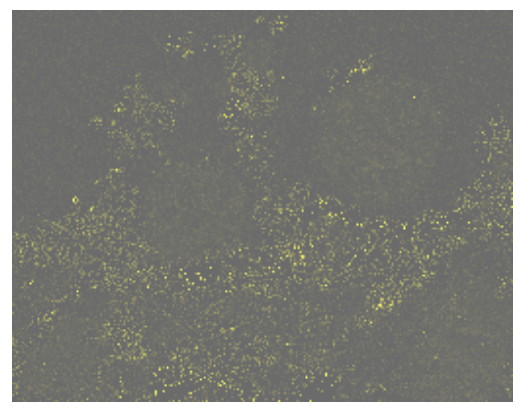

$\mathrm{Cr}$

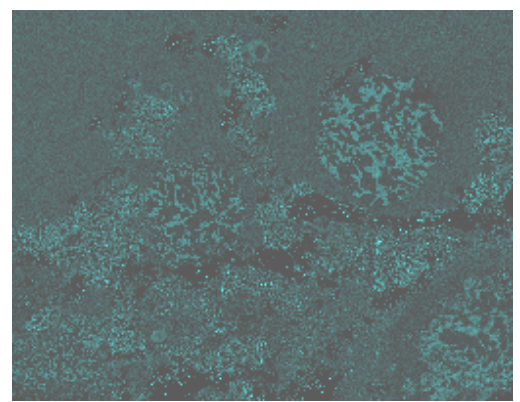

$\mathrm{Zr}$

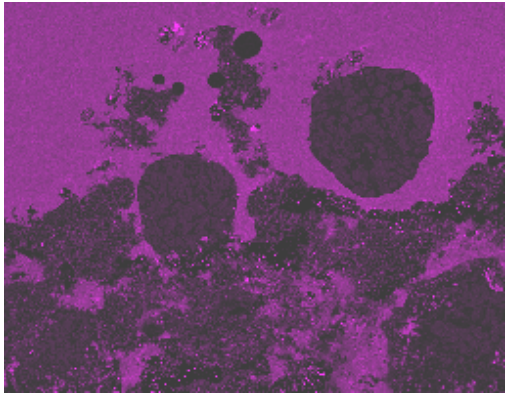

$\mathrm{Si}$

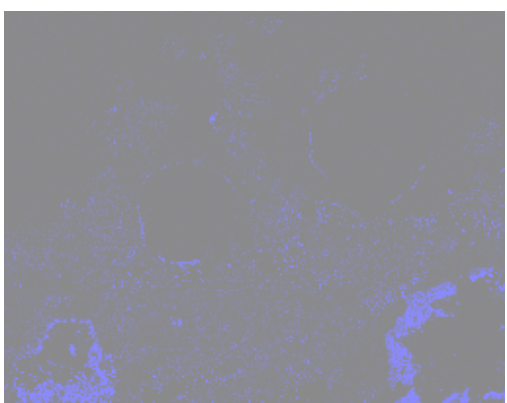

$\mathrm{Ti}$

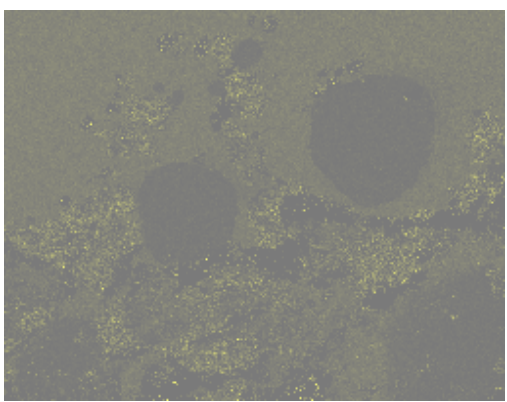

$\mathrm{Al}$

Figure 6.29(c). EDS Dot Map of Iron Droplets in ES-1-3

The glass block is surrounded by a layer of adhered course sand as shown in Figure 6.11. To determine the concentration of sand in this layer quantitative XRD was performed. Two samples of the sand-glass interface were taken - one on the bottom corner of the block and one on the bottom of the block. These samples were sectioned in roughly $5 \mathrm{~mm}$ slices along the axis perpendicular to the interface plane. The 
samples were ground with an internal standard of $\mathrm{CaF} 2$ and analyzed by XRD. The XRD patterns were evaluated by Reitvelt refinement using RIQAS Software (MDI, Livermore, CA) and the mass fraction of $\mathrm{SiO}_{2}$ was determined. The results are shown in Figure 6.30. The transition begins with roughly 50 mass $\%$ of an amorphous phase and develops gradually to a fully amorphous material over roughly $4 \mathrm{~cm}$ in both sample locations.

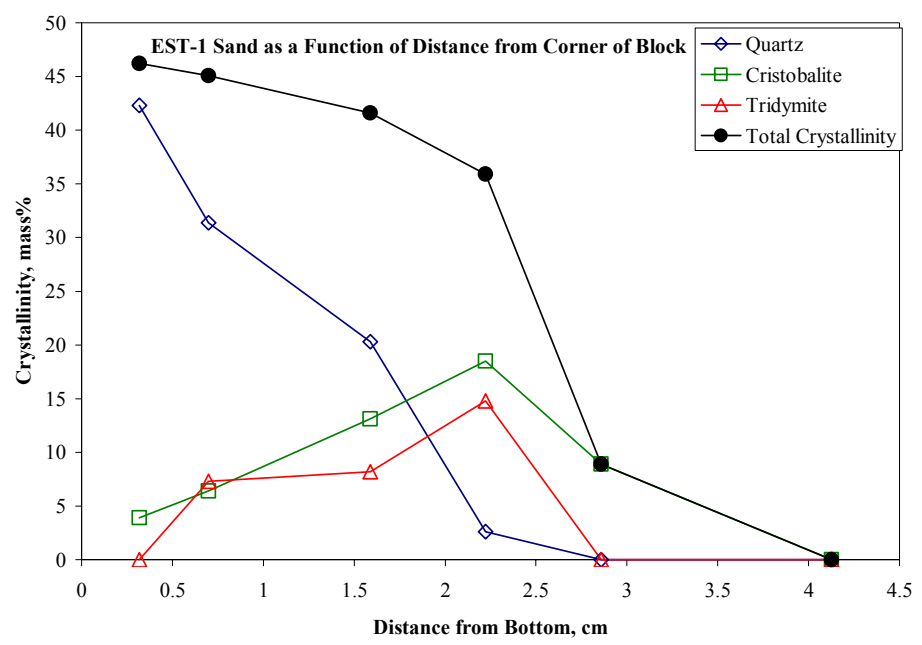

(a) Bottom Corner of the Block

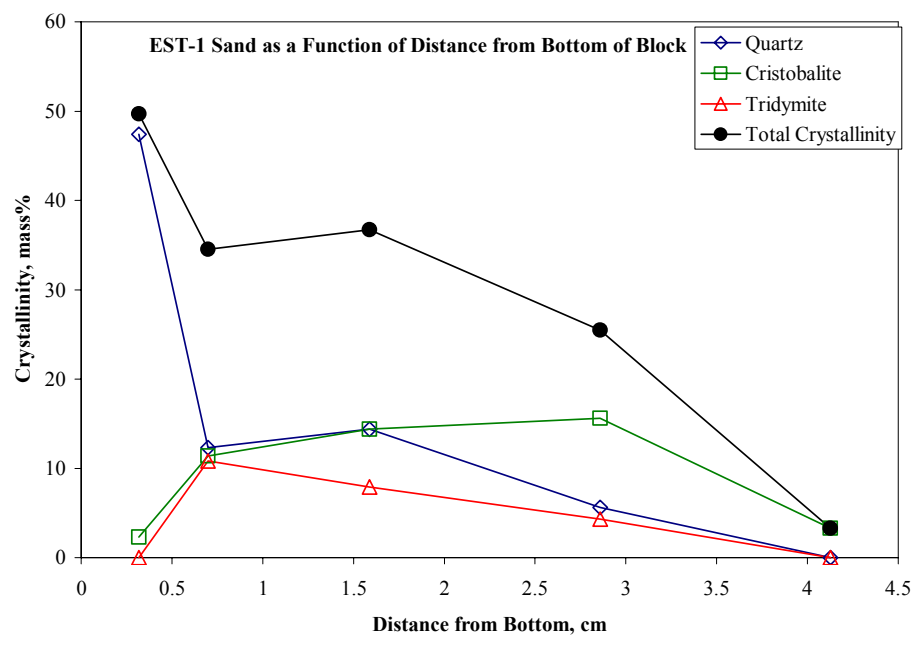

(b) Bottom Surface of the Block

Figure 6.30. $\mathrm{SiO}_{2}$ Concentration as a Function of Distance from the Surface of the ES-1 Block

\subsection{Sample Position and Identification for ES-2 Glass Composition Analyses}

After the melt of ES-2, the glass block was broken into several big pieces and transported to the area where they were prepared for chemical analysis. Five pieces were selected (see Figure 6.31) for analysis by ICP-AES, and Re and Tc by ICP-MS. This melt was spread into a thin monolith with pools of glass near each electrode and an expanded crust above the melt. The melt perimeter was impregnated with insulating sand that had been pulled into the melt and in some areas completely mixed through the entire glass. It was difficult to locate areas that were sand free so that the samples that were taken for analysis 
would not be biased by the sand particles. ES-2-1 and ES-2-5 samples were taken from the center area on the melt. ES-2-3 and ES-2-4 were taken from the electrode areas where the melt pool was swollen, and ES-2-2 was taken from a section of the crust.

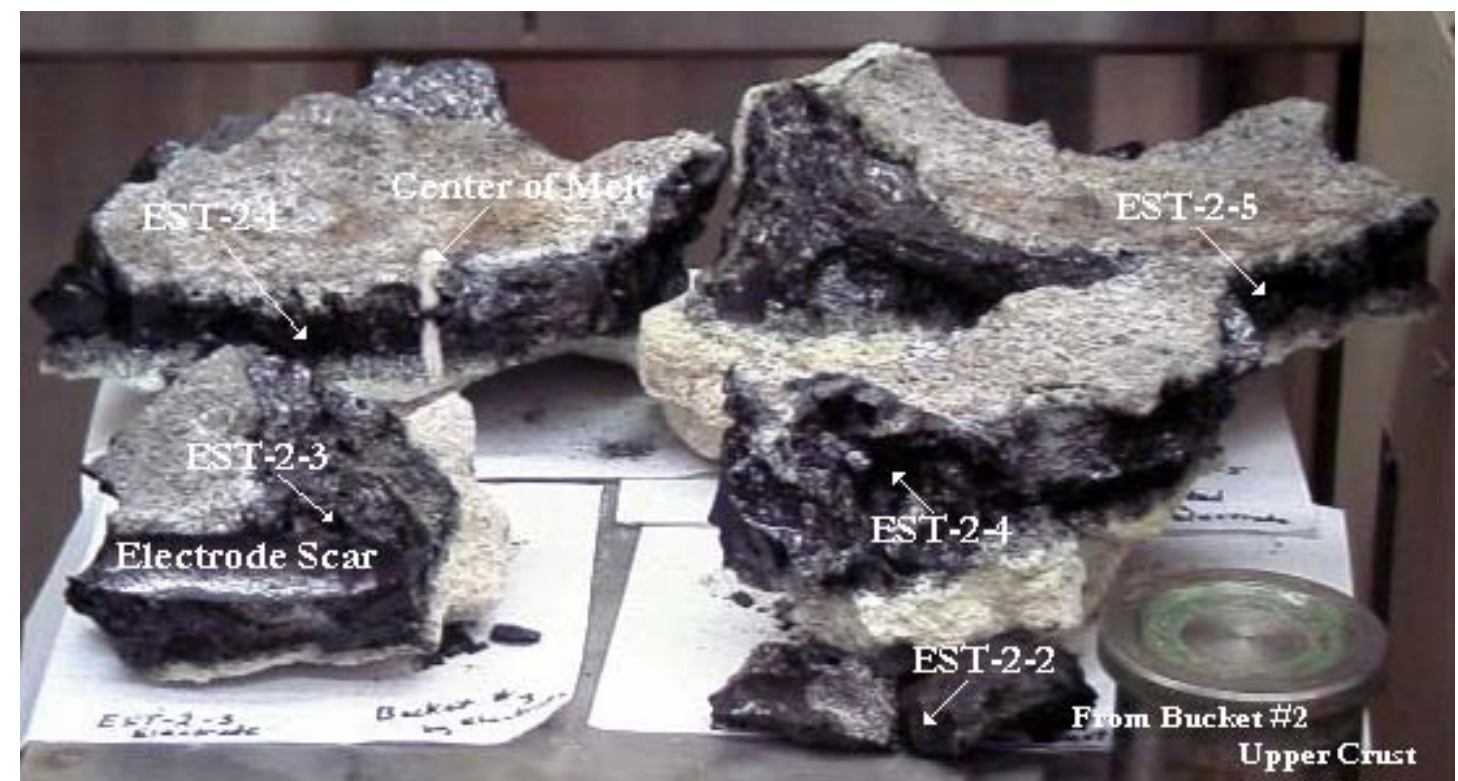

Figure 6.31. ES-2 Melt Samples with Designation of Where Analytical Samples Were Obtained ${ }^{(a)}$

\subsection{ES-2 Glass Composition Analyses Results and Comparison with ES-1}

Table 6.13 summarizes the results of glass-composition analyses of five samples taken from different locations of the ES-2 glass block (see Figure 6.31). Figure 6.32 shows the comparison of measured and target concentrations of major components (those with a target mass fraction higher than 0.03). As in the ES-1 discussed in Section 6.3, the effect of sand dissolution during the ES-2 process is evident. Overall, the deviation of the measured concentrations from the targets is slightly smaller compared to that in the ES-1 process (shown in Figure 6.13). The same assessment to estimate the mass fraction of sand dissolved in ES-2 glass was performed, and the result is summarized in Table 6.14. The extent of sand dissolution in ES-2 ranged from 0.18 to 0.30 , which was slightly less than in ES-1.

(a) The term "EST" used within the picture is the same as "ES." 
Table 6.13. Analyzed Compositions (in mass fractions) of ES-2 Glasses

\begin{tabular}{|c|c|c|c|c|c|c|}
\hline Component & ES-2-1 & ES-2-2 & ES-2-3 & ES-2-4 & ES-2-5 & Average \\
\hline $\mathrm{Al}_{2} \mathrm{O}_{3}$ & 0.0818 & 0.0853 & 0.0834 & 0.0763 & 0.0823 & 0.0818 \\
\hline $\mathrm{B}_{2} \mathrm{O}_{3}$ & 0.0382 & 0.0413 & 0.0390 & 0.0343 & 0.0382 & 0.0382 \\
\hline $\mathrm{CaO}$ & 0.0239 & 0.0250 & 0.0238 & 0.0220 & 0.0237 & 0.0237 \\
\hline $\mathrm{Cr}_{2} \mathrm{O}_{3}$ & 0.0006 & 0.0006 & 0.0006 & 0.0005 & 0.0005 & 0.0005 \\
\hline $\mathrm{Fe}_{2} \mathrm{O}_{3}$ & 0.0257 & 0.0303 & 0.0267 & 0.0208 & 0.0256 & 0.0258 \\
\hline $\mathrm{K}_{2} \mathrm{O}$ & 0.0117 & 0.0125 & 0.0117 & 0.0109 & 0.0109 & 0.0115 \\
\hline $\mathrm{MgO}$ & 0.0124 & 0.0130 & 0.0125 & 0.0115 & 0.0124 & 0.0123 \\
\hline $\mathrm{Na}_{2} \mathrm{O}$ & 0.1448 & 0.1570 & 0.1529 & 0.1368 & 0.1462 & 0.1475 \\
\hline $\mathrm{P}_{2} \mathrm{O}_{5}$ & 0.0038 & 0.0049 & 0.0042 & 0.0030 & 0.0039 & 0.0040 \\
\hline $\mathrm{ReO}_{2}$ & $\mathrm{NA}^{(\mathrm{a})}$ & $\mathrm{NA}^{(\mathrm{a})}$ & $\mathrm{NA}^{(\mathrm{a})}$ & $\mathrm{NA}^{(\mathrm{a})}$ & $\mathrm{NA}^{(\mathrm{a})}$ & \\
\hline $\mathrm{SiO}_{2}$ & 0.5571 & 0.5175 & 0.5625 & 0.5828 & 0.5721 & 0.5584 \\
\hline $\mathrm{SO}_{3}$ & $\mathrm{NA}^{(\mathrm{a})}$ & $\mathrm{NA}^{(\mathrm{a})}$ & $\mathrm{NA}^{(\mathrm{a})}$ & $\mathrm{NA}^{(\mathrm{a})}$ & $\mathrm{NA}^{(\mathrm{a})}$ & \\
\hline $\mathrm{TiO}_{2}$ & 0.0061 & 0.0064 & 0.0062 & 0.0057 & 0.0061 & 0.0061 \\
\hline $\mathrm{ZrO}_{2}$ & 0.0517 & 0.0551 & 0.0538 & 0.0431 & 0.0538 & 0.0515 \\
\hline Total & 0.9161 & 0.9131 & 0.9352 & 0.8990 & 0.9329 & 0.9193 \\
\hline 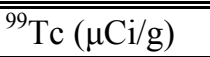 & " 0.0142 & (20.0305 & " 0.0149 & ב 0.0103 & 0.0142 & 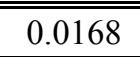 \\
\hline \multicolumn{7}{|c|}{$\begin{array}{l}\text { (a) Not analyzed-the analytical instruments used for these radioactive glasses were not } \\
\text { capable of detecting these components. Re in ES-2 glasses was measured separately later } \\
\text { (but S was not measured). }\end{array}$} \\
\hline
\end{tabular}

Table 6.14. Estimated Mass Fraction of Sand Dissolved in the ES-2 Glass Samples (S) Calculated from Analyzed Glass Compositions

\begin{tabular}{|c|c|c|c|c|c|c||}
\hline \hline Component & ES-2-1 & ES-2-2 & ES-2-3 & ES-2-4 & ES-2-5 & Average \\
\hline$S$ & 0.25 & 0.18 & 0.24 & 0.30 & 0.26 & 0.25 \\
\hline
\end{tabular}




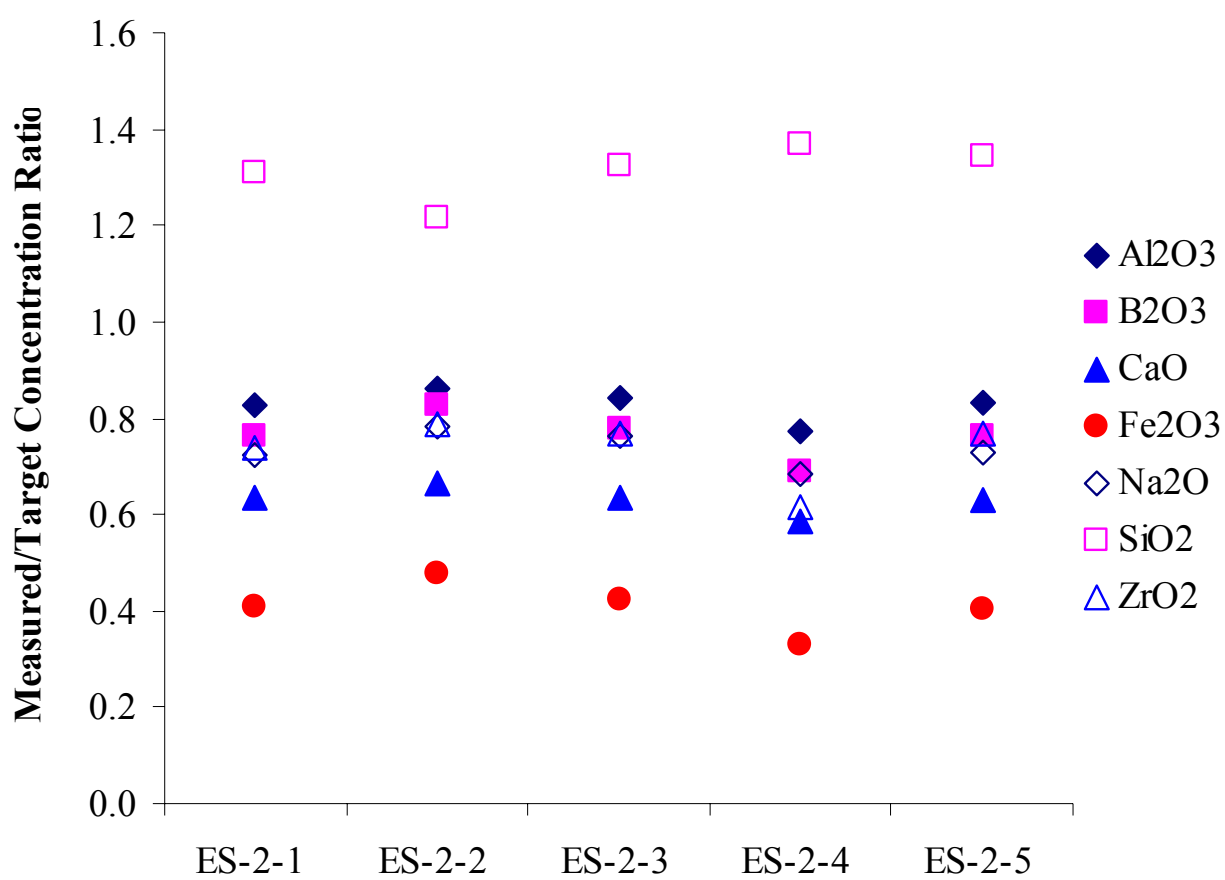

ES-2 Sample ID

Figure 6.32. Ratio of Measured and Target Concentrations of Selected Major Components in ES-2 Glasses

\subsubsection{Homogenization and Reanalysis for Te and Re}

The variation in Tc concentrations in the samples (which were specifically taken to represent the range of product) made mass balance of Tc uncertain. Therefore, the entire ES-2 glass block was ground to $\leq 1.5$ $\mathrm{mm}$ size with a most of the material significantly finer (e.g., $100 \mu \mathrm{m})$. The material was well blended and sampled for analyses of Tc and Re concentrations. The mass of this material was measured at $57.5 \mathrm{Kg}$ but was ground and homogenized after tanking samples for previous analyses that totaled $0.7 \mathrm{Kg}$ of material (a total of $58.2 \mathrm{Kg}$ of waste form were obtained during the test including the $35.5 \mathrm{Kg}$ of feed material plus the dissolved sand and the adhered sand layer minus the volatiles). The results showed that $20.78 \pm 1.67 \mu \mathrm{Ci} / \mathrm{g}$ of ${ }^{99} \mathrm{Tc}$ and $30.1 \pm 4.0 \mu \mathrm{g} / \mathrm{g}$ of Re were retained in the waste form. Multiplying the analyzed concentrations of ${ }^{99} \mathrm{Tc}$ and $\mathrm{Re}$ in the feed material, times the feed material mass yields $1.21 \mathrm{mCi}$ of ${ }^{99} \mathrm{Tc}$ and $1.75 \mathrm{~g}$ of Re total for the block. This represents $93 \%$ and $79 \%$ of the Tc and Re retained in the waste form.

Table 6.15. Measured Concentrations of ${ }^{99} \mathrm{Tc}$ and Re in ES-2 Homogenized Samples ${ }^{(a)}$

\begin{tabular}{||l|c|c||}
\hline Sample ID & ${ }^{99} \mathrm{Tc}(\mu \mathrm{Ci} / \mathrm{g})$ & $\mathrm{Re}(\mu \mathrm{g} / \mathrm{g})$ \\
\hline ES2-GVP-1a & 22.21 & 31.6 \\
\hline ES2-GVP-1b & 22.03 & 33.0 \\
\hline ES2-GVP-2 & 22.35 & 31.6 \\
\hline ES2-GVP-3 & 19.64 & 27.4 \\
\hline
\end{tabular}




\begin{tabular}{|c|c|c|}
\hline ES2-GVP-4 & 18.30 & 23.2 \\
\hline ES2-GVP-5 & 20.15 & 33.6 \\
\hline Average & 20.78 & 30.1 \\
\hline Standard Dev. & 1.67 & 4.0 \\
\hline Total amount & $1.21 \mathrm{mCi}$ & $1.75 \mathrm{~g}$ \\
\hline Target amount & $1.30 \mathrm{mCi}$ & $2.21 \mathrm{~g}$ \\
\hline Fraction in waste-form & $93 \%$ & $79 \%$ \\
\hline \multicolumn{3}{|c|}{$\begin{array}{l}\text { (a) Chemical analyses were performed by } \\
\text { Southwest Research Institute. }\end{array}$} \\
\hline
\end{tabular}

\subsubsection{Analyses of $\mathrm{Tc}$ and $\mathrm{Re}$ in Condensates in Foam Glass samples}

As both the ES-1 and ES-2 melts progressed, large bubbles (up to a liter in volume) formed in viscous glass around the four carbon electrodes where the off-gas from the melt was escaping. Bubbles collapsed as the gas was released and formed a mass of irregular glass lobes above the insulating sand layer over the melt surface. Condensed volatiles were found on inner surfaces of the glass bubbles at the end of the melter experiment (Figure 6.33). Condensate consisted of a white, powdery, substance that is easily smeared off the surface. Other inner-bubble surfaces appeared more reddish to metallic. Figure 6.34 shows SEM micrographs of the very porous condensate materials taken from the ES-1 test, which are similar to the condensate samples from ES-2 that were dissolved in DIW. Pieces of the glass were directly counted using a Geiger-Muller probe to qualitatively determine the location of the ${ }^{99} \mathrm{Tc}$ before and after the test. Before the test, a piece of glass had a count rate of $4000 \mathrm{cpm}$ in almost direct contact with the white condensate layer. A smear of the white layer had a count rate of roughly $400 \mathrm{cpm}$. After the test, there were no prominent white condensate layers. A piece of glass roughly $250 \mathrm{~g}$ in weight had a count rate of $8,000 \mathrm{cpm}$ along the inner surfaces of the bubble and a rate of $6,000 \mathrm{cpm}$ along the outer surfaces of the sample. The outer surface of the sample contained a slight amount of sand fixed to the glass. A smear was also taken from the inside of the bucket used to contain the glass and DIW for the test. The smear had a count rate of $600 \mathrm{cpm}$. The count rate for these readings is influenced by the background reading in the laboratory. The background reading for the laboratory at the time of the measurements was $200 \mathrm{cpm}$. Portions of glass with the powdered condensate were separated from the main body and were dissolved in DIW. The solution was filtered through a $0.45-\mu \mathrm{m}$ filter into a $20-\mathrm{mL}$ scintillation vial and analyzed with ICP-MS.

The total mass of Tc in the solution was $49.0 \mu \mathrm{g}$, and the total mass of Re was $26.2 \mathrm{mg}$. Assuming that nearly all of the condensate on the surfaces of the glass dissolved into the solution, these amounts represent $0.06 \%$ of the Tc and $1.12 \%$ of the Re in the starting melter feed. 


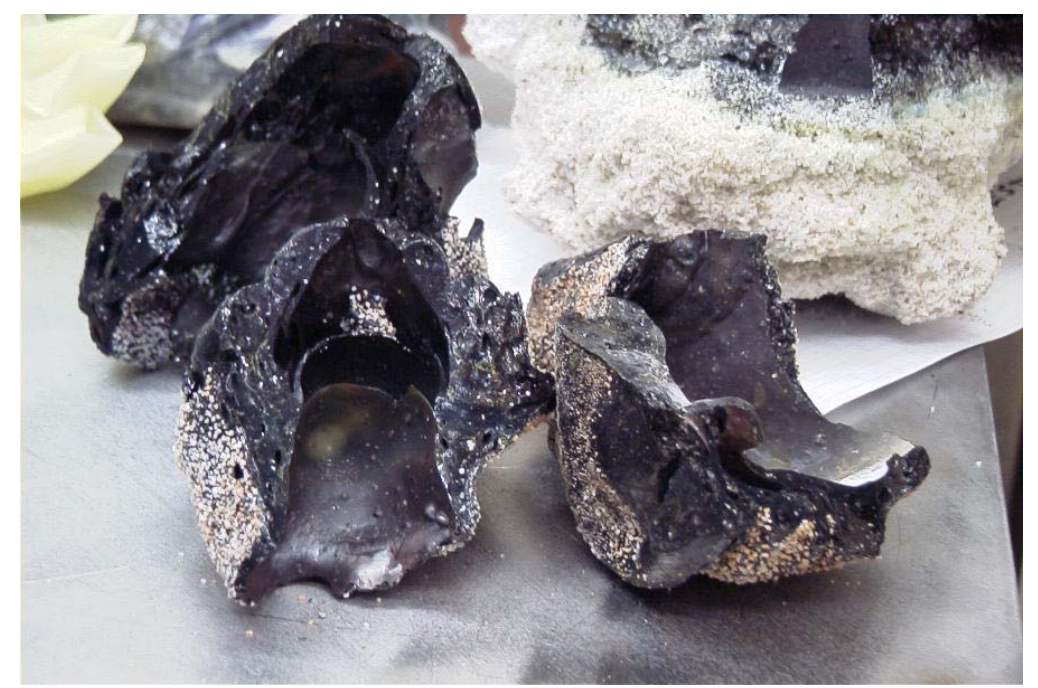

Figure 6.33. Cavities from the Top of ES-2 Melt Near an Electrode with White- to Reddish-Colored Condensate
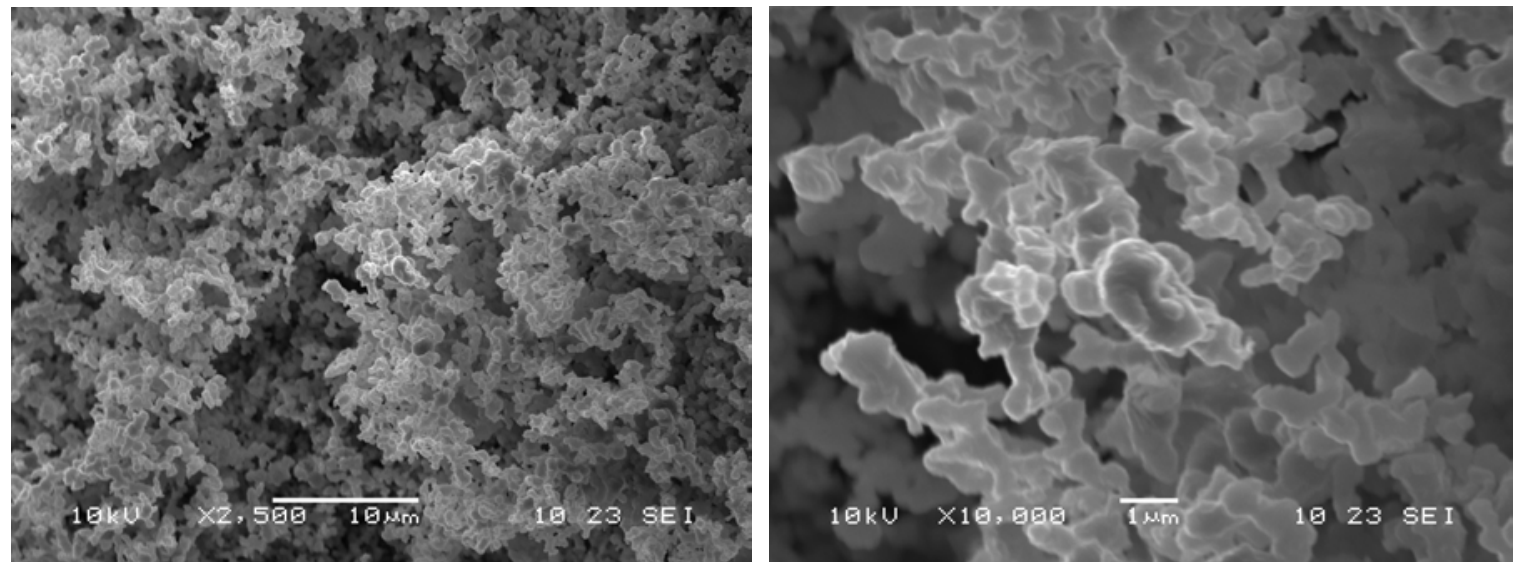

Figure 6.34. SEM Micrographs of White Condensate on the Inside of Large Glass Bubble from ES-1 Melter Test (similar to the condensate from ES-2 that was dissolved in DIW for analyses) 


\subsection{Summary and Conclusions}

A study was performed to formulate and test simulated and actual Hanford LAW glasses to be produced by the ICV process. This study was performed in five phases; the results of these phases are briefly discussed in this section along with pertinent conclusions.

\subsection{Preliminary Glass Melts}

A preliminary study was performed to identify a baseline glass that met the processing, product quality, and economic constraints of the ICV process applied to Hanford LAW. Sixteen glasses were formulated, fabricated, and tested. The key parameters varied were waste loading, additive composition (e.g., $\mathrm{B}_{2} \mathrm{O}_{3}$, $\mathrm{ZrO}_{2}$, soil) and $\mathrm{Al}_{2} \mathrm{O}_{3}$ and $\mathrm{Fe}_{2} \mathrm{O}_{3}$ concentrations in soil. All glasses were characterized for VHT and PCT responses and crystallinity (both quenched and slow cooled samples), while selected glasses were tested for TCLP responses, viscosity, and electrical conductivity. The VHT response was found to be the most restrictive property on waste loading and glass composition. The AMBG-13 containing 20 mass $\% \mathrm{Na}_{2} \mathrm{O}$ (17.8 mass \% from waste and 2.2 mass $\%$ from soil) and 5 mass $\% \mathrm{~B}_{2} \mathrm{O}_{3}$ and 7 mass $\% \mathrm{ZrO}_{2}$ (both from additive) was adopted as a glass suitable for scale up and radioactive demonstrations of the ICV process since it has the best mix of properties - it has outstanding PCT, VHT, and TCLP responses, does not contain any crystals after SC heat treatment, and has 20 mass $\% \mathrm{Na}_{2} \mathrm{O}$.

The temperature required to obtain a glass viscosity of $10 \mathrm{~Pa} \cdot \mathrm{s}$ was $1238^{\circ} \mathrm{C}$. The electrical conductivity at this temperature was $39.7 \mathrm{~S} / \mathrm{m}$. This glass was by no means optimized, and further work will be required to develop an optimum glass for the ICV process with Hanford LAW.

\subsection{Simulant Crucible Melts}

In crucible tests performed with the LAW simulant supplied by CH2M Hill Hanford Group, five glasses with $\mathrm{Na}_{2} \mathrm{O}$ concentration ranging from 17 to 24 mass \% (waste loading ranging from 16.4 to 24.4 mass $\%$ on a glass-oxide basis) were formulated based on the AMBG-13 composition and tested. The purpose of these tests was to generate data on glasses fabricated at crucible scale, to determine waste-loading bounds, and to supply samples to CHG for further testing. These glasses were characterized for VHT, PCT, and TCLP responses, crystallinity, density, and redox. All the glasses passed the PCT and TCLP requirements with a large margin. The VHT requirement was met in all glasses except for the highest waste-loading sample ASCM-05 (with target and measured $\mathrm{Na}_{2} \mathrm{O}$ concentrations of 24 and 25.5 mass\%). This indicates that the current baseline glass at 20 mass $\% \mathrm{Na}_{2} \mathrm{O}$ is appropriate, i.e., it is safely below the loading at which glasses begin to fail constraints. It should be emphasized that the loading at which a glass meets the VHT (or any other) constraint is highly dependent on the base-glass composition, and the AMBG-13 is not an optimized composition. As in preliminary crucible test glasses, crystallization was observed in some of these glasses, but did not significantly detract from the chemical durability of the final product.

\subsection{Redox Effect on VHT Response}


One of the most significant differences in composition of glass within the large or full-scale ICV process is expected to be the oxygen fugacity or redox state (since the glass is melted using graphite electrodes on opposing ends of the melt). To determine the impact of redox on VHT response, a series of crucible melts were performed with varying redox ratios. The melts were based on ASCM-04 glass, which was found to have an acceptable but borderline VHT response. It was found that as the glass became more reduced, the VHT response improved. Since the ASCM melt series were all generally oxidized, this result suggests that they represent a conservative case. By extrapolation (to the more durable ASCM-01 glass), the baseline formulation should perform well below the constraints, irrespective of the iron redox state.

\subsection{Radioactive Crucible Melt}

A radioactive glass (ARCM-01) with almost the same target composition as AMBG-13 (from preliminary tests) and ASCM-01 (from simulant crucible melts) was prepared from the actual Hanford LAW to validate the data obtained using the simulant, to generate data on radionuclide and hazardous component corrosion/leaching, and to supply a portion of the sample to $\mathrm{CHG}$ for further testing. The difference in composition was caused by a slight difference in simulant and actual waste. No noticeable difference in measured properties was observed between these two glasses confirming the validity of data obtained using simulated LAW. The normalized Tc release was several times lower than normalized $\mathrm{Na}$ or B release, suggesting that there was no selective leaching of Tc under the PCT condition.

\subsection{Engineering Scale Simulant Melt}

An engineering-scale test with LAW simulant was performed to demonstrate ICV process feasibility with Hanford LAW simulant and to generate data related to product quality and off-gas. The chemical analyses of the glasses taken from various positions of the test-glass block indicated that the mixing of glass was very good. Multiple solid phases were found in the engineering-scale glass block. Samples from extreme regions of the glass block were sampled and subjected to a durability test. It was found that the glass performed (e.g., VHT, PCT, and TCLP responses) as well or better than comparable crucible melts and well below any imposed constraints. There was significant dissolution of sand used to line the container walls as an insulating barrier. However, the dissolution of sand is expected to be less pronounced in larger tests or a prototypic ICV process (since the engineering-scale system has a much higher surface area per unit volume). The dissolution of sand was the main cause of the improved glass responses under PCT, VHT and TCLP conditions as compared to crucible melts.

\subsection{Engineering Scale Technetium Tracer Melt}

An engineering-scale test was performed with the same LAW simulant as used for ES- 1 and ASCM glasses with ${ }^{99} \mathrm{Tc}$ as a tracer. A series of glass-block samples was taken and analyzed for composition, including the Tc analysis. Like ES-1, the composition of the glass from extreme points within the block had similar bulk glass compositions. Data collected from the ES-2 test is also being used to document a mass balance on Tc; $93 \%$ of the Tc was found to remain in the final waste form and the fate of the remaining Tc is beyond the scope of this study. 


\subsection{References}

40 CFR 268.40. 2001. U.S. Environmental Protection Agency. "Applicability of Treatment Standards." (Land Disposal Restrictions). U.S. Code of Federal Regulations.

40 CFR 268.48. 2001. U.S. Environmental Protection Agency. "Universal Treatment Standards." (Land Disposal Restrictions). U.S. Code of Federal Regulations.

Allen, G. K., S. Blacker, R. Blackmon, P. J. Certa, W. Hamel, I. G. Papp, S. A. Saunders, K. R. Wells, and R. D. Williamson. 2002. River Protection Project System Plan, ORP-11242, Rev. 0, U. S.

Department of Energy, Office of River Protection, Richland, Washington.

AMEC. 2002. "Demonstration and Test Plan," in AMEC Proposal to Bulk Vitrification RFP \#93505, to CH2M Hill Hanford Group, November 2002.

American Society for Testing and Materials (ASTM). 1998. "Standard Test Methods for Determining Chemical Durability of Nuclear, Hazardous, and Mixed Waste Glasses: The Product Consistency Test (PCT)," C 1285-97 in 1998 Annual Book of ASTM Standards Vol. 12.01, ASTM, West Conshohocken, Pennsylvania.

American Society for Testing and Materials (ASTM). 1999. "Standard Test Methods for Electrical Conductivity and Resistivity of Water," ASTM D 1125-95 (Reapproved 1999), West Conshohocken, Pennsylvania.

Bechtel National, Inc. 2003. Design, Construction, and Commissioning of the Hanford Tank Waste Treatment and Immobilization Plant Contract, DE-AC27-01RV14136, US Department of Energy, Office of River Protection, Richland, Washington.

Buelt, J. L., C. L. Timmerman, K. H. Oma, V. F. FitzPatrick, and J. G. Carter. 1987. In Situ Vitrification of Transuranic Waste: An Updated Systems Evaluation and Applications Assessment, PNL-4800, Suppl. 1, Pacific Northwest Laboratory, Richland, Washington.

Darab J. G., D. D. Graham, B. D. MacIsaac, R. L. Russell, D. K. Peeler, H. D. Smith, and J. D. Vienna. 2001. Sulfur Partitioning During Vitrification of INEEL Sodium Bearing Waste: Status Report. PNNL13588, Pacific Northwest National Laboratory, Richland, WA.

Ebert, W.L. and S.F. Wolf. 2000. "An Interlaboratory study of a standard glass for acceptance testing of low-activity waste glass," J. Nuclear Materials, Vol. 282, 112-124.

EPA, see U.S. Environmental Protection Agency

Geosafe. 1998. Treatment Study for Planar In Situ Vitrification of INEEL Test Area North V-Tanks, INEEL/EXT-98-00854, Idaho National Engineering and Environmental Laboratory, Idaho Falls, Idaho.

Goles, R. W. 1996. Determination of Halogen Content in Glass for Assessment of Melter

Decontamination Factors, PNNL-11060, Pacific Northwest National Laboratory, Richland, Washington. 
Hrma P., G. F. Piepel, M. J. Schweiger, D. E. Smith, D-S. Kim, P. E. Redgate, J. D. Vienna, C. A. LoPresti, D. B. Simpson, D. K. Peeler, and M. H. Langowski. 1994. Property/Composition Relationships for Hanford High-Level Waste Glasses Melting at $1150^{\circ} \mathrm{C}$. PNL-10359, Vol. 1 and 2, Pacific Northwest Laboratory, Richland, WA.

Hrma, P., P. Izak, J.D. Vienna, G.M. Irwin and M-L. Thomas. 2002. "Partial Molar Liquidus Temperatures of Multivalent Elements in Multicomponent Borosilicate Glass." Phys. Chem. Glasses 43 (2) $128-136$.

Jantzen, C. M., K. G. Brown, and J. B. Pickett. 2001. Impact of Phase Separation on Durability in Phosphate Containing Borosilicate Waste Glasses: Relevance to Vitrification of INEEL High Level Waste (U). WSRC-MS-2000-00307, Westinghouse Savannah River Company, Aiken, SC.

Kim, D-S. and J. D. Vienna. 2002. Model for TCLP Releases from Waste Glasses, PNNL-14061, Pacific Northwest National Laboratory, Richland, Washington.

Kot, W. K., and I. L. Pegg. 2001. Glass Formulation and Testing with RPP-WTP HLW Simulants - Final Report, VSL-01R2540-2, Vitreous State Laboratory, The Catholic University of America, Washington D.C.

Mann, F. M., K. C. Burgard, W. R. Root, R. J. Puigh, S. H. Finfrock, R. Khaleel, S. H. Bacon, E. J. Freeman, B. P. McGrail, S. K. Wurstner, and P. E. Lamont. 2001. Hanford Immobilized Low-Activity Waste Performance Assessment: 2001 Version, DOE/ORP-2000-24, Rev. 0, U. S. Department of Energy, Office of River Protection, Richland, Washington.

Muller, I. S., and I. L. Pegg. 1998. Glass Formulation and Testing with TWRS LAW Simulants, Final Report for GTS Durateck Inc. and BNFL Inc., Catholic University of America, Washington D.C.

Muller, I. S., A. C. Buechele, I. L. Pegg. 2001. Glass Formulation and Testing with RTP-WTP LAW Simulants-Final Report, VSL-01R3560-2, Vitreous State Laboratory at The Catholic University of America, Washington, D.C.

National Institute of Standards and Technology (NIST). 1980. Standard Reference Material 773, SodaLime-Silica Glass for Gradient-Furnace Liquidus Temperature. Washington, D.C.

Rapko, B. M., S. I. Sinkov, and T. G. Levitskaia. 2003. Removal of ${ }^{137}$ Cs from Dissolved Hanford Tank Saltcake by Treatment with IE-911, PNNL-14250, Pacific Northwest National Laboratory, Richland, Washington.

Rassat, S. D., L. A. Mahoney, R. L. Russell, S. A. Bryan, and R. L. Sell. 2003. Cold Dissolved Saltcake Waste Simulant Development, Preparation, and Analysis, PNNL-14194, Pacific Northwest National Laboratory, Richland, Washington.

Spalding, B. P., G. K. Jacobs, N. W. Dunbar, M. T. Naney, J. S. Tixier, and T. D. Powell. 1992. Tracerlevel Radioactive Pilot-scale Test of In Situ Vitrification for the Stabilization of Contaminated Soil Sites at ORNL, ORNL/TM-12201, Oak Ridge National Laboratory, Oak Ridge, Tennessee.

U.S. Environmental Protection Agency (EPA). 1992. Toxicity Characteristic Leach Procedure, SW-846 Method 1311, Washington, D. C. 
Vienna J. D., P. Hrma, A. Jiricka, D. E. Smith, T. H. Lorier, I. A. Reamer, and R. L. Schulz. 2001 Hanford Immobilized LAW Product Acceptance Testing: Tanks Focus Area Results, PNNL-13744, Pacific Northwest National Laboratory, Richland, Washington.

Vienna, J. D., D. S. Kim, and P. Hrma. 2002. Database and Interim Glass Property Models for Hanford $H L W$ and LAW Glasses, PNNL-14060, Pacific Northwest National Laboratory, Richland, Washington.

Weier, D. R. and G. F. Piepel. 2003. Methodology for Adjusting and Normalizing Analyzed Glass Compositions, PNWD-3260 WTP-RPT-049, Rev. 0, Pacific Northwest National Laboratory, Richland, Washington.

Wolf, S. F., W. L. Ebert, J. S. Luo, and D. M. Strachan. 1998. "A Data Base and a Standard Material for Use in Acceptance Testing of Low-Activity Waste Products. ANL-98/9, Argonne National Laboratory, Argonne, IL. 
Appendix A

\section{PNNL Technical Procedures Used}




\section{Appendix A: PNNL Technical Procedures Used}

APEL-PAD-V, Rev. 2, Operation of Scintag Pad-V X-Ray Diffractometer, Safe Operating Procedure, 2002.

APEL-PIP-4, Rev. 2, Gas Pycnometry Method for Apparent Specific Gravity Determination of consolidated Solids, PNNL Technical Procedure, 2001.

GDL-ECC, Electrical Conductivity Calibration Procedure for Molten Glass, Pacific Northwest National Laboratory, Technical Procedure, 2003.

GDL-ELC, Electrical Conductivity Measurement Procedure, Pacific Northwest National Laboratory, Technical Procedure, 2003.

GDL-GBM, Rev. 3, Glass Batching and Melting, Pacific Northwest National Laboratory, Technical Procedure, 2002.

GDL-VHT, Vapor Hydration Test Procedure, Pacific Northwest National Laboratory, Technical Procedure, 2000.

GDL-VIS, Standard Viscosity Measurement Procedure for Vitrified Nuclear Waste, Pacific Northwest National Laboratory, Technical Procedure, 1998.

GDL-VSC, Standard Viscosity Calibration Procedure, Pacific Northwest National Laboratory, Technical Procedure, 1998.

GDL-XRD, Quantitative and Semi-quantitative analysis using X-Ray Diffraction, Pacific Northwest National Laboratory, Technical Procedure, 2002.

RPL-PIP-1, Rev.2, Preparation, Processing, and Testing of Radioactive Glass and Ceramics, PNNL Technical Procedure, 2001.

RPL-PIP-4, Rev. 2, Mounting Radioactive Samples in PIP XRD Sample Holder Base, Technical Procedure, 2002. 
Appendix B

\section{XRD Patterns of the SC Treated Glasses}




\section{Appendix B: XRD Patterns of the SC Treated Glasses}

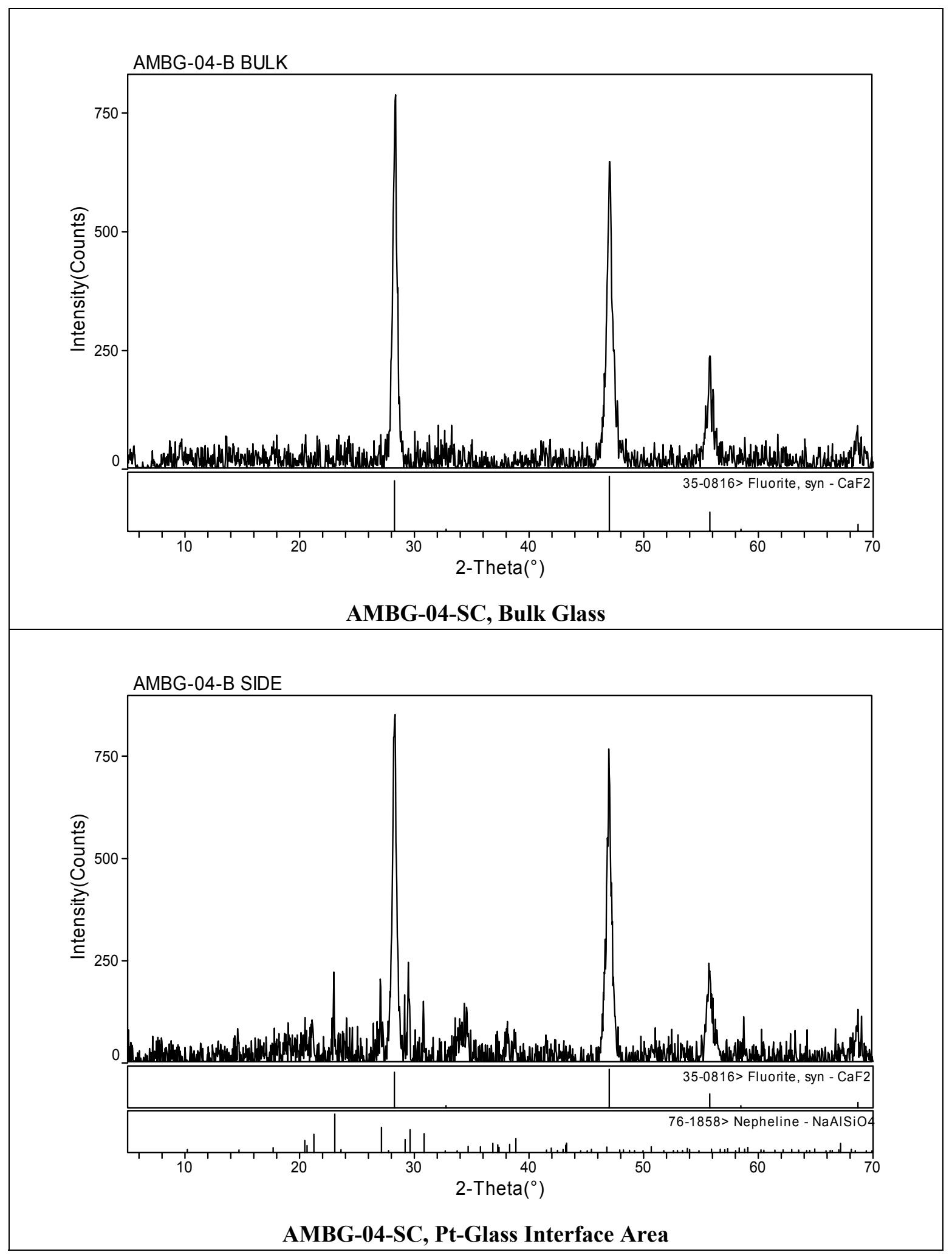

B. 1 


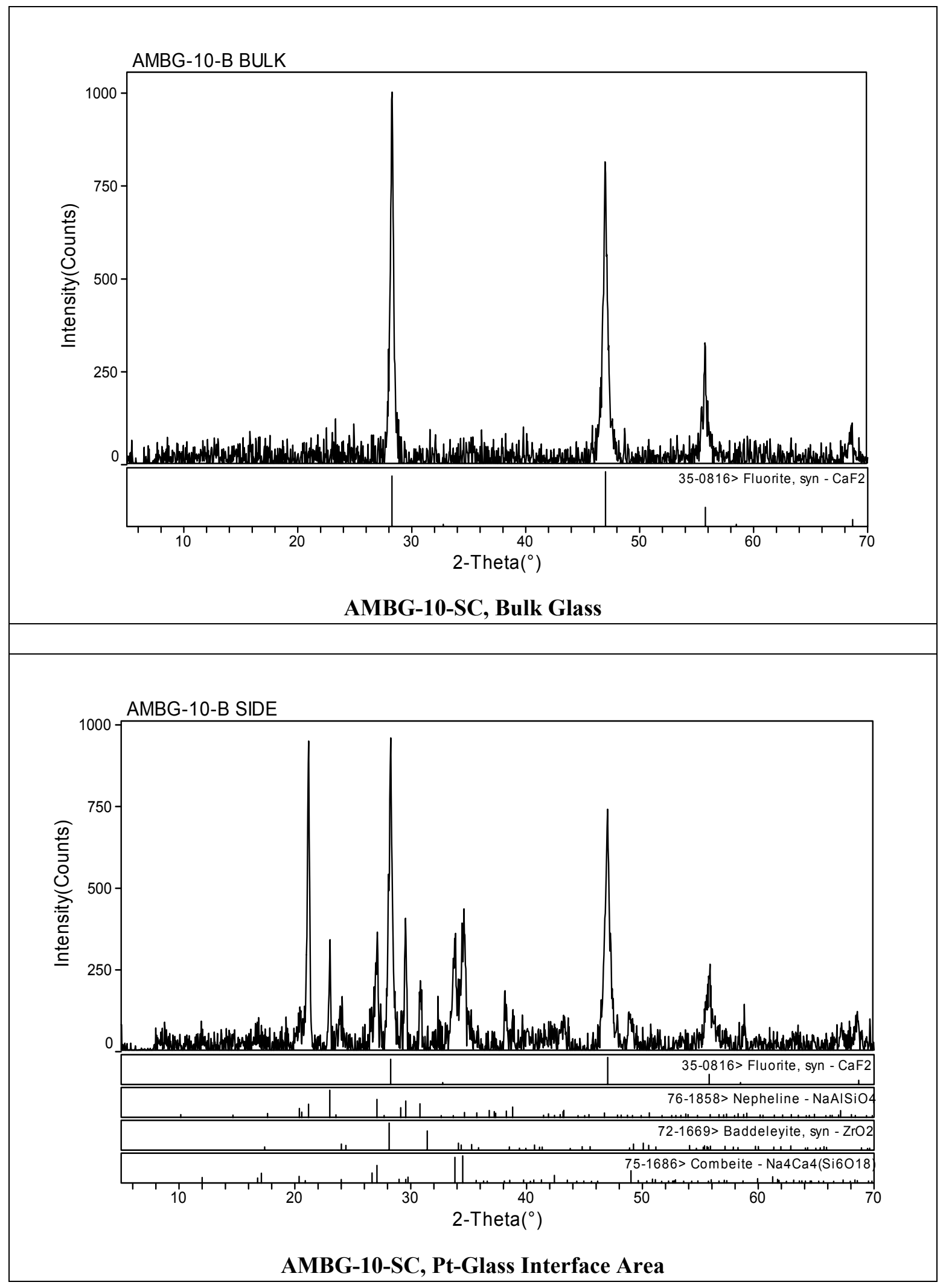

B. 2 


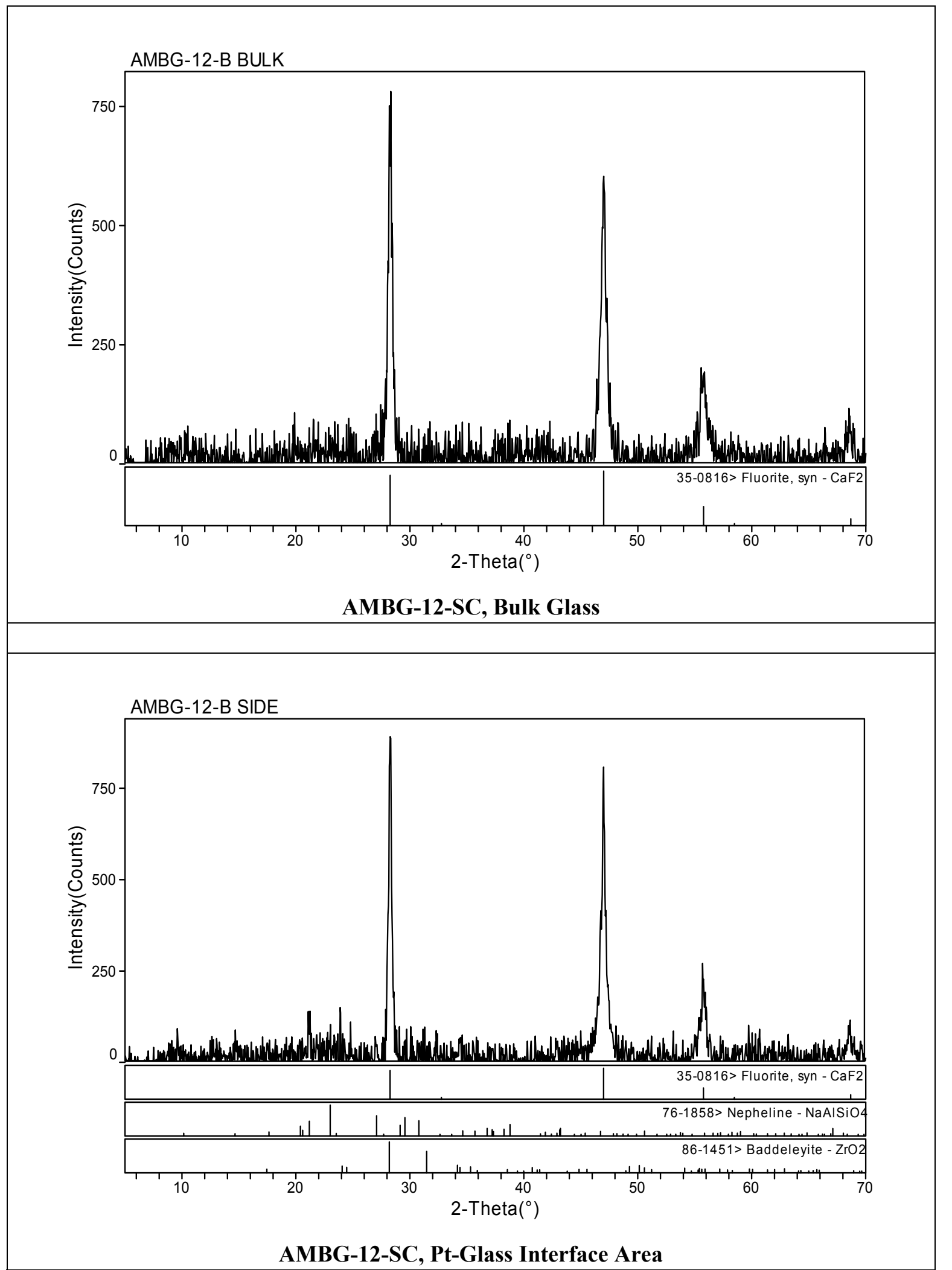

AMBG-12-SC, Pt-Glass Interface Area 


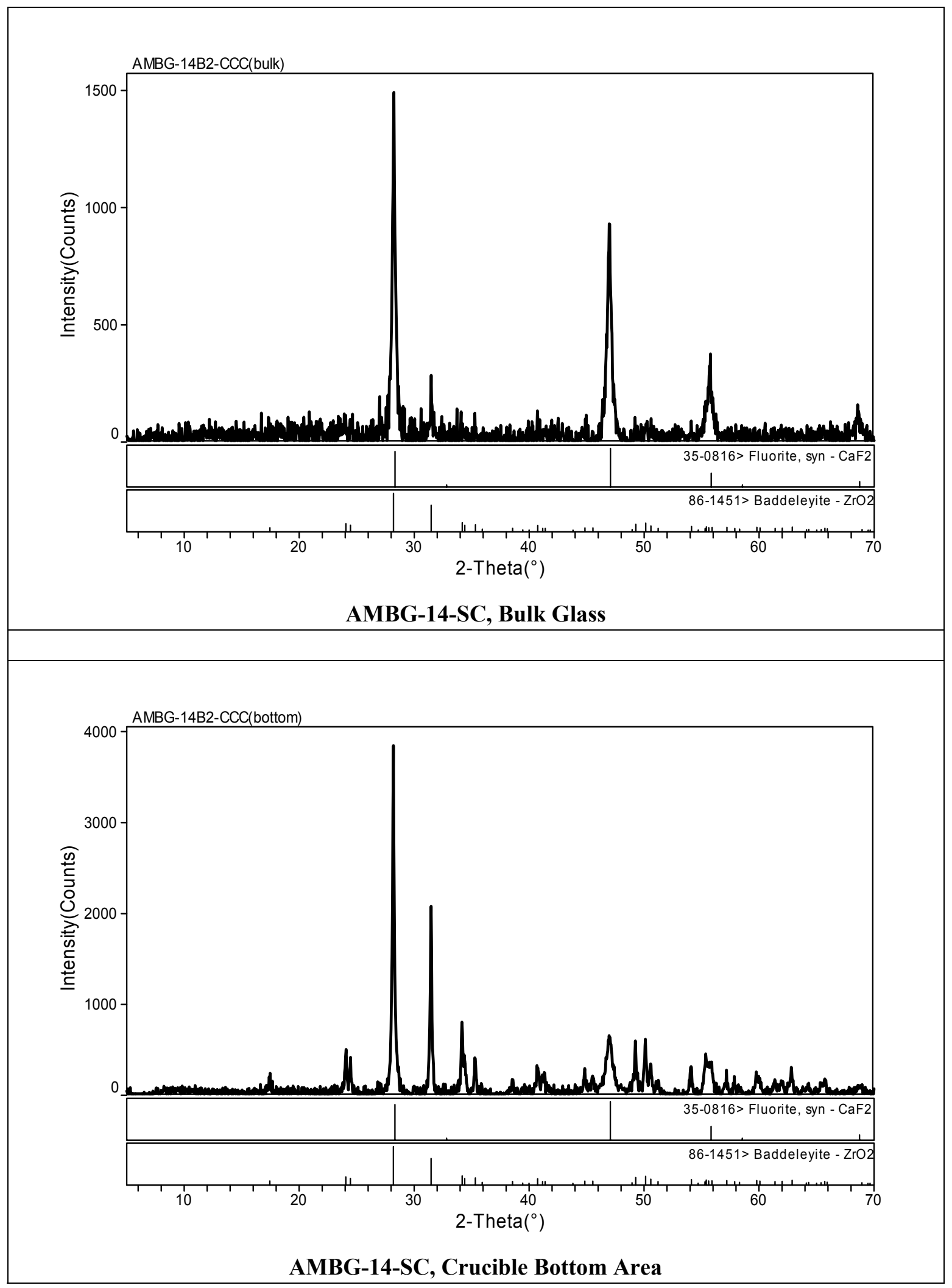

B. 4 


\section{Distribution}

No. of

Copies

OFFSITE

11 AMEC, Earth and Environmental, Inc.

Geomelt Division

309 Bradley Blvd, Suite 115

Richland, WA 99352, Attn:

L. Thompson (10)

P. Lowery

3 Westinghouse Savannah River Company

Aiken, SC 29808, Attn:

D. Best

$773-43 \mathrm{~A}$

E. W. Holtzscheiter

D. K. Peeler
$773-\mathrm{A}$

999-W
No. of

Copies

ONSITE

3 DOE/Office of River Protection

W. F. Hamel H6-60

B. M. Mauss H6-60

R. J. Schepens H6-60

6 CH2M Hill Hanford Group

D. W. Hamilton (3) H6-03

G. W. Reddick R1-44

M. E. Johnson R1-44

K. D. Boomer R1-44

33 Pacific Northwest National Laboratory

E. G. Baker

$\mathrm{K} 2-20$

K. B. Belew

K6-24

T. M. Brouns

K9-69

W. C. Buchmiller

K6-24

J. L. Buelt

P7-27

J. V. Crum

K6-24

P. A. Gauglitz

K6-28

L. K. Holton

H6-61

P. R. Hrma

K6-24

E. O. Jones

K6-24

D. S. Kim (10)

K6-24

J. P. LaFemina

K9-02

J. Matyas

K6-24

B. P. McGrail

K6-81

J. F. Mucha

K9-73

R. K. Quinn

K9-01

M. J. Schweiger

K6-24

G. J. Sevigny

P7-27

D. E. Smith

K6-24

D. M. Strachan

K6-24

J. S. Tixier, Jr.

K6-24

J. D. Vienna

K6-24

W. C. Weimer

K9-09

J. D. Yeager

K6-24

Total: 56 Copies 